Monastères et couvents de montagne : circulation, réseaux, influences au Moyen Âge

Daniel Le Blévec (dir.) 


\section{Monastères et couvents de montagne : circulation, réseaux, influences au Moyen Âge}

Daniel Le Blévec (dir.)

DOI : $10.4000 /$ books.cths. 4875

Éditeur : Éditions du Comité des travaux historiques et scientifiques Année d'édition : 2019

Date de mise en ligne : 24 janvier 2019

Collection : Actes des congrès nationaux des sociétés historiques et scientifiques

ISBN électronique : 9782735508907

\section{GboOoks}

http://books.openedition.org

\section{Référence électronique}

LE BLÉVEC, Daniel (dir.). Monastères et couvents de montagne : circulation, réseaux, influences au Moyen Âge. Nouvelle édition [en ligne]. Paris : Éditions du Comité des travaux historiques et scientifiques, 2019 (généré le 21 décembre 2020). Disponible sur Internet : <http://books.openedition.org/cths/ 4875>. ISBN : 9782735508907. DOI : https://doi.org/10.4000/books.cths.4875.

Ce document a été généré automatiquement le 21 décembre 2020.

(C) Éditions du Comité des travaux historiques et scientifiques, 2019 Conditions d'utilisation :

http://www.openedition.org/6540 
Au Moyen Âge, des religieux trouvent en montagne l'isolement nécessaire à l'épanouissement de leur spiritualité. Les maisons de prière qu'ils y fondent participent néanmoins au développement des relations entre les hauteurs et la plaine : en dépit de leur idéal de solitude, elles n'en sont pas moins ouvertes sur le monde extérieur, beaucoup d'entre elles sont aussi des lieux de passage, des points de contact, des espaces symboliques dans les activités humaines et économiques. En croisant des perspectives historiques, archéologiques et géographiques, cet ouvrage collectif apporte un nouveau regard sur les monastères et les couvents de montagne.

Le Congrès national des sociétés historiques et scientifiques rassemble chaque année universitaires, membres de sociétés savantes et jeunes chercheurs. Ce recueil est issu de travaux présentés lors du $142^{\mathrm{e}}$ Congrès sur le thème "Circulations montagnardes, circulations européennes ».

\section{DANIEL LE BLÉVEC}

Professeur émérite d'histoire médiévale de l'université Paul-Valéry - Montpellier III. 


\section{SOMMAIRE}

Introduction
Daniel Le Blévec

La circulation des chanoines prémontrés à travers les Pyrénées (XII ${ }^{e}-X V^{e}$ siècle)

Stéphane Abadie

Les nécrologes prémontrés, indice d'une intense circulation régionale

La circarie de Gascogne, un espace transpyrénéen : fondations et visites

Des chanoines voyageurs : éléments de prosopographie

Evidencias arqueológicas de un monasterio de los siglos VI-VII en el Prepirineo catalán: Santa Cecilia de Els Altimiris

Marta Sancho i Planas

Contexto historiográfico

Santa Cecilia de Els Altimiris: un monasterio de montaña de los siglos VI-VII

Marges et marches seigneuriales aux confins du Velay: réflexion sur les implantations des abbayes cisterciennes de Clavas et de La Séauve-Bénite Emma Bouvard-Mor

Abbaye de Clavas

Abbaye de La Séauve-Bénite

Implantations cisterciennes et recompositions territoriales

Des moines et des sapins : monastères et mise en valeur de la haute chaîne jurassienne au milieu du Moyen Âge

Valentin Chevassu

Contexte des sites étudiés

Synthèse

Le prieuré de Saint-Ours d'Aoste au $\mathrm{XV}^{e}$ siècle : un carrefour au milieu des réseaux de pouvoir en Savoie

Elena Corniolo

Sources et bibliographie

Esquisse de l'histoire institutionnelle du prieuré de Saint-Ours

Prieurs de Saint-Ours et évêques d'Aoste au Xve siècle

Le réseau canonial de Sainte-Christine du Somport : mécanismes de son développement sur le versant nord

Jean Claude Lassègues

La naissance du réseau de Sainte-Christine et son développement sur le versant nord au XII ${ }^{\mathrm{e}}$ siècle

Un instantané au début du XIV siècle, du temps de Marguerite Moncade

Émigrer après la mort : le transfert du corps du roi Sanche VII de Navarre à Roncevaux et l'hypothèse Fontevraud

Fermín Miranda García

Les antécédents immédiats

L'enterrement de Sanche VII à Roncevaux

Le panthéon de la dynastie Plantagenêt à Fontevraud

Un panthéon navarrais à Roncevaux?

Cherchez la femme... sur le mont Athos?

Diane Pasquier-Chambolle

Des femmes sur le mont Athos?

Une présence hors de l'Athos, mais à proximité

L'argent n'a pas d'odeur... ni de sexe : les ventes et les dons des femmes en faveur de l'Athos 
Ancrage territorial d'une communauté monastique : le mont Athos

Pierre-Yves Péchoux

Longue consécration religieuse de l'Athos

Interrogations sur l'autorité exercée dans la montagne

Masculinité exclusive de l'Athos

Trois types d'occupation du sol dans l'Athos

Permanence des relations entre l'Athos et le monde profane

Architecture et décor des couvents mendiants dans le Massif central (début du XIII siècle-fin $d u x v^{e}$ siècle) : tradition, expérimentation ou modernité des modèles gothiques?

Claire Bourguignon

L'architecture : tradition romane et modernité des modèles gothiques

Le décor : entre tradition et expérimentation des modèles gothiques 


\section{NOTE DE L'ÉDITEUR}

Les articles de cet ouvrage ont été validés par le comité de lecture des Éditions du Comité des travaux historiques et scientifiques dans le cadre de la publication des actes du $142^{\mathrm{e}}$ Congrès national des sociétés historiques et scientifiques tenu à Pau en 2017. 


\title{
Introduction
}

\author{
Daniel Le Blévec
}

1 Le texte programmatique proposé à la réflexion des participants du Congrès national des sociétés historiques et scientifiques de Pau en 2017 précisait que la montagne, «propice à l'isolement et au refuge, [...] est également un lieu de franchissement et de passage ». Nous ajouterions volontiers « et de contacts ", s'agissant des monastères et des couvents implantés dans des sites de hauteur. Ce n'est pas en effet le moindre des paradoxes que des religieux ayant choisi, au Moyen Âge, le milieu montagnard pour y installer leur maison, mus par une exigence de solitude et d'isolement, aient été intégrés après quelques années d'existence à des courants de circulation induits par les déplacements des pèlerins, des marchands ou d'autres catégories de voyageurs. Due au hasard ou plus souvent à la nécessité, cette évolution n'a pu qu'être renforcée par des facteurs internes, propres à la configuration même des communautés concernées, qu'elles aient habité des prieurés dépendant d'une maison mère extérieure ou qu'ellesmêmes soient devenues la tête d'un réseau de filiales dispersées, générant dans l'un et l'autre cas des relations et des échanges imposés par leurs statuts : déplacements des frères chargés de l'exploitation des domaines ou envoyés à l'extérieur pour l'approvisionnement, la vente ou les quêtes, venue de visiteurs chargés de missions d'inspection périodiques ou encore, dans le cas de certains ordres, impératifs pastoraux, notamment lorsque des paroisses leur étaient confiées par les évêques, sans omettre les relations d'amitié entretenues entre eux par les supérieurs de ces maisons.

2 Toutes les montagnes de la chrétienté, en Orient comme en Occident, ont abrité des serviteurs de Dieu attirés au départ en ces lieux dans l'espoir d'y trouver une tranquillité favorable à la louange et à la méditation, à commencer par les ermites, suivis au cours des temps par les communautés bénédictines, cisterciennes, cartusiennes, canoniales, hospitalières, soucieuses de ne pas laisser à l'abandon ces espaces d'altitude, peu voire pas du tout humanisés, estimés sans doute par eux propices, plus que d'autres, à la poursuite de leur idéal spirituel. La recherche d'un tel environnement est toujours, pour ceux qui sont en quête de solitude, fortement déterminée par la dimension symbolique que revêt la montagne, comme lieu sacré et souvent même comme lieu de théophanie. Car la montagne touche le ciel et la gravir est un acte à forte connotation religieuse : «L'Éternel est un dieu des montagnes et non 
un dieu des vallées » (I Rois, 20, 28). La montagne est par excellence l'endroit où Dieu se révèle. Elle est omniprésente dans l'Ancien comme dans le Nouveau Testament (Sinaï, Nebo, Carmel, Sion, Tabor, montagne des Béatitudes, entre autres). Très tôt donc des moines, à côté de ceux qui peuplaient les déserts de Syrie et d'Égypte, se sont installés sur ces monts sacrés de la Bible, comme gardiens des lieux et hôtes des pèlerins, qui s'y rendirent dès que les pèlerinages en Terre sainte furent rendus possibles. Puis, lors de l'expansion du christianisme, grâce notamment aux moines, tous profondément imprégnés des textes de l'Écriture sainte et des œuvres des Pères d'Orient qu'ils ruminaient quotidiennement, l'envie de se conformer à une géographie sacrée, par laquelle ils transposaient les épisodes les plus caractéristiques de l'histoire du peuple de Dieu, les a conduits à s'installer sur des montagnes.

3 Ce fut le cas dans l'Empire romain d'Orient: dès la deuxième moitié du IV siècle, saint Basile organise la vie monastique dans les montagnes de Cappadoce. La recherche de lieux isolés et élevés est bien représentée ensuite dans l'Empire byzantin, notamment en Grèce. $\mathrm{Au} \mathrm{vII}{ }^{\mathrm{e}}$ siècle, des ermites investissent la péninsule du mont Athos, s'installant d'abord dans des grottes, puis se regroupant dans des laures, s'efforçant de mener, tout au long des siècles, une existence résolument fidèle au propos de vie primitif, à l'abri des tentations du monde, comme l'évoquent ici les articles de Diane PasquierChambolle («Cherchez la femme... sur le mont Athos?») et de Pierre-Yves Péchoux ("Ancrage territorial d'une communauté monastique : le mont Athos »).

4 En Occident, les formes les plus anciennes de vie monastique, en revanche, ne se sont pas développées de manière privilégiée dans des sites de montagne. La recherche des hauteurs ne semble pas être le souci premier des pères fondateurs du monachisme d'Occident que furent Martin de Tours, Augustin d'Hippone, Jean Cassien. Il faut attendre la période des invasions pour voir se manifester dans les préoccupations des moines la recherche de lieux protégés des troubles, de la guerre et de ses périls. Dans les montagnes de Campanie et de Calabre, ermites et petites communautés de religieux conquièrent des zones accidentées qui vont devenir, tout au long du Moyen Âge, des foyers actifs de vie spirituelle et des lieux d'expérimentation de diverses formules d'observances régulières. Reconnaissons toutefois que si le modèle élaboré par saint Benoît au mont Cassin a connu le succès universel qui a été le sien, il ne le doit pas au modeste site de hauteur qui en fut le point de départ, mais bien plutôt à la qualité de la règle qu'il avait élaborée pour ses frères. Néanmoins, à mesure que le christianisme progressait en Europe et que des fondations monastiques nouvelles voyaient le jour, quadrillant peu à peu l'espace, quelques-unes renouèrent avec la tradition des implantations de hauteur. Ce furent plutôt des établissements de moyenne montagne, situés au bord de routes menant vers les cols, comme Saint-Maurice d'Agaune, dans le Valais suisse ; l'abbaye de la Novalaise, en Piémont, fondée au viII ${ }^{e}$ siècle sur la route menant au mont Cenis ; Saint-Chaffre du Monastier, en Velay ; Saint-Oyend, qui devint Saint-Claude au viI ${ }^{\mathrm{e}}$ siècle, dans le Jura; ou encore l'abbaye de Hohenbourg, sur le mont Sainte-Odile, dans les Vosges alsaciennes, fondée à la fin du VII siècle, pour ne donner que quelques exemples. Dans les Pyrénées catalanes, c'est à une véritable " prolifération de communautés » qu'on assiste aux $\mathrm{VI}^{\mathrm{e}}$ et $\mathrm{VII}^{\mathrm{e}}$ siècles, comme le signale Marta Sancho i Planas dans son article consacré à l'étude archéologique de l'un de ces monastères ( Evidencias archeológicas de un monasterio de los siglos VI-VII en el Prepireneo catalán: Santa Cecilia de Els Altimiris »). 
$5 \quad \mathrm{Au} \mathrm{XI}{ }^{\mathrm{e}}$ siècle, le monachisme réformé se caractérise volontiers par des implantations d'altitude, avec les cas symboliques de La Chaise-Dieu et de la Grande Chartreuse. Plusieurs grandes abbayes de plaine, aux origines plus anciennes et désormais à la tête de congrégations souvent étendues, mais diffuses, comme Cluny ou Saint-Victor de Marseille, ont également fondé ou rattaché à elles des prieurés de montagne sur des terres qui leur avaient été données par des bienfaiteurs, nobles pour la plupart. Il en fut de même, au XII ${ }^{\mathrm{e}}$ siècle, des cisterciens. Ceux-ci n'ont certes pas de vocation particulière à occuper des sites de hauteur, contrairement aux chartreux, mais leur recherche d'isolement et de solitude les a poussés à accepter des donations de domaines montagnards isolés, en conformité avec leur idéal. S'ils ont souvent préféré les fonds de vallées humides, l'activité rurale qui caractérise le mieux les zones de montagne, à savoir l'élevage, répondait parfaitement à l'une de leurs orientations économiques privilégiées. Si seules des granges marquaient la présence cistercienne dans ces espaces d'altitude, quelques abbayes cependant peuvent sans conteste être considérées comme des «monastères de montagne », compte tenu de leur situation. À côté des exemples étudiés ici par Emma Bouvard-Mor («Marges et marches seigneuriales aux confins du Velay : réflexion sur les implantations des abbayes cisterciennes de Clavas et de La Séauve-Bénite »), bien d'autres noms pourraient être cités : Tamié, Aulps, Valcroissant, Valsainte, Mont-Sainte-Marie, Mazan, Les Chambons, pour n'en mentionner que quelques-uns. À l'élevage pratiqué sur une vaste échelle par les cisterciens se sont souvent ajoutées pour les monastères de montagne d'autres activités propres à leur environnement, en particulier l'exploitation de la forêt et celle de la tourbe, comme on le lira, pour le Jura, dans l'article de Valentin Chevassu («Des moines et des sapins : monastères et mise en valeur de la haute chaîne jurassienne au milieu du Moyen Âge »).

La thématique des circulations en montagne a ainsi permis aux participants du colloque, par les cas qui ont été présentés - et qui sont loin naturellement d'épuiser toute la richesse d'un tel sujet - de réaliser combien les religieux rattachés aux divers ordres, même les plus soucieux de se conformer à un idéal de solitude, ont développé au Moyen Âge des contacts avec la société environnante, générateurs de circulations d'hommes, de marchandises, d'idées et d'influences diverses, notamment artistiques, ainsi que le développe Claire Bourguignon dans son étude « Architecture et décor des couvents mendiants dans le Massif central (début du XIII ${ }^{\mathrm{e}}$ siècle-fin du Xv $\mathrm{xv}^{\mathrm{e}}$ siècle) : tradition, expérimentation ou modernité des modèles gothiques?». Moines et chanoines réguliers ont noué des relations avec l'aristocratie locale, dont ils avaient accepté les générosités, ils ont entretenu des liens plus ou moins forts, plus ou moins cordiaux, avec la hiérarchie ecclésiastique et les pouvoirs princiers (Elena Corniolo, «Le prieuré de Saint-Ours d'Aoste au Xve siècle : un carrefour au milieu des réseaux de pouvoir en Savoie »; Fermín Miranda García, « Émigrer après la mort : le transfert du corps du roi Sanche VII de Navarre à Roncevaux et l'hypothèse Fontevraud»), ils ont mis en place un réseau souvent dense de maisons dans la perspective d'entretenir ou de renforcer leur vocation de prédication ou d'encadrement des fidèles (Stéphane Abadie, "La circulation des chanoines prémontrés à travers les Pyrénées, $\mathrm{XII}^{\mathrm{e}}-\mathrm{XV}{ }^{\mathrm{e}}$ siècle ») ou de soins et d'accueil des pèlerins et des voyageurs (Jean Claude Lassègues, «Le réseau canonial de Sainte-Christine du Somport: mécanismes de son développement sur le versant nord »). Mis à part les chanoines et les religieux mendiants, dont la vocation est précisément d'agir dans le siècle, on résoudra volontiers, à propos des moines cloitrés, le paradoxe apparent qu'on évoquait en commençant - celui d'une vocation d'isolement, recherchée dans un environnement d'altitude, confrontée à la réalité 
d'une intégration dans des courants de circulation parfois dynamiques - en rappelant que dans la plupart des ordres, les moines de chœur, voués à la prière et à la méditation, ont su protéger leur solitude en déléguant à quelques-uns d'entre eux seulement (abbés, procureurs, hôteliers) et aux frères convers la mission d'entretenir les contacts avec le monde extérieur : juste partage des tâches, permettant la continuité de la louange divine en dépit des agitations du monde. La devise des chartreux, ordre « montagnard » s'il en est, n'est-elle pas : Stat crux dum volvitur orbis?

\section{AUTEUR}

\section{DANIEL LE BLÉVEC}

Professeur émérite d'histoire médiévale de l'université Paul-Valéry - Montpellier III 


\title{
La circulation des chanoines prémontrés à travers les Pyrénées $\left(\mathrm{XII}^{\mathrm{e}}-\mathrm{XV}^{\mathrm{e}}\right.$ siècle)
}

\author{
Stéphane Abadie
}

1 L'ordre de Prémontré, fondé au XII ${ }^{\mathrm{e}}$ siècle, est encore mal connu pour son implantation en Gascogne et dans les Pyrénées. Cet ordre de chanoines augustiniens fondé par Norbert de Xanten et développé par Hugues de Fosses à partir des années $1120^{1}$ a pourtant connu un important essor dans le sud de la France et au nord de l'Espagne ${ }^{2}$, comme en témoignent la fondation de trente-quatre abbayes, prieurés et prieuréshôpitaux ${ }^{3}$ et la conservation actuelle de quelques monastères, comme Arthous, dans les Landes, Lahonce et Sarrance, dans les Pyrénées-Atlantiques ou encore Combelongue, dans l'Ariège, qui attestent par leur architecture la vitalité de cet ordo novus aux XII et XIII ${ }^{\mathrm{e}}$ siècles (fig. 1). 
Fig. 1. - Les fondations prémontrées dans la circarie de Gascogne : abbayes, prieurés, hôpitaux ( $\mathrm{XII}^{\mathrm{e}}$-XIV $\mathrm{e}$ siècle). Toutes ces fondations ne sont pas contemporaines, en particulier les fondations féminines, disparues ou cédées aux cisterciens avant le troisième quart du XII siècle. Urdax : Urdache ; Bellpuig : Belpech ; La Retuerta : La Retorte.

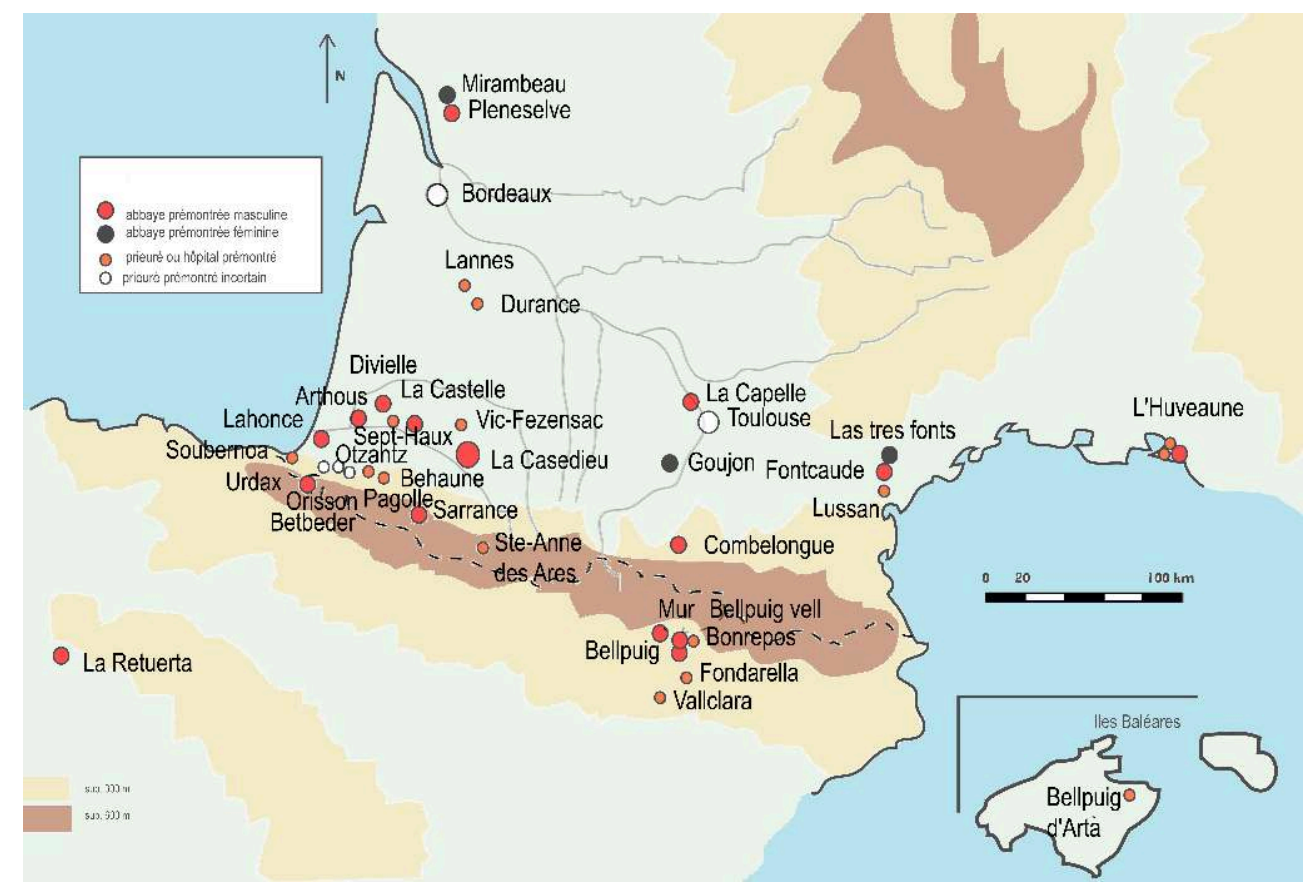

(c) Stéphane Abadie.

Les premières fondations espagnoles (Belpech, La Retorte et Urdache) connaissent également un succès rapide, accéléré par la Reconquista: plusieurs dizaines de monastères prémontrés sont fondés en Espagne et au Portugal dans cette même période, finissant par former une circonscription religieuse ou «circarie» indépendante de la maison mère gasconne ${ }^{4}$. Après une période de croissance importante, les prémontrés connaissent un relatif déclin à partir du milieu du XIII $^{\mathrm{e}}$ siècle, avec l'arrivée des ordres mendiants, qui captent désormais les rentes d'une bourgeoisie en fort développement dans les bastides et villes au sud de la Garonne.

Parmi les nombreuses questions que pose l'étude de cet ordre, celle de la circulation des chanoines augustiniens n'est pas la moindre: du fait même de leur règle, les chanoines prémontrés avaient vocation à sortir de leurs monastères pour évangéliser les laïcs et assurer la cure de paroisses, un siècle avant les franciscains. Par ailleurs, la formation d'un important réseau d'abbayes et prieurés, de Bayonne à Marseille, luimême constitué localement d'un dense semis de paroisses, de granges et d'autres biens à gérer, impliquait de fréquents déplacements, à différentes échelles. Nous nous interrogerons donc, dans le cadre limité de cet article, sur les indices de circulation des chanoines prémontrés dans leur circarie $\mathrm{du} \mathrm{XII}^{\mathrm{e}}$ au $\mathrm{xV}^{\mathrm{e}}$ siècle. Nous utiliserons tout d'abord les nécrologes, qui fournissent des preuves de contacts directs ou indirects entre les différentes abbayes dès leur fondation ${ }^{5}$. Nous étudierons ensuite les diverses sources traitant des fondations et visites effectuées dans le cadre ecclésiastique prémontré, la circarie, qui livrent de nombreux indices de circulation des chanoines, à toutes les échelles. Dans un dernier temps, nous tenterons de reconstituer quelques carrières de chanoines attestant aussi les nombreux déplacements et mutations de ces religieux. 


\section{Les nécrologes prémontrés, indice d'une intense circulation régionale}

4 La documentation la plus ancienne est fournie par les nécrologes que rédigeaient les prémontrés pour garder le souvenir des disparus de la communauté et des donateurs. Ces listes se présentent comme des calendriers reprenant, jour par jour, la liste des morts à célébrer. Quatre nécrologes sont actuellement connus pour la circarie de Gascogne, sous la forme de copies d'époque moderne : les nécrologes de Saint-Jean de La Castelle ${ }^{6}$, d'Arthous ${ }^{7}$, de La Casedieu ${ }^{8}$ et de La Capelle ${ }^{9}$. Il n'est pas question d'entreprendre ici l'étude de ces importants documents encore peu connus. J'ai utilisé ici seulement la liste des abbés d'abbayes prémontrées liées par des prières réciproques : ces listes révèlent la circulation, depuis le XII siècle et jusqu'à l'époque moderne, d'informateurs entre ces abbayes, qui donnaient les noms de ces morts à rappeler à la mémoire des communautés. C'est ainsi par exemple que l'abbaye de La Casedieu, abbaye mère, était en relation avec une dizaine d'abbayes prémontrées; elle priait pour leurs abbés défunts au milieu d'une foule d'autres noms. Il faut noter que les trois monastères gascons étudiés reprennent les noms d'abbés des trois monastères prémontrés espagnols, preuve d'une circulation transpyrénéenne régulière (fig. 2).

Fig. 2. - Les mentions d'abbés de monastères prémontrés de la circarie de Gascogne dans trois nécrologes (XII ${ }^{\mathrm{e}}$-XIV ${ }^{\mathrm{e}}$ siècle).

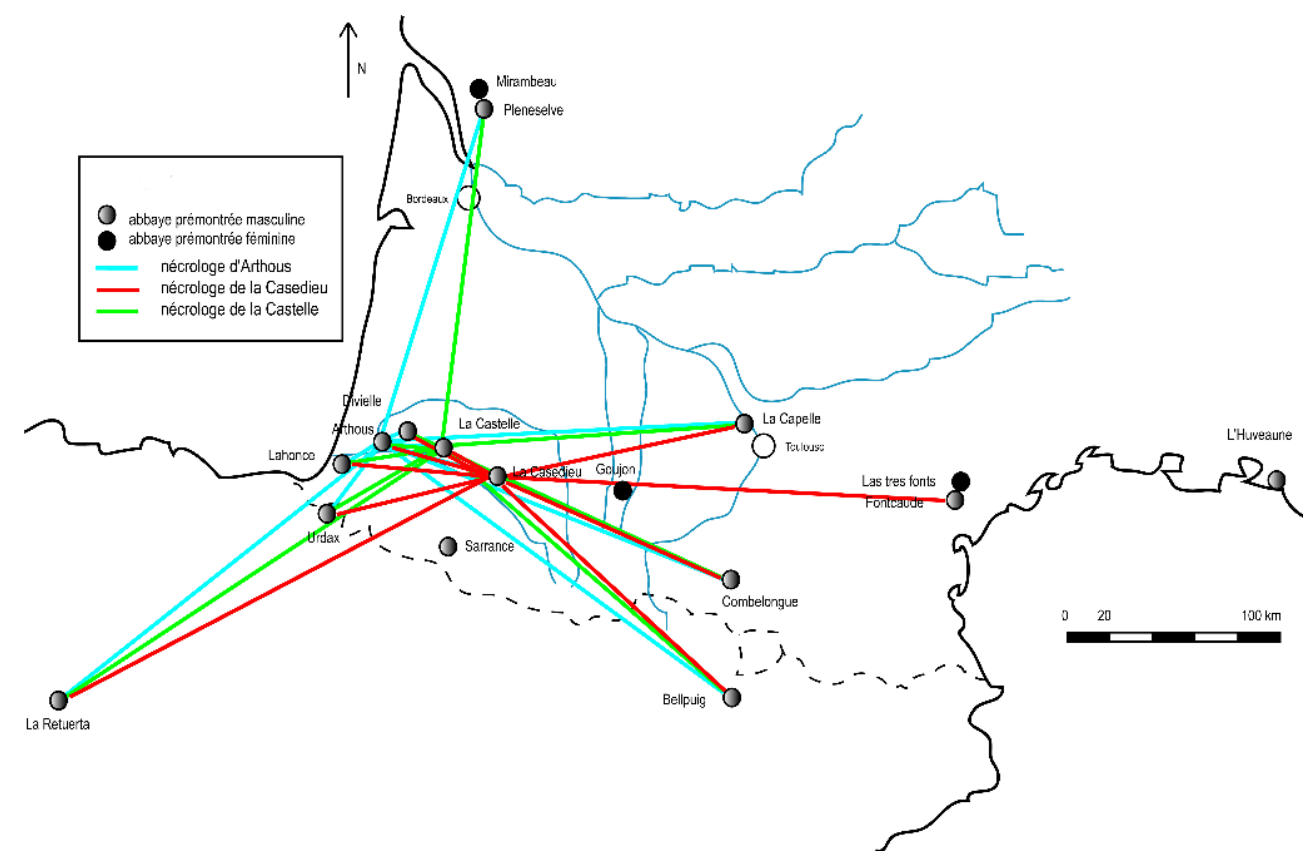

(c) Stéphane Abadie.

\section{La circarie de Gascogne, un espace transpyrénéen : fondations et visites}

Les chanoines de La Casedieu ont directement participé à la fondation de la majorité des abbayes de la circarie, en envoyant des frères assurer les premières constructions 
et la direction de ces nouveaux monastères prémontrés. Si l'on en croit différents auteurs, c'est le cas à La Capelle, Arthous, Divielle, La Castelle, Lahonce et peut-être à Combelongue et dans les premiers monastères de la péninsule Ibérique (Belpech, La Retorte et Urdax).

Le premier abbé de La Casedieu, Bernard, venu de Saint-Martin de Laon jusqu'en Gascogne, est par exemple physiquement présent en 1138 à la fondation de l'abbaye de Combelongue, en Ariège (à 160 kilomètres de La Casedieu); en 1143 à la fondation de La Capelle, près de Toulouse (à 125 kilomètres de La Casedieu); en 1148 à celle de La Retorte, près de Palencia, en Espagne ${ }^{10}$ (à 600 kilomètres de La Casedieu). Inversement, on trouve aussi des abbés prémontrés dans des monastères d'autres ordres : le même abbé Bernard est fréquemment invité chez les cisterciens de l'abbaye de Berdoues ${ }^{11}$ (à 35 kilomètres de La Casedieu). On remarque de même, vers 1200-1210, un abbé Pierre Géraud, abbé de Combelongue, présent à la donation d'une vigne au monastère bénédictin de Madiran ${ }^{12}$, à 25 kilomètres de l'abbaye de La Casedieu et à plus de 160 kilomètres du monastère dont il avait la charge.

$7 \mathrm{Au}$ milieu du XIII ${ }^{\mathrm{e}}$ siècle, à l'exception de Sarrance, toutes les abbayes prémontrées identifiées sont en place entre Bayonne et Marseille: elles forment l'armature d'une circonscription prémontrée, la circarie de Gascogne, dont la tête est l'abbaye mère de La Casedieu, première fondée dans la région. Cette structure impose de visiter régulièrement l'ensemble des abbayes et d'en régler les problèmes de discipline. Cela impose aussi, tous les ans, de "monter " à Prémontré pour participer au chapitre général de l'ordre.

Un règlement fut écrit en 1354 pour organiser la participation "par roulement » au chapitre général. La première année, les abbés de La Casedieu, La Castelle, Belpech et Urdache se déplaçaient à Prémontré ; la seconde année, c'étaient les abbés de Divielle, Arthous et Lahonce ; la troisième, les abbés de Combelongue, La Capelle, Fontcaude et Pleneselve ${ }^{13}$. Ce mode de fonctionnement semble avoir été pratiqué assez régulièrement, car le texte le réglementant fut encore collationné en $1630^{14}$.

9 Les abbés de La Casedieu étaient chargés de visiter les abbayes de la circarie pour « réformer, ordonner, corriger, confirmer les abbés, donner les bénéfices ${ }^{15}$ ». En $1401^{16}$, la visite annuelle concerne par exemple sept abbayes de la circarie, dont trois abbayes espagnoles (fig. 3). Le déplacement était réalisé à partir d'une lettre de commission ou de visite qui était envoyée par l'abbé de Prémontré à la suite d'un chapitre général. L'inventaire des archives de La Casedieu conserve la trace de commissions de visite à partir de 1490, mais il est probable que ces commissions existaient au moins depuis le siècle précédent et que les visites étaient déjà organisées sous forme embryonnaire précédemment ${ }^{17}$. Des abbés d'autres abbayes de la circarie pouvaient être chargés des visites, comme en 1465 Bernard, abbé de La Capelle ${ }^{18}$. 
Fig. 3. - La visite de la circarie de Gascogne en 1401.

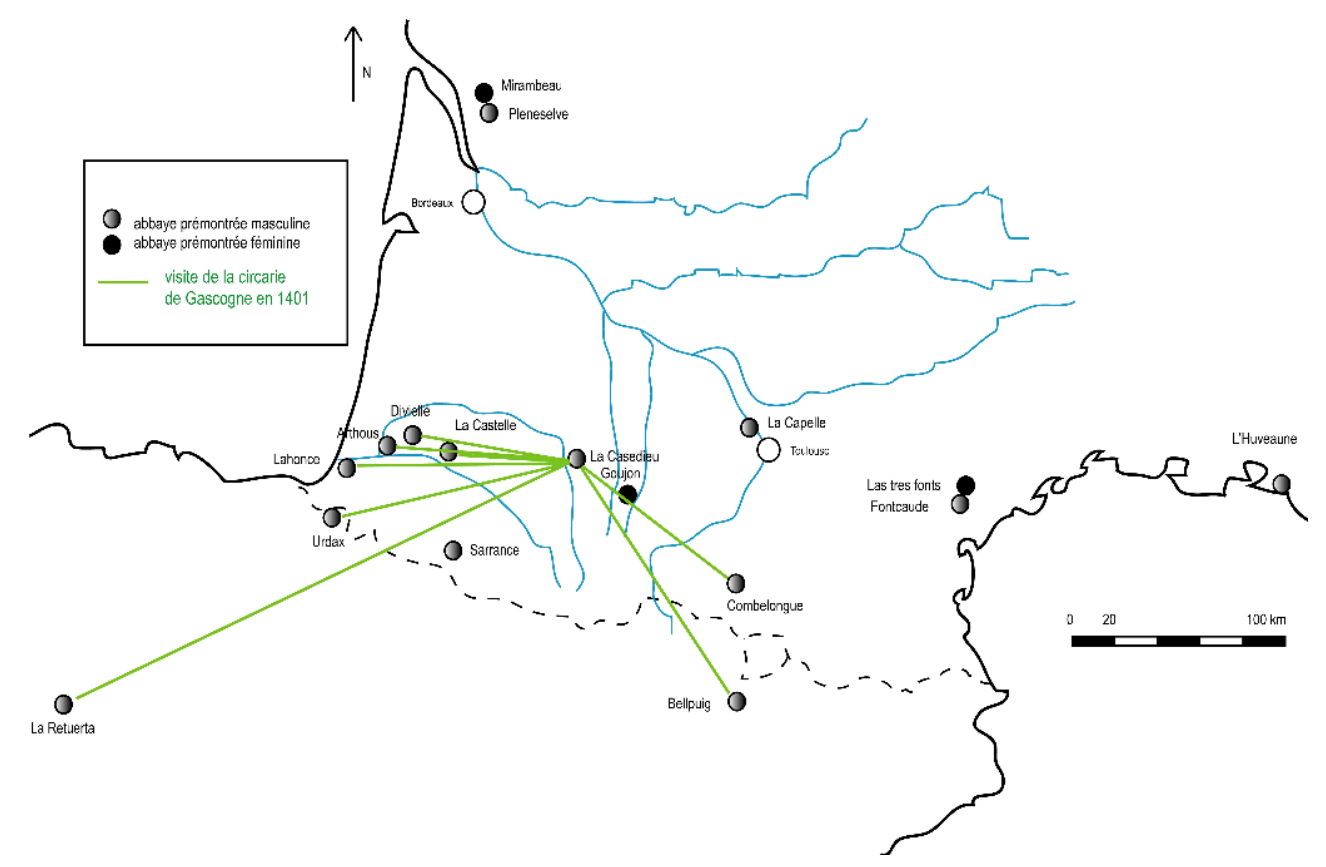

(c) Stéphane Abadie.

10 L'analyse d'une lettre de 1403 concernant l'abbé de La Retorte prouve que l'abbé de La Casedieu était chargé de la résolution de certains conflits internes dans sa circarie. Dans ce cas précis, l'abbé défend aux autres abbés de se prononcer sur l'abbé de La Retorte pour ses méfaits supposés, le cas lui étant réservé ${ }^{19}$. On sait par d'autres exemples que l'abbé de La Casedieu validait les désignations d'abbés effectuées par élection dans certains monastères, comme à Belpech en $1348^{20}$ ou à Urdache en 1386. En 1440, par exemple, Jean de Bahalon est élu abbé de La Retorte. Son élection est confirmée par l'abbé de La Casedieu ${ }^{21}$.

11 Comment s'effectuaient les déplacements? Les sources consultées sont totalement muettes sur ce point. En Gascogne, les granges monastiques et les couvents amis, notamment cisterciens, pouvaient servir de relais d'hébergement. Pour passer en Espagne, les prémontrés de La Casedieu possédaient au col des Ares un petit prieuré de montagne nommé Sainte-Anne-des-Arres, près de Saint-Bertrand-de-Comminges, sur la route du val d'Aran et de la Catalogne, ce qui leur permettait d'accéder ensuite au monastère de Belpech, au nord de Lérida. Les chanoines de Saint-Jean de La Castelle possédaient aussi (repris dans les années 1340) le petit monastère de Sarrance, dans la vallée d'Aspe (Pyrénées-Atlantiques), vallée qui permettait de passer, via le Somport, au monastère de La Retorte, près de Palencia, à trois semaines de marche. Les prémontrés disposaient également d'un ensemble de petits hôpitaux au Pays basque, sur les chemins de Saint-Jacques, qui permettaient de circuler sur les voies jacquaires, par exemple vers l'abbaye d'Urdache (fig. 1 et 3). 


\section{Des chanoines voyageurs : éléments de prosopographie}

12 À l'échelle locale, les chanoines d'une abbaye prémontrée circulaient en permanence entre les granges monastiques et les églises dont ils avaient la charge. Par exemple, le prieuré de Vic-Fezensac, dépendance de l'abbaye de La Casedieu, avait en charge vers 1460 cinq églises paroissiales et quatre granges dans un rayon d'une dizaine de kilomètres, obligations que se partageaient les douze chanoines résidant dans ce prieuré alors récemment rebâti. Des chanoines portaient le titre de frères grangers, d'autres prenaient en charge une paroisse pour une ou plusieurs années ${ }^{22}$ (fig. 4).

Fig. 4. - Granges et églises dépendant du prieuré prémontré de Vic-Fezensac (Gers) vers 1460. Les chanoines prémontrés devaient assurer quotidiennement le service divin dans les paroisses dont ils avaient la charge.

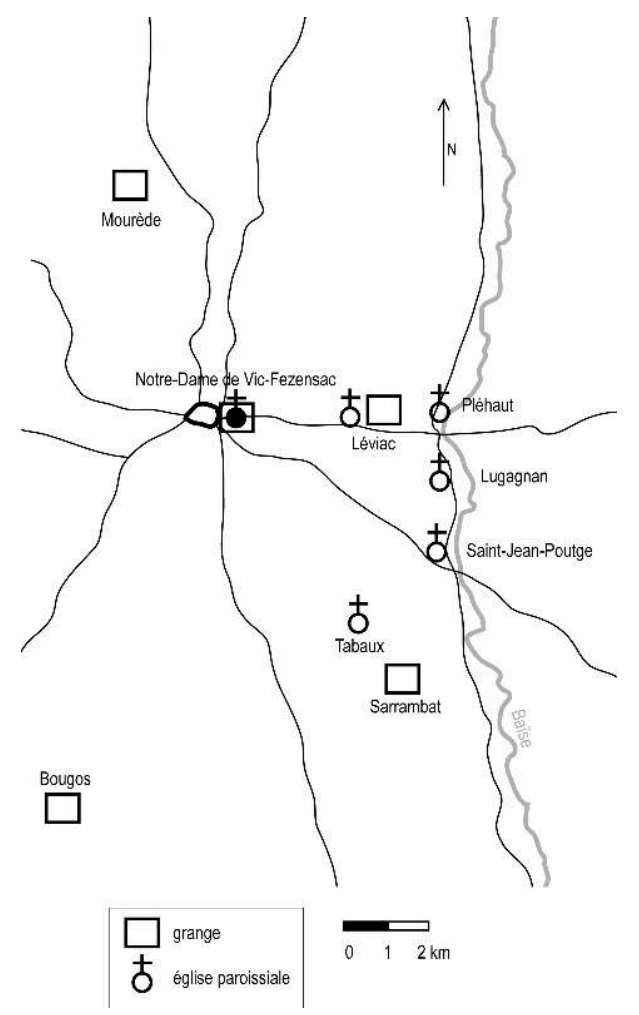

(c) Stéphane Abadie.

À l'échelle de la circarie, certains visiteurs pouvaient, à l'occasion, être particulièrement appréciés lors de leur passage et devenir par la suite abbés dans une des abbayes visitées. C'est par exemple le cas d'un Jacques, abbé de La Capelle, qui devint abbé de Combelongue en $1322^{23}$. Une note de Larcher ${ }^{24}$ fait également entrevoir des échanges fréquents, épistolaires et physiques, des visites entre monastères proches, des prises d'habit... L'abbé de Lahonce, Pierre Beyries, donna par exemple l'habit au futur abbé d'Urdache, Pierre de Saint-Martin, en 1474, et organisa le procès d'un chanoine d'Arthous avec ce même abbé d'Urdache en 1480. Arnaud de Saint-Loubouey fut successivement abbé de Divielle, abbé de La Capelle puis abbé de La Casedieu vers $1265^{25}$. L'abbé Jean II de Cers, abbé de La Casedieu vers 1366, qui fonde une chapelle abbatiale et une chapellenie dans cette abbaye, est d'abord abbé de Fontcaude, près de 
Béziers ${ }^{26}$. Un siècle plus tard, l'abbé Arnaud de Melhon est successivement abbé de La Capelle, de Belpech puis de La Casedieu. Il termine visiteur général de l'ordre à Avignon après $1413^{27}$ (fig. 5). Pierre II de Montus, docteur en droit canon, fut élu abbé de La Casedieu le 17 août 1459. Il prêta serment de fidélité au roi le 6 novembre 1459. Il partit ensuite pour Rome, où il obtint pour lui et ses successeurs en 1462 l'usage de la mitre et des ornements pontificaux ${ }^{28}$.

Fig. 5. - Représentation graphique de carrières de chanoines prémontrés (XIII ${ }^{\mathrm{e}} \mathrm{xV} \mathrm{V}^{\mathrm{e}}$ siècle).

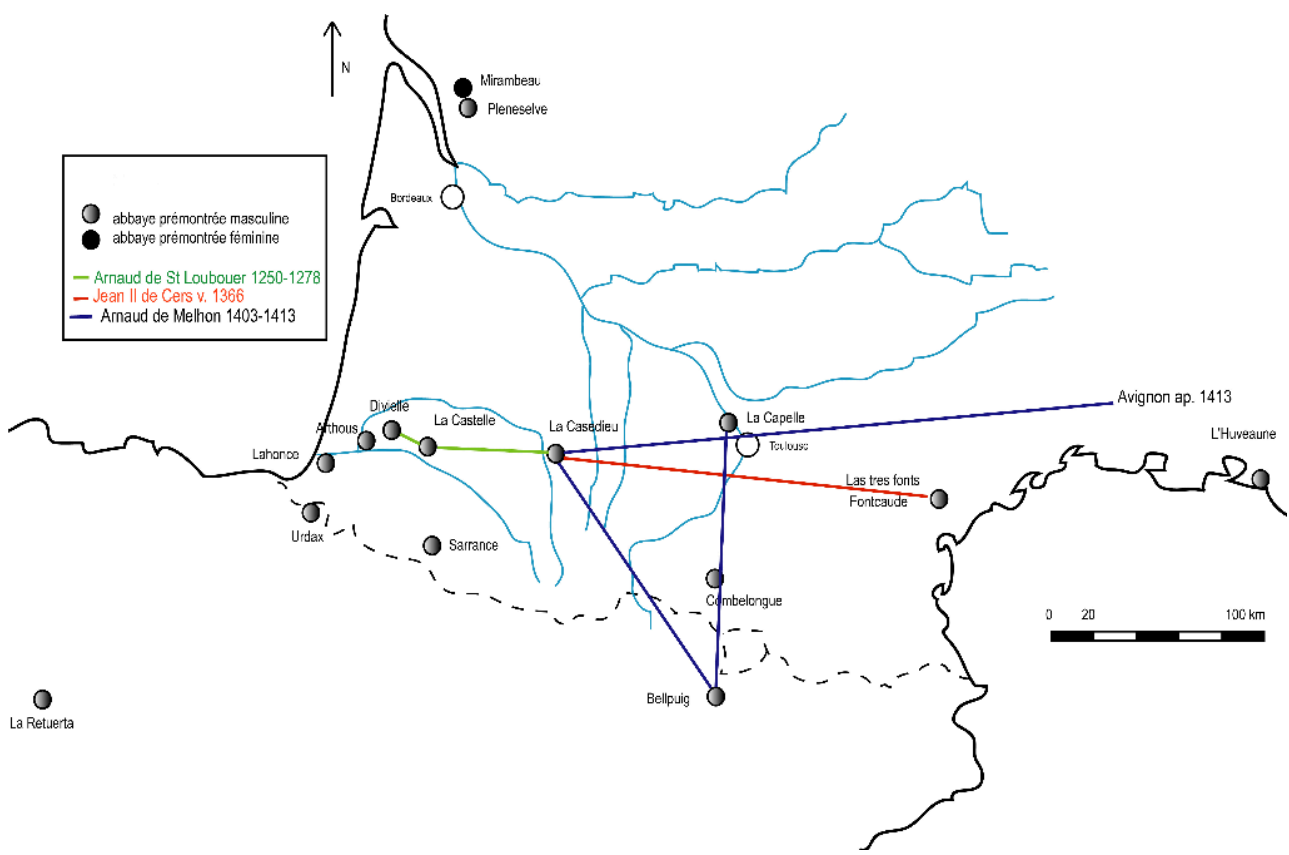

(c) Stéphane Abadie.

Il faut noter également la relative porosité sociale entre les abbés, souvent bien formés intellectuellement et titulaires de grades universitaires ${ }^{29}$, et le milieu épiscopal local. Par exemple Martin, abbé de La Castelle, est nommé évêque d'Aire en 1194. Navarre d'Acqs, abbé de Combelongue, devient évêque de Couserans (1208-1211) et participe également à la fondation de l'abbaye de Divielle, dans les Landes ${ }^{30}$. Jean I ${ }^{\mathrm{er}}$, abbé de La Casedieu, devient évêque d'Aire en $1215^{31}$. En 1410, l'abbé de La Castelle, Pierre III de Castelnau, devient évêque de Dax $^{32}$, etc.

Les chanoines prémontrés de la circarie de Gascogne, on le voit, étaient particulièrement mobiles, dès la fondation de l'abbaye de La Casedieu et de ses premières abbayes filles dans les années 1130 . Du fait de leur fonctionnement interne et d'une règle libérale n'imposant pas la clôture stricte, tous les chanoines étaient amenés à circuler entre les granges monastiques, les hôpitaux et les églises dont ils avaient la charge; à l'échelle de la circarie, les abbés et prieurs voyageaient presque chaque année pour visiter les membres de l'ordre en France et en Espagne. L'implantation de prieurés et d'hôpitaux dans les vallées permettait de circuler à travers les Pyrénées sans faire appel à de trop nombreuses étapes hors de l'ordre : pour les prémontrés, les Pyrénées ne furent manifestement jamais une barrière. Ces fréquents déplacements 
expliquent en partie les carrières parfois spectaculaires d'abbés prémontrés, qui passent de la tête d'une abbaye à une autre et parfois d'une abbaye à un siège épiscopal, voire à la curie.

Ces multiples contacts avec le monde appellent d'autres réflexions : quels sont, par exemple, les auteurs des bâtiments et des sculptures très variées présentes dans les abbayes prémontrées pendant tout le Moyen Âge ? C'est un champ qui commence à peine à être exploré pour cette région.

In fine, il serait souhaitable que des études comparables soient menées pour d'autres ordres, dont les cisterciens, proches "cousins" des prémontrés, pour vérifier si ce caractère voyageur des abbés et prieurs se retrouve également, malgré le caractère apparemment plus contraignant de leurs règles monastiques.

\section{BIBLIOGRAPHIE}

ABADIE Stéphane, « Un temporel monastique dans l'espace médiéval gascon : l'abbaye prémontrée de La Casedieu $\left(\mathrm{XII}^{\mathrm{e}}-\mathrm{XVI}^{\mathrm{e}} \mathrm{s}\right.$.) », thèse de doctorat, Toulouse, université de Toulouse - Jean-Jaurès, 2016.

ARDURA Bernard, Prémontrés, histoire et spiritualité, Saint-Étienne, CERCOR, 1995.

BACKMUND Norbert, Monasticon Praemonstratense : id est, historia circarium atque canoniarum candidi et canonici Ordinis Praemonstatensis, Staubing, 1949-1956.

CAZAURAN Jean-Marie, Cartulaire de Berdoues, La Haye, Nijhoff, 1905.

CLERGEAC Adrien, Chronologie des archevêques, évêques et abbés de l'ancienne province ecclésiastique d'Auch, et des diocèses de Condom et de Lombez, 1300-1801, Paris / Auch, Société historique de Gascogne, 1912.

DAUZET Dominique-Marie, Petite vie de saint Norbert : 1080-1134, Paris, Desclée de Brouwer, 1995. DEGERT Antoine, « Le nécrologe d'Arthous », Bulletin de la Société de Borda, 1924, p. 175-187. DEGERT Antoine, «Le nécrologe de Saint-Jean de La Castelle », Bulletin de la Société de Borda, 1925, p. 36-46.

GRAUWEN Wilfried-Marcel (éd.), Het leven van Heer Norbert Artbisschop van Maagdenburg: Vita Norberti A, Avebode, Bibliotheca analectorum præmonstratensium, 1984.

LEMAITRE Jean-Loup, Répertoire des documents nécrologiques français, Paris, De Boccard, 1980.

LÓPEZ DE GUEREÑO SANZ Maria Teresa, « Los patios premonstratenses », dans Yarza Luaces J. et Boto Varela G. (dir.), Claustros románicos hispanos, Madrid, Edilesa, 2003. 


\section{NOTES}

1. La bibliographie sur Norbert de Xanten est essentiellement écrite en langue allemande et flamande; par exemple, pour l'édition latine de la vita norbertine : W.-M. Grauwen (éd.), Het leven van Heer Norbert Artbisschop van Maagdenburg. En langue française: D.-M. Dauzet, Petite vie de saint Norbert; B. Ardura, Prémontrés, histoire et spiritualité. Un panel bibliographique important est disponible à la bibliothèque du CERCOR, à l'université de Saint-Étienne.

2. Les monastères prémontrés ont été étudiés par N. Backmund, Monasticon Praemonstratense, qui consacre une notice en latin à chaque abbaye.

3. Sur la circarie de Gascogne, voir S. Abadie, « Un temporel monastique dans l'espace médiéval gascon: l'abbaye prémontrée de La Casedieu ", t. III (volume consacré aux abbayes filles sous la forme de courtes notices).

4. Voir M. T. López de Guereño Sanz, « Los patios premonstratenses », p. 207 sq.

5. Sur les nécrologes, leur origine et leurs usages, voir J.-L. Lemaitre, Répertoire des documents nécrologiques français, en particulier l'introduction.

6. A. Degert (éd.), « Le nécrologe de Saint-Jean de La Castelle».

7. A. Degert (éd.), «Le nécrologe d'Arthous". Ce nécrologe comporte des mentions d'abbés jusqu'au Xvir ${ }^{\mathrm{e}}$ siècle. La majorité des mentions de ces nécrologes remonte cependant aux XII ${ }^{\mathrm{e}}$-XIV ${ }^{\mathrm{e}}$ siècles.

8. Bib. mun. Tarbes, J.-B. Larcher, Glanage ou preuves, t. V, p. 16 sq. (publication en cours sous la direction de Xavier Ravier).

9. Arch. dép. Haute-Garonne, série B, copie du XVII siècle inédite.

10. Arch. dép. Gers, H5, fol. 495.

11. J.-M. Cazauran (éd.), Cartulaire de Berdoue: l'abbé de La Casedieu, Bernard, est témoin de donations aux cisterciens dans les actes 94, 96, 266, 268, 388, 447, 765.

12. BNF, ms. Doat, vol. 152 , fol. $184 \mathrm{v}^{\circ}-185 \mathrm{r}^{\circ}$ : «[ [donatio facta] in manu Petri Geraldi abbatis de Comalonche [...] ».

13. Arch. dép. Gers, H5, p. 49, $n^{\circ} 1$.

14. Ibid., $\mathrm{n}^{\circ} 2$. Dans le $\mathrm{n}^{\circ} 4$ cependant, daté de 1516 , le chapitre général se plaint du manque de régularité de la participation des abbés de la circarie de Gascogne aux réunions à Prémontré.

15. Arch. dép. Gers, H5, p. 57, $\mathrm{n}^{\circ} 7$ : « Extrait de la lettre de commission de 1615 donnée au prieur de La Casedieu ».

16. Arch. dép. Gers, H5, p. 55.

17. Arch. dép. Gers, H5, «Catalogue des abbés » : par exemple, en 1185, l'abbé de La Casedieu, Ponce II, confirme la soumission de La Vid à La Retorte.

18. Arch. dép. Gers, H5, p. 12, no 3.

19. Ibid., p. $53, n^{\circ} 6$.

20. Arch. dép. Hautes-Pyrénées, J.-B. Larcher, Dictionnaire, p. 171, art. «Dangais »: "Gaillard, abbé de Belpech, mourut le $29^{\mathrm{e}} \mathrm{d}$ 'aout 1348. Quelques religieux elirent Berenger Alegir de Corta, d'autres Jean d'Andrest, sous-prieur de La Casedieu. Dangais confirma comme pere abbé l'election d'Alegir ».

21. Ibid., p. $53, \mathrm{n}^{\circ} 8$. 
22. De nombreux exemples sont recensés dans l'inventaire des titres de l'abbaye aux Arch. dép. Gers, H5 ; transcription intégrale du volume dans S. Abadie, «Un temporel monastique dans l'espace médiéval gascon ", t. II. À l'époque moderne, des chanoines de Vic-Fezensac obtinrent la construction de presbytères près des églises paroissiales dont ils avaient la charge, pour éviter les déplacements quotidiens depuis le prieuré.

23. A. Clergeac, Chronologie des archevêques, évêques et abbés..., p. 70.

24. Arch. dép. Hautes-Pyrénées, J.-B. Larcher, Dictionnaire, p. 496, art. « Beyries ».

25. Ibid., p. 577, art. «Divielle ».

26. Arch. dép. Gers, H5, p. 497.

27. Ibid.

28. Ibid.

29. Les prémontrés fondent par exemple en 1488 un collège universitaire à Toulouse, pour y former des chanoines en droit canon. Voir S. Abadie, « Un temporel monastique dans l'espace médiéval gascon ", t. VI, p. 175-176, fiche $n^{\circ} 84$.

30. Navarre d'Acqs ou de Dax, abbé de Combelongue, évêque de Couserans (1208-1211), fonde l'abbaye prémontrée de Divielle en 1209. Il a été légat du pape Innocent III lors des querelles religieuses entre catholiques et cathares à Montréal et au colloque de Pamiers (1207). Voir A. Clergeac, Chronologie des archevêques, évêques et abbés...

31. Arch. dép. Gers, H5, p. 496.

32. J.-B. Larcher, Glanage ou preuves, t. XXI, p. 372-373.

\section{RÉSUMÉS}

Les chanoines prémontrés ou norbertins ont connu une implantation importante dans le sud de la France et le nord de l'Espagne, avec une trentaine de monastères et prieurés dès les années 1135. On peut observer les mouvements de ces religieux à partir de sources originales: les nécrologes de trois monastères permettent d'appréhender le va-et-vient des chanoines et de leurs rouleaux des morts aux XII ${ }^{\mathrm{e}}$ et XIII ${ }^{\mathrm{e}}$ siècles ; la mise en place d'une circonscription religieuse, la circarie de Gascogne, imposa des visites régulières de tous les membres; enfin une reconstitution de la carrière de quelques ecclésiastiques éclaire également sur les déplacements de ces chanoines.

\section{AUTEUR}

\section{STÉPHANE ABADIE}

Docteur en histoire médiévale, enseignant au lycée Marie-Curie (Tarbes) 


\title{
Evidencias arqueológicas de un monasterio de los siglos VI-VII en el Prepirineo catalán: Santa Cecilia de Els Altimiris
}

\author{
Marta Sancho i Planas
}

1 El período que se sitúa entre la desestructuración del imperio romano y la consolidación de los condados catalanes presenta numerosos vacíos interpretativos, achacados con demasiada facilidad, a la falta de fuentes para su estudio. Afortunadamente, en los últimos años, la investigación arqueológica está aportando datos de gran interés permitiéndonos identificar distintos modelos de ocupación del territorio a los que van unidos diferentes tipologías de asentamientos, estructuras sociales y caracterizaciones culturales. Probablemente la característica principal de dicho período consiste en la variabilidad y diversidad de modelos que conviven en un mismo espacio físico y temporal. Este artículo tiene como objetivo establecer un marco interpretativo que nos permita ubicar el yacimiento de Els Altimiris dentro de un contexto histórico que se extiende desde finales del siglo V hasta inicios del siglo VIII.

\section{Contexto historiográfico}

2 El paso de la hegemonía romana a la diversidad medieval se ha intentado explicar tanto como una evolución llena de continuidades como a través de rupturas y cambios bruscos cronológicamente diversos. Estos discursos se han visto influenciados por la necesidad de explicar el origen y las diferencias de realidades culturales que están en la base de buena parte de los estados europeos actuales. Este es el caso del territorio catalán en el que la génesis, consolidación y posterior decadencia del imperio carolingio, paralelo a la evolución de Al-Andalus, ha permitido construir un discurso historiográfico sólido y coherente ${ }^{1}$. Los siglos anteriores -VI, VII y parte del VIII- no 
resultan útiles, tienen poco interés historiográfico y son vistos como un período decadente.

3 Situados en este modelo interpretativo, tan solo las aportaciones de la arqueología pueden ofrecernos nuevos datos sobre los que construir un nuevo discurso capaz de superar viejos esquemas historiográficos. Este período, que cronológicamente podemos denominar como la Temprana Edad Media, lo podemos definir, desde el punto de vista socio-cultural, como protomedieval.

4 Frente a las interpretaciones que destacan el retroceso técnico, la decadencia económica, el declive demográfico y la desestructuración social y política, proponemos un cambio en les formes de ocupación del territorio y del modelo socioeconómico como consecuencia de la adaptación a una nueva realidad y a unas necesidades distintas.

5 Buscamos alternativas para superar una cierta invisibilidad de los grupos que habitaban un determinado territorio y el vacío dejado por una historiografía que se ha limitado a la lectura de actas de concilios y compendios jurídicos. Algunas de estas aportaciones, más afortunadas que otras, constituyen buenas síntesis y nos presentan un marco político en el que se cuestionan algunos de los planteamientos más tradicionales ${ }^{2}$.

6 Por lo que respecta a las fuentes arqueológicas, la poca entidad de las estructuras correspondientes a los siglos VI-VII, y los materiales y objetos, pobres y poco definidos, dificultan enormemente su interpretación. Las producciones cerámicas ya no aportan la datación precisa característica de períodos anteriores, y perderán su papel como fósil director de tota intervención. En definitiva, todo un reto para los arqueólogos que se enfrentan a estas realidades.

7 Estas dificultades, junto con la escasa vistosidad de los descubrimientos que aporta la arqueología de este período, han provocado un cierto abandono por parte de la práctica investigadora. Afortunadamente, este panorama ha cambiado radicalmente con el desarrollo de una arqueología más profesionalizada y ligada a la obra pública y privada, a través de protocolos de actuación marcados por las administraciones. Debemos destacar los trabajos de prospección y excavación ligados a la construcción de grandes infraestructuras (carreteras y vías férreas) y a las promociones urbanísticas realizadas en les periferias de les aglomeraciones urbanas.

8 Durante la década de los 90 del siglo pasado destacan, para Francia, los resultados del seguimiento arqueológico realizado con motivo de la construcción del TGVMéditerranée a su paso por el valle del Rhone, que sacó a la luz un total de 14 yacimientos de época medieval, de los cuales 9 presentan cronologías anteriores al siglo IX ${ }^{3}$. Una década más tarde, el crecimiento urbanístico ha posibilitado la localización de una serie de yacimientos que presentan cronologías de los siglos VI y VIII ${ }^{4}$. En España, destacan los trabajos realizados en las inmediaciones de ciudades como Madrid y Toledo, también vinculados a la obra pública y privada, con resultados similares ${ }^{5}$.

9 La concentración de intervenciones en zonas urbanas y periurbanas ha provocado una distorsión en el conocimiento de este tipo de yacimientos, ya que casi no disponemos de ejemplos para las zonas más ruralizadas. Algunas iniciativas, como la realizada recientemente por Guidi y Villuendas, con datos sobre yacimientos excavados anteriores al siglo XI para diversas comarcas catalanas, nos permiten construir un contexto y puede servir de punto de partida para futuras investigaciones ${ }^{6}$. 
10 Progresivamente la investigación arqueológica empieza a dar sus frutos y de ellos se derivan debates que nos permitirán construir un marco interpretativo más completo. A grandes rasgos, podemos decir que con la desarticulación de las estructuras romanas, precedida de una serie de crisis de diferentes características e intensidades, se producen una serie de cambios en los modelos de hábitat y de ocupación del territorio que en cada zona seguirán caminos distintos.

11 Las ciudades perderán buena parte de su población, y solamente conservarán un cierto carácter urbano aquellas que se convirtieron en sede episcopal. En este caso, los obispados substituirán progresivamente las estructuras de poder propias del imperio ${ }^{7}$. Las villae de su territorio entrarán en decadencia y muchas de ellas desaparecerán definitivamente, mientras que otras se transformarán manteniendo su espacio de cultivo y generando nuevos asentamientos en sus proximidades.

12 Mientras se desarrollaba este proceso en las zonas más romanizadas, en las zonas montañosas, las pocas ciudades existentes se veían afectadas del mismo modo por la crisis, aunque probablemente la actividad productiva, basada en la explotación de los recursos naturales y en la ganadería, no se vería tan afectada por los cambios acaecidos. Los habitantes de zonas como la pirenaica continuarían desarrollando sus actividades, adaptándose a la nueva situación de descenso de la demanda de sus productos. Se trataba de colectivos muy bien adaptados a las condiciones específicas de los entornos montañosos, que habitaban y se organizaban para explotar unos recursos esencialmente forestales, minerales y ganaderos ${ }^{8}$. Durante el período romano no estuvieron sometidos a ningún tipo de servilismo, disponían de una sólida estructura social, probablemente con líderes propios dentro de la comunidad y, sobretodo, eran libres ${ }^{9}$. Los recursos que explotaban no estaban sometidos a ningún tipo de carga fiscal, a excepción de las tierras agrícolas centuriadas próximas a las pocas ciudades existentes. En definitiva, a pesar de la crisis, creemos que la crisis del imperio afectó en menor medida estas zonas debido a su situación periférica dentro del sistema.

13 Dado que no se encontraba excesivamente lejos de las áreas más romanizadas, la zona pirenaica se convirtió en una tierra de oportunidades para los desplazados que provocó la crisis, desde los esclavos fugitivos hasta los miembros de la aristocracia romana, pasando por artesanos y trabajadores urbanos de distinto nivel socioeconómico. La huida de las obligaciones fiscales que se mantuvieron en las zonas urbanas, impuestas por las élites eclesiásticas, fue un incentivo para muchos de ellos, especialmente para los que no consiguieron mantener su nivel socioeconómico a raíz de la caída del imperio.

14 La montaña ofrecía grandes extensiones de terreno que no era de nadie y era de todos, una forma de explotación de los recursos bien adaptada y practicada por sus habitantes, basada en la ganadería y en el bosque, y un modelo de cooperación y cohesión social entre hombres libres. La base legal está presente en el código visigodo desde la primera mitad del siglo VII; la prescripción de los 30 años, por la cual cualquiera que pueda demostrar que posee un bien durante treinta años sin que nadie se la reclame, pasará a ser de su propiedad ${ }^{10}$.

15 En este contexto, las noticias de la existencia de comunidades monásticas que proliferan por la zona del Pirineo, especialmente en las actuales provincias de Lleida y Huesca, se ajusta a este movimiento de ocupación del territorio de montaña por parte de personas procedentes de áreas del llano y la costa. 
Durante el siglo VI, la proliferación de comunidades de este tipo provocó la reacción del poder episcopal, como se detecta en los cánones de diversos concilios, entre ellos el celebrado en Lleida en el año 546. En las actas de este concilio encontramos un canon que pretende regular la existencia de los nuevos monasterios, evitando, así, que amparados en este modelo, se constituyesen como falsos monasterios con la única finalidad de quedar exentos de cualquier obligación tributaria con el obispado. La única injerencia episcopal consistía en la aprobación de la regla por la que se regía la comunidad $^{11}$. Este modelo interpretativo es el que más se adecúa a las evidencias arqueológicas descubiertas en el yacimiento de Els Altimiris, las características del cual exponemos a continuación ${ }^{12}$.

\section{Santa Cecilia de Els Altimiris: un monasterio de montaña de los siglos VI-VII}

Desde el año 2004 estamos realizando intervenciones arqueológicas en este yacimiento situado en la vertiente Norte del Montsec d'Ares (St. Esteve de la Sarga - Pallars Jussà) (fig. 1). Las campañas se limitan a dos semanas anuales por lo que los resultados son lentos y más si tenemos en cuenta las dificultades logísticas que plantea su excavación (desforestación de un frondoso bosque de encinas y acceso andando durante más de una hora superando un desnivel, próximo a los $400 \mathrm{~m}$., diariamente).

Fig. 1. - Ubicación de Els Altimiris dentro de la península ibérica, Catalunya y en su entorno inmediato.

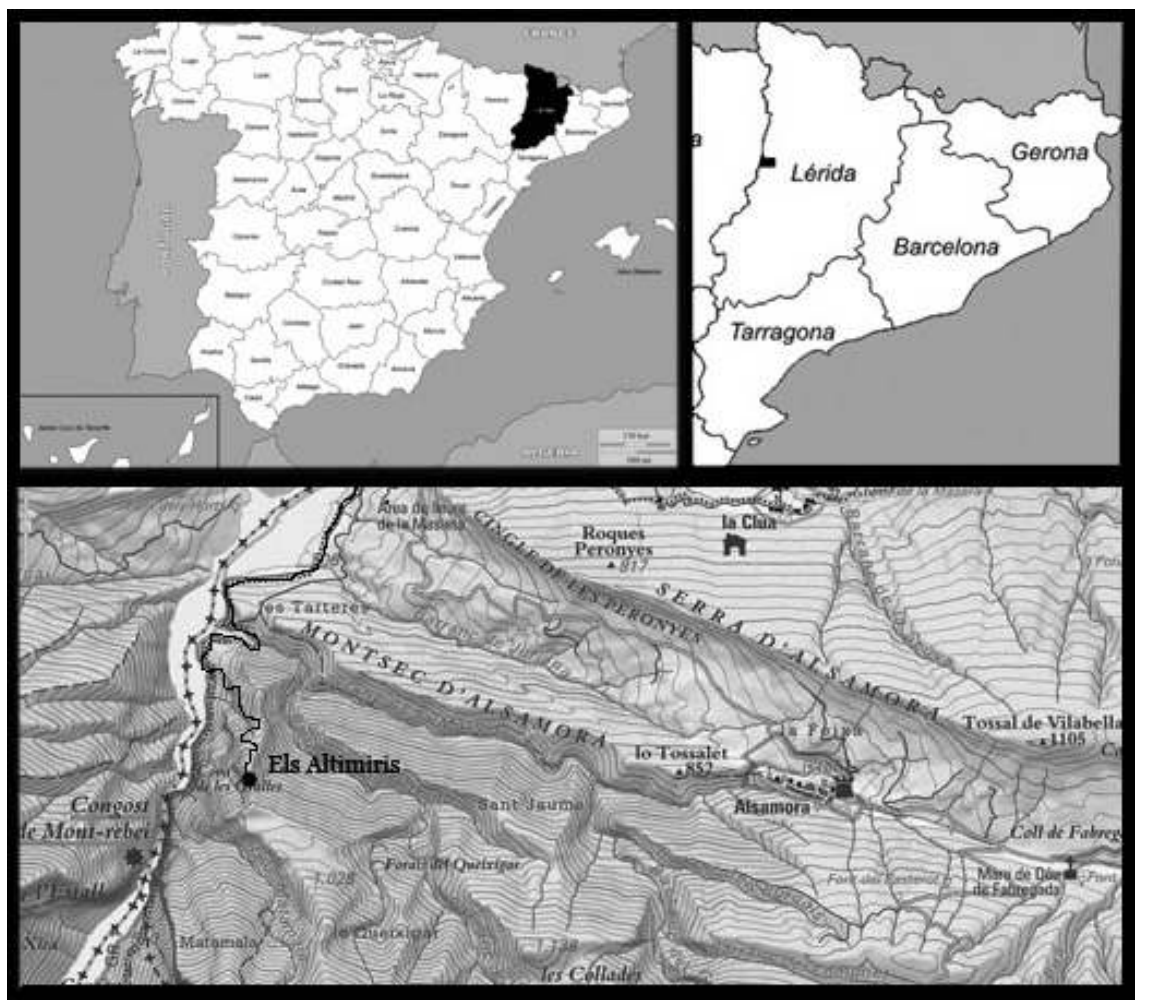

(c) Marta Sancho i Planas.

Las catorce campañas realizadas hasta la actualidad nos han permitido completar la excavación del interior de la iglesia y de su entorno, abarcando una franja de 
aproximadamente 7 metros, tanto por su lado sur como por el norte. También hemos completado la excavación de un edificio residencial situado en la parte más alta del yacimiento, de tres fondos de cabaña y de una de las tres cisternas existentes.

Los primeros fondos de cabaña que excavamos (cabañas 1 y 2) se encuentran situados a pocos metros al este de la cabecera de la iglesia. La cabaña 1 presenta unas dimensiones de $2 \times 3$ '5 metros y la 2 de $3 \times 3$ metros aproximadamente. Limitan una con la otra de forma que constituyen un conjunto único. La cabaña 1 presenta una estructura excavada en la misma roca de $100 \times 80$ centímetros, que interpretamos como la base de un fuego, ya que la roca presentaba indicios de rubefacción. La cabaña 2 dispone de una banqueta de piedras en todo su perímetro, un agujero de poste en el lado oriental y dos canales de drenaje del agua, uno en el exterior y otro que atraviesa toda la estructura por el interior. La localización de pequeñas escorias de hierro y de fragmentos de pedernal, en los niveles de la cabaña 1, nos permiten proponer como interpretación de este espacio la de un taller de herrero de pequeñas dimensiones. A pesar de las escasas evidencias de que disponemos, la recuperación de objetos de hierro y de escorias en otras zonas del yacimiento evidencian la presencia de una actividad siderúrgica de transformación en dicho lugar (fig. 2).

Fig. 2. - Topográfico de la parte central del yacimiento con los elementos más destacados. Conjunto monástico realizado con técnicas fotogramétricas.

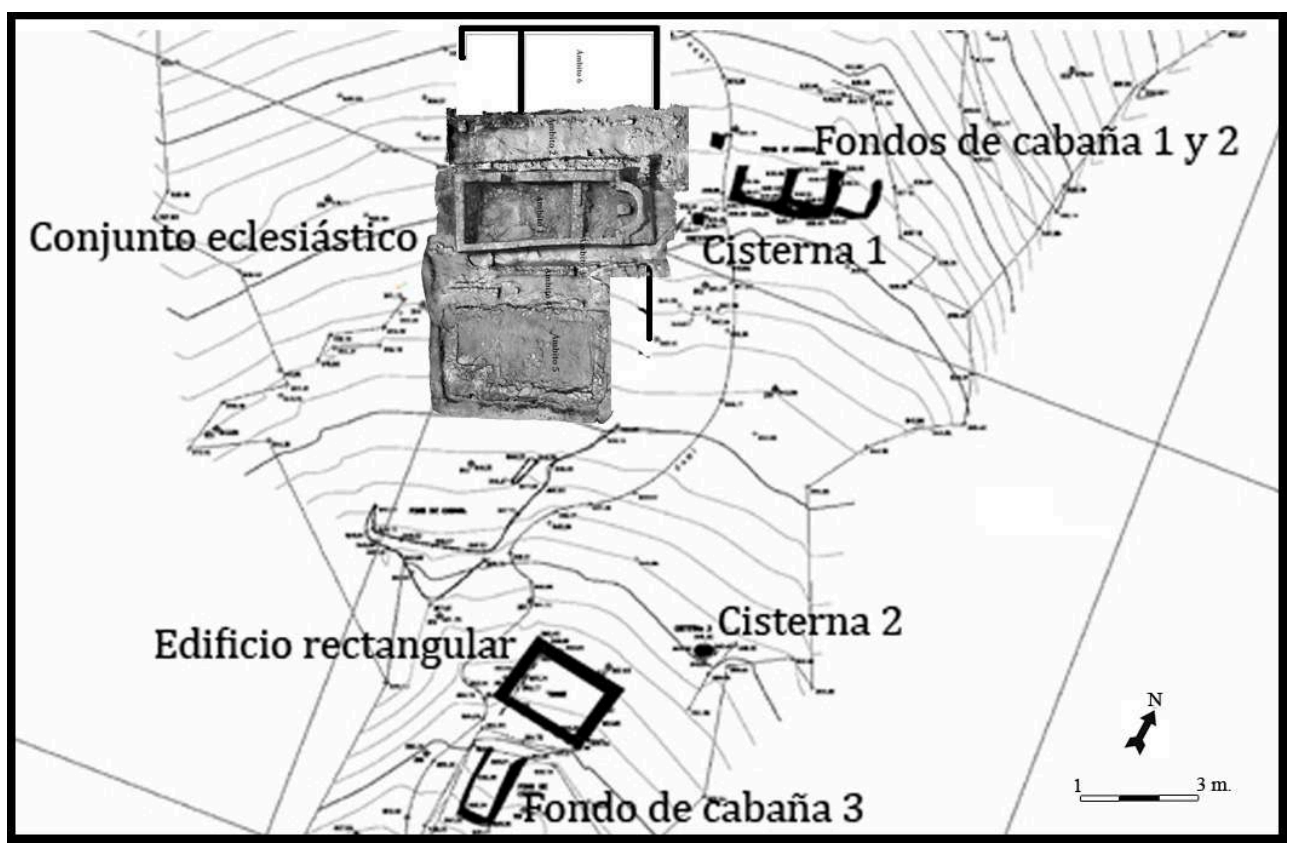

(C) Marta Sancho i Planas.

El fondo de cabaña 3 se encuentra situado al sur del edificio residencial que describiremos a continuación, a escasa distancia de este (fig. 3). Sus dimensiones aproximadas son de $3 \times 6$ metros y el zócalo de roca es mucho más profundo que en las dos anteriores superando los 1'5 metros. Presenta una banqueta picada en la roca en el lado este y diversos encajes y recortes de la roca que corresponden a los apoyos de la parte construida con materiales perecederos. A pesar de la escasez de los materiales recuperados en los fondos de cabaña, hemos podido identificar algunas piezas que presentan cronologías de los siglos V-VI. 
Fig. 3. - Fotogrametría de la cabaña 3. Se pueden observar los encajes para la cubierta y la banqueta picada en la roca en el lado oriental de la estructura.

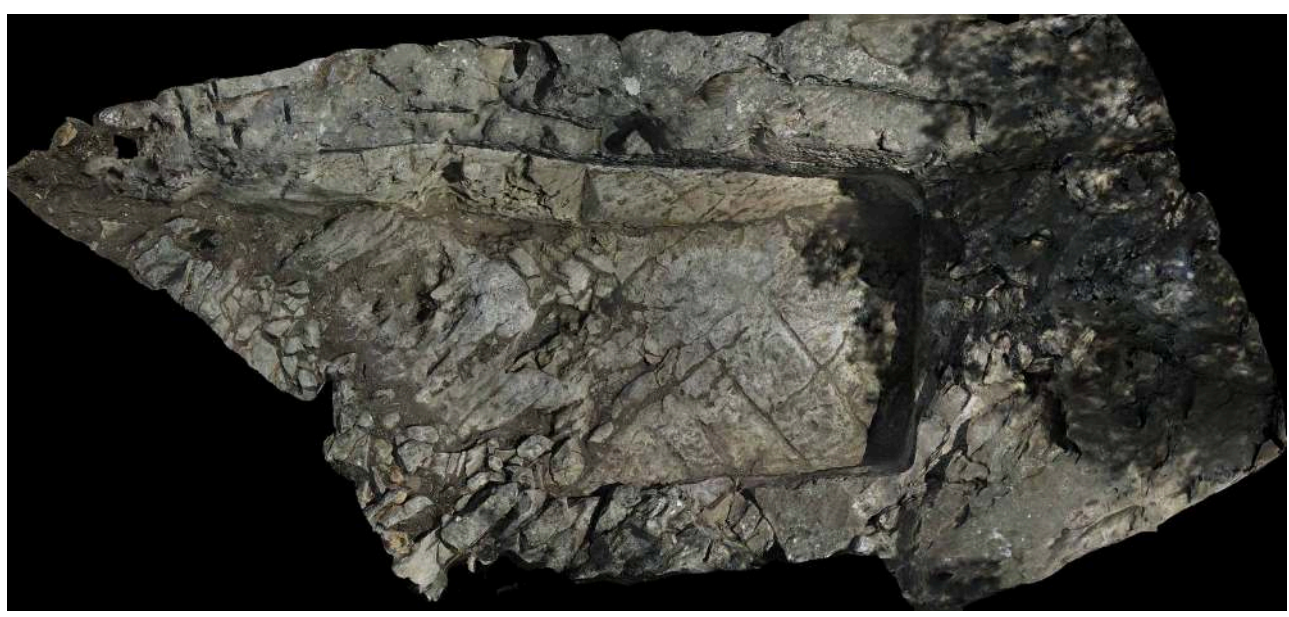

(c) Marta Sancho i Planas.

21 En la parte alta del yacimiento, hemos excavado una estructura parcialmente visible antes de iniciar el trabajo de campo y que inicialmente identificamos como una torre. Se trata de un edificio ligeramente rectangular de 7×5'80 metros, del que eran visibles dos tramos de los muros oriental y occidental, construidos con la técnica del encofrado, tipo opus caementicium. El muro norte presenta una base realizada con grandes bloques de piedra, con la clara finalidad de reforzar este muro, dado que se encuentra en la zona más baja y de más pendiente. Por el contrario, el muro sur, que es conservado en muy mal estado, fue construido con opus caementicium desde su misma base. A pesar de la fuerte bioturbación de la mayoría de los estratos, pudimos identificar un fragmento de pavimento de opus signinum y su preparación, formada por una capa de tegulae fragmentadas y, por debajo, un nivel de piedras tipo rudus. La identificación inicial que propusimos como una torre presenta problemas, ya que no parece que tuviera más de una planta baja con cubierta de materiales perecederos. No hemos podido localizar la entrada que podría estar situada en cualquiera de sus lados, en alguno de los puntos donde el muro se encuentra más arrasado. El pavimento de opus signinum parece indicar un espacio de relativo confort, de hábitat o un espacio de uso colectivo. De esta edificación debemos destacar la presencia de canales de recogida de agua por el exterior, con la finalidad de conducirla hacia la cisterna situada a pocos metros en dirección norte.

La iglesia se encuentra situada en el centro del yacimiento, unos metros al norte del edificio residencial que hemos descrito. Se trata de una construcción con aparejo de mampostería, con piedras de tamaño mediano ligeramente desbastadas y unidas con un muy buen mortero de cal y arena. Por su exterior mide $14 \times 6$ metros y dispone de un espacio interior de $12 \times 4$ metros, dividido en 3 sectores de $4 \times 4$ metros desde el extremo del ábside hasta el cancel, de este a la puerta de acceso y desde esta hasta el muro de los pies. La puerta está situada en el muro norte, el cual dispone, por el exterior, de una banqueta corrida de entre 80 y 100 centímetros de ancho, que refuerza la construcción en el punto de más pendiente (fig. 4). 
Fig. 4. - Vista desde el lado occidental de la iglesia después de las tareas de consolidación. A la izquierda la puerta de acceso en el lado norte; en primer plano la nave y al fondo el cancel con la puerta que da acceso al coro y al ábside donde se encuentra la base del altar.

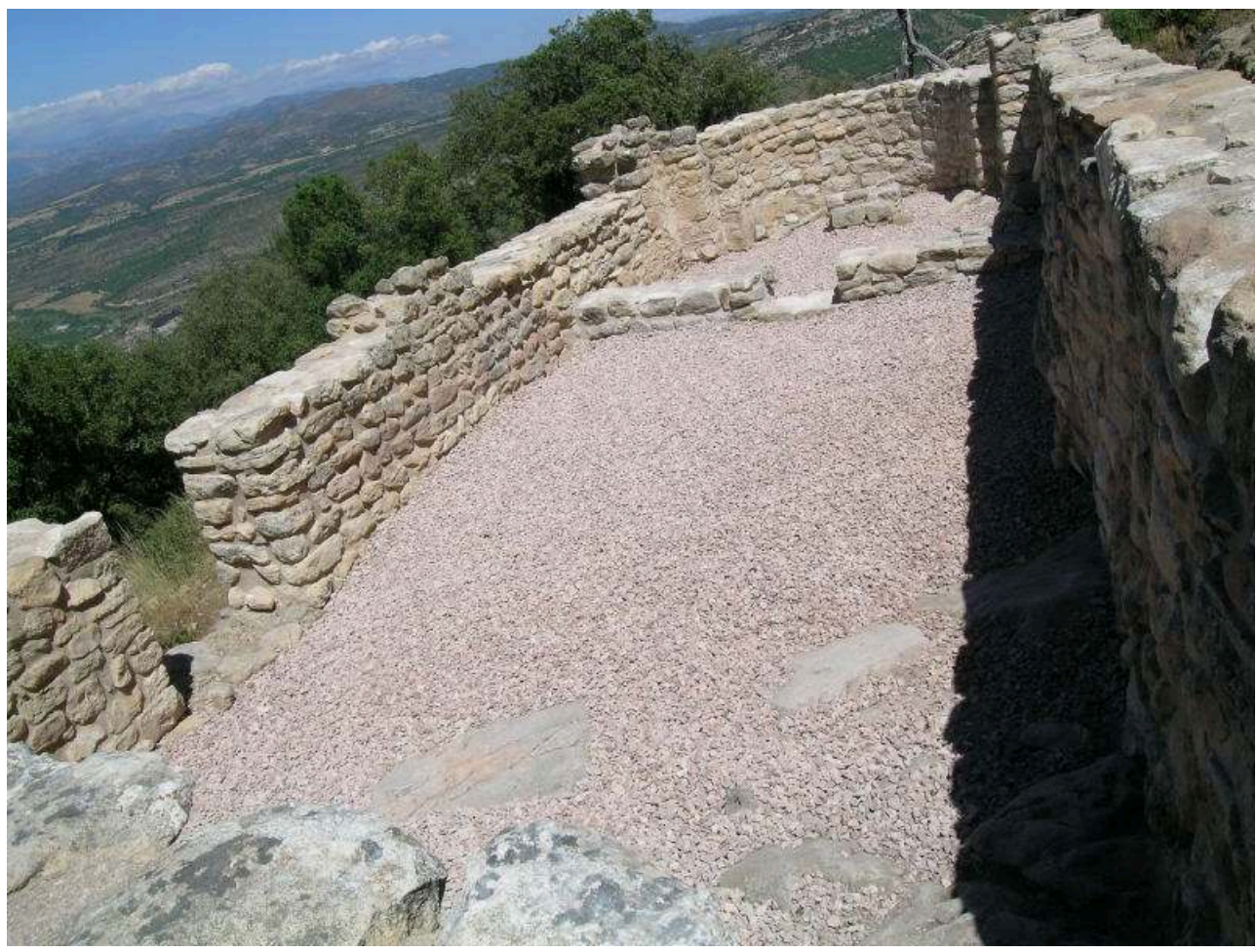

(c) Marta Sancho i Planas.

El nivel de circulación de la nave era la misma roca, en algunos puntos, ligeramente retocada y con algunas losetas cubriendo las irregularidades más evidentes. En el cancel encontramos una pequeña puerta central que da paso al coro, probablemente pavimentado con losas y situado en una cota más elevada que el nivel de circulación de la nave. Desde el coro se accede al ábside por dos escalones, por lo que aún se encuentra en una cota más elevada y pavimentado con diversas capas de mortero de cal. En medio del ábside encontramos la base del altar (fig. 5). La losa del mismo la encontramos a sus pies, reutilizada en una fase posterior como pavimento. 
Fig. 5. - Fotogrametría de la cabecera de la iglesia con los niveles de ocupación del siglo VI. Se ha indicado la posición de la puerta de acceso y del escalón que separaba el coro del ábside.

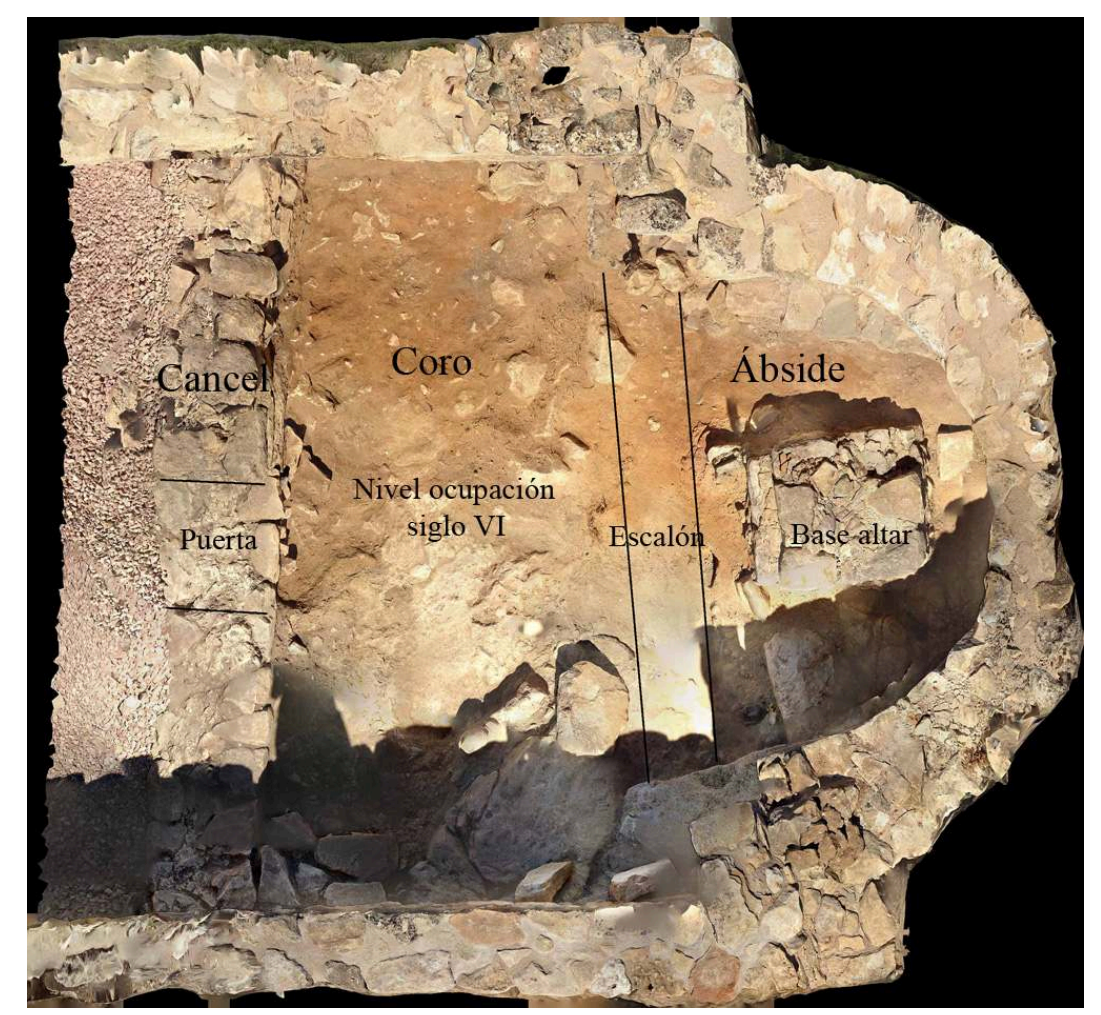

(c) Marta Sancho i Planas.

La iglesia se vio afectada en su totalidad por un incendio, después del cual sólo se rehabilitó la parte del coro y el ábside, abandonando la nave que presenta evidentes signos de rubefacción en la misma roca.

En las tres últimas campañas hemos realizado una intensa tarea de desforestación y de levantamiento de niveles superficiales del entorno de la iglesia, tanto por su lado sur como por el norte. Estas tareas han sacado a la luz diversos muros que definen espacios cerrados comunicados a través de corredores entre ellos y el templo. Estas estructuras definen un conjunto complejo de edificaciones que actualmente interpretamos como las dependencias del monasterio. Falta completar la excavación para poder definir la función de cada uno de estos espacios y su articulación espacial. Por el momento ya hemos identificado dos fases consecutivas en las que se amortizan algunas estructuras y se construyen otras nuevas. Estas dos fases corresponden a los siglos V-VI la primera y VI-VII la segunda.

Las producciones cerámicas más significativas por su cantidad son las ánforas, con predominio de las de procedencia norteafricana, con una cronología que se extiende entre finales del siglo IV hasta la primera mitad del VI. Su contenido sería mayoritariamente aceite ${ }^{13}$. Las ánforas sudhispánicas contendrían aceite y aceitunas y corresponden a una cronología que podemos situar entre el siglo III y mediados del VI ${ }^{14}$. Las orientales contendrían vino o aceite y se sitúan cronológicamente entre finales del siglo IV y el siglo VII, aunque algunos autores indican que sólo llegan al puerto de Tarragona hasta inicios del siglo VI.

Por lo que respecta a las cerámicas de mesa de lujo, disponemos de platos y boles de distintas procedencias, con cronologías que van desde finales del siglo IV hasta inicios 
del siglo VI y con alguna tipología que llegaría hasta inicios del siglo VII ${ }^{15}$. La cerámica de cocina presenta un repertorio diverso con ollas, cazuelas, jarras, botellas y algún mortero, en todos los casos encuadradas en una cronología entre los siglos V-VII ${ }^{16}$.

Estas producciones cerámicas son las que nos han permitido fechar los niveles fundacionales de la iglesia a finales del siglo V e inicios del VI.

Así mismo nos aportan una valiosa información sobre los contactos que se realizaban a través del comercio, con la llegada de productos como el aceite desde el sud de la península, el norte de África y oriente o con producciones cerámicas procedentes de Francia y de otros centros de producción peninsulares. El puerto de Tarraco sería el receptor de estas importaciones que, posteriormente circularían por vías terrestres hacia Lleida y de allí en dirección al Pirineo, vía de Àger.

Dado que la mayoría de producciones presentan una cronología dentro de los siglos VVI, consideramos que este es el momento fundacional y con más intensidad de contactos con el exterior. Nos inclinamos a proponer un inicio del asentamiento hacia un siglo $\mathrm{V}$ avanzado, dado que no disponemos de cerámica de cocina norte africana más propia de la primera mitad del siglo $\mathrm{V}$.

31 No descartamos la posibilidad que algunas de estas piezas pudieran responder a una reutilización posterior a su función inicial. En todo caso quedaría demostrado que los primeros moradores de Els Altimiris dispondrían de estas producciones que habrían llegado desde su lugar de origen dentro de las cronologías propuestas.

32 Así mismo, debemos considerar la posibilidad que sólo una parte de los habitantes de Els Altimiris siguiera las costumbres alimenticias de tradición romana con el aceite como grasa principal, mientras que otros podrían adaptarse a las nuevas costumbres basadas en grasas de origen animal. En todo caso, el avances progresivo hacia el período plenamente medieval supondrá el abandono definitivo del aceite.

Para el período final del yacimiento, que situamos a inicios del siglo IX, disponemos de algunas muestras de cerámicas que presentan ciertas similitudes con producciones del sur de Francia correspondientes al siglo VIII. En este siglo, la irrupción del emirato omeya marca un antes y un después, aunque hasta la fecha, su impacto no está bien definido en nuestra zona de estudio. Finalmente disponemos de algunas cerámicas con decoración en zig-zag, bien identificadas en entornos de inicios del siglo IX, las cuales nos indican la fase final de ocupación más o menos estable del asentamiento ${ }^{17}$.

La ausencia de algunas formas, como las sitras, características de los entornos carolingios, nos inducen a proponer un momento final de la ocupación estable durante las primeras décadas del siglo IX.

A partir de esta cronología, no disponemos de materiales cerámicos en contextos de ocupación, lo que no impediría una cierta transitación del lugar, por parte de pastores trashumantes, que se mantendría hasta mediados del siglo XX. A este fenómeno correspondería el enterramiento fechado por radiocarbono en el siglo XI, los restos carbonizados de unos troncos de encina fechados a inicios del siglo XIII, un fragmento cerámico encontrado en el derribo superficial, del siglo XVI, y una muestra de carbón del fondo de una cisterna con una datación del siglo XX. 
En conclusión, a nivel cronológico situamos el inicio del yacimiento en un momento avanzado del siglo $\mathrm{V}$, con un momento álgido de máxima actividad entre los siglos VIVII. A partir del siglo VIII detectamos un debilitamiento de la actividad, a pesar de que la difícil identificación de materiales cerámicos para este período puede influenciar en esta interpretación. Detectamos para este momento un incendio de la iglesia la cual sería restaurada solamente en la zona de la cabecera, quedando la nave inutilizada. A partir de este momento el asentamiento se iría despoblando progresivamente, probablemente por la influencia del proceso repoblador que, por esas fechas, se vendría desarrollando entorno al monasterio de Alaón, visible desde Els Altimiris y del que disponemos de documentación escrita muy relevante ${ }^{18}$.

El mantenimiento del culto en la iglesia de Santa Cecilia de Els Altimiris será una realidad hasta el sigloXI, ya que por esas fechas encontramos algún que otro enterramiento en su entorno inmediato. Debemos insistir en que no disponemos de ningún material posterior al siglo IX por lo que cualquier presencia en el lugar la debemos relacionar con estancias puntuales, relacionadas con la actividad ganadera que utilizaría el camino de acceso para subir a la cima de la sierra y las cisternas para abastecerse de agua. Podemos entender este lugar como un refugio para pastores que sería utilizado hasta mediados del siglo XX, tal y como nos han confirmado diversos informantes orales. A esta misma práctica correspondería la cerámica del siglo XVI hallada entre el derribo más superficial de la iglesia.

Desde el punto de vista tipológico, Els Altimiris es un ejemplo de asentamiento en altura que se aleja tanto de las pautas propias de la Antigüedad Tardía como de las que encontramos a partir del siglo IX y que van ligadas al movimiento aprisiador. Su ubicación, su ordenación interna y sus estructuras son evidencias de una personalidad propia por lo que no debería ser clasificado ni como la degradación de un modelo ni como el precedente de otro. Tampoco lo podemos considerar un hábitat marginal o temporal sino que refleja una clara voluntad de estabilización (por ejemplo a través del sistema de recogida, conducción y almacenaje de agua) y una cierta jerarquización social, a través del contraste entre los fondos de cabaña y las distintas construcciones del complejo eclesiástico.

Desde un punto de vista territorial, escapa del control de las antiguas ciudades romanas, como Aeso, la más próxima al asentamiento, en franco retroceso desde la crisis del siglo III y prácticamente abandonada durante el siglo IV ${ }^{19}$. Tampoco las nuevas ciudades episcopales, Lleida, la más próxima, se encuentra a más de $80 \mathrm{~km}$., disponen de la fuerza suficiente, durante los siglos V-VII, como para ejercer un control efectivo en un lugar tan alejado ${ }^{20}$. Visto de este modo, proponemos otra opción que nos permite encajar Els Altimiris dentro de una articulación territorial más amplia, al tiempo que superamos la visión demasiado autárquica, de un asentamiento aislado. Creemos que Els Altimiris corresponde a una primitiva comunidad monástica vinculada al movimiento eremítico-cenobítico bien representado por San Victorián de Asán y su comunidad instalada cerca de Lainsa, a unos $40 \mathrm{~km}$. al oeste de Els Altimiris. El monasterio de Els Altimiris sería una forma más de asentamiento en un período, el correspondiente a la dominación visigoda, caracterizado por la diversidad y atomización de los modelos de ocupación del territorio. 


\section{BIBLIOGRAPHIE}

ALEGRÍA Walter y SANCHO I PLANAS Marta, "Comunitat de muntanya - comunitat monàstica: els Altimiris, un enclavament cristià a la serra del Montsec", en Primeres Jornades d'Arqueologia $i$ Paleontologia del Pirineu i Aran, Lleida, Generalitat de Catalunya, 2015, p. 215-221.

ARIÑo Enrique y DíAz Pablo C., "Poblamiento y organización del espacio: la Tarraconense pirenáica en el siglo VI", Antiquité tardive, 11, 2003, p. 223-237.

BELTRAN Julia, “Los contextos altomedievales de la Plaza del Rey de Barcelona: la cerámica de tradición carolingia (siglos IX-X)", Quaderns d'Arqueologia i Història de la ciutat de Barcelona, Època II, 2, 2006, p. 108-139.

BONIFAY Michel, Études sur la céramique romaine tardive d'Afrique, Oxford, British Archaeological Reports, International Series, 2004.

CATHMA, “Céramiques languedociennes du haut Moyen Âge ( $\mathrm{VII}^{\mathrm{e}}-\mathrm{IX}{ }^{\mathrm{e}} \mathrm{s}$.): études micro-régionales et essai de synthèse”, Archéologie du Midi médiéval, XI, 1993, p. 112-228.

CORRAL José Luís, Cartulario de Alaón (Huesca), Zaragoza, Anubar Ediciones, 1984.

GARCIA Gemma, MORO Antonio, TUSET Francesc, La seu episcopal d'Ègara. Arqueologia d'un conjunt cristià del segle IV al X, Tarragona, ICAC, 2009.

GARCíA Joan E., MIRó Núria, REVILLA Emili, “Un context paleoandalusí a l'excavació de l'Arxiu Administratiu de Barcelona (1998)" en II Congrés d'Arqueologia Medieval i Moderna a Catalunya, vol. I, Sant Cugat del Vallès, Associació Catalana per a la Recerca en Arqueologia Medieval, 2003, p. 363-380.

GUIDI José Javier y VILLUENDAS Alberto, "Residens in territorio Penetense. Poblament i estratègies d'hàbitat a l'Antinguitat Tardana i l'Alta Edat Mitjana al Penedès històric", TFG inedit, Universitat de Barcelona, 2010.

HAYES John W., Late Roman Pottery, Roma, British School at Rome, 1972.

JUNYENT Emili y PÉREZ Arturo, L'antiguitat, d'Iltirta a Ilerda, en Història de Lleida, vol. 1, Lleida, Pagès, 2003.

KEAY S. J., Late Roman Amphora in the Western Mediterranean: a typology and economic study: the Catalan evidence, Oxford, British Archaeological Reports, International Series, 1984.

MACIAS Josep Maria, La ceràmica comuna tardoantiga a Tàrraco. Anàlisis tipològica i històrica (segles VVII), Tarragona, TULCIS (Monografies Tarraconenses), 1999.

MAUFRAS Odile (ed). Habitats, nécropoles et paysages dans la moyenne et la basse vallée du Rhône (VII -XV s.): contribution des travaux du TGV Méditerranée à l'étude des sociétés rurales médiévales, Paris, Maison des sciences de l'homme (DAF, 98), 2006.

ORFILA Margarita, "Producciones de vajilla en la parte meridional de la península ibérica en el bajo imperio", en A. Malpica (ed.), Estudios de cerámica tardorromana y altomedieval, Granada, Universidad de Granada, 2007, p. 90-112.

PASSI Siro, ROTSCHILD-BOROS Monica C., FASELLA Paolo, NAZZARO-PORRo Marcella, wHITEHOUSE David, "An application of high performance liquid chromatography to analysis of lipids in archaeological samples”, Journal of Lipid Research, 22, 1981, p. 778-784. 
REMOLÀ Josep Anton, Las ánforas tardo-antíguas en Tarraco (Hispania Tarraconensis). Siglos IV-VII d.C., Barcelona, Universitat de Barcelona, 2000.

REYES Teresa, GONZÁLEZ Ricardo, GARCíA Joan E., “Estudi de l'Ager Aesonensis (Isona i Conca Dellà, Pallars Jussà)", Revista d'Arqueologia de Ponent, 8, 1998, p. 35-59.

REYNOLDS Paul, “Cerámica, comercio y el Imperio Romano (100-700 d.C): perspectivas desde Hispania, Africa y el Mediterraneo oriental”, en A. Malpica (ed.), Estudios de cerámica tardorromana $y$ altomedieval, Granada, Universidad de Granada, 2007, p. 13-82.

RIERA Santi, “Canvis ambientals i modelació antròpica del territori entre l'època ibèrica i

l'altmedieval a Catalunya: aportacions de la palinologia", Cota zero, 20, 2005, p. 99-107.

RIERA Santi y ESTEBAN Agustí, "Vegetation history and human activity during the last 6.000 years on the central Catalan coast (northeastern Iberian Peninsula)", Vegetation History and Archeobotany, 3, 1, 1994, p. 7-23.

RIGOIR Jacqueline, “Les sigillées paléochrétiennes grises et orangées”, Gallia, 1, 1968, p. 167-244. RIGOIR Yves y RIGOIR Jacqueline, “Les dérivées des sigillées paléochrétiennes en Espagne”, Revue d'études ligures, XXXVII, 1973, p. 33-68.

RIPOLL Gisela y VELÁzQUEz Isabel, La Hispania visigoda. Del rey Ataulfo a Don Rodrigo, Madrid, Historia 16, 1995.

ROIG Jordi, “Asentamientos rurales y poblados tardoantiguos y altomedievales en Cataluña (siglos VI al X)", en Quirós Juan Antonio (ed)., The Archaeology of Early Medieval Villages in Europe, Bilbao, Universidad del País Vasco, 2009, p. 207-252.

SALRACH Josep Maria, Catalunya a la fi del primer mil·lenni, Vic, Eumo, 2004.

UYÁ Jaime, Fuero Juzgo o Libro de los Jueces, Barcelona, Ed. Zeus, 1968.

VIGIL-ESCALERA Antonio, “Granjas y aldeas altomedievales al norte de Toledo (450-800 d.c.)”, Archivo Español de Arqueología, 80, 2007, p. 239-284.

WICKHAM Chris, Una historia nueva de la Alta Edad Media, Barcelona, Crítica, 2009.

\section{NOTES}

1. J. M. Salrach, Catalunya a la fi del primer mil·lenni, p. 128-149.

2. G. Ripoll y I. Velázquez, La Hispania visigoda. Del rey Ataulfo a Don Rodrigo, p. 76-80.

3. O. Maufras (ed.), Habitats, nécropoles et paysages..., p. 57-160.

4. J. Roig, “Asentamientos rurales y poblados tardoantiguos y altomedievales en Cataluña", p. 207-252.

5. A. Vigil-Escalera, “Granjas y aldeas altomedievales al norte de Toledo (450-800 d.C.)”, p. 275-277.

6. J. Guidi y A. Villuendas, Residens in territorio Penetense..., p. 112-145.

7. G. García et al., La seu episcopal d'Ègara, p. 11-17.

8. S. Riera y A. Esteban, "Vegetation history and human activity during the last 6.000 years..." p. 7-23; S. Riera, "Canvis ambientals i modelació antròpica del territori", p. 99-107. 
9. C. Wickham, Una historia nueva de la Alta Edad Media, p. 545-838.

10. Lei promulgada durante el reinado de Chindasvinto: J. Uyá, Fuero Juzgo o Libro de los Jueces, p. 205.

11. E. Ariño y P. Díaz, "Poblamiento y organización del espacio", p. 223-237.

12. Para una descripción más detallada remitimos a una de las últimas publicaciones sobre este yacimiento: W. Alegría y M. Sancho i Planas, "Comunitat de muntanya comunitat monàstica", p. 215-221.

13. Hemos identificado ánforas norteafricanas de los siguientes tipos: Keay 8b, Keay 27b, Keay 35a, Keay 36a y 36b, Keay 41, Keay 56, Keay 57 y Keay 62q. Para las sudhispánicas tenemos la forma Dressel 23 y entre las orientales domina la forma LRA4, aunque también disponemos de algún fragmento de LRA1; S. J. Keay, Late Roman Amphora in the Western Mediterranean; M. Bonifay, Études sur la céramique romaine tardive d'Afrique; P. Reynolds, “Cerámica, comercio y el Imperio Romano", p.13-82; J. A. Remola, ánforas tardo-antíguas en Tarraco.

14. S. Passi et al., "An application of high performance liquid chromatography...", p. 778-784.

15. DSP (Dérivées de Sigillées Paléochrétiennes) boles con las formas Rigoir 6,9 y sobretodo 18, y platos Rigoir 1 y 4 . TSHT (Terra Sigillata Hispànica Tardana) boles de las formas Dragendorff 27 o 37 tardías. ARS (African Red Slip) platos de la forma Hayes 104; J. Rigoir, "Les sigillées paléochrétiennes grises et orangées", p. 167-244; Y. Rigoir y J. Rigoir, "Les dérivées des sigillées paléochrétiennes en Espagne“, p. 33-68; M. Orfila, "Producciones de vajilla en la parte meridional...", p. 90-112; J. W. Hayes, Late Roman Pottery.

16. J. M. Macias, La ceràmica comuna tardoantiga a Tàrraco.

17. CATHMA, "Céramiques languedociennes du haut Moyen Âge", p. 11-228; J. Beltrán, "Los contextos altomedievales de la Plaza del Rey de Barcelona", p.108-139; J. E. García et al., "Un context paleoandalusí a l'excavació de l'Arxiu Administratiu de Barcelona (1998)", p. 363-380.

18. J. L. Corral, Cartulario de Alaón (Huesca), p. 10-27.

19. T. Reyes et al., "Estudi de l'Ager Aesonensis (Isona i Conca Dellà, Pallars Jussà)", p. 35-59.

20. E. Junyent y A. Pérez, L'antiguitat, d'Iltirta a Ilerda, p. 420-424.

\section{RÉSUMÉS}

La excavación del yacimiento de Els Altimiris ha sacado a la luz un establecimiento monástico correspondiente al período visigodo (ss. VI-VII) enclavado en una zona montañosa del Prepirineo catalán. La comprensión e interpretación de las evidencias arqueológicas nos ha llevado a indagar sobre la estructuración del territorio pirenaico durante ese período, las características y procedencia de sus pobladores, la presencia de élites y las bases de su economía. Presentamos los resultados de nuestra investigación basada en el registro arqueológico de dicho yacimiento, 
contextualizado a partir de las investigaciones realizadas sobre este período en los últimos años. El objetivo es el de ofrecer una propuesta interpretativa que nos permita comprender las causas de la formación de este establecimiento así como las que originaron su decadencia a partir del siglo VIII y su total abandono a inicios del siglo IX.

\section{AUTEUR}

MARTA SANCHO I PLANAS

Universitat de Barcelona 
Marges et marches seigneuriales aux confins du Velay : réflexion sur les implantations des abbayes cisterciennes de Clavas et de La Séauve-Bénite

\author{
Emma Bouvard-Mor
}

Cette communication prendra la forme d'un petit dossier historique extrait d'un corpus et d'une analyse plus vaste concernant les cisterciens et cisterciennes des anciens diocèses de Clermont et du Puy ${ }^{1}$ (fig. 1). 
Fig. 1. - Implantations cisterciennes des anciens diocèses de Clermont et du Puy, d'après D. Martin (dir.), L'identité de l'Auvergne et P. Charbonnier, Histoire de l'Auvergne.
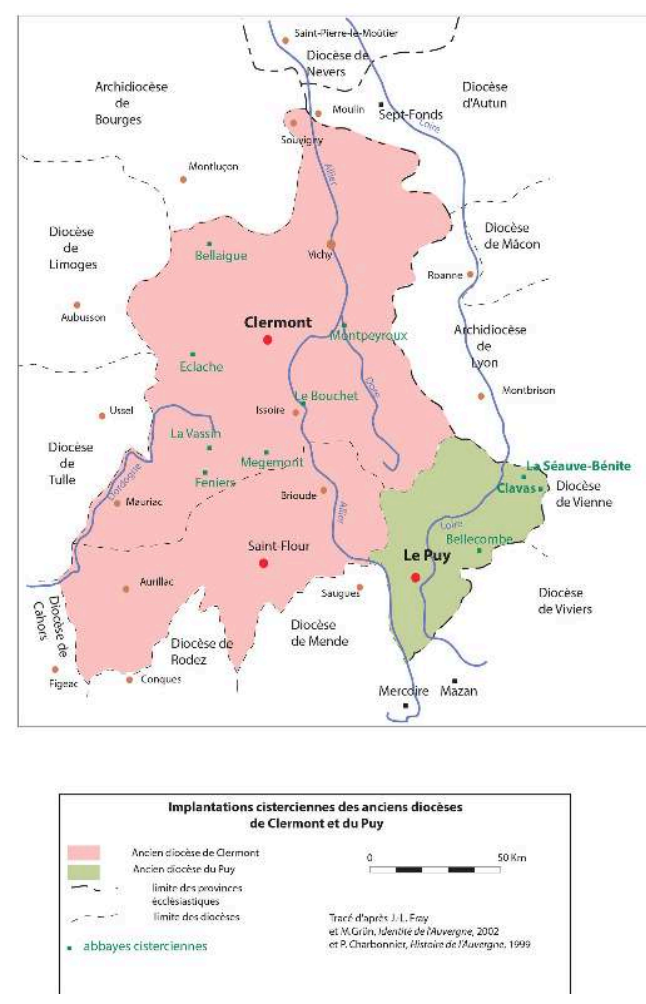

(c) Emma Bouvard-Mor.

2 Nous proposons d'interroger la nature frontalière des abbayes cisterciennes de Clavas (commune de Riotord, Haute-Loire) et de La Séauve-Bénite (commune de La Séauvesur-Semène, Haute-Loire) en prenant en considération les facteurs géopolitiques qui ont présidé à leur érection à la fin du XII ${ }^{e}$ siècle. Clavas et La Séauve-Bénite intègrent la frange orientale de l'ancien diocèse du Puy, ce qui sera plus tard nommé le Velay « delà les bois ${ }^{2} »$. Ces deux établissements de moniales sont issus du parthénon plus ancien de Bellecombe et sont soumis au contrôle de l'abbaye de Mazan, au diocèse de Viviers (lignée de Cîteaux, via Bonnevaux). Cette sujétion masculine, coutumière pour les monastères de femmes de l'orbite de Cîteaux, induit d'emblée une certaine intensité des relations (voire des circulations) entre les représentants des communautés de femmes vellaves et les abbés vivarois ${ }^{3}$. Le propos consistera à démontrer la part stratégique de ces fondations, qui servent l'aristocratie régionale dans un dessein d'affirmation dynastique et territoriale. Nous verrons aussi que l'essaimage cistercien accompagne d'une certaine manière la reconquête de terres montagnardes; il participe à la recomposition des interactions sociales, et peut accompagner la mobilité humaine transfrontalière.

\section{Abbaye de Clavas}

Les historiographes s'accordent à attribuer la fondation de ce monastère à la famille des Pagan d'Argental ${ }^{4}$. Cette hypothèse est motivée par la situation géographique de Clavas par rapport aux confins de la seigneurie et par les diverses tractations passées entre l'abbaye avec le prieuré de Saint-Sauveur-en-Rue, fondation voisine due à la 
même lignée aristocratique. Le château d'Argental occupait un promontoire des monts du Pilat, à 690 mètres d'altitude, dans les terres viennoises mais du ressort du Forez (département de la Loire) ${ }^{5}$. La seigneurie était confinée au sud par la tête du bassin versant de la Dunières (émissaires sud du ruisseau la Clavarine, coulant à Clavas) ; elle était limitée au nord par le cours de la Semène (sur la ligne d'interfluve avec le bassin versant de l'Ondaine), à l'est par les monts du Pilat et du Vivarais, et à l'ouest par la rive droite de la Loire (fig. 2). La complexité et la labilité des enjeux territoriaux de cet espace sont effectives durant tout le Moyen Âge et l'époque moderne; c'est pourquoi elles nécessitent un examen circonstancié afin d'appréhender les diverses influences politiques et religieuses entourant la communauté de moniales et son domaine.

Fig. 2. - La seigneurie d'Argental, d'après J.-E. Dufour, Dictionnaire topographique du Forez et E. Perroy, Les familles nobles du Forez au xIII' siècle, échelle 1/25 000.

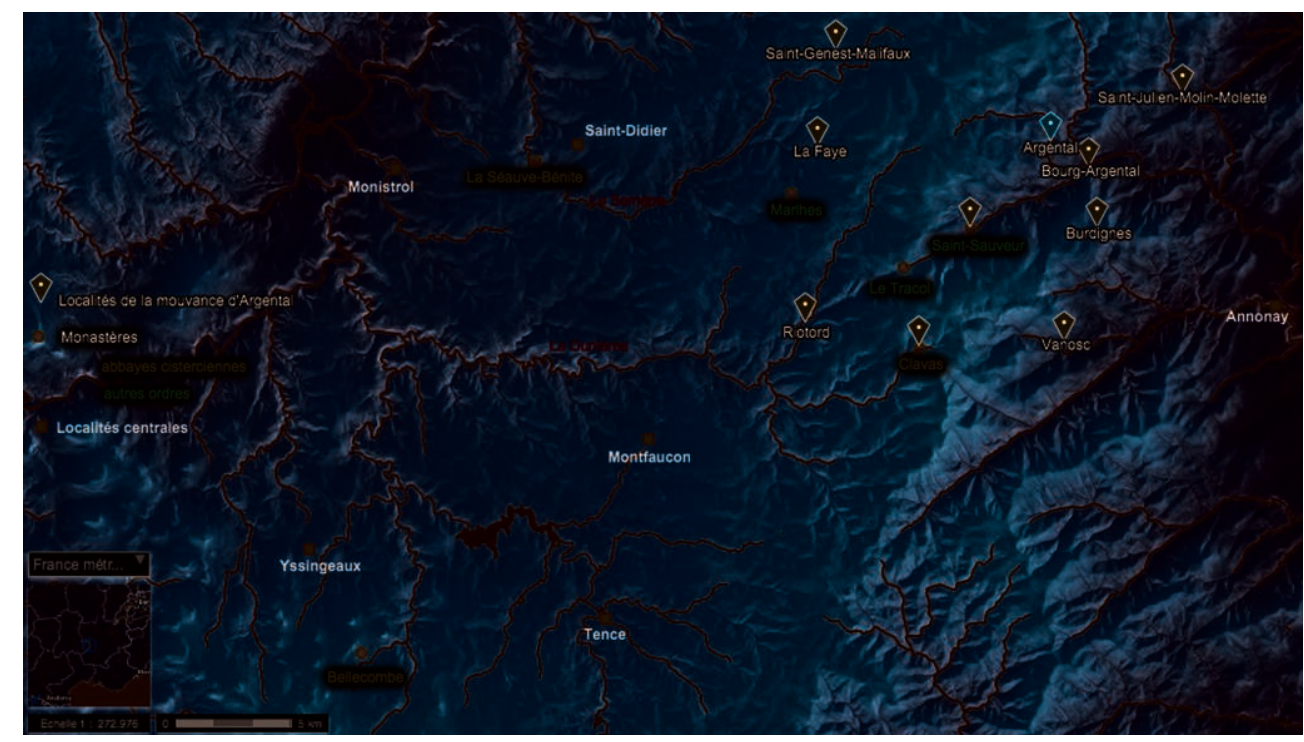

(c) Emma Bouvard-Mor - (c) IGN, 2015 (fond de carte).

\section{Les Pagan d'Argental, fondateurs viennois}

En 844, le comte Archimbault de Vienne donne à l'un de ses vassaux, du nom de Rostaing, la terre d'Argental, sise dans l'ager d'Annonay ${ }^{6}$, au comté viennois. La localité occupe une zone frontière, carrefour entre les diocèses de Lyon, de Vienne et du Puy, soit à la confluence de quatre grandes mouvances (Forez, Lyonnais, Viennois et Velay). Un château y est construit, donnant ensuite naissance à un bourg, dont la situation géopolitique assure la prospérité. Au xiII ${ }^{\mathrm{e}}$ siècle, les seigneurs du lieu portent le nom de Pagan, qu'Édouard Perroy transcrit par Payan, seigneurs du mandement de La Fay, seigneurs d'Argental et en partie de Fontanès ${ }^{7}$. Le Dictionnaire topographique de la Loire signale qu'au XII ${ }^{\mathrm{e}}$ siècle, la seigneurie de Saint-Julien-Molin-Molette appartient aux Pagan, qui en devaient l'hommage aux dauphins du Viennois. En 1293, ils détiennent la seigneurie de La Fay, pour laquelle ils rendent aussi hommage aux dauphins ${ }^{8}$. En 1296, à la faveur d'un transport des possessions delphinales aux comtes du Forez par le mariage d'Alix de La Tour du Pin, dame du Viennois, avec le comte Jean I ${ }^{\text {er }}$, la directe des Pagan passe dans le ressort forézien. 
On doit aux Argental la création du puissant prieuré casadéen de Saint-Sauveur-en-Rue, situé dans la Loire, à dix kilomètres au nord de Clavas9, mais relevant de l'ancien diocèse de Vienne; la charte de fondation, datée de 1061, nomme Artaud seigneur d'Argental, de Saint-Sauveur, de Saint-Genest, de Malifaux, de Burdigne, de Vanosc et de Riotord ${ }^{10}$. L'emplacement de ce monastère est fort bien choisi, car implanté sur un point de contrôle de la route joignant Vienne au Puy, empruntée tant par les pèlerins se rendant à Compostelle que par les militaires et les commerçants souhaitant relier le Velay à la vallée du Rhône. On signale à proximité du col du Tracol (1 023 mètres d'altitude) un hôpital Saint-Maxime lié au prieuré Saint-Sauveur, destiné à accueillir les voyageurs durant le $\mathrm{xIII}^{\mathrm{e}}$ siècle, ainsi que la présence des fourches patibulaires de l'évêque du Puy signalant la limite nord-orientale de son ressort comtal, face à celui de l'évêque de Vienne ${ }^{11}$. Le paysage religieux est complété par la commanderie templière de Marlhes (temple de Marlhette), toujours dans la Loire, mais dans le diocèse du Puy, fondée avant 1272, date de la première mention textuelle en faisant cas ${ }^{12}$.

6 L'abbaye de Clavas, nichée en bordure occidentale des monts du Pilat, à 1092 mètres d'altitude, se situe donc sur un carrefour territorial, au débouché d'un point de franchissement majeur. Il s'agit d'un lieu de rencontre entre Forez, Velay et Vivarais, et surtout d'un couloir d'échanges entre la vallée du Rhône et le Massif central d'est en ouest, et un accès vers les axes commerciaux méditerranéens en direction du sud par la voie Régordane. D’après Franck Brechon, certaines routes médiévales doivent leur tracé et leur entretien à la présence de maisons de réguliers et à la nécessité de contrôler leur vaste temporel : ce serait entre autres le cas sur l'itinéraire entre Viviers et Le Puy, dont la vitalité devrait beaucoup à l'abbaye Saint-Chaffre du Monastier. Selon le même auteur, le grand parcours de Vienne au Puy, passant non loin de l'abbaye de Clavas, était emprunté dès l'Antiquité13 ${ }^{13}$ et sa fréquentation durant le Moyen Âge aurait été stimulée par le pèlerinage du Puy-en-Velay.

7 Dans ce contexte, on peut légitimement se demander quel rôle aurait pu jouer l'établissement de Clavas dans l'accueil de voyageurs, même si la question ne trouve pas de réponse en l'état de la documentation. La présence d'hôtellerie au sein des complexes monastiques cisterciens est pourtant une constante réglementaire. Un tel équipement est d'ailleurs mentionné pour l'abbaye de Bellecombe ${ }^{14}$. Enfin, une telle situation topographique a sans aucun doute favorisé le développement tous azimuts d'un domaine dont l'étendue est démontrée par les sources modernes, de part et d'autre des limites entre Forez, Velay et Vivarais ${ }^{15}$.

8 La première mention nous est livrée par le cartulaire de l'abbaye de Bonnefoy. On y apprend que Géraud du Béage obtient entre 1176 et 1179 que ses deux filles prennent le voile aux frais des chartreux dudit monastère vivarois. L'une de ses filles est envoyée à Comps (monastère casadéen de Lavaudieu), l'autre à Enclavas, situé à 71 kilomètres du château seigneurial ${ }^{16}$. Par des processus de topolignage, divers établissements d'ordres et de ressorts diocésains différents se trouvent ainsi mis en lien. Ils entraînent la mobilité des membres de l'aristocratie et des communautés régulières régionales.

9 Nous avons donc établi que l'abbaye de Clavas aurait été fondée avant le dernier tiers $\mathrm{du} \mathrm{XII}^{\mathrm{e}}$ siècle par un ressortissant de l'aristocratie moyenne, vassal des comtes du Viennois, sur un territoire soumis à diverses influences laïques et religieuses. Dès la fin $\mathrm{du}$ XIII ${ }^{\mathrm{e}}$ siècle, soit un siècle après l'érection du monastère, ce dernier échoit civilement au Forez. Clavas est un établissement sis au diocèse ecclésiastique du Puy, mais dont le ressort civil et les influences seigneuriales semblent davantage tournés vers la 
moyenne vallée du Rhône, ainsi que vers le nord, en direction des terres comtales du Forez.

\section{Un « pays en litige »}

10 On trouve dans le Mémoire pour les co-seigneurs de la baronnie de la Faye en Forez, au sujet $d u$ droit de mi-lod nombre de mentions des plus éclairantes à propos de l'aire géopolitique dans laquelle l'abbaye de Clavas a été implantée. Rappelons que La Faye est une seigneurie vassale des Pagan, située dans la Loire, sur la commune de Marlhes, à une quinzaine de kilomètre de Clavas. Ce mémoire de 1769 est un plaidoyer sous forme d'enquête menée pour le compte de François-Marie-Courbon de Perusel, co-seigneur de la baronie de Faye, et d'Antoinette Thiolière, mère d'Antoine Chovet, co-seigneur de la baronnie de Faye. Tous deux font appel d'une sentence de 1751 concernant leur droit de mi-lod ou du muage, c'est-à-dire la perception d'une taxe sur la mutation de bien d'un tenancier à un autre hors vente du bien. L'argumentaire du/des auteur(s) (?) a donc pour but avoué de s'opposer à celle du bénéficiaire de la sentence, le sieur Verne. Malgré ce parti pris évident, l'analyse qu'ils fournissent, à grand renfort de mentions historiques vérifiables par la littérature scientifique postérieure ${ }^{17}$ et certaines sources éditées (cartulaire de Saint-Sauveur-en-Rue notamment), nous paraît fiable, c'est pourquoi nous en reprenons les principaux points afin d'alimenter notre discours sur les enjeux territoriaux médiévaux des confins nord-orientaux du Velay.

11 L'ouvrage s'articule en cinq propositions visant à rétablir les realia politiques de la baronnie de Faye du haut Moyen Âge au XviII ${ }^{\mathrm{e}}$ siècle :

- première proposition : relative à l'appartenance de certaines localités de la rive droite du Rhône à la Lotharingie, puis au royaume de Bourgogne-Provence, dont Argental et SaintSauveur, et sûrement par contact et logique seigneuriale, la Faye ;

- deuxième proposition: «La Faye ne fut jamais du comté de Velay, ni d'aucun autre du Languedoc »;

- troisième proposition : « La Faye n’a jamais été du ressort royal du Languedoc »;

- quatrième proposition: «Jamais la Faye n'a été du pays de Velai, ni d'aucun autre du Languedoc »;

- cinquième proposition : «La Faye ni les Ressorts de Forès n'ont jamais été de la Langue de Velai, ni de celle de Languedoc ».

Le terme employé par les auteurs afin de désigner le territoire en débat, le " pays en litige ${ }^{18}$ ", nous semble des mieux choisis tant il rend compte de la labilité politique de cette enclave réputée appartenir à la seigneurie épiscopale du Puy (en témoigne la présence des fourches patibulaires au Tracol), pourtant revendiquée par le Forez juridictionnel et occupée par des vassaux viennois. Il appert de leur démonstration que parmi les forces en présence ou au contact de Clavas, la mouvance forézienne est prééminente :

«Lesdits ressorts dont assis ès-anciens marches du Comté de Forez. C'est par rapport aux nouveaux marches du Comté de Forez, que les ressorts de Forez seroient appelés ressorts, et non Comté de Forez; parce qu'ayant été distraits du Comté de Forez vers la fin du $12^{\mathrm{e}}$ siècle, et n'y ayant été réunis qu'en 1296, on se seroit accoutumé durant l'intervalle à ne pas les comprendre dans le Comté de Forez, de manière qu'à la réunion ils auroient pris le nom de ressorts du Comté de Forez, pour les distinguer du tronc qui avoit subsisté plus d'un siècle sans eux ${ }^{19}$.» 
13 Cet extrait prétend que cette prééminence s'applique y compris avant la fin du XII siècle, soit avant la permutatio de $1173^{20}$. En ce cas, Clavas verrait le jour peu de temps après la substitution du ressort viennois au comté de Forez.

La chronologie des aléas territoriaux autour de l'abbaye s'articulerait donc ainsi : historiquement, Clavas se situe au carrefour des territoires antiques ségusiave, allobroge, helvien et vellave. Durant tout le Moyen Âge et l'époque moderne, les terres de Clavas, comprises dans la seigneurie d'Argental, occupent les marges nordorientales de l'ancien diocèse ecclésiastique du Puy et du comté épiscopal du Velay, à la jonction entre les pays de Velay et de Forez. Au XI ${ }^{\mathrm{e}}$ siècle, les terres d'Argental, limitrophes du Forez, du Velay et du Viennois, appartiennent au comte de Vienne, qui les confie à un vassal ; en 1266, un autre acteur intervient dans les conflits seigneuriaux qui nous occupent: l'Église de Lyon dispute l'hommage des châteaux d'Argental et d'Annonay au dauphin du Viennois. Guy Pagan, seigneur de la Faye et d'Argental, est alors arbitre dans ce procès ${ }^{21}$.

Jusqu'à la fin du XII ${ }^{\mathrm{e}}$ siècle, la seigneurie d'Argental, à part le diocèse du Puy, dépend du ressort juridictionnel du Forez, tout en étant vassale des dauphins du Viennois ${ }^{22}$. Durant le $\mathrm{XIII}^{\mathrm{e}}$ siècle, il semblerait que le pouvoir seigneurial soit partagé entre celui du comte-évêque du Puy et celui du dauphin du Viennois, bien que l'influence de se dernier s'étiole ${ }^{23}$. Dès 1296, le comté de Forez acquiert (ou récupère ?) l'ensemble des possessions d'Argental par mariage; alors que le ressort comtal forézien s'arrêtait jusque-là sur le cours de l'Ance, dans la marge septentrionale du diocèse du Puy, il pratique une percée jusqu'à Riotord (et Clavas). Parallèlement, en réaction à l'érection $\mathrm{du}$ baillage royal de Montfaucon, qui tend à englober tout le nord-est du Velay, les comtes de Forez établissent leur propres baillages et des cours d'appeaux ambulatoires là où localement l'autorité royale est très contestée : en 1341, le baillage forézien de Saint-Ferréol comprend alors le ressort des justices de Cornillon, de Clavas, de Riotord, de Marlhes et de la Faye. Un baillage comtal existe aussi à Malleval, puis à BourgArgental $^{24}$ (fig. 3). 
Fig. 3. - Ancien diocèse du Puy et circonscription civile du Velay : confrontation des juridictions médiévales, d'après N. Sanson, Evesché du Puy Le Velay l'un des vingt deux dioceses du Languedoc dressé sur plusieurs mémoires par le Sr Sanson, Paris, P. Mariette, 1670.

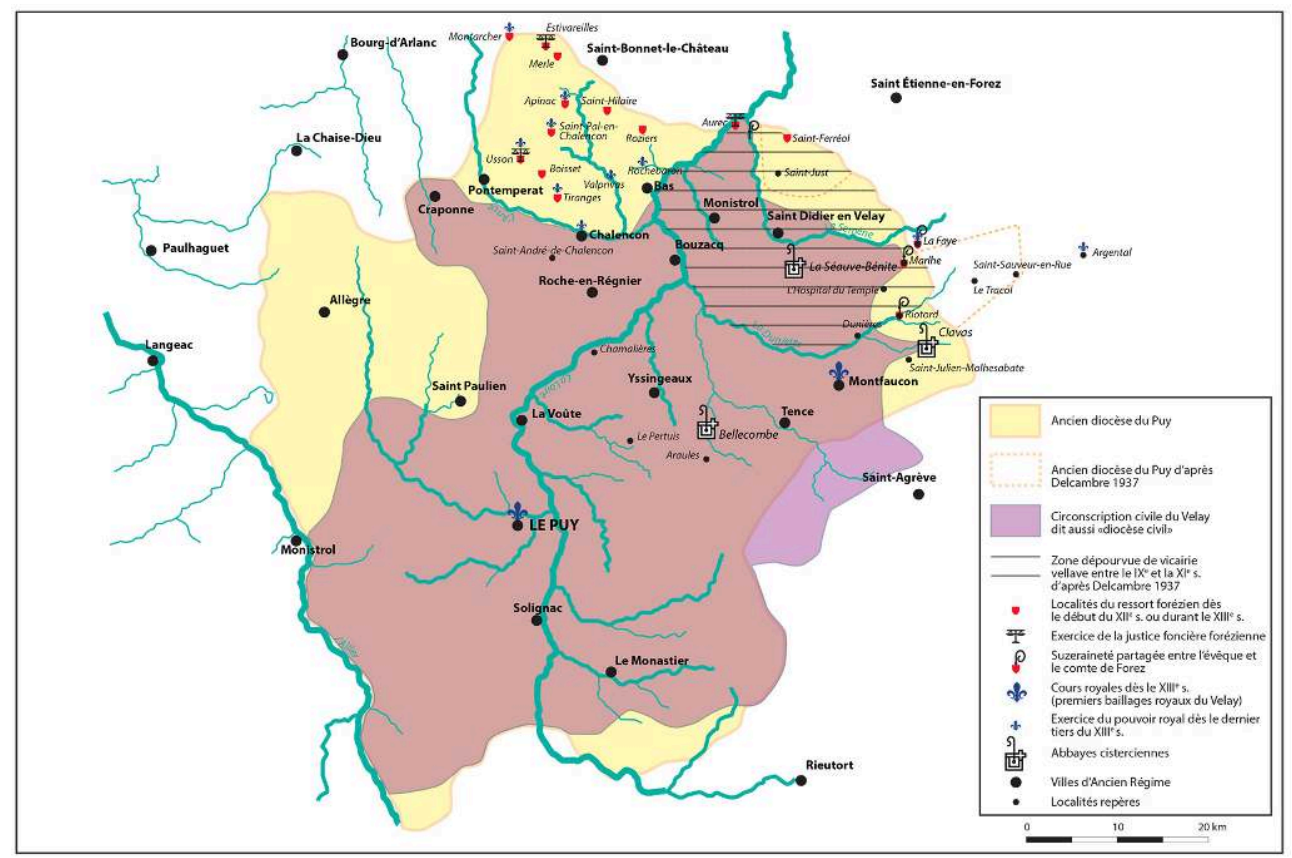

(c) Emma Bouvard-Mor et Blandine Passemard.

En 1769, la situation de Clavas est la suivante :

«L'abbaye de Clavas, qui vient d'être réunie à celle de Seauve, est sur les dernières limites de Forez, vers le Velai ; ses directes s'étendent dans les deux Provinces. La partie qui est dans le Forez, ainsi que le monastère même, et le lieu de Clavas, paroissent visiblement un démembrement de la Faye. Aussi voit-on les abbesses, dans les anciens titres, reconnoître sans difficulté que les seigneurs de la Faye étoient en partie les fondateurs de leur maison [seigneurs d'Argental, qui étaient aussi seigneurs de La Faye]. C'est ainsi qu'en parloit en 1412 l'abbesse Marguerite de Conis, en se plaignant d'Ybod de Chaste, seigneur de la Faye, qui, au lieu de vexer la maison de Clavas, auroit dû la protéger, maximè, ajoute-t-elle, cum per suos predecessorum hujusmodi monasterium fuerit partim fundatum; et depuis des siècles, il $\mathrm{y}$ a encore entre les abbesses et les seigneurs de Faye un procès qui n'est point encore terminé, au sujet de la justice de Clavas même ${ }^{25}$. »

L'abbaye de Clavas est donc fondée dans les limites du diocèse du Puy, sur des terres de la mouvance viennoise, elles-mêmes sises dans le ressort forézien. Une centaine d'années après son érection, elle est incontestablement soumise à la juridiction comtale forézienne. Aussi pouvons-nous considérer que l'espace qu'elle occupe cristallise les enjeux seigneuriaux laïcs et religieux, mais n'est en aucun cas un monopole vellave : seules ses possessions au sud de la Clavarine, sur la paroisse de Saint-JulienMolhesabate ${ }^{26}$, dépendent du ressort du comtal du Velay ${ }^{27}$. Avec la commanderie de Marlhes, l'hôpital Saint-Maxime et le prieuré de Saint- Sauveur, elle participe à la matérialisation d'un limes entre les seigneuries laïques et l'évêque du Puy, puis entre les justices vellave (royale) et forézienne. Le comte-évêque est finalement hors jeu des dynamiques locales, malgré la présence de son allié royal à Montfaucon dès la fin du $\mathrm{XIII}^{\mathrm{e}}$ siècle. Clavas est un établissement cistercien en pays historique vellave, soumis à l'administration religieuse du diocèse du Puy, mais en prise effective avec la justice forézienne et une dynamique territoriale rhodanienne et ligérienne. 


\section{Abbaye de La Séauve-Bénite}

La période de fondation communément admise par la littérature oscille entre la fin du $\mathrm{XII}^{\mathrm{e}}$ siècle et 1228. Mais une mention de Sybille Du Béage, abbesse de La Séauve en 1183 (est-ce la moniale donnée à Clavas un peu plus tôt, ou une parente ?) permet de préciser ces terminus. La seigneurie du Béage est éloignée de 73 kilomètres de La Séauve-Bénite, et une journée de marche est nécessaire pour joindre les abbayes sœurs de La Séauve-Bénite et de Clavas. L'implication de la famille Du Béage dans les parthénons de cisterciennes illustre l'intrication des liens organiques de l'ordre de Cîteaux avec la parenté aristocratique et son impact dans les circulations et le maillage territorial ${ }^{28}$. À cette date, il semblerait que la baronnie de Saint-Didier soit tenue par Guillem, célèbre troubadour, qui aurait vécu jusqu'en $1194^{29}$. Cette hypothèse s'accorde avec celle de Philippe Peyron, qui voit dans les seigneurs de Saint-Didier les fondateurs potentiels, alors que la plupart des travaux historiques sur la question reconnaissent les comtes de Forez en raison de quelques bienfaits alloués à La Séauve ${ }^{30}$. La dynastie des Saint-Didier élit par ailleurs sépulture dans cette même abbaye ${ }^{31}$.

\section{Saint-Didier, baronnie de la mouvance épiscopale en Forez}

Le cartulaire de Chamalières livre une première mention textuelle attestant l'existence d'une paroisse et un château à Saint-Didier dans le courant du XI ${ }^{e}$ siècle ${ }^{32}$. Si l'on en croit une bulle papale de 1164, l'église et le château de Saint-Didier dépendent alors de l'église du Puy ${ }^{33}$. Édouard Perroy confirme la vassalité du mandement de Saint-Didier

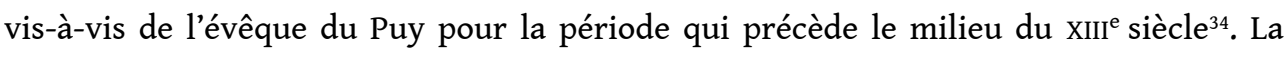
localité est le siège d'une baronnie mitoyenne de la seigneurie d'Argental, puisqu'elle s'étend à l'est jusqu'à Jonzieux et Marlhes, au sud, jusqu'à la Dunières ; elle est confinée à l'ouest par la Loire et par La Chapelle-d'Aurec au nord (fig. 4).

Fig. 4. - La seigneurie de Saint-Didier, d'après P.-É. Poble, La citadelle royaliste du Velay « delà les bois "; échelle 1/25 000.

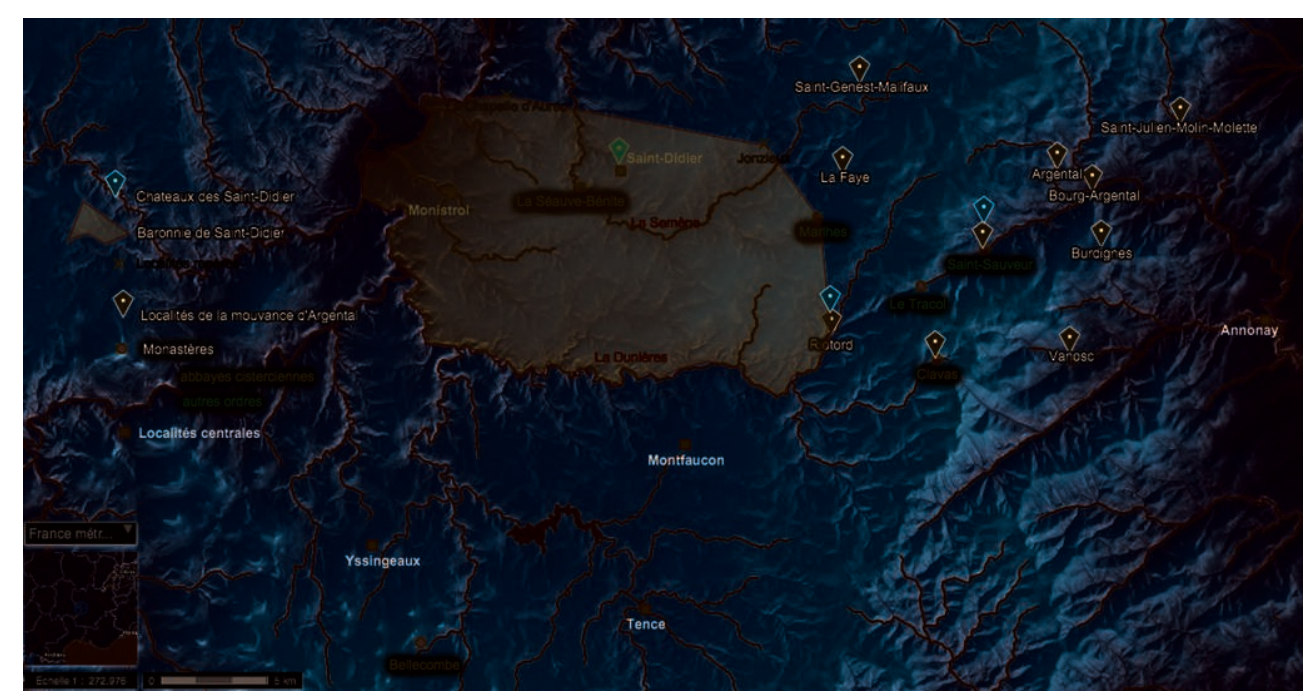

(c) Emma Bouvard-Mor - (c) IGN, 2015 (fond de carte). 
Elle appartient donc au pays en litige précédemment décrit, à savoir la marge septentrionale de l'ancien diocèse du Puy, dans un espace historiquement du pays forézien, que les comtes du Forez annexent progressivement durant le Moyen Âge. Étienne Delcambre fournit en creux quelques arguments attestant l'appartenance de Saint-Didier au pagus forensis : sa liste des vicaries et des aises (territorium) connues pour le pagus aniciensis entre l'époque carolingienne et le $\mathrm{xI}^{\mathrm{e}}$ siècle reste lettre morte à propos de Saint-Didier et des autres localités situées entre le cours de la Dunières et la rive droite de la Loire (soit au nord-est de l'ancien diocèse du Puy). Cette absence de Saint-Didier ne peut être interprétée comme un effet de sources, car sa place forte est connue dès avant 1030 ou $1061^{35}$ : si Saint-Didier était déjà à la tête d'une seigneurie haute-justicière vellave, elle aurait donc été à même de prendre la direction d'une division administrative civile (vicarie ou aise) autour de l'an mil, d'autant qu'elle sera plus tard le siège d'un mandement ${ }^{36}$. C'est pourquoi nous la plaçons en Forez.

Le bourg castral primitif connaît une réelle prospérité durant le Moyen Âge central. Il polarise la population et les richesses, et se pare d'une seconde enceinte ; les habitants obtiennent des chartes de franchise à la toute fin du XIII ${ }^{e}$ siècle et dans le courant du XIV ${ }^{e}$ siècle. L'abbaye de La Séauve-Bénite est fondée à moins de trois kilomètres au sudouest de cette centralité ; au XVI ${ }^{\mathrm{e}}$ siècle, La Séauve forme un véritable bourg inféodé à Saint-Didier ${ }^{37}$, évolution suffisamment rare dans le monde cistercien pour être soulignée. $\mathrm{Au} \mathrm{XVI}^{\mathrm{e}}$ siècle, à l'instar de Clavas, La Séauve est un mandement, c'est-à-dire une seigneurie à partir de laquelle est calculée l'assiette fiscale, et dont le siège est l'abbaye.

\section{Les comtes de Forez : une influence limitée}

En 1260, Jocerand de Saint-Didier inféode au comte de Forez Guy V son château de Riotord et sa maison forte de La Bastie, près de Saint-Sauveur-en-Rue. Ces lieux encadrent un point stratégique majeur pour l'évêque, qui y a dressé ses fourches patibulaires. Jocerand et son successeur restent cependant fidèles au prélat pour les seigneuries de Saint-Didier et de La Séauve, ainsi que pour le fief du Chambon, en aval de Bas-en-Basset ${ }^{38}$. En 1332, Jocerand de Saint-Didier se reconnaît à nouveau vassal du comte de Forez pour le château de Riotord, mais fait réserve de l'hommage lige à l'évêque, qui s'assure donc de son soutien armés ${ }^{39}$.

23 Les incursions foréziennes au plus proche de Saint-Didier se borneront finalement à de pieux bienfaits en direction de l'abbaye de La Séauve: le comte Guy y fonde un anniversaire en 1239 ; le 16 octobre 1226, l'archevêque Renaud de Forez teste en faveur des moniales ; Renaud de Forez, petit-neveu du précédent, fait don de 5 sols viennois en 1270 ; divers seigneurs foréziens dotent le monastère, à l'instar d'autres maisons cisterciennes ${ }^{40}$.

La Séauve-Bénite, fondation aristocratique et mausolée familial, est un établissement implanté dans l'ancien pagus forézien, mais dans les limites de l'ancien diocèse du Puy. Bien que sa portée religieuse outrepasse les limites ecclésiastiques, elle reste dans la mouvance épiscopale, malgré la politique offensive de ses voisins foréziens. 


\section{Implantations cisterciennes et recompositions territoriales}

On a pu constater la présence des abbayes cisterciennes sur des frontières interseigneuriales : elles se situent en marge des sièges féodaux dont elles dépendent, mais en position de marche vis-à-vis des voisins. Parfois, elles intègrent un limes entre deux puissances concurrentes, comme c'est le cas à La Séauve-Bénite, où le comte-évêque et le seigneur de Saint-Didier, son vassal, font face à la pression forézienne.

Ces fondations participent d'une politique territoriale offensive, mais pacifiste. En cela, on pourrait y voir les instruments de la prolongation de la Paix de Dieu dans le courant $\mathrm{du} \mathrm{XII}{ }^{\mathrm{e}}$ siècle ${ }^{41}$. En effet, elles confèrent aux terres qu'elles investissent une certaine forme de sacralité, ainsi que l'immunité qui leur est due, tout en servant les prétentions d'expansion des seigneuries laïques, sans coup férir. En ce cas, la ligne est-ouest établie par les établissements religieux de La Séauve-Bénite, de Clavas, de Marlhes, du Tracol et de Saint-Sauveur-en-Rue entre la mouvance forézienne et les terres comtales vellaves formerait une sorte de "muraille sacrée» en renfort des places fortes appartenant aux seigneurs de Saint-Didier. L'ancrage territorial réaffirmé par les seigneurs locaux par le biais de leurs fondations cisterciennes est renforcé par la présence de leurs sépultures. L'accueil des laïcs et de leurs legs en argent contre le soin de leurs défunts parents et de leurs âmes n'est pas conforme à la règle de l'ordre de Cîteaux. Pourtant, l'usage est courant et précoce à tous les échelons de la hiérarchie féodale, et se répand dans bien des sanctuaires cisterciens, notamment au sein des établissements féminins ${ }^{42}$.

Nous venons d'aborder la portée politique de ce positionnement géographique, il nous faut interroger à présent le rôle économique des domaines cisterciens de confins. En l'état de la recherche, les sources médiévales font souvent défaut pour en donner une juste et complète cartographie ; mais l'existence de granges médiévales est attestée à Clavas et est très fortement suspectée par la toponymie à La Séauve-Bénite. Ces centres d'exploitation mettent en valeur le terroir, et par conséquent attirent les populations.

À Clavas, pour le XIII ${ }^{\mathrm{e}}$ siècle nous avons la certitude, grâce à une charte du cartulaire de Saint-Sauveur-en-Rue, de l'existence de laïcs, « mercenaires » (salariés) et familiers ne portant pas l'habit de convers mais résidant et travaillant sur les granges de l'abbaye ${ }^{43}$. Le faire-valoir indirect est donc pratiqué dès le premier siècle d'existence de l'abbaye féminine, et ses domaines génèrent suffisamment de richesses pour entretenir des communautés villageoises. Ces dernières sont d'ailleurs si polarisées sur les terres de Clavas qu'elles en viennent à fréquenter et à élire sépulture dans l'église abbatiale, au détriment de la paroisse de Riotord, dont elles dépendent. Le prieur de Saint-Sauveuren-Rue, qui est collateur de la dîme sur cette paroisse, est d'autant plus lésé que les vavasseurs d'Argental abandonnent le cimetière de Saint-Sauveur au profit de celui de l'abbaye de Clavas ${ }^{44}$, bien que celle-ci soit plus éloignée du pôle seigneurial, distant de 23 kilomètres, soit une journée de marche. Cette situation fait tout l'objet de la charte précédemment citée: le prieur de Saint-Sauveur-en-Rue établit un accord avec le chapelain et l'abbesse de Clavas afin que ceux-ci ne reçoivent plus les fidèles dépendant de ladite paroisse, tant pour les saints sacrements que pour les principales fêtes du calendrier liturgique. Les bornes dîmières des deux territoires sont rappelées à cette occasion. 

dialectiques spirituelles et économiques locales, jusqu'à créer de nouveaux pôles de peuplement suffisamment importants pour déjouer la géographie pastorale locale. Elle suscite aussi une dilatation étonnante des déplacements à des fins sépulcrales et commémoratives. On peut alors s'interroger sur la part intentionnelle et stratégique de cette fondation et de son implantation: les Pagan d'Argental avaient-ils anticipé ce changement de paradigme, et auquel cas, comment en tiraient-ils profit? La question concerne les rapports de concurrence et de complémentarité entre pouvoirs religieux et laïc sur des territoires de marges ou de marches. Il faudrait pour y répondre ouvrir une enquête sur les relations entre le prieuré casadéen et la seigneurie riveraine d'Argental, mais cela nous écarterait bien trop de notre propos.

En outre, l'acte de fondation de l'abbaye de Clavas et les premières donations qui en découlent ne sont pas connus. On ne peut donc pas savoir si les lieux mentionnés dans la charte de Saint-Sauveur-en-Rue étaient déjà occupés et exploités avant la colonisation cistercienne. Toutefois, l'emploi du terme yssartis (essarts) dans la charte ci-avant mentionnée nous permet d'envisager, si ce n'est la création d'un front pionnier de défrichement initié par la communauté cistercienne, au moins une intensification des activités de mise en valeur des terres par un encadrement rapproché des locaux qui essartent. On gagne donc du terrain sur l'inculte, sur le saltus, et on augmente la valeur des territoires de marge devenant attractifs pour les populations.

3

Nous sommes encore très éloignés d'une démonstration suffisamment nourrie, par manque de données sérielles touchant l'intégralité de notre corpus, les dix abbayes cisterciennes en Auvergne et Velay. Cependant, il serait intéressant de poursuivre les investigations en direction de l'aristocratie locale: dans quelle mesure bâtit-elle une stratégie de contrôle et de fructification de ses marges territoriales par le biais des ordres monastiques réformateurs? Ceux-ci, et particulièrement Cîteaux, sont, d'une part, suffisamment désintéressés par le siècle pour obtenir la confiance des dynastes, et recherchent d'autre part les conditions de leur autosubsistance: la collaboration conviendrait donc aux deux parties.

Les abbayes de Clavas et de La Séauve-Bénite ont été fondées dans le territoire du Velay ecclésiastique. Pour autant, elles doivent leur existence à des lignages extra-diocésains ou liés à des mouvances externes. En ce sens, leur rayonnement spirituel et leurs interactions territoriales sont davantage tournées vers les mouvances foréziennes, vivaroises et viennoises, voire même lyonnaises. Cette dynamique exogène au Velay historique, mise en lumière par une nouvelle lecture des contextes seigneuriaux, rend plus ou moins caduc le cadre territorial d'étude traditionnellement choisi pour les études monastiques, à savoir les limites diocésaines. Bien que ces dernières rendent compte d'une réalité administrative médiévale conforme à la chronologie de notre étude, elles gomment, si on n'y prend garde, les particularités géopolitiques microrégionales, véritables révélateurs de sens. On pourra à ce titre interroger la dénomination même d'abbayes cisterciennes " vellaves » ou de «l'ancien diocèse du Puy »: d'un point de vue strictement topologique, elles se situent dans les limites de l'ancien diocèse du Puy et en position de marge par rapport aux anciens pays vellaves 
et foréziens ; mais leur situation frontalière, soumise à diverses influences territoriales et seigneuriales, ne permet pas de lier exclusivement leur fortune au Velay historique et/ou au Velay ecclésiastique.

Par ailleurs, les finages relativement éloignés du cœur historique et dynamique des seigneuries seraient spécifiquement choisis pour être donnés aux cisterciens dans une optique de (re)conquête du saltus, notamment sur des terrains relativement écartés, situés en zone de moyenne montagne : c'est le cas à Clavas, mais cela a été établi pour six autres domaines de notre corpus - L'Éclache, La Vassin, Feniers, Mègemont, Bellecombe, La Séauve-Bénite -, dont les possessions connues ou supposées sont réparties entre deux gradients altimétriques: de 681 à 1020 mètres d'altitude, et de 1021 à 1360 mètres d'altitude.

Les abbayes cisterciennes peuvent participer au déploiement de nouvelles communautés humaines et à des changements de dialectiques économiques par une nouvelle distribution des activités sur le territoire. Elles endossent aussi le rôle de gardiennes d'un certain patrimoine foncier seigneurial un peu trop distant des organes de contrôle laïcs, et potentiellement menacé en contexte de conflit régional ou d'éloignement temporaire des suzerains. Enfin, desservies par des axes routiers majeurs, elles peuvent faire office de lieu d'accueil sur des itinéraires empruntés tant pour des motivations économiques (gestion du temporel monastique, commerce) que pieuses (pèlerinages). Cette situation leur assure un rayonnement transcendant les limites diocésaines, de part et d'autre de montagnes qui, bien loin d'exercer une quelconque répulsion ou un rôle de barrage, sont traversées, occupées et exploitées.

\section{BIBLIOGRAPHIE}

BALUZE Étienne, Regum francorum capitularia, t. II. Paris, 1677.

BERGERON Robert, «L'abbaye cistercienne de Notre-Dame-de-Clavas au XVIII ${ }^{\mathrm{e}}$ siècle », Cahiers de la

Haute-Loire, 2002, p. 237-264.

BERGERON Robert, «L'abbaye cistercienne de Notre-Dame de Clavas aux XVI ${ }^{\mathrm{e}}$ et XVII ${ }^{\mathrm{e}}$ siècles », Cahiers de la Haute-Loire, 2004, p. 59-78.

BERTHOLET Christian, « Bellecombe, une abbaye cistercienne en Velay au XVIII ${ }^{\mathrm{e}}$ siècle ", Per Lou Chamis, $\mathrm{n}^{\circ} 43-44,1984$, p. 58-76 et p. 36-60.

BESSON Charles, « XV et XVI ${ }^{\mathrm{e}}$ siècles, moniales cisterciennes en Gévaudan et en Velay : les abbayes de Mercoire, Clavas, Bellecombe et Séauve-Bénite », Cahiers de la Haute-Loire, 2003, p. 133-156.

BOUVARD Emma, «Empreintes monastiques en moyenne montagne du XII siècle à l'actuel : archéologie des espaces et des paysages cisterciens dans les anciens diocèses de Clermont et du Puy », thèse de doctorat d'archéologie médiévale, Lyon, université Lumière - Lyon II, 2016.

BRECHON Franck, « Réseau routier et organisation de l'espace en Vivarais et sur ses marges au Moyen Âge ", thèse de doctorat d'histoire médiéviale, Lyon, université Lumière - Lyon II, 2000. 
CARRAZ Damien, « Un revival de la paix de Dieu ? Les paix diocésaines du XII ${ }^{\mathrm{e}}$ siècle dans le Midi », dans La réforme " grégorienne » dans le midi de la France, Toulouse, Privat (Cahiers de Fanjeaux, 48), 2013, p. 523-558.

CATARINA Didier, «Les mandements du Velay : essai de géographie », Cahiers de Haute-Loire, 2000, p. 31-101.

CHARBONNIER Pierre, Histoire de l'Auvergne des origines à nos jours, Clermont-Ferrand, De Borée, 2001. CHASSAING Augustin, Cartulaire de Chamalières-sur-Loire en Velay, prieuré conventuel dépendant de l'abbaye de Saint-Chaffre, Paris, Picard, 1895.

CHASSAING Augustin et JACOTIN Antoine, Dictionnaire topographique du département de la Haute-Loire, Paris, Imprimerie nationale, 1907.

COOMANS Thomas, « Moniales cisterciennes et mémoire dynastique : églises funéraires princières et abbayes cisterciennes dans les anciens Pays-Bas médiévaux », Cîteaux, t. LVI, fasc. I-IV, 2005, p. 87-145.

COTTINEAU L. H. (dom), Répertoire topo-bibliographique des abbayes et prieurés, Mâcon, Protat, 1939. DELCAMBRe Étienne, « Géographie historique du Velay : du Pagus au comté et au baillage », Bibliothèque de l'École des chartes, t. XCVIII, 1937, p. 17-63.

DUFOUR Jean- Étienne, Dictionnaire topographique du Forez et des paroisses du Lyonnais et du Beaujolais formant le département de la Loire, Mâcon, impr. Protat, 1946.

EXCOFFON Sylvain, «Les chartreuses et leurs limites ( $\mathrm{XI}^{\mathrm{e}}-\mathrm{XV}^{\mathrm{e}}$ siècle) », dans Lienhard Th. (dir.), Construction de l'espace au Moyen Âge : pratiques et représentations, Paris, Publications de la Sorbonne, 2007, p. 87-101.

FABRE Césaire, « Notes sur les troubadours Guillem et Gauceran de Saint-Didier », Annales du Midi : revue archéologique, historique et philologique de la France méridionale, vol. 23, nº 90, 1911, p. 161-179. GRÉLOIS Alexis, « Les cisterciennes auvergnates face aux crises de la fin du Moyen Âge », Cîteaux Commentarii cistercienses, t. 67, fasc. 1-2, 2016, p. 29-66.

GUIGUE Marie-Claude et CHARPIN-FEUGEROLlEs Hippolyte André (éd.), Cartulaire de l'abbaye de SaintSauveur-en-Rue (Forez) dépendant de l'abbaye de La Chaise-Dieu, 1062-1401, Lyon, impr. A.-L. Perrin, 1881.

JOURDA DE VAUX Gaston de, Le nobiliaire du Velay et de l'ancien diocèse du Puy (noms féodaux), t. VI, Le Puy, impr. La Haute-Loire, 1931.

LAFFONT Pierre-Yves, Atlas des châteaux du Vivarais, $X^{e}$-XIII ${ }^{e}$ siècle, Lyon, ALPARA / ministère de la Culture (Documents d'archéologie en Rhône-Alpes et Auvergne, 25), 2004.

LEMAITRE Jean-Loup, Cartulaire de la chartreuse de Bonnefoy, Paris, CNRS éditions, 1990.

MARTIN Daniel (dir.), L'identité de l'Auvergne : mythe ou réalité historique, Saint-Just-près-Brioude, Créer, 2002.

Mémoire pour les co-seigneurs de la baronnie de la Faye en Forez, au sujet du droit de mi-lod, Paris, chez Saugrain Jeune, 1769.

PAYRARD Jean-Baptiste (abbé), « Chartes inédites concernant l'histoire du Velay », Tablettes du Velay, $\mathrm{n}^{\circ} 8,1877-1878$, p. 6-7. 
PÉLAQUIER Élie, Atlas historique de la province de Languedoc, Montpellier, Centre de recherches interdisciplinaires en sciences humaines et sociales, université Paul Valéry - Montpellier III, 2009.

PERROY Édouard, Les familles nobles du Forez au XIII siècle : essais de filiation, t. I, université de SaintÉtienne (Thèses et mémoires, 8) / Centre d'études foréziennes (Recueils de mémoires et de documents sur le Forez publiés par la Société de la Diana, XX), 1976.

PEYRON Philippe, Abbaye cistercienne de La Séauve-Bénite en Velay : quelques points d'histoire, SaintÉtienne, mémoire dactylographié, 1992.

PEYRON Philippe, «Cisterciennes et bernardines dans le nord-est du Massif central (Auvergne, Forez, Lyonnais, Velay, Gévaudan) aux XVII et XVIII siècles », Saint-Étienne, mémoire de DEA d'histoire, université Jean-Monnet - Saint-Étienne, 1993.

PEYRON Philippe, «L'abbaye cistercienne de La Séauve-Bénite en Velay : quelques points d'histoire et reconstitution architecturale », Cahiers de la Haute-Loire, 1998, p. 155-205.

PEYVEL Pierre, «Épiscopat et réseaux monastiques : le cas du diocèse du Puy ", dans Bouter Nicole (dir.), Naissance et fonctionnement des réseaux monastiques et canoniaux, Presses universitaires de Saint-Étienne, 1991, p. 373-407.

POBLE Pierre-Éric, La citadelle royaliste du Velay « delà les bois »: Saint-Didier-La-Seauve dans la seconde moitié du XVI siècle, Saint-Étienne, Yves Touron imprimeur, 1997.

ROCHER Charles, « Pouillé du diocèse du Puy (suite) », Tablettes du Velay, nº 4, 1873-1874, p. 470.

SAINTE-MARTHE Denis (dom), Gallia christiana in provincia ecclesiasticas distributa qua series et historia archiepiscoporum, episcoporum et abbatum Franciae vicinarumque ditionum, ab origine ecclesiarum ad nostra tempora deducitur, et probatur ex authenticis instrumentis ad calcem appos, itis [...], t. II, Paris, 1720.

THEILLIÈRE Jean (abbé), Notes historiques sur les monastères de La Séauve, Bellecombe, Clavas et Montfaucon, Saint-Étienne, J.-M. Freydier, 1872-1880.

\section{NOTES}

1. E. Bouvard, «Empreintes monastiques en moyenne montagne du XII siècle à l'actuel ».

2. Cette appellation est tardive. Au XVI ${ }^{\mathrm{e}}$ siècle, on différencie le Velay "delà les bois " du Velay "deçà les bois "; les bois en question sont ceux qui s'étendent selon un zonage relativement irrégulier d'axe nord-ouest/sud-est depuis le cours de l'Ance au nord, jusqu'au massif du Meygal au sud. Tout ce qui se situe à l'est de cette frontière sylvestre appartient à notre zone d'étude "delà les bois ", dont les localités centrales répertoriées par P.-É. Poble pour cette période sont Saint-Didier, Monistrol, Tence, Montfaucon et Yssingeaux (La citadelle royaliste du Velay "delà les bois ", p. 39 et suiv.).

3. L'amplitude des déplacements potentiels varient entre 64 et $94 \mathrm{~km}$ entre Mazan et les monastères de moniales, dans un contexte de moyenne montagne (les monts d'Ardèche, le massif du Mézenc et le Pilat), soit entre trois et quatre jours de marche.

4. J. Theillière, Notes historiques sur les monastères de La Séauve, Bellecombe... ; C. Besson, « $\mathrm{XV}^{\mathrm{e}}$ et $\mathrm{XVI}^{\mathrm{e}}$ siècles, moniales cisterciennes en Gévaudan et en Velay "; R. Bergeron, «L'abbaye cistercienne de Notre-Dame-de-Clavas au XVIII ${ }^{\mathrm{e}}$ siècle » et "L'abbaye 
cistercienne de Notre-Dame de Clavas aux $\mathrm{XVI}^{\mathrm{e}}$ et $\mathrm{XVII}^{\mathrm{e}}$ siècles »; P. Peyron, «Cisterciennes et bernardines dans le nord-est du Massif central ».

5. P.-Y. Laffont, Atlas des châteaux du Vivarais, $X^{e}$-XIII ${ }^{e}$ siècle.

6. E. Baluze, Regum francorum capitularia, col. 1443 : In agro Ananocense in loco qui vocatur Argentaus.

7. E. Perroy, Les familles nobles du Forez au XIII siècle, p. 432.

8. J.-E. Dufour, Dictionnaire topographique du Forez, p. 331 et 885.

9. Distance piétonne par le GR 65, censé reprendre l'itinéraire ancien de Vienne au Puy, sur la route de Saint- Jacques-de-Compostelle.

10. M.-Cl. Guigue et H. A.Charpin-Feugerolles (éd.), Cartulaire de l'abbaye de SaintSauveur-en-Rue, charte 1 : De fundatione et dono monasterii Sancti Salvatoris, 1061.

11. J.-E. Dufour, Dictionnaire topographique du Forez, p. $448: 1265$, Ultra Dermam vel stratam Sancti Maximi ; 1280, hospitale Sancti Maximi juxta furcas ; 1331, Tracolum Sancti Maximi [...] juxta iter quod descendit de Clavasio per tracollum versus Sanctum Salvatorem.

12. M.-Cl. Guigue et H. A.Charpin-Feugerolles (éd.), Cartulaire de l'abbaye de SaintSauveur-en-Rue, p. 129, charte CLXVIII, Compositio templi de Marlhetis.

13. F. Brechon, «Réseau routier et organisation de l'espace en Vivarais », p. 391 et suiv. et p. 648 et suiv.

14. C. Bertholet, l'un des biographes de Bellecombe, signale l'écroulement d'une partie de l'hôtellerie pour l'année 1738 (voir « Bellecombe, une abbaye cistercienne en Velay au XVIII siècle »). Géographiquement plus éloignée, mais sise à un carrefour entre deux axes majeurs reliant Clermont à Limoges et à Bordeaux, l'abbaye féminine de L'Éclache possédait un " hôtel des étrangers » mentionné en 1369 (A. Grélois, « Les cisterciennes auvergnates face aux crises de la fin du Moyen Âge »).

15. R. Bergeron, «L'abbaye cistercienne de Notre-Dame de Clavas aux $x I^{e}$ et $x V I I^{e}$ siècles ".

16. J.-L. Lemaitre, Cartulaire de la chartreuse de Bonnefoy, p. 127-128 (charte $\mathrm{n}^{\circ} 151$ ).

17. É. Delcambre, «Géographie historique du Velay »; P.-É. Poble, La citadelle royaliste du Velay «delà les bois »; D. Catarina , «Les mandements du Velay »; É. Pélaquier, Atlas historique de la province de Languedoc.

18. Mémoire pour les co-seigneurs..., seconde partie : "Moyen d'appel contre le second chef de la sentence du 12 août 1761 », p. 2 : « Il y a donc outre La Faye un pays en litige. C'est toute l'extrémité méridionale du Forez actuel, sur les confins du haut Vivarais et du Velai, depuis le Rhône jusqu'à l'Auvergne ».

19. Mémoire pour les co-seigneurs..., "Quatrième proposition ", p. 4-5.

20. La permutatio désigne la répartition des droits entre l'archevêque de Lyon et le comte du Forez établie en 1173, qui aura pour suite le renoncement de ce dernier au titre de " comte de Lyon " afin de faire accéder la lignée à la charge épiscopale (S. Excoffon, «Les chartreuses et leurs limites $\left(\mathrm{XI}^{\mathrm{e}}-\mathrm{XV}^{\mathrm{e}}\right.$ siècle)»). Les possessions foréziennes sont donc réévaluées à cette occasion. Les auteurs du Mémoire pour les coseigneurs... avancent que des confins méridionaux de la Loire sont soustraits au comté du Forez à cette occasion, alors que jusque-là ils en auraient fait partie intégrante.

21. Mémoire pour les co-seigneurs..., « Troisième proposition », p. 80. 
22. Une charte inédite de 1060, publiée dans les Tablettes du Velay, expose la donation de l'église de Riotord à La Chaise-Dieu par Arthaldus de Argentan, sur les conseils et la volonté de sa femme et de tous les miles d'Argentan (J.-B. Payrard, «Chartes inédites concernant l'histoire du Velay »). L'article 36 du pouillé du diocèse du Puy relate pour l'année 1087 la donation des églises de Riotord et d'Usson par l'évêque du Puy au prieur de Saint-Sauveur-en-Rue. Outre le mouvement de rétrocessions laïques au clergé dans le contexte de la réforme grégorienne, ces deux actes consécutifs illustrent la présence conjointe de l'évêque vellave et des seigneurs de la mouvance viennoise sur ce même territoire (C. Rocher, « Pouillé du diocèse du Puy »).

23. É. Delcambre, « Géographie historique du Velay ».

24. Ibid.

25. Mémoire pour les co-seigneurs..., p. 71.

26. A. Chassaing et A. Jacotin, Dictionnaire topographique du département de la Haute-Loire, p. 255-256.

27. La borne septentrionale de la seigneurie épiscopale est Riotord (É. Delcambre, "Géographie historique du Velay »).

28. G. de Jourda de Vaux, Le nobiliaire du Velay et de l'ancien diocèse du Puy, p. 214.

29. C. Fabre, « Notes sur les troubadours Guillem et Gauceran de Saint-Didier ».

30. D. Sainte-Marthe, Gallia christiana in provincia ecclesiasticas; J. Theillière, Notes historiques sur les monastères de La Séauve...; L. H. Cottineau, Répertoire topo-bibliographique des abbayes et prieurés; P. Peyvel, «Épiscopat et réseaux monastiques : le cas du diocèse du Puy». Ce dernier adopte comme terminus ante quem le 25 juin 1223, tant pour l'abbaye de Clavas que pour celle de La Séauve, toutes deux citées dans le testament de Guillaume de Chapteuil.

31. J. Theillière, Notes historiques sur les monastères de La Séauve..., p. 50 : Amphélise de Chalencon, épouse de Jocerand de Saint-Didier, demande à être inhumée à La Séauve dans son testament de 1266 . Son époux, son fils et deux de ses petits-enfants la suivront dans ce choix.

32. A. Chassaing, Cartulaire de Chamalières-sur-Loire en Velay, p. 51, charte $\mathrm{n}^{\circ} 99$ : In perochia castri de Sancti Desiderio [1031-1060].

33. P.-E. Poble, La citadelle royaliste du Velay « delà les bois », p. 20.

34. É. Perroy, Les familles nobles du Forez au XIII ${ }^{e}$ siècle, notice 168, p. 734 et suiv.

35. A. Chassaing, Cartulaire de Chamalières-sur-Loire en Velay.

36. Mandement de Saint-Didier-de-Joyeuse (É. Delcambre, « Géographie historique du Velay $»)$.

37. P.-É. Poble, La citadelle royaliste du Velay « delà les bois », p. 23-24.

38. É. Perroy, Les familles nobles du Forez au XIII siècle.

39. É. Delcambre, « Géographie historique du Velay ».

40. P. Peyron, Abbaye cistercienne de La Séauve-Bénite en Velay, p. 11, d'après les Chartes du Forez.

41. D. Carraz, « Un revival de la paix de Dieu?».

42. T. Coomans « Moniales cisterciennes et mémoire dynastique... ». 
43. M.-Cl. Guigue et H. A.Charpin-Feugerolles (éd.), Cartulaire de l'abbaye de SaintSauveur-en-Rue, p. 133, CLXIX: " Habitatores laicos et mercanarios in territorio de Clavata, seu familiares, donatos seu oblatos ipsius domus, qui non gestant habitum conversorum, in ecclesia sua de Clavata recipiebant ": "Les habitants laïques et les travailleurs du territoire de Clavas, ainsi que les familiers, les donnés ou oblats de cette même maison, qui ne portent pas l'habit des convers, reposent dans l'église de Clavas. »

44. M.-Cl. Guigue et H. A. Charpin-Feugerolles, Cartulaire de l'abbaye de Saint-Sauveur-enRue, p. 133, CLXIX: "[...] Philippus de Laval, domicellus, vavassor [sic] d'Argentau, parrochianus dicti prioris, ad sepulturam dicto monasterio de Clavata dicitur reliquisse et apud eos eligerat sepeliri [...]»: «[...] Philippe de Laval, damoiseau, vavasseur d'Argental, paroissien dudit prieur [de Saint-Sauveur], dit avoir abandonné [des terres] pour des funérailles au dit monastère de Clavas où il a choisi de s'y faire enterrer [...]. »

\section{RÉSUMÉS}

Les abbayes cisterciennes d'Auvergne et du Velay sont établies sur des frontières interseigneuriales. Ces fondations participent d'une politique territoriale offensive, mais pacifiste, au risque de l'oxymore. Elles confèrent aux terres qu'elles investissent une certaine forme de sacralité, ainsi que l'immunité qui leur est due, tout en servant les prétentions d'expansion des seigneuries laïques. Au travers des exemples des établissements féminins de Clavas et de La Séauve-Bénite (ancien diocèse $\mathrm{du}$ Puy), nous approcherons le rôle qu'a pu leur donner l'aristocratie locale dans les enjeux territoriaux du $\mathrm{xII}^{\mathrm{e}}$ siècle. L'enquête prend en compte les données prosopographiques et l'histoire seigneuriale locale (sources éditées, historiographie ancienne et récente), et use de la géographie historique afin d'illustrer l'affirmation dynastique de ces fondations monastiques de montagne. Elle met aussi en lumière les dynamiques frontalières générées par ces parthénons.

\section{AUTEUR}

\section{EMMA BOUVARD-MOR}

Docteure en archéologie médiévale, archéologue/archéoanthropologue au service archéologique de la Ville de Lyon, chercheure associée au laboratoire Archéologie et archéométrie (ArAr, UMR 5138), université Lumière - Lyon II / CNRS 


\title{
Des moines et des sapins :
} monastères et mise en valeur de la haute chaîne jurassienne au milieu du Moyen Âge

\author{
Valentin Chevassu
}

1 Les monastères médiévaux jurassiens, liés au monachisme des pères du Jura ou dus à l'essor des ordres clunisien et cistercien, sont considérés traditionnellement comme étant à l'origine des premières initiatives de peuplement et de défrichement du massif Jurassien. Les archives monastiques constituant souvent les seules sources écrites anciennes disponibles pour la haute chaîne du Jura, les recherches historiques ont longtemps eu tendance à confirmer cette vision et à surestimer le rôle des abbayes comme vecteurs d'anthropisation du massif au milieu du Moyen Âge.

2 La multiplication des analyses paléoenvironnementales et le développement des recherches archéologiques permettent aujourd'hui de nuancer largement ces hypothèses. L'impact des monastères jurassiens sur la mise en valeur des montagnes environnantes peut être remis en perspective avec l'évolution des activités humaines dans la longue durée. Ces questionnements sont au cœur d'un travail de thèse, débuté en 2015, visant à synthétiser les informations issues des travaux archéologiques, paléoenvironnementaux et historiques menés sur le Jura central, ou Haut-Doubs, région située autour de Pontarlier et au cœur du massif jurassien ${ }^{1}$.

3 Constitué de vastes plateaux et d'une haute chaîne au relief plissé, cet espace se définit actuellement par la grande extension de ses forêts de résineux. Le secteur est également fameux pour ses températures rigoureuses, plus ou moins contraignantes selon les évolutions climatiques. Du XI ${ }^{\mathrm{e}}$ au XIII ${ }^{\mathrm{e}}$ siècle, on assiste au développement de quatre monastères, le prieuré clunisien Saint-Pierre de Morteau, l'abbaye augustine de Montbenoît, l'abbaye cistercienne de Mont-Sainte-Marie et le prieuré bénédictin SaintSimon de Mouthe, implantés dans quatre vallées de la haute chaîne jurassienne (fig. 1). Tous ont été documentés par divers travaux historiques, dont les résultats peuvent être croisés avec les apports des analyses paléoenvironnementales et des quelques 
découvertes archéologiques réalisées à proximité. Nous livrons ici une première tentative de synthèse de ces données, afin de confronter l'histoire des monastères et de leurs temporels avec l'évolution du paysage observée par ailleurs.

Fig. 1. - Localisation des quatre monastères étudiés.

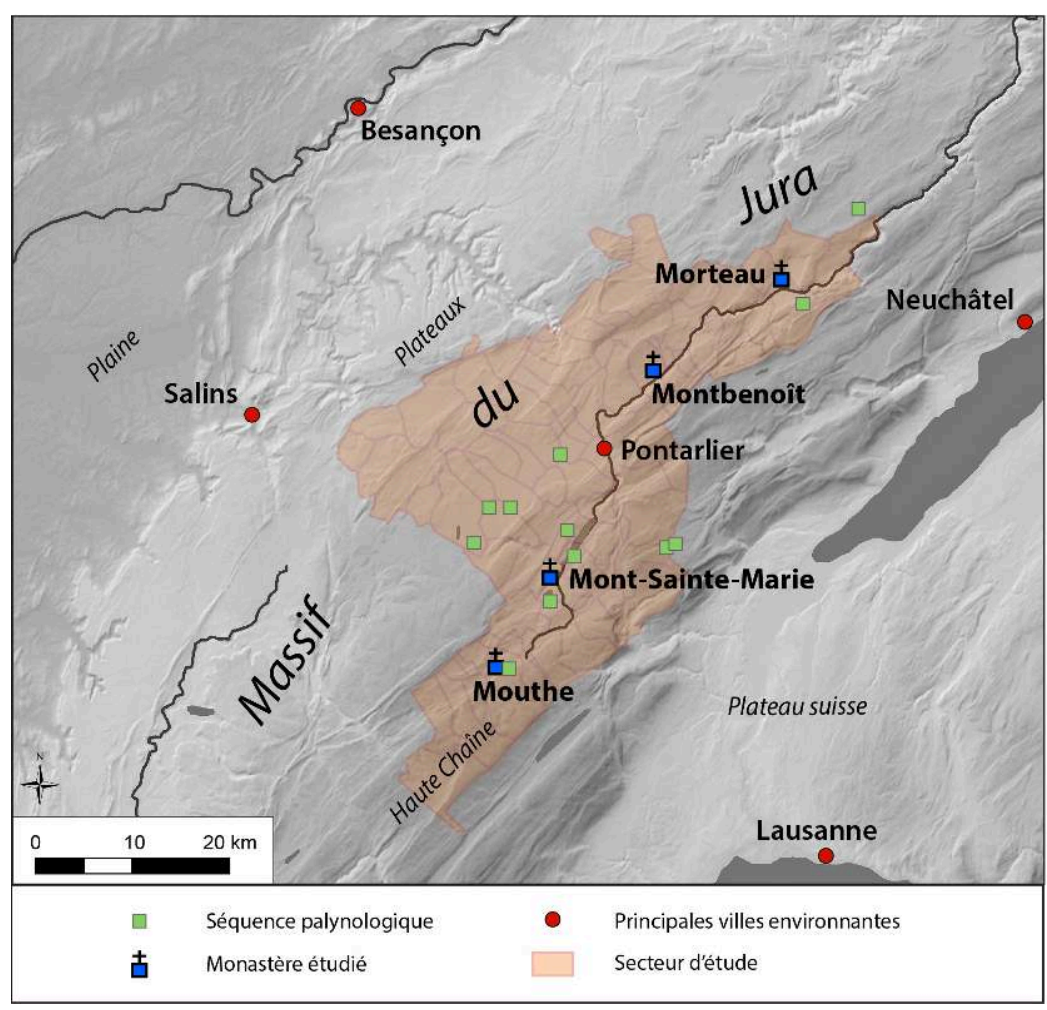

(c) Valentin Chevassu - (c) IGN, 2013 (fond de carte).

\section{Contexte des sites étudiés}

\section{Morteau}

4 À trente kilomètres au nord de Pontarlier, le val de Morteau occupe un synclinal limité par des reliefs montagneux culminant entre 1100 et 1300 mètres d'altitude. Placé à quelques dizaines de mètres au-dessus du niveau de la rivière, un fond de vallée marécageux confère son nom au site de Morteau (Mortua Aqua). Quelques vestiges archéologiques témoignent d'une occupation antérieure à la période médiévale. Une dizaine de sites préhistoriques sont ainsi répertoriés dans le val ${ }^{2}$. Trois découvertes de monnaies romaines sont également signalées à la fin $\mathrm{du} \mathrm{XIX}^{\mathrm{e}}$ siècle ${ }^{3}$, tandis qu'une sépulture mérovingienne fouillée en 1978 et la découverte ancienne d'une probable nécropole à sarcophages attestent une occupation alto-médiévale ${ }^{4}$.

La fréquente répétition des troubles militaires et des incendies a laissé peu de chose des constructions du milieu du Moyen Âge. Une église romane, dont les derniers vestiges ont disparu au XIX ${ }^{e}$ siècle, est néanmoins décrite à distance du prieuré : il pourrait s'agir soit d'un emplacement primitif du monastère, soit d'une autre église qui lui était contemporaine ${ }^{5}$. Le site actuel du monastère est occupé dès les $\mathrm{XIII}^{\mathrm{e}}$ et $\mathrm{XIV}^{\mathrm{e}}$ siècles, comme le démontrent plusieurs inhumations fouillées en $2001^{6}$. Sur ce même site, les 
archives mentionnent deux reconstructions de l'église au $\mathrm{xv}^{\mathrm{e}}$ siècle, dont le chœur actuel est le dernier vestige. Les fonts baptismaux et le clocher témoignent quant à eux de réaménagements $d u \mathrm{XVI}^{\mathrm{e}}$ siècle, tandis que le reste de l'église a été entièrement reconstruit à la fin du XVII ${ }^{e}$ siècle $^{7}$.

6 L'analyse palynologique de la séquence tourbeuse de Montlebon "Sur la Seigne» apporte quelques informations sur l'évolution du paysage du val aux périodes historiques ${ }^{8}$. À une dizaine de kilomètres au nord, la tourbière de Narbief a également fait l'objet d'un forage palynologique, mais l'exploitation de la tourbe a détruit les niveaux médiévaux et modernes'. Les deux séquences présentent les traces d'une modeste occupation protohistorique et antique.

7 Il faut par ailleurs attendre le développement du prieuré de Morteau puis des seigneuries alentour pour avoir des informations textuelles sur la région ${ }^{10}$. Un prieur de Morteau est mentionné pour la première fois en $1105^{11}$. En 1188, une convention passée entre le prieur et les habitants du val donne une première description des droits seigneuriaux possédés par le monastère sur les environs ${ }^{12}$. La documentation s'étoffe ensuite progressivement. De même que Mouthe et Mont-Sainte-Marie, le prieuré disparaîtra à la Révolution.

\section{Montbenoît}

8 La vallée de Montbenoît, ou val du Saugeais, constitue un second ensemble géographique d'environ quinze kilomètres de long, entre 800 et 1200 mètres d'altitude. Comme à Morteau, le site monastique est placé en pied de pente, à proximité du cours d'eau et au carrefour de deux itinéraires traversant le val. Mis à part la découverte isolée d'une monnaie romaine ${ }^{13}$, aucun vestige antérieur à la période médiévale n'est répertorié dans le Saugeais, qui n'a jamais fait l'objet de prospections ni de recherches archéologiques. Toutefois, de nombreuses occupations antiques et alto-médiévales ont été reconnues à l'extrémité sud de la vallée, à proximité d'un itinéraire de franchissement du Jura ${ }^{14}$. Par ailleurs, l'absence d'analyses paléoenvironnementales dans la vallée ne permet pas de combler les lacunes des connaissances archéologiques par ce biais.

9 L'abbaye de Montbenoît forme un des rares ensembles médiévaux préservés du HautDoubs dont l'architecture ait été décrite à plusieurs reprises, même si l'on peut déplorer l'absence d'analyse archéologique du bâti ${ }^{15}$. L'église abbatiale présente une nef du XII ${ }^{e}$ siècle; les travées ouest, le chœur et les chapelles latérales ont été ajoutés durant les $\mathrm{XV}^{\mathrm{e}}$ et $\mathrm{XVI}^{\mathrm{e}}$ siècles. Le cloître et les bâtiments claustraux datent des $\mathrm{XIV}^{\mathrm{e}}$, $\mathrm{XV}^{\mathrm{e}}$ et $\mathrm{XVI}^{\mathrm{e}}$ siècles. L'histoire de l'abbaye est documentée par un important dossier d'archives ${ }^{16}$. Montbenoît est mentionnée pour la première fois en 1117, en tant que prieuré dédié à sainte Marie ${ }^{17}$. Devenu avant 1150 une abbaye de chanoines augustins, le monastère apparait au XII ${ }^{e}$ siècle dans de nombreux actes de donations. Trois actes de 1141, 1169 et 1189 fournissent ainsi une longue liste des biens, parfois éloignés, possédés par l'abbaye ${ }^{18}$. La documentation reste ensuite abondante jusqu'à la sécularisation de l'abbaye en 1773. 


\section{Mont-Sainte-Marie}

10 L'abbaye cistercienne de Mont-Sainte-Marie prend place dans une vaste vallée occupée par les lacs de Saint-Point et de Remoray, au sud de Pontarlier. Le site contrôle un point de franchissement du Doubs entre les deux lacs, au débouché d'une petite vallée transversale. Les tracés de diverses voies anciennes et des vestiges probables du pont sont encore repérables ${ }^{19}$. Comme les espaces présentés précédemment, la vallée de Saint-Point reste archéologiquement très mal connue. Quelques découvertes anciennes attestent ponctuellement d'occupations néolithiques, hallstattiennes et antiques ${ }^{20}$. Les trois séquences palynologiques analysées dans la vallée montrent qu'une présence humaine accompagnée d'activités agricoles existe dès le Néolithique, même si les indices d'activités anthropiques restent assez discrets avant le viII ${ }^{\mathrm{e}}$ siècle $^{21}$.

11 Les vestiges médiévaux ne sont pas beaucoup plus nombreux ; les bâtiments de l'abbaye ont été presque entièrement détruits à la fin $\mathrm{du} \mathrm{XVIII}^{\mathrm{e}}$ siècle. Ils nous restent connus par plusieurs plans et procès-verbaux de visites modernes, grâce à une petite fouille de 1955 et par quelques vestiges architecturaux restés en place ou remployés à proximité 22. Ces éléments témoignent principalement des reconstructions de la fin du Moyen Âge et de l'époque moderne. De même, les granges dépendantes de l'abbaye ont été étudiées mais présentent au mieux des vestiges du XVII ${ }^{e}$ siècle $^{23}$.

12 Les archives de l'abbaye ont fait l'objet de plusieurs études, concernant surtout la période médiévale ${ }^{24}$. Un premier établissement monastique dépendant de l'abbaye de Romainmôtier (Suisse, canton de Vaud) s'installe au XII siècle à proximité du site actue $^{25}$. À cet ermitage succède l'abbaye de Mont-Sainte-Marie, fondée en 1199 par Gaucher IV de Salins et rattachée à l'ordre cistercien ${ }^{26}$. Le début du XIII siècle voit la création de plusieurs granges monastiques, autour desquelles les moines accumulent progressivement terres et droits seigneuriaux tout au long des XIII et XIV ${ }^{e}$ siècles. En 1243 , un acte autorise le transfert de la communauté monastique à l'emplacement actuel de l'abbaye ${ }^{27}$.

\section{Mouthe}

13 À la limite sud du département du Doubs, le val de Mouthe constitue un espace compris entre 930 et 1370 mètres d'altitude. Le prieuré de Mouthe se situe en fond de vallée, au croisement de deux axes de communications et à proximité d'une vaste zone de tourbières. De même que le Saugeais, le val de Mouthe est un désert archéologique: l'analyse d'une séquence palynologique prélevée à quelques centaines de mètres du prieuré atteste une mise en valeur de la vallée dès la protohistoire ${ }^{28}$, mais les occupations humaines les plus anciennes connues à ce jour restent celles mentionnées par les sources écrites.

Le site monastique médiéval n'a laissé aucun vestige en élévation, à l'exception d'une maison de la fin du Xvi ${ }^{e}$ siècle identifiée traditionnellement comme l'ancienne étable du prieuré. L'église priorale, elle, a été rasée en 1732 pour laisser place à l'édifice actuel. Les archives nous apprennent que cet édifice, qui est en 1400 une construction «très petite, ruineuse et quasiment toute de bois ${ }^{29}$ ", avait été reconstruit à quatre reprises durant les $\mathrm{XV}^{\mathrm{e}}$ et $\mathrm{XVII} \mathrm{e}^{\mathrm{e}}$ siècles. 
Contrairement aux monastères précédents, les archives du prieuré de Mouthe ont été peu étudiées ${ }^{30}$. Un ermitage est fondé vers 1077 par saint Simon, aristocrate du nord de la France devenu moine dans l'abbaye de Saint-Oyend (Saint-Claude, Jura). L'église de Mouthe, prieuré bénédictin dépendant de Saint-Claude, est ensuite citée comme point de repère dans plusieurs actes de délimitations au cours du XII ${ }^{e}$ siècle. Au siècle suivant, le monastère reçoit diverses donations foncières sur les plateaux et dans le vignoble jurassien. Il devient en 1582 une dépendance du collège des jésuites de Dole (Jura).

\section{Synthèse}

\section{Contexte d'implantation des monastères}

16 Le Jura central connaît un développement plutôt tardif du monachisme, alors que de nombreux monastères sont présents dès le haut Moyen Âge sur les marges du massif ou à son extrémité sud. La région de Pontarlier reste a priori à l'écart du mouvement, puisque seuls quelques établissements modestes, relais d'abbayes lointaines comme Agaune, Saint-Bénigne, Saint-Claude et Romainmôtier, apparaissent autour des $\mathrm{IX}^{\mathrm{e}}-\mathrm{X}^{\mathrm{e}}$ siècles $^{31}$. Il faut souligner le manque flagrant de données archéologiques pour décrire le cadre dans lequel s'implantent Montbenoît, Morteau, Mouthe ou Mont-Sainte-Marie. Comme le montrent les diagrammes palynologiques et quelques découvertes archéologiques éparses, ces monastères s'installent dans un milieu déjà occupé. Nos connaissances restent toutefois largement insuffisantes pour décrire les formes de peuplement dans la haute chaîne du Jura au début du Moyen Âge central. De même, aucune étude archéologique n'est venue préciser la date de création de ces monastères. Sur le pourtour du massif jurassien, les fouilles réalisées à Luxeuil, Saint-Claude ou Baume-les-Messieurs ont montré qu'il ne fallait pas toujours accorder foi aux descriptions des fondations monastiques par les textes médiévaux ${ }^{32}$. De même, non loin de Montbenoît et Morteau, l'étude archéologique du site de Môtiers (Suisse, canton de Neuchâtel) a révélé l'existence d'un établissement religieux des $\mathrm{VII}^{\mathrm{e}}$-VIII ${ }^{\mathrm{e}}$ siècles sous un prieuré attesté seulement au $\mathrm{XI}^{\mathrm{e}}$ siècle $^{33}$. Une fondation ancienne n'est donc pas non plus à exclure pour les monastères étudiés ici.

\section{Organisation et évolution des seigneuries monastiques}

Les quatre fondations étudiées présentent de nombreuses similitudes, non seulement à cause du cadre géographique dans lequel elles sont créées, mais également par l'évolution et la structuration de leur temporel. Ainsi, chacun des monastères prend place au centre d'une vallée assez fermée, dont il contrôle entièrement le territoire. Par ailleurs, les sites choisis sont toujours à proximité directe d'axes de communications, de rivières et de points de passages contrôlés par les moines. À Montbenoît et MontSainte-Marie, une première implantation précède l'installation définitive de l'abbaye, liée à la donation d'un vaste territoire environnant. Mouthe connaît apparemment une évolution semblable. Cette fondation en deux étapes peut être liée à un transfert de site, comme c'est le cas avec l'abbaye de Mont-Sainte-Marie et l'ermitage non localisé du Mons de Furno. Ce phénomène a été observé par ailleurs sur de nombreux sites monastiques $^{34}$. 
Les quatre établissements présentent un temporel en deux parties, composé de la vallée autour du monastère, où les moines accaparent la totalité des droits seigneuriaux, et de possessions plus lointaines, éparpillées sur les plateaux et les piémonts jurassiens. Mont-Sainte-Marie, forment ainsi des entités géographiques bien délimitées ${ }^{35}$. Tandis que sur les plateaux voisins les droits seigneuriaux et les fiefs sont assez morcelés, ces quatre vallées sont placées entièrement sous l'autorité monastique. Jusqu'au XIV ${ }^{\mathrm{e}}$ siècle, les écrits évoquent l'ensemble des habitants de chaque vallée comme une communauté homogène, définie par un ensemble de droits et de devoirs vis-à-vis des moines. Les habitants sont en particulier assujettis à la mainmorte et à différents usages communautaires, comme la tenue d'un troupeau commun évoqué en 1459 dans le Saugeais $^{36}$. Tous les habitants de la vallée sont enfin réunis au sein d'une vaste et unique paroisse placée sous le patronage des moines. À Mouthe, Montbenoît et Morteau, l'église du monastère constitue ainsi l'unique lieu de culte paroissial de la vallée ; à Mont-Sainte-Marie, une église paroissiale est créée à côté de l'abbaye. Il faut attendre la fin du Moyen Âge pour que les moines autorisent la création de chapelles annexes. Toutes ces caractéristiques se retrouvent plus au sud dans la haute chaîne jurassienne, dans les seigneuries monastiques de Saint-Claude ou du Grandvaux (Jura) ${ }^{37}$.

Le second élément du domaine monastique est constitué par un ensemble de biens fonciers et de droits seigneuriaux variés situés à distance du monastère, ensemble accru au fur et à mesure de donations et d'acquisitions diverses. Ces biens sont situés soit dans les secteurs de plateaux, à l'ouest de la haute chaîne du Jura, souvent le long des principaux axes permettant la traversée du massif, soit dans les secteurs viticoles et salifères des piémonts. Ainsi, Montbenoît possède des patronages paroissiaux et des terres dans le val de Vennes et sur le plateau de Valdahon, mais également des maisons relais à Besançon et Salins, ainsi que des parcelles de vignes dans les actuels vignobles jurassien et suisse ${ }^{38}$ (fig. 2).

Fig. 2. - Le temporel de l'abbaye de Montbenoît au XII et au XV siècle.

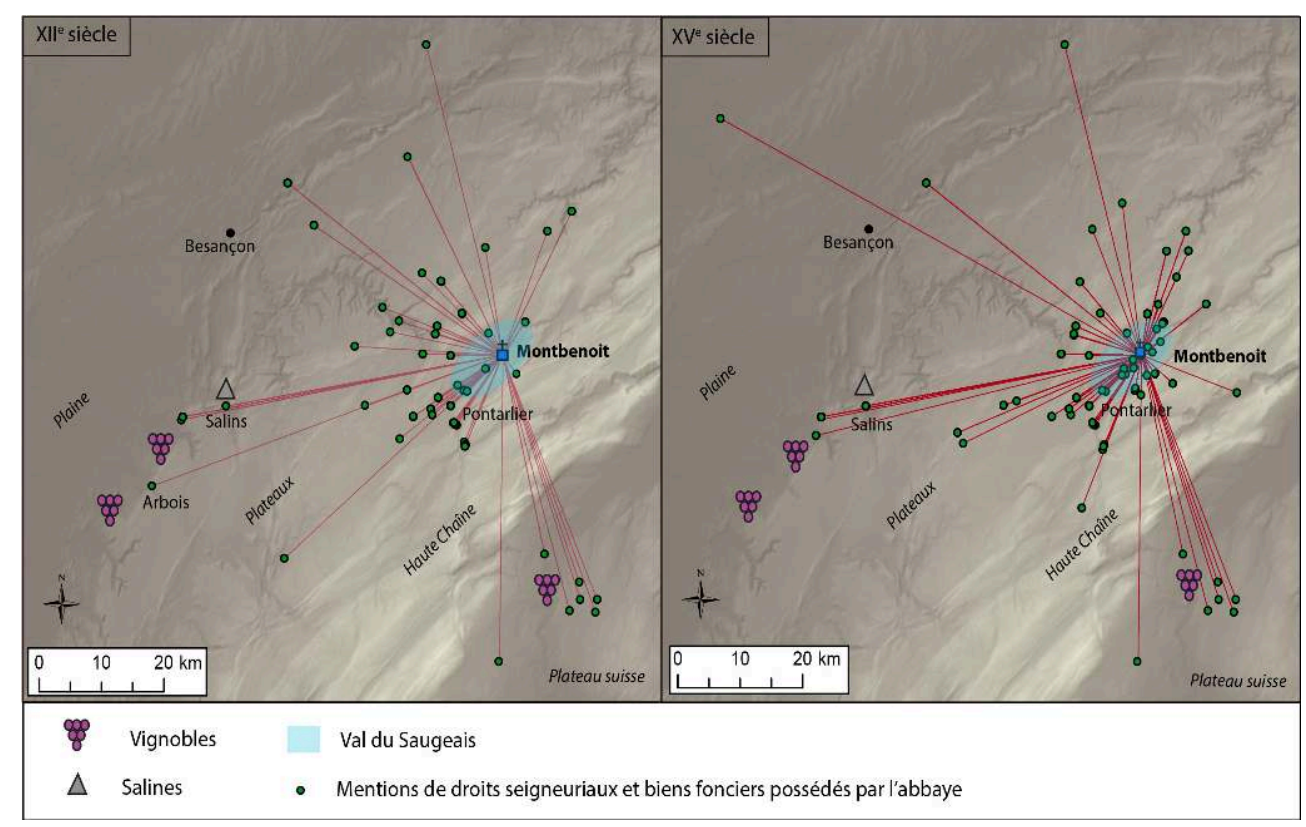

(c) Valentin Chevassu - (c) IGN, 2013 (fond de carte). 
De même, Mont-Sainte-Marie essaime ses granges le long des itinéraires menant à Besançon et Salins, accumule petit à petit des biens fonciers autour de ces granges, mais acquiert aussi des vignes et des droits paroissiaux autour d'Arbois et de Montignyles-Arsures ${ }^{39}$ (fig. 3).

Fig. 3. - Le temporel de l'abbaye de Mont-Sainte-Marie au XIII' et au XVI

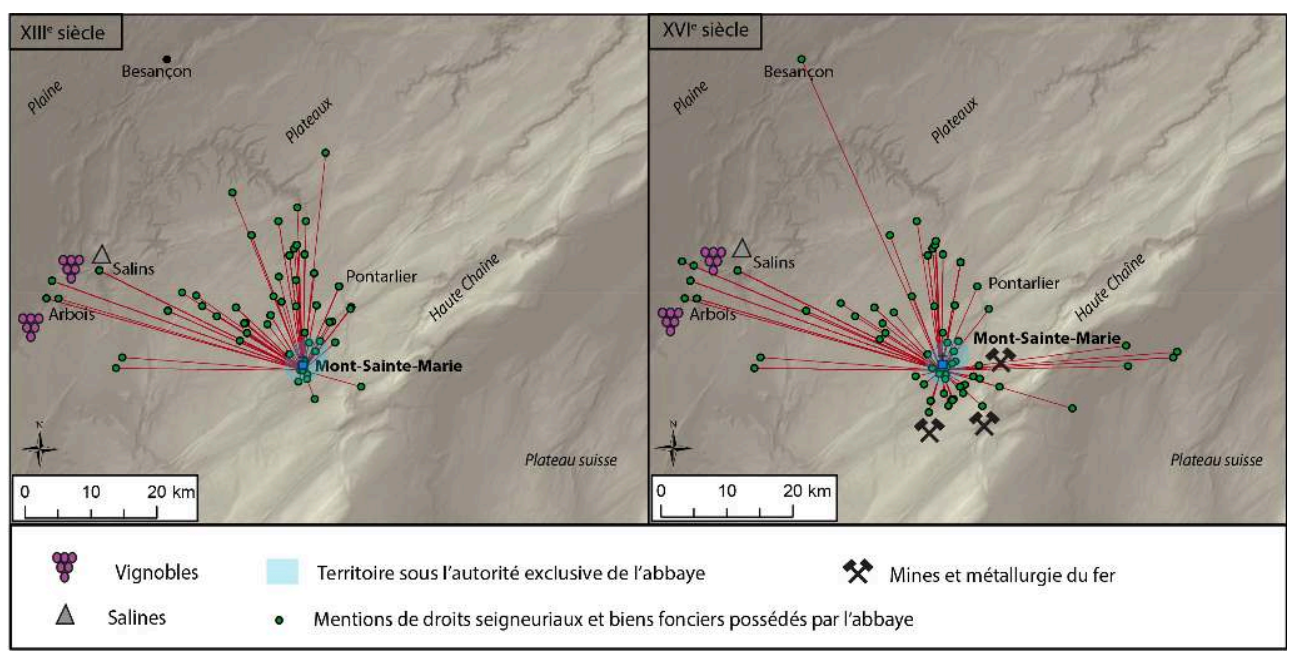

(C) Valentin Chevassu - (c) IGN, 2013 (fond de carte).

Les quatre établissements profitent également de rentes en sel prélevées sur la production des salines de Salins, comme par ailleurs la majorité des monastères comtois $^{40}$.

\section{Du Xe au XIII' siècle : une exploitation accrue de la haute chaîne du Jura}

Bien qu'une implantation humaine ancienne soit attestée par l'archéologie et la palynologie, le paysage de la haute chaîne du Jura reste très forestier avant le milieu du Moyen Âge. La période $\mathrm{X}^{\mathrm{e}}-\mathrm{XIII}{ }^{\mathrm{e}}$ siècle marque incontestablement une rupture dans la mise en valeur de la région, avec une phase d'intensification des défrichements et des activités agropastorales. Malheureusement, la précision variable des modèles d'âge associés aux diagrammes palynologiques permet rarement de déterminer la contemporanéité de ces changements avec la fondation des monastères. Dans le cas de la région de Mont-Sainte-Marie, documentée par une analyse palynologique à haute résolution datée très précisément, la recrudescence des défrichements et des activités agropastorales précède de plusieurs siècles l'établissement de l'abbaye. Même si le monastère peut avoir une origine plus ancienne qu'on le soupçonne, sa fondation ne semble donc pas être la cause d'une rupture dans la mise en valeur du milieu.

Qu'elle en soit à l'origine ou non, la création de ces quatre monastères accompagne un mouvement d'intensification de l'exploitation des vallées de la haute chaîne du Jura, sensible tant à travers les études paléoenvironnementales que grâce à la documentation écrite. Ainsi, à proximité de Mont-Sainte-Marie, la séquence de Remoray montre un impact anthropique très discret durant les $\mathrm{V}^{\mathrm{e}}$ et $\mathrm{VI}^{\mathrm{e}}$ siècles. En revanche, à partir du VIII ${ }^{\mathrm{e}}$, et surtout après le $\mathrm{x}^{\mathrm{e}}$ siècle, le taux des pollens d'arbre baisse 
nettement, alors que celui des pollens de céréales et des plantes rudérales augmente ${ }^{41}$. Les séquences voisines de Saint-Point et Malpas présentent des évolutions parallèles ${ }^{42}$. Malgré des incertitudes liées à des études plus anciennes, les séquences étudiées à Mouthe et Morteau montrent que les défrichements s'élargissent et deviennent mieux visibles seulement à partir des XII ${ }^{\mathrm{e}}$ et XIII ${ }^{\mathrm{e}}$ siècles ${ }^{43}$.

Plusieurs donations et traités de délimitation évoquent également la réalisation de défrichements pour l'ouverture de champs et de pâturages. La mise en valeur des forêts et pâturages d'altitude est également mentionnée. La fabrication de la poix est ainsi attestée à Montbenoît et Morteau en 1169 et $1296^{44}$. À partir de 1310, diverses transactions entre les seigneurs de Neuchâtel et les prieurs de Morteau évoquent l'inféodation de terres d'altitude situées à l'est du val en échange de rentes en argent, cire et fromages. Un document de 1373 décrit dans ce secteur la présence de prairies, de bois pâturés et de granges, à l'origine des hameaux actuels du val de la Brévine (Suisse, canton de Neuchâtel) ${ }^{45}$. À la même époque, l'abbaye de Montbenoît exploite également des terres d'altitude appartenant aux Neuchâtel et leur doit aussi des redevances en fromages, fait rare qui souligne la vocation pastorale de ces territoires.

Par ailleurs, la documentation écrite suggère une réorganisation du peuplement et la création de nouvelles implantations dans les vallées de la haute chaîne du Jura. Dans le Saugeais, les habitants étant toujours mentionnés comme une communauté homogène sans division géographique, les noms des villages ne sont cités qu'à la fin du XIII ${ }^{\mathrm{e}}$ siècle. Ces toponymes, de langue romane comme La Chaux, Le Grand Saugeois ou Hauterive, paraissent récents et mal fixés. Jusqu'au $\mathrm{xvI}^{\mathrm{e}}$ siècle, ils varient constamment d'un document à l'autre et compliquent ainsi l'identification des différents hameaux. Des créations d'habitats sont explicitement évoquées avec l'installation, ou « abergement ", d'hommes dits « allemands » au lieu-dit L'Arcenet en 1337, mais aussi avec la création d'une grange sur des alpages concédés par les comtes de Neuchâtel en $1342^{46}$. De même, les hameaux du val de Mouthe apparaissent pour la première fois dans un texte de $1331^{47}$ et l'acte de 1296 décrivant les redevances des habitants est un acte $\mathrm{d}^{\prime}$ " habergeage ${ }^{48}$ ", qui évoque donc l'installation de nouveaux arrivants ${ }^{49}$. Enfin, à Mont-Sainte-Marie, un acte de 1243 donne aux moines l'autorisation de créer des villages sur leur territoire et leur concède le patronage de ces implantations ${ }^{50}$. La création de deux paroisses en 1264 et 1266 semble faire suite à cet acte ${ }^{51}$.

Tous ces éléments semblent suggérer l'extension, la fixation ou la stabilisation progressive d'un peuplement jusque-là dispersé et peut-être en partie temporaire. Les contraintes seigneuriales, et notamment la mainmorte, ont sans doute joué un rôle dans cette mutation du peuplement. Les actes d'abergements montrent ainsi que les moines attirent de nouveaux habitants et les fixent sur leurs terres, mais d'autres textes suggèrent également qu'ils cherchent à empêcher leur départ en cas de crise, comme c'est le cas à la fin du XIV siècle $^{52}$.

\section{Une seconde phase de mise en valeur du $X V^{e}$ au $X V I I^{e}$ siècle}

Les crises épidémiques et politiques de la seconde moitié du XIV siècle semblent en effet frapper fortement les vallées de la haute chaîne du Jura, dans lesquelles les activités humaines connaissent un repli marqué et durable. La déprise est sensible dans les séquences palynologiques de la vallée de Saint-Point et des environs de Pontarlier, qui montrent des indices d'enfrichement, mais également dans plusieurs textes 
évoquant des habitats en cours de désertion. En revanche, la période comprise entre le $\mathrm{XV}^{\mathrm{e}}$ siècle et la première moitié $\mathrm{du} \mathrm{XVII}^{\mathrm{e}}$ est marquée par une intensification des activités anthropiques dans la montagne jurassienne, avec des conséquences paysagères de plus en plus marquées. On remarque d'abord l'émergence de nouveaux modes de gestion dans le temporel des différents monastères, qui font de plus en plus appel aux amodiations et accensements pour gérer leurs domaines éloignés, puis pour la perception des droits seigneuriaux.

Par ailleurs, les communautés villageoises réussissent petit à petit, malgré les réticences des moines, à négocier la mise à disposition d'une parcelle de forêt, d'un moulin, voire l'édification de leur propre lieu de culte. Une première chapelle vicariale est ainsi fondée dans le val de Morteau en $1509^{53}$, et de nombreuses autres créations suivront au $\mathrm{xvII}^{\mathrm{e}}$ siècle. Les revendications portent également sur le droit de mainmorte, mais ce dernier est aboli très tardivement, en 1600 à Morteau et en 1744 en Saugeais ${ }^{54}$.

L'autre fait marquant est la multiplication des installations hydrauliques et artisanales : une dizaine de nouvelles usines hydrauliques sont créées dans le val de Morteau de 1530 à $1580^{55}$. De leur côté, les moines de Mont-Sainte-Marie acquièrent deux hauts fourneaux en 1487, puis ouvrent des mines de fer en $1631^{56}$. Les XVI ${ }^{e}$ et XVII ${ }^{e}$ siècles sont enfin marqués par une recrudescence des défrichements liés à l'ouverture de prairies d'altitude et à la création de granges d'estive: plus d'une trentaine de ces granges apparaissent dans le val de Mouthe entre 1400 et $1670^{57}$. Le développement de l'élevage est également visible par la fondation de nouvelles foires à Morteau en 1514 et à Montbenoît en $1550^{58}$. La prospérité économique de la période est enfin visible à travers les nombreuses constructions ou reconstructions qui ont lieu dans les quatre monastères étudiés.

31 Face à la multiplication de ces différentes activités, certaines ressources commencent à se raréfier. Les conflits de délimitation se multiplient ainsi entre les seigneurs, mais également entre les communautés villageoises, à propos des droits de parcours du bétail ou pour l'exploitation des forêts. Face à la pénurie, des parcelles de forêt sont mises en réserve ou en banalité, c'est-à-dire soustraites aux droits d'usages habituels pour favoriser la repousse des arbres. Une telle opération est notamment pratiquée à Arçon, dans le Saugeais, en $1533^{59}$.

32 Cette intensification des déboisements est directement sensible dans les diagrammes palynologiques, où les taxons forestiers enregistrent à chaque fois une baisse sans précédent durant le $\mathrm{XVI}^{\mathrm{e}}$ siècle. Ainsi, à Remoray et Malpas, les indices de défrichements et d'activités agricoles augmentent de la fin du XIV siècle aux années 1650. Au XVII ${ }^{\mathrm{e}}$ siècle, les violents troubles liés à la Guerre de Dix Ans sont suivis par une déprise agricole visible dans plusieurs diagrammes palynologiques. Les monastères et les établissements qui en dépendent souffrent également de nombreuses destructions, comme l'abbaye de Mont-Sainte-Marie incendiée en 1639. La difficile reconstruction de la contrée semble par la suite favoriser l'émancipation des communautés villageoises de la haute chaîne du Jura. L'influence des communautés monastiques se restreint ainsi progressivement jusqu'à la fin du XVIII ${ }^{e}$ siècle, qui les voit disparaître. 
Malgré des données archéologiques encore trop restreintes, le croisement entre sources écrites et analyses paléoenvironnementales nous permet de restituer en partie le rôle des monastères du Jura central dans la mise en valeur des vallées et montagnes environnantes. Contrairement à ce que laisse penser le topos du désert hagiographique, ces monastères ne sont pas fondés dans des montagnes entièrement boisées et vides d'hommes. Les vallées de la haute chaîne du Jura paraissent en effet cultivées et habitées dès la protohistoire. L'installation des abbayes et prieurés de Montbenoît, Mont-Sainte-Marie, Mouthe et Morteau aux $\mathrm{XI}^{\mathrm{e}}$ et $\mathrm{XII}^{\mathrm{e}}$ siècles accompagne néanmoins une véritable rupture dans l'exploitation de la montagne jurassienne. On observe alors une extension sans précédent des défrichements et des activités agricoles, accompagnée d'une probable fixation et stabilisation du peuplement, peut-être favorisée par les nouvelles coutumes seigneuriales. Le début de la période moderne marque ensuite une phase d'intensification supplémentaire des activités humaines, durant laquelle les monastères participent au développement d'activités artisanales et pastorales spécialisées. Brièvement interrompus par les crises des $\mathrm{XIV}^{\mathrm{e}}$ et $\mathrm{XVII}^{\mathrm{e}}$ siècles, les déboisements atteignent progressivement une importance qui deviendra problématique. Les anciennes seigneuries monastiques disparaissent alors progressivement, mais les spécificités de leur évolution laissent de nombreuses traces dans la structuration actuelle du peuplement et des paysages.

\section{BIBLIOGRAPHIE}

BARTHELET Alexandre, Histoire de l'abbaye de Montbenoît du val du Saugeois et des anciennes seigneuries d'Arçon et de Lièvremont ; suivie d'un Coup d'œil sur le patois du Saugeois, Besançon, Jacquin, 1853.

BARTHELET Alexandre, Recherches historiques sur l'abbaye de Mont-Sainte-Marie et ses possessions, Pontarlier, A. Simon, 1858.

BERNARD Auguste et BRUEL Alexandre, Recueil des chartes de l'abbaye de Cluny, t. V : 1091-1210, Paris, Imprimerie nationale, 1894.

BERNARD Olivier, GUIRAUD Joël, MALFROY Michel, Histoire de Jougne, Besançon, Cêtre, 1988.

BONVALOT Nathalie, Granges cisterciennes de Franche-Comté : prospection thématique, rapport triannuel d'activité, Besançon, Service régional de l'archéologie de Franche-Comté, 2004.

BOURGEOIS Éliane, «Évolution du peuplement et de la végétation, à travers les données palynologiques, dans le Val de Mouthe », mémoire de DEA, Besançon, université de FrancheComté, 1990.

BOUVARD Emma, « Empreintes monastiques en moyenne montagne du XII ${ }^{\mathrm{e}}$ siècle à l'actuel : archéologie des espaces et des paysages cisterciens dans les anciens diocèses de Clermont et du Puy ", thèse de doctorat en archéologie, Lyon, université Lumière - Lyon II, 2016.

BUJARD Jacques, «Les églises de Môtiers : premiers résultats des recherches archéologiques », Zeitschrift für Schweiserische Kirchengeschichte, $\mathrm{n}^{\circ}$ 95, 2001, p. 7-17. 
BULLY Sébastien, «Étude de topographie monastique : l'ancien palais abbatial de Saint-Claude (Jura), $\mathrm{v}^{\mathrm{e}}$-XVIII ${ }^{\mathrm{e}}$ siècle », Bulletin du centre d'études médiévales d'Auxerre [en ligne], nº 12, 2008.

BULLY Sébastien, BULLY Aurélia, CAUSEVIC-BULLY Morana, « Les origines du monastère de Luxeuil (Haute-Saône) d'après les récentes recherches archéologiques ", dans Gaillard Michèle (dir.), L'empreinte chrétienne en Gaule du IV au IX siècle, Turnhout, Brepols, 2014, p. 311-355.

CHEVASSU Valentin, « Étude comparative de l'évolution du peuplement médiéval et des paysages en contexte de moyenne montagne : les cas du Morvan et du haut Jura central ", thèse en cours, Besançon, université de Bourgogne - Franche-Comté.

CLERC Édouard et SUCHET Jean-Marie, «Chartes et diplômes inédits ", Mémoires et documents inédits pour servir à l'histoire de la Franche-Comté, n² 2, 1838, p. 443-523.

CLERC Édouard et SUCHET Jean-Marie, "Chartes des communes de l'ancien comté de Bourgogne », Mémoires et documents inédits pour servir à l'histoire de la Franche-Comté, nº 4, 1867, p. 423-481.

CORRIOL Vincent, Les serfs de Saint-Claude : étude sur la condition servile au Moyen Âge, Rennes, Presses universitaires de Rennes, 2009.

COURTIEU Jean, Dictionnaire des communes du département du Doubs, Besançon, Cêtre, 1987.

CUPILLARD Christophe, « La haute vallée du Doubs entre 13000 et 5000 av. J.-C. : des derniers chasseurs de rennes aux premiers agriculteurs ", Mémoires de la Société d'émulation du Doubs, $\mathrm{n}^{\circ} 55$, 2013, p. 188-227.

DROMARD Denise, « Le val et la seigneurie de Morteau, $\mathrm{XII}^{\mathrm{e}}-\mathrm{XV}^{\mathrm{e}}$ siècles : aspects politiques, sociaux et économiques », mémoire de maîtrise en histoire, Besançon, université de Besançon, 1971.

DROZ Édouard, Mémoires pour servir à l'histoire de la ville de Pontarlier, Pontarlier, Éditions du Bastion, 1840.

DUNOD DE CHARNAGE François-Ignace, Histoire de l'église, ville et diocèse de Besançon, Besançon, Daclin, 1750.

DUPARC Pierre, « Les tenures en hébergement et en abergement ", Bibliothèque de l'École des chartes, $\mathrm{n}^{\circ} 122,1964$, p. 5-88.

GAUTHIER Émilie, Forêts et agriculteurs du Jura : les quatre derniers millénaires, Besançon, Presses universitaires franc-comtoises, 2004.

GAILLARD Annie, « Abbaye de Montbenoît, étude économique et sociale (du XII siècle au début du $\mathrm{XIV}^{\mathrm{e}}$ s.) », mémoire de maîtrise en histoire, Besançon, université de Besançon, 1973.

GINGINS-LA SARRAZ Frédéric de, Cartulaire de Romainmôtier, Lausanne, Ducloux, 1843.

GRESSER Pierre et RICHARD Hervé, « Palynologie et sources écrites : le cas du Jura à l'époque médiévale », Hommes et terres du Nord, n 2-3, 1986, p. 102-105.

GUILLAUME Jean-Baptiste (abbé), Histoire généalogique des sires de Salins au comté de Bourgogne, avec des notes historiques et généalogiques sur l'ancienne noblesse de cette province, Besançon, Daclin, 1757. JEANNIN Luc, « L'abbaye de Mont-Sainte-Marie à l'époque moderne d'après les inventaires et procès-verbaux de visite ", mémoire de maîtrise en histoire, Besançon, université de FrancheComté, 1997.

JEANNIN Yves, «L'Homme et le Jura dans l'Antiquité », Procès-verbaux et mémoires de l'Académie des sciences, belles-lettres et arts de Besançon, $\mathrm{n}^{\circ} 178$ bis, 1972, p. 131-171. 
JEANTET Martial (abbé), L'abbaye de Montbenoît, Nancy, SAEP, 1977.

LEISER Henri (dir.), Morteau : l'église et son prieuré, Pontarlier, Éd. du Belvédère, 2013.

LEROUX Aurélie, « Caractérisation et évolution des flux détritiques et authigènes en contexte lacustre carbonate au cours du Tardiglaciaire et de l'Holocène (lac Saint-Point, Haute-Chaîne du Jura) : implications paléoclimatiques et paléoenvironnementales ", thèse de doctorat, Besançon, université de Franche-Comté, 2010.

LOCATELLI René, Sur les chemins de la perfection : moines et chanoines dans le diocèse de Besançon : vers 1060-1220, Saint-Étienne, Publications de l'université de Saint-Étienne, 1992.

LOCATELLI René, L'abbaye de Mont-Sainte-Marie et le Haut-Doubs forestier : 800 ans d'histoire, Labergement-Sainte-Marie, Amis de l'abbaye de Mont-Sainte-Marie et de Saint-Théodule, 1999. MARTY Florent, «Le domaine de l'abbaye de Mont-Sainte-Marie du XIII ${ }^{\mathrm{e}}$ au XV siècle », mémoire de maîtrise en histoire, Besançon, université de Franche-Comté, 1999.

MATILE Georges-Auguste, Monuments de l'histoire de Neuchâtel, Neuchâtel, Attinger, 1848.

MOYSE Gérard, Les origines du monachisme dans le diocèse de Besançon, $V^{e}-X^{e}$ siècle, Paris, École des chartes, 1973.

MURGIA Laurie, « Mémoire des lacs et mémoire des sociétés du Moyen Âge à nos jours : approche palynologique et historique de la moyenne montagne jurassienne et alpine (lac de Remoray, Doubs ; glissement du mont Granier, Savoie) », thèse de doctorat, Besançon, université de Franche-Comté, 2016.

MUSY Jean, Mouthe : histoire du prieuré et de la terre seigneuriale, Pontarlier, La Gentiane bleue, 1930. NARBEY Claude, Les hautes montagnes du Doubs entre Morteau, Le Russey, Belvoir et Orchamps-Vennes depuis les temps celtiques, Paris, Bray, 1868.

OFFREDI Élisabeth, «L'abbaye cistercienne de Mont-Sainte-Marie, $\mathrm{XIV}^{\mathrm{e}}$ et XV siècles », mémoire de maîtrise en histoire, Besançon, université de Franche-Comté, 1979.

PERRECIOT Claude Joseph, De l'état civil des personnes et de la condition des terres dans les Gaules, dès les temps celtiques, jusqu'à la rédaction des coutumes, [Besançon, 1786].

PROST Bernard et BOUGENOT Étienne-Symphorien, Cartulaire de Hugues de Chalon (1220-1319), Lons-leSaunier, Declume, 1904.

SUCHET Jean-Marie et GAUTHIER Jules, « L'abbaye de Mont-Sainte-Marie et ses monuments », Procèsverbaux et mémoires de l'Académie des sciences, belles-lettres et arts de Besançon et Franche-Comté, 1883, p. 230-266.

TOURNIER René, Les églises comtoises : leur architecture des origines au XVIII siècle, Paris, Picard, 1954.

TRUCHIS DE VARENNE Albéric de, «Le coutumier du val de Saugeais », Mémoires et documents inédits pour servir à l'histoire de la Franche-Comté, nº 9, 1900, p. 411-487.

TRUCHIS DE VARENNE Albéric de, «Le Livre Noir, ou le recueil des franchises, lois et règlements particuliers du val de Morteau », Mémoires et documents inédits pour servir à l'histoire de la FrancheComté, no 11,1919 , p. 306-518. 


\section{NOTES}

1. V. Chevassu, «Étude comparative de l'évolution du peuplement médiéval et des paysages en contexte de moyenne montagne: les cas du Morvan et du haut Jura central ", thèse en cours sous la direction d'é. Gauthier (université de Bourgogne Franche-Comté / UMR 6249 Chrono-Environnement) et P. Nouvel (université de Bourgogne - Franche-Comté / UMR 6298 ArTeHis).

2. C. Cupillard, « La haute vallée du Doubs entre 13000 et 5000 av. J.-C ».

3. Y. Jeannin, «L'Homme et le Jura dans l'Antiquité », p. 162-165.

4. H. Leiser, Morteau : l'église et son prieuré, p. 41-45.

5. J. Courtieu, Dictionnaire des communes du département du Doubs, t. IV, p. 2275 ; carte archéologique du Service régional de l'archéologie de Franche-Comté.

6. H. Leiser, Morteau : l'église et son prieuré, p. 15-24.

7. J. Courtieu, Dictionnaire des communes du département du Doubs, t. IV, p. 2275;

R. Tournier, Les églises comtoises, p. 182, 224.

8. P. Gresser et H. Richard «Palynologie et sources écrites: le cas du Jura à l'époque médiévale ", p. 75.

9. É. Gauthier, Forêts et agriculteurs du Jura : les quatre derniers millénaires.

10. Voir notamment A. de Truchis de Varenne, "Le Livre Noir, ou le recueil des franchises... »; D. Dromard, « Le val et la seigneurie de Morteau »; C. Narbey, Les hautes montagnes du Doubs...

11. A. Bernard et A. Bruel, Recueil des chartes de l'abbaye de Cluny, t. V, p. 190-191.

12. É. Clerc et J.-M. Suchet, " Chartes et diplômes inédits... », p. 455.

13. Y. Jeannin, «L'Homme et le Jura dans l'Antiquité », p. 162-165.

14. Carte archéologique du Service régional de l'archéologie de Franche-Comté.

15. M. Jeantet, «L'abbaye de Montbenoît »; R. Tournier, Les églises comtoises, p. 131-132, 140, 185-186, 217, 282.

16. E. Droz, Mémoires pour servir à l'histoire de la ville de Pontarlier ; A. Barthelet, Histoire de l'abbaye de Montbenoît; A. Gaillard, Abbaye de Montbenoit ; Arch. dép. Doubs, $69 \mathrm{H}$.

17. A. Barthelet, Histoire de l'abbaye de Montbenoit du val du Saugeois, p. 5 ; F.-I. Dunod de Charnage, Histoire de l'église, ville et diocèse de Besançon, t. I, p. 144.

18. É. Droz, Mémoires pour servir à l'histoire de la ville de Pontarlier, p. 210-211, 215-216 et 221-225.

19. Analyse des relevés LiDAR Life SMMAHD 2015 ; prospections subaquatiques dirigées par A. Stock, UMR 6249 Chrono-Environnement, 2015-2017.

20. Carte archéologique du Service régional de l'archéologie de Franche-Comté.

21. A. Leroux, «Caractérisation et évolution des flux détritiques... »; É. Gauthier, Forêts et agriculteurs du Jura ; L. Murgia, "Mémoire des lacs et mémoire des sociétés du Moyen Âge à nos jours " .

22. L. Jeannin, «L'abbaye de Mont-Sainte-Marie à l'époque moderne»; R. Locatelli, L'abbaye de Mont-Sainte-Marie...; carte archéologique du Service régional de l'archéologie de Franche-Comté.

23. N. Bonvalot, « Granges cisterciennes de Franche-Comté ». 
24. A. Barthelet, «Recherches historiques sur l'abbaye de Mont-Sainte-Marie et ses possessions »; J.-M. Suchet et J.Gauthier "L'abbaye de Mont-Sainte-Marie et ses monuments "; R. Locatelli, L'abbaye de Mont-Sainte-Marie et le Haut-Doubs forestier; F. Marty, «Le domaine de l'abbaye de Mont-Sainte-Marie... »; E. Offredi, «L'abbaye cistercienne de Mont-Sainte-Marie ».

25. F. de Gingins-La Sarraz, Cartulaire de Romainmôtier, p. 440.

26. J.-B. Guillaume, Histoire généalogique des sires de Salins, p. 92.

27. É. Droz, Mémoires pour servir à l'histoire de la ville de Pontarlier, p. 238-240.

28. É. Bourgeois « Évolution du peuplement et de la végétation... ».

29. J. Musy, Mouthe : histoire du prieuré et de la terre seigneuriale, t. 1, p. 122.

30. Ibid.

31. G. Moyse, «Les origines du monachisme dans le diocèse de Besançon »; R. Locatelli, Sur les chemins de la perfection.

32. S. Bully et al., "Les origines du monastère de Luxeuil...»; S. Bully, «Étude de topographie monastique ».

33. J. Bujard, «Les églises de Môtiers: premiers résultats des recherches archéologiques".

34. Voir notamment E. Bouvard, «Empreintes monastiques en moyenne montagne... », p. 80-85.

35. Ces vallées présentent encore de nos jours une identité forte héritée de cette géographie seigneuriale, comme en témoigne une folklorique «République du Saugeais » fondée en 1947, dont les contours épousent ceux de l'ancienne seigneurie monastique.

36. A. de Truchis de Varenne, « Le coutumier du val de Saugeais », p. 420-487.

37. V. Corriol, Les serfs de Saint-Claude : étude sur la condition servile au Moyen Âge.

38. É. Droz, Mémoires pour servir à l'histoire de la ville de Pontarlier, p. 210-211, 215-216 et 221-225

39. E. Offredi, «L'abbaye cistercienne de Mont-Sainte-Marie »; F. Marty, «Le domaine de l'abbaye de Mont-Sainte-Marie du XIII ${ }^{\mathrm{e}}$ au XV siècle »; R. Locatelli, L'abbaye de MontSainte-Marie et le Haut-Doubs forestier.

40. R. Locatelli, Sur les chemins de la perfection.

41. L. Murgia, "Mémoire des lacs et mémoire des sociétés du Moyen Âge à nos jours ", p. 125-133.

42. A. Leroux, "Caractérisation et évolution des flux détritiques... », p. 209-211, 231 ;

É. Gauthier, Forêts et agriculteurs du Jura, p. 57-59.

43. P. Gresser et H. Richard, « Palynologie et sources écrites : le cas du Jura à l'époque médiévale », p. 75.

44. É. Droz, Mémoires pour servir à l'histoire de la ville de Pontarlier, p. 215-216; B. Prost et E.-S. Bougenot, Cartulaire de Hugues de Chalon, p. 270.

45. G.-A. Matile, «Monuments de l'histoire de Neuchâtel », vol. 1, p. 304 ; A. de Truchis de Varenne, « Le Livre Noir », p. 329, 333, 336.

46. A. de Truchis de Varenne, «Le coutumier du val de Saugeais », p. 498 ; G.-A. Matile, «Monuments de l'histoire de Neuchâtel », vol. 1, p. 491. 
47. J. Musy, Mouthe : histoire du prieuré et de la terre seigneuriale, vol. 1, p. 59, 111.

48. C.-J. Perreciot, De l'état civil des personnes et de la condition des terres dans les Gaules, t. 2, p. 361-363.

49. P. Duparc, «Les tenures en hébergement et en abergement ».

50. E. Droz, Mémoires pour servir à l'histoire de la ville de Pontarlier, p. 238-240.

51. J. Courtieu, Dictionnaire des communes du département du Doubs, t. 6, p. $3292 ;$ t. 5 , p. 2729.

52. É. Clerc et J.-M. Suchet, « Chartes des communes de l'ancien comté de Bourgogne », p. 459.

53. J. Courtieu, « Dictionnaire des communes du département du Doubs », t. III, p. 1513.

54. A. de Truchis de Varenne, "Le Livre Noir», p. 501; «Le coutumier du val de Saugeais », p. 506.

55. Arch. dép. Doubs, 34H180-34H182.

56. O. Bernard et al., Histoire de Jougne, p. 54 ; Arch. dép. Doubs, 64H294-64H296.

57. J. Musy, Mouthe: histoire du prieuré et de la terre seigneuriale; Arch. dép. Doubs, 35H $247-35 \mathrm{H} 468$.

58. A. de Truchis de Varenne, «Le Livre Noir », p. 490 ; Arch. dép. Doubs, 69H42.

59. A. Barthelet, Histoire de l'abbaye de Montbenoit du val du Saugeois, p. 86.

\section{RÉSUMÉS}

Les monastères médiévaux jurassiens ont été considérés traditionnellement comme étant à l'origine des premières initiatives de peuplement et de défrichement de ce massif montagneux, théorie qui semble aujourd'hui devoir être largement nuancée. Dans le secteur du Jura central, la synthèse de données archéologiques, paléoenvironnementales et textuelles permet de décrire l'évolution du paysage autour des monastères de Morteau, Montbenoit, Mont-Sainte-Marie et Mouthe. Ces quatre établissements sont fondés aux $\mathrm{XI}^{\mathrm{e}}$ et $\mathrm{XII}^{\mathrm{e}}$ siècles dans les vallées montagnardes de la région de Pontarlier. Si ces espaces sont exploités par l'homme dès la protohistoire, la période d'implantation des monastères coïncide avec une nette recrudescence de l'agriculture et du pastoralisme. Dans un second temps, la période moderne amène une intensification supplémentaire de l'impact anthropique, avec le développement d'activités spécialisées, encouragées notamment par les seigneuries monastiques.

\section{AUTEUR}

\section{VALENTIN CHEVASSU}

Doctorant en archéologie, laboratoire Chrono-Environnement (UMR 6249) et MSHE Ledoux, université de Bourgogne - Franche-Comté / CNRS 


\title{
Le prieuré de Saint-Ours d'Aoste au $\mathrm{XV}^{\mathrm{e}}$ siècle : un carrefour au milieu des réseaux de pouvoir en Savoie
}

\author{
Elena Corniolo
}

1 Mon sujet de recherche nous amène au cœur des Alpes, dans le duché de Savoie au XV siècle. Il s'agit d'un État qui, à l'époque d'Amédée VIII, premier duc, comprenait des territoires appartenant aujourd'hui à trois pays différents: la France, la Suisse et l'Italie. Cette structure nous indique déjà que les montagnes, à cette époque, ne représentaient pas du tout des frontières, des obstacles à franchir, mais plutôt des lieux d'échanges, offrant des voies de communication faciles à surveiller et, revers de la médaille, devant être bien défendues.

2 Nous focaliserons notre attention sur une aire qui relevait de l'organisation de l'église savoyarde, le diocèse d'Aoste. Pendant le $\mathrm{xv}^{\mathrm{e}}$ siècle, les protagonistes actifs sur ce territoire à la fois administratif et géographique étaient caractérisés par une évidente mobilité transalpine interne au duché. Dans ce contexte, qui est le reflet d'un changement administratif et politique de l'Église locale, le prieuré de Saint-Pierre et Saint-Ours d'Aoste représente un point d'observation instructif, qui n'a pas encore été étudié jusqu'à présent.

3 L'histoire institutionnelle de cette église capitulaire nous permettra en effet de mettre en évidence en quoi l'histoire personnelle de ses protagonistes, et surtout leur origine géographique et leurs déplacements, représentent en même temps la cause et le produit des changements politiques et sociaux qu'ils vécurent en tant que représentants d'une institution. Réfléchir sur les possibles relations existant entre les origines et les déplacements de ces personnages d'un côté, et les équilibres politiques à l'intérieur du diocèse d'Aoste de l'autre, nous donnera de surcroît une clé pour l'interprétation des événements complexes de l'histoire institutionnelle du prieuré de Saint-Ours pendant le $\mathrm{xV}^{\mathrm{e}}$ siècle.

4 Voici donc les trois variables qui vont définir notre contexte d'étude : le $\mathrm{xv}^{\mathrm{e}}$ siècle, époque de réorganisation des rapports de pouvoir à l'intérieur des églises locales; le 
duché de Savoie ; le diocèse d'Aoste, et en son sein le prieuré de Saint-Pierre et SaintOurs. Nous nous intéresserons en particulier aux relations existant entre ces différentes entités.

\section{Sources et bibliographie}

5 Travailler sur l'histoire institutionnelle de Saint-Ours au $\mathrm{xv}^{\mathrm{e}}$ siècle signifie se confronter à des archives historiques qui n'ont pas encore été exploitées ${ }^{1}$. Les historiens de l'art ont beaucoup travaillé sur le complexe monumental, avec son église, son cloître et son prieuré ${ }^{2}$; la figure de Georges de Challant en particulier, premier prieur commendataire de Saint-Ours (1468-1509), promoteur de la rénovation de l'église, du cloître et du prieuré, a attiré leur attention ${ }^{3}$. En revanche, les historiens ont négligé l'étude de cette institution, aussi bien de sa vie administrative que des relations sociales des chanoines. Un intérêt plus vif a été manifesté pour l'histoire patrimoniale et la liturgie liée au culte de saint Ours ${ }^{4}$. La base bibliographique de départ reste ainsi formée par les œuvres les plus anciennes, dédiées à la reconstruction de l'histoire générale de l'institution, souvent avec une intention apologétique ${ }^{5}$.

6 Les documents originaux des archives historiques de Saint-Ours ont été consultés; il s'agit de registres, de chartes et de parchemins concernant essentiellement la matière féodo-patrimoniale ${ }^{6}$. Les visites pastorales par contre, conservées dans les archives de l'évêché et très importantes pour l'analyse des rapports entre le prieuré de Saint-Ours et l'évêque d'Aoste, ont été transcrites et publiées récemment par Marie-Rose Colliard'.

Dans un deuxième temps de la recherche, j'ai mis en correspondance la documentation fournie par les Archives historiques de Saint-Ours et celle relative au prieuré du $\mathrm{Xv}^{\mathrm{e}}$ siècle conservée dans les Archives historiques de l'évêché et du diocèse ${ }^{8}$. Cela m'a permis de tracer les lignes d'orientation de la vie institutionnelle du prieuré entre le début du siècle et l'introduction de la commende, en 1468.

On perçoit en particulier deux tendances : d'une part la naissance et le développement d'un problème interne au chapitre, lié à la division des pouvoirs entre le prieur et les chanoines en ce qui concernait l'administration du patrimoine; d'autre part la manifestation d'une forte opposition du prieuré au pouvoir épiscopal croissant, pour conserver son autonomie administrative. Ces deux problématiques se développèrent pendant les prieurés d'Antoine de Vallaise (1406-1440) et d'Humbert Anglici (1440-1468).

\section{Esquisse de l'histoire institutionnelle du prieuré de Saint-Ours}

9 Avant de commencer cette analyse, voire ce voyage à travers les Alpes du Xve siècle, il faut dire quelques mots sur le prieuré de Saint-Ours, afin de le situer dans le contexte que je viens de décrire. Cela nous aidera à mieux comprendre comment et pourquoi l'analyse des vécus personnels des protagonistes de cette histoire et surtout leurs origines géographiques peuvent aider à l'interprétation des changements qui intéressèrent aussi bien la collégiale de Saint-Ours que le diocèse d'Aoste pendant ce siècle. 
Cette institution, avec son église, se trouve dans le bourg de la Porte Saint-Ours, une zone située à l'est de la cité d'Aoste, qui s'était développée sur le tracé des enceintes romaines vers l'an mil ${ }^{9}$ (fig. 1).

Fig. 1. - Plan de la ville d'Aoste au $\mathrm{Xl}^{\mathrm{e}}$ siècle, avec les églises principales et les cours d'eau. À droite, à l'intérieur du bourg de la porte Saint-Ours, les églises Saint-Laurent et Saint-Ours.

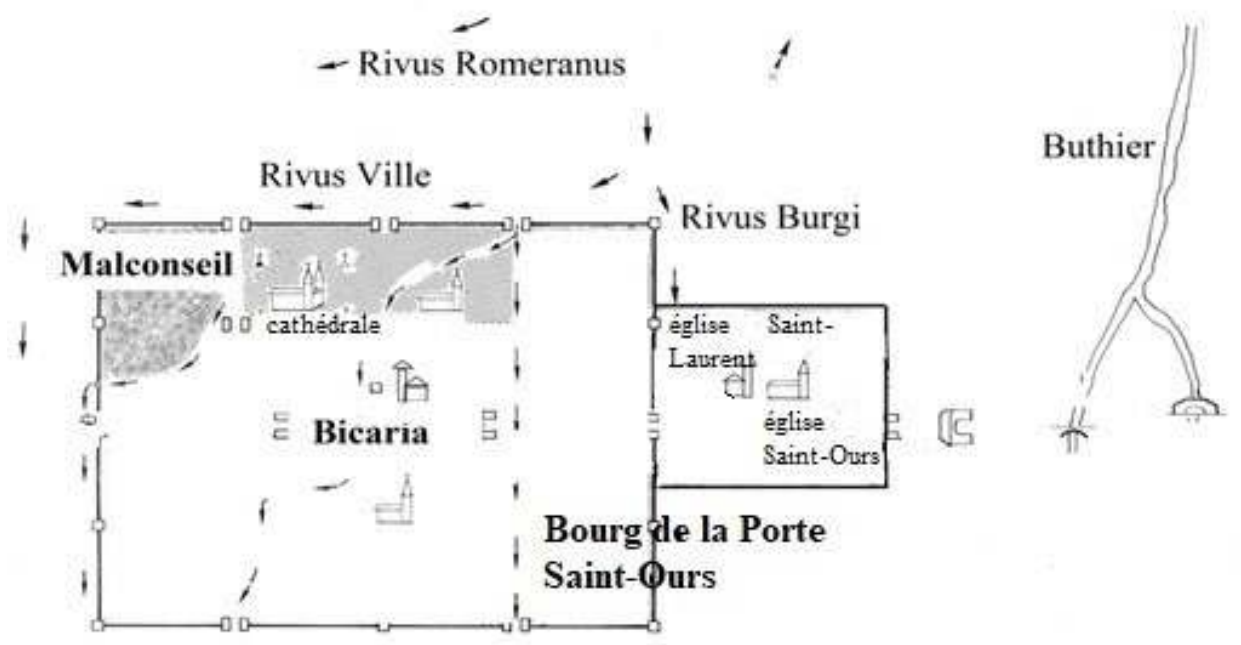

(C) Elena Corniolo.

Bientôt les chanoines s'enracinèrent dans le tissu territorial et social du bourg, aidés en cela par leur rôle pastoral, exercé dans l'église voisine de Saint-Laurent. Les chanoines de Saint-Ours suivaient la règle de saint Augustin depuis 1132. Le cloître fut bâti justement à cette époque ; cet événement est rappelé par un chapiteau (fig. 2). Celui-ci représente saint Augustin faisant le geste de relever le prieur Arnulphe penché devant lui. Juste à côté se trouvent saint Ours, patron originaire de la communauté, et saint Pierre, symbole de la protection de Rome ${ }^{10}$.

Fig. 2. - Chapiteau n 35 , côté sud-est, du cloître de Saint-Ours : le prieur Arnulphe est au centre ; saint Augustin à gauche; saint Ours à droite.

image

(c) Elena Corniolo.

12 Entre le XIII ${ }^{e}$ et le $\mathrm{XIV}^{\mathrm{e}}$ siècle, le prieuré agrandit son patrimoine et ses richesses grâce aux donations, aux échanges et aux achats, qui mirent les chanoines en contact avec la population locale. Celle-ci, et non pas les grandes familles aristocratiques, constitua le principal maillon du réseau social de l'église Saint-Ours. D'une part, cela permit aux religieux du bourg de gérer leurs propres richesses et de s'administrer en toute autonomie; de l'autre cela influença la composition interne de la communauté11. Entre les années trente du XII ${ }^{e}$ siècle et le milieu du Xve , en effet, presque tous les prieurs ont appartenu à des familles d'origine valdôtaine ${ }^{12}$. Entre 1416 et 1440 , la majorité des chanoines identifiés dans les sources (dix sur dix-neuf) était aussi liée à des familles du contexte valdôtain. Parmi les neuf noms restants, un seulement renvoie avec certitude à une localité externe au territoire valdôtain, tandis qu'on ne peut pas définir la 
provenance des huit autres, soit parce qu'il manque leur toponyme, soit parce qu'il est trop général ${ }^{13}$.

$\mathrm{Au}$ début $\mathrm{du} \mathrm{Xv}^{\mathrm{e}}$ siècle, la situation patrimoniale et sociale est similaire. Quelque chose, pourtant, commençait à changer aussi bien à l'intérieur du chapitre que dans le contexte diocésain. Cette dimension locale du patrimoine et des relations se trouverait bientôt face à une rapide modification du mode de recrutement de l'élite ecclésiastique qui monopolisait le pouvoir au sein de l'Église valdôtaine.

\section{Prieurs de Saint-Ours et évêques d'Aoste au Xve siècle}

Antoine de Vallaise (1406-1440) et Humbert Anglici (1440-1467/68), ainsi que les évêques Oger Moriset (1411-1433), Antoine de Prez (1444-1464) et son neveu François (1464-1511) furent les protagonistes, malgré eux peut-être, d'une phase délicate de la vie institutionnelle du diocèse, pendant laquelle le modèle d'une administration centralisée se substitua lentement à l'organisation traditionnelle, qui laissait de larges marges d'autonomie aux institutions religieuses et ecclésiastiques présentes sur le territoire. Eux-mêmes, pourtant, considérés en tant qu'individus avec une histoire personnelle, et pas seulement comme représentants d'une institution, étaient le produit de ce processus.

\section{Le prieur Antoine de Vallaise et l'évêque Oger Moriset}

Les vies personnelles et institutionnelles d'Antoine de Vallaise et d'Oger Moriset se croisèrent dans les années 1411-1433: il s'agit des vingt-deux années pendant lesquelles l'épiscopat de monseigneur Moriset se superposa au long prieuré d'Antoine de Vallaise. Les deux hommes, cependant, quoique actifs dans le même territoire, vécurent dans deux horizons géographiques et mentaux très différents.

Antoine de Vallaise appartenait à une des familles nobles les plus importantes de la vallée d'Aoste au Moyen Âge. La seigneurie de Vallaise s'étendait, pour ce qui concerne les possessions valdôtaines, dans la basse vallée, plus précisément dans la vallée du Lys $^{14}$. C'est là qu'Antoine demeurait ou, plutôt, qu'il se réfugiait pendant les phases les plus animées du conflit avec ses chanoines ${ }^{15}$. Étant un fils cadet, ses parents - Amédée d'Arduçon et Alexine, de la famille des Tizzoni de Vercelli - lui réservèrent la carrière ecclésiastique ${ }^{16}$. Le jeune Antoine étudia le droit alors qu'il était déjà chanoine à SaintOurs. Dans cette institution, avant d'en devenir le prieur, il revêtit même la charge de procureur ${ }^{17}$.

17 Pendant son long priorat, le double niveau de conflit, avec l'évêque et avec les chanoines, fut évident. La volonté d'Antoine de Vallaise d'obtenir la gestion autonome de ses biens engendra de très violents conflits avec les chanoines de Sainte-Christine, qui défendaient une gestion communautaire des ressources. Ces derniers, pendant la visite pastorale de 1419 et à l'occasion de la visite de l'archevêque de Tarentaise de 1427, accusèrent Vallaise d'avoir rempli la charge de procureur sans avoir été élu, de gérer les biens du prieuré pour son propre avantage et de mener une vie séparée des frères ${ }^{18}$. L'arrivée de monseigneur Oger Moriset à Saint-Ours, due probablement à un accord établi précédemment entre l'évêque et les chanoines en révolte, fut en revanche pour le prieur l'occasion de nier la légitimé du pouvoir épiscopal de visite. Vallaise 
revendiquait en effet un lien direct du prieuré avec le Saint-Siège. Il refusait toute ingérence de l'évêque dans la vie interne de l'institution, ce qui menaçait son pouvoir même de sanction des chanoines ${ }^{19}$. On se trouve donc face à plusieurs revendications d'autonomie : des chanoines envers le prieur ; du prieur envers les chanoines et envers l'évêque.

Malgré les conflits qui l'ont opposé à sa communauté, il est clair que ce personnage fut le produit des relations sociales de l'église Saint-Ours avec le territoire local. Bien que sa famille n'ait point de relations particulières avec les chanoines, Antoine décida quand même de se lier à une des institutions religieuses les plus prestigieuses et puissantes du territoire valdôtain. L'élection d'Antoine comme prieur confirmait de plus que les chanoines cherchaient leur chef parmi les membres de l'institution, de préférence nobles et liés au contexte local.

L'évêque d'Aoste, Oger Moriset, était en revanche originaire de Conflans (aujourd'hui le bourg médiéval d'Albertville) ; il y passa sa jeunesse, en réussissant à s'introduire parmi l'élite savoyarde en dépit de ses humbles origines. Il avait en effet de fréquents contacts avec des membres importants de la cour d'Amédée VIII. Oger se déplaça bientôt en Italie pour faire ses études. On le trouve à Aoste, en tant qu'archidiacre de l'église cathédrale, à partir de 1405. À cette époque, il voyageait beaucoup à la suite du pape Jean XXIII, dont il était le référendaire, cubicularius, et ensuite conseiller à la Chambre apostolique. Quand il fut nommé évêque d'Aoste, Oger se trouvait à Bologne ; ses engagements apostoliques déterminèrent ainsi son absence initiale du diocèse. C'est pourquoi il ne visita sa circonscription qu'en $1419^{20}$. Pendant qu'il était évêque, Oger Moriset prit encore part aux principaux conciles de l'époque : Constance (1414), puis Bâle (où il mourut le 11 janvier 1441). En 1433, après vingt-deux ans passés à Aoste, il fut déplacé au siège de Saint-Jean-de-Maurienne, par la volonté d'Eugène IV. Un déplacement sur ce siège avait déjà été proposé par Jean XXIII en 1415 : à cette époque, l'évêque de Saint-Jean-de-Maurienne aurait dû aller à Lausanne, tandis qu'à Aoste serait arrivé l'archevêque de Rouen. Pourtant le nouveau pape, Martin V, avait empêché tout changement ${ }^{21}$.

La vie d'Oger Moriset s'inscrit parfaitement dans un réseau social qui dépasse la dimension locale. Il voyagea beaucoup à l'intérieur des domaines savoyards, à travers les Alpes, mais aussi en Italie, à travers les territoires pontificaux. Au vu de son existence, il paraît clair qu'Oger dut sa fortune à ses rapports avec la cour savoyarde et surtout avec la curie. Contrairement à Vallaise, appuyé uniquement sur un réseau local, monseigneur Moriset trouva dans la dimension savoyarde et papale de ses liens la voie de son succès personnel aussi bien que du renforcement de son évêché.

\section{Le prieur Humbert Anglici et les évêques de Prez}

21 Avec Humbert Anglici et les deux évêques de Prez, la distinction entre les origines familiales et géographiques des personnages à la tête des deux institutions - prieuré et évêché - disparaît. Les deux familles provenaient en effet des territoires suisses et appartenaient à l'élite savoyarde.

Si le jeune François de Prez, en 1464, au moment de sa nomination par le pape Pie II, se trouvait déjà à Aoste, en tant que bénéficié de la cathédrale et commendataire de l'église de Saint-Martin-de-Corléans, son oncle Antoine, par contre, avant d'arriver en vallée d'Aoste, avait été chanoine et chantre de la cathédrale de Lausanne et chanoine 
de Sion (1436) ${ }^{22}$. La famille de Prez était en effet originaire de Rue, à cette époque située dans le canton de Vaud. Antoine était clerc de la Chambre apostolique quand Félix V, en 1444 , le nomma évêque d'Aoste. Il ne perdit pourtant jamais ses liens avec la terre suisse de ses origines. Son attachement à sa terre natale se manifeste avec évidence dans les dispositions de son testament, écrit à Aoste le 4 janvier $1464^{23}$. Dans la section dédiée aux donations en faveur des institutions religieuses et des églises, on perçoit clairement, en effet, une prédilection pour le territoire vaudois ${ }^{24}$. Encore une fois, donc, on constate d'une part que les relations sociales et politiques des familles de l'élite savoyarde favorisaient leur mobilité à l'intérieur des domaines savoyards, de l'autre que l'évêché d'Aoste faisait désormais partie des bénéfices ecclésiastiques lucratifs convoités par les rejetons des familles nobles.

Humbert Anglici interrompit la longue séquence des prieurs de Saint-Ours d'origine valdôtaine. Sa famille était originaire de la Bresse, d'où, vers les années trente du Xve siècle, elle se déplaça, à la suite d'Humbert le Bâtard de Savoie, pour rejoindre les territoires compris entre les lacs Léman et de Neuchâtel. Le Bâtard était en effet l'oncle maternel d'Humbert Anglici ${ }^{25}$. Sa mère, Jeanne, qui avait épousé en deuxièmes noces Pierre Anglici, était sœur du Bâtard et, comme lui, fille naturelle du comte Amédée VII et demi-sœur d'Amédée VIII (fig. 3) ${ }^{26}$.

Fig. 3. - Arbre généalogique illustrant le rapport entre Humbert Anglici, prieur de Saint-Ours d'Aoste, et la maison de Savoie. La ligne en pointillés représente la descendance bâtarde du comte Amédée VII de Savoie.

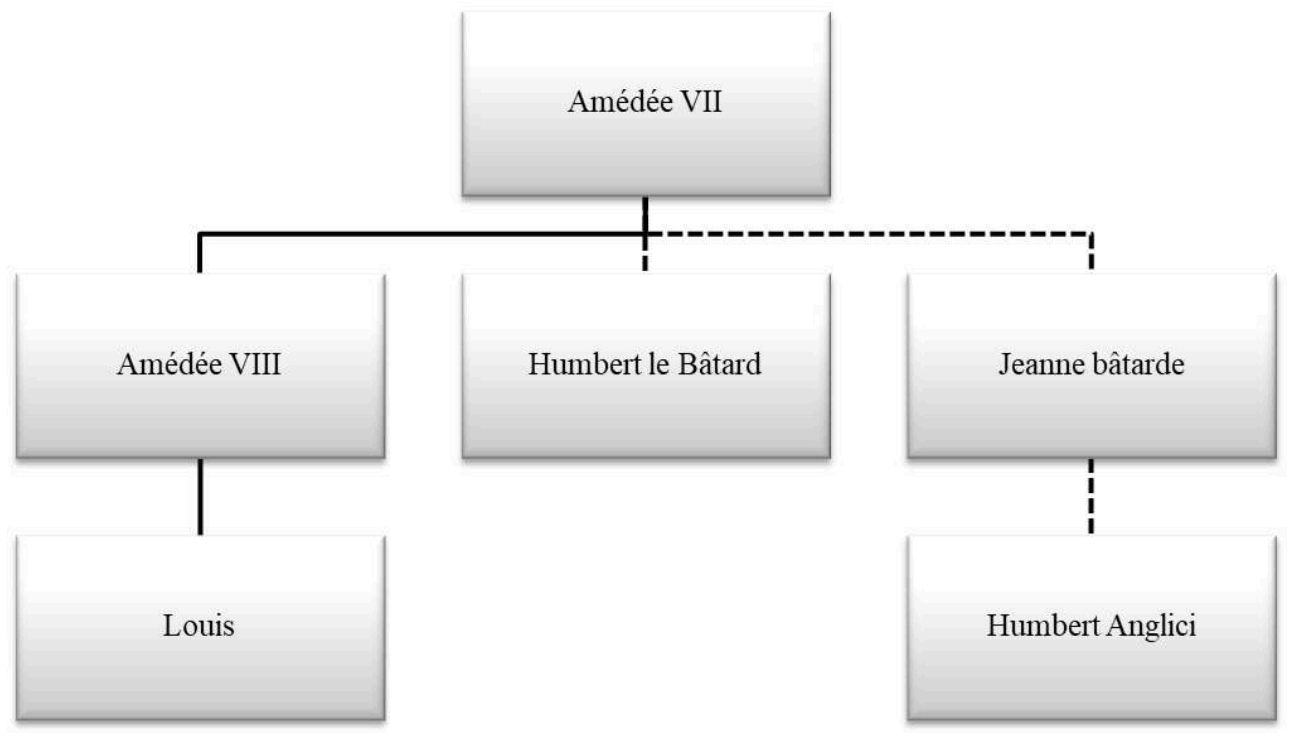

(c) Elena Corniolo.

Docteur ès lois avant de devenir prieur de Saint-Ours, Anglici assuma pendant quinze ans la charge de prévôt de la communauté augustinienne de Saint-Gilles de Verrès, dans la basse vallée d'Aoste ${ }^{27}$. Il arriva à Saint-Ours pour succéder à Antoine de Vallaise ${ }^{28}$ seulement deux mois après l'élection en tant que prieur de transition de Boniface Bordon, un des plus vieux chanoines du chapitre. La collaboration manifeste des chanoines à l'administration d'Humbert et son parcours pour améliorer l'organisation administrative et patrimoniale du prieuré font penser qu'il ne fut pas imposé à ce poste par son cousin le duc de Savoie, mais qu'il fut plutôt choisi par les chanoines eux-mêmes pour ses capacités et pour ses origines ${ }^{29}$. Ses liens avec la famille 
princière et l'élite de Savoie, un réseau savoyard qui prenait désormais les principales décisions pour le diocèse d'Aoste, représentaient en effet un atout pour l'institution.

Anglici fut le reflet d'un changement de politique des chanoines face aux mutations du contexte diocésain. La diffusion de la commende, qui à cette époque avait déjà touché la prévôté du Grand-Saint-Bernard (1438), les prieurés de Saint-Bénin (1444), du PetitSaint-Bernard (1461) et de nombreuses églises, révélait de façon évidente que les affaires du diocèse d'Aoste ne se réglaient plus à l'intérieur du diocèse lui-même ${ }^{30}$. La mobilité des hauts ecclésiastiques savoyards, des évêques surtout, en donnait une autre confirmation $^{31}$. Avec Humbert Anglici, le mécanisme du recrutement du prieur se rapprocha donc de celui des évêques.

L'appartenance d'Anglici au même réseau social que celui des évêques de Prez lui permit de se confronter à eux au même niveau, ce qui lui donna la force de pousser le conflit pour l'autonomie de son institution jusqu'à l'extrême. L'opposition atteignit son point culminant pendant les premiers mois de 1464, quand, au moment de la succession d'Antoine de Prez, le prieuré de Saint-Ours opposa son propre candidat au successeur légitime, nommé par le pape. Ce geste, volontairement provocateur, visait à donner au prieuré plus de poids pour négocier la modification de ses statuts. En effet, une fois cet objectif atteint, les chanoines annulèrent sans protester leur élection ${ }^{32}$.

Humbert Anglici, en tant que dernier prieur régulier, incarna ainsi l'espoir des chanoines de pouvoir interagir avec ce nouveau réseau de relations - à la fois sociales, politiques et économiques - sans pourtant modifier leur aménagement interne. Plus concrètement, Anglici donna à la communauté de Saint-Ours la chance de se préparer au niveau administratif et patrimonial au changement institutionnel imminent, c'est-àdire à l'arrivée du premier prieur commendataire. Après des décennies de luttes internes au sein du chapitre, commencées avec le prieuré d'Antoine de Vallaise, Anglici réussit en effet à modifier les statuts avec l'approbation des chanoines. Par cet acte on sépara, avec beaucoup de dispositions en faveur des biens communautaires, la mense des chanoines de celle du prieur ${ }^{33}$. On assiste ainsi à un changement de la politique du prieuré, qui, de strictement régionale, devient tout à fait princière. La commende, introduite en 1468 en tant que manifestation la plus évidente de l'entrée du prieuré dans le réseau relationnel savoyard, ne fut donc que l'aboutissement d'un processus anticipé par la figure d'Humbert Anglici.

Réfléchir sur l'origine des prieurs de Saint-Ours et des évêques d'Aoste entre le début $\mathrm{du} \mathrm{xv}^{\mathrm{e}}$ siècle et ses années soixante nous a permis d'interpréter l'histoire institutionnelle du prieuré en fonction des changements des liens politiques et familiaux à l'intérieur du diocèse. Les événements complexes de l'histoire institutionnelle du prieuré pendant cette période trouvent dans l'analyse des origines familiales et géographiques de ses protagonistes une confirmation du fait que les chanoines de Saint-Ours eurent la capacité d'interpréter le contexte qui les entourait et d'agir en conséquence. Face à un épiscopat ouvert sur des réseaux savoyards et à une diffusion croissante de la commende à l'intérieur du diocèse d'Aoste, le prieuré de Saint-Ours délégua, ironie du sort, à un noble vaudois, bâtard des Savoie, la défense d'un système administratif et patrimonial appuyé sur un réseau local. Ce fonctionnement n'était pourtant plus soutenable dans un contexte où les églises et les 
institutions religieuses représentaient une monnaie d'échange facile et rentable aux plus hauts niveaux diplomatiques. Le prestige du prieuré de Saint-Ours et le développement du système bénéficial, désormais lié à la curie de Rome et aux cours princières, déterminèrent ainsi l'intégration du prieuré aux réseaux des riches bénéfices de l'église savoyarde.

\section{BIBLIOGRAPHIE}

BARBERO Alessandro, « Una comunità di canonici riformati nei secoli XII e XIII : il capitolo di S. Orso ad Aosta ", dans Barbero Alessandro (dir.), Valle d'Aosta medievale, Naples, Liguori (Bibliothèque de l'Archivum Augustanum, 27), 2000, p. 79-125.

BERTOLIN Roberto, « Arnad : dalla casa forte della Costa al castello Vallaise. L'evoluzione della dimora e gli inventari del suo mobilio », Archivum Augustanum, vol. 5 n.s., 2004, p. 7-128. BORDON Roberta, BORETTAZ Omar, COLLIARD Marie-Rose, VALLET Viviana Maria (dir.), Georges de Challant priore illuminato, atti delle giornate di celebrazione del V centenario della morte 1509-2009, Aoste, Issogne, 18-19 settembre 2009, Aoste, Tipografia valdostana (Documenti, 9), 2011.

BOSON Justin, L'insigne collégiale d'Aoste, Ivrea, Viassone, 1929.

BRONDY Réjane, DEMOTZ Bernard, LEGUAY Jean-Pierre, La Savoie de l'an mil à la Réforme : $\mathrm{XI}^{e}$-début XVI siècle, Rennes, Ouest-France (Histoire de la Savoie, 2), 1985.

BRUNOD Edoardo, La collegiata di Sant'Orso, Aoste, Musumeci Editore (Arte sacra in Valle d'Aosta, 2), 1977.

CASTELNUOVo Guido, " Humbert le Bâtard : un seigneur itinérant au service de son prince ", dans Paravicini Bagliani Agostino, Pibiri Eva, Reynard Denis (dir.), L'itinérance des seigneurs (XIV $-X V I^{e}$ siècle), Lausanne (Cahiers lausannois d'histoire médiévale, 34), 2003, p. 5-25.

CAVALLARo Antonina Maria, « Ipotesi sullo sviluppo urbanistico di Aosta altomedievale », Bollettino storico-bibliografico subalpino, vol. 94, $\mathrm{n}^{\circ}$ 1, 1996, p. 5-94.

CLOTTU Olivier, « Prélats vaudois à Aoste avant la réformation », Archivum Augustanum, nº 7 , 1974-1975, p. 337-345.

COLLIARD Marie-Rose, « Culto e religiosità di popolo nella diocesi di Aosta nella prima metà del XV secolo », mémoire de maîtrise en histoire du christianisme, Turin, université de Turin, 1994.

COLLIARD Marie-Rose, Atti sinodali e visite pastorali nella città di Aosta del XV secolo, Aoste, Tipografia valdostana (Écrits d'histoire, de littérature et d'art, 14), 2015.

CORNIOLo Elena, « Patrimonio e clientele di Sant'Orso : Aosta e il suo territorio tra XII e XIII secolo ", mémoire de maîtrise en histoire médiévale, Turin, université de Turin, 2012. CORNIOLo Elena, «Istituzioni, famiglie e territorio. I canonici di Sant'Orso nel borgo di Aosta », Bollettino storico-bibliografico subalpino, vol. 114, n² 2, 2016, p. 437-465.

CORNIOLO Elena, «Chiesa locale e relazioni di potere attorno al priorato di Sant'Orso d'Aosta (1406-1468) », thèse, Turin, université de Turin, 2018. 
DOMAINE Jean, Les constitutions des chanoines de Saint-Ours à Aoste d'après un manuscrit du XIII siècle, Aoste, Imprimerie valdôtaine, 1978.

Duc Étienne-Pierre, La prévôté et la paroisse de St.-Gilles abbé à Verrès, diocèse d'Aoste, Ivrée, Imprimerie du séminaire, 1873.

DUC Étienne-Pierre, Le prieuré de Saint-Pierre et Saint-Ours d'Aoste, Aoste, Imprimerie catholique, 1899.

Duc Étienne-Pierre, « Testament d'Antoine de Prez, évêque d'Aoste (1464) », Revue historique vaudoise, vol. 12, suppl., 1904, p. 305-320.

Duc Joseph-Auguste, Histoire de l'église d'Aoste, vol. IV, Châtel-Saint-Denis, impr. H. Leibzig, 1909. ERBA Achille, La Chiesa sabauda tra Cinque e Seicento. Ortodossia tridentina, gallicanesimo savoiardo e assolutismo ducale (1580-1630), Rome, Herder (Italia sacra : studi e documenti di storia ecclesiastica, 29), 1979.

FRUTAZ Aimé-Pierre, Le fonti per la storia della Valle d'Aosta, Aoste, Tipografia valdostana (Thesaurus ecclesiarum Italiae, série I : Piemonte), 1998.

GAL Jean-Antoine, L'insigne collégiale de S. Pierre et de S. Ours d'Aoste, Aosta, Lyboz, 1864.

JACCOD Luca (éd.), « Archives de la collégiale de Saint-Pierre et de Saint-Ours. Aoste. Inventaire sommaire », dactylographié auprès du Grand Séminaire d'Aoste, Aoste, 2003.

LA FERLA Anna, « Giorgio di Challant, un grande mecenate », dans Barberi Sandra (dir.), Il castello di Issogne in Valle d'Aosta. Diciotto secoli di storia e quarant'anni di storicismo, Grugliasco (To), Allemandi (Documenti, 4), 1999.

LA FERLA Anna, « La figura di Giorgio di Challant », dans Orlandoni Bruno et Rossetti Brezzi Elena (dir.), Sant'Orso di Aosta. Il complesso monumentale, t. I : Aosta, Tipografia valdostana, 2001, p. 133-142.

LA FERLA Anna, «"Et per tutto il suo nome era celebre" : Giorgio di Challant », dans Pagella Enrica, Rossetti Brezzi Elena, Castelnuovo Enrico (dir.), Corti e città. Arte del Quattrocento nelle Alpi occidentali, cat. exp. (Turin, 7 février-14 mai 2006), Milan, Skyra, 2006, p. 423-426.

ORLANDONI Bruno et ROSSETTI BREZZI Elena (dir.), Sant'Orso di Aosta. Il complesso monumentale, Aoste, Tipografia valdostana, 2001.

PAPONE Paolo, Il chiostro di Sant'Orso in Aosta e la sua interpretazione, Aoste, Tipografia valdostana (Bibliothèque de l'Archivum Augustanum, 36), 2011.

PAPONE Paolo et VALLET Viviana, «Storia e liturgia nel culto di Sant'Orso », Bulletin de la Société académique religieuse et scientifique du duché d'Aoste (Bulletin Académie Saint-Anselme), vol. 7, n.s., 2000, p. 217-400.

PLATANIA Daniela, Oger Moriset. Vescovo di Aosta e Saint-Jean-de-Maurienne (1411-1441). Vita e committenza artistica, Aoste, Le Château (Biographica, 16), 2003.

QUAGLIA Lucien, La maison du Grand-Saint-Bernard, Aoste, impr. ITLA, 1955.

RIEDMATTEN Adrien de, Humbert le Bâtard : un prince aux marches de la Savoie (1377-1443), Lausanne, Éditions Féryane (Cahiers lausannois d'histoire médiévale, 35), 2004.

RIVOLIN Joseph-Gabriel, Pollein, materiali per una storia, Quart (Ao), Musumeci Editore, 1993. 
ROULLET Elfrida, « Vita religiosa nella diocesi di Aosta tra il 1444 e il 1525 », mémoire de maîtrise en histoire du christianisme, Turin, université de Turin, 1982.

SERGI Giuseppe, «Il Medioevo : Aosta periferia centrale », dans Noto Sergio (dir.), La Valle d'Aosta e l'Europa, Florence, Leo S. Olschki, 2008, p. 29-62.

THIÉBAT Piergiorgio, La collegiata di Sant'Orso in Aosta. Guida al complesso monumentale, Aoste,

Tipografia valdostana, 1995.

TILLIER Jean-Baptiste de, Nobiliaire du duché d'Aoste, Zanotto Andrea (éd.), Aoste, La Tourneuve, 1970.

VEVEY Hubert de, «La famille Angleis d'Estavayer », Annales fribourgeoises, vol. XXVIII, n 3, 1950, p. 65-71.

ZANOLLI Orphée (éd.), Cartulaire de Saint-Ours, Quart (Ao), Imprimerie valdôtaine (Bibliothèque de l'Archivum Augustanum, 5), 1975.

ZANOLLI Orphée, « La question inédite des fiefs des seigneurs de Vallaise en la vallée de Challand et des fiefs des seigneurs de Challand à Gressoney ", Le Flambeau, nº 2, 1979, p. 47-55.

ZANOTTO Andrea, « Note sull'assetto urbanistico medievale della città di Aosta », dans Atti del congresso sul bimillenario della città di Aosta (Aoste, 5-20 octobre 1975), Bordighera, Istituto internazionale di studi liguri, 1982, p. 431-436.

\section{NOTES}

1. Les Archives historiques de Saint-Ours (désormais AHSO) sont accessibles, depuis l'année 2003, à travers un inventaire sommaire (L. Jaccod, « Archives de la collégiale de Saint-Pierre et Saint-Ours »), une mise à jour d'un précédent inventaire réalisé en 1981 par les Archives historiques régionales en collaboration avec le chanoine Borettaz (A.P. Frutaz, Le fonti per la storia della Valle d'Aosta, p. 39). Il n'est pas possible de connaître en amont le contenu précis des cartons et des registres, mais seulement, à partir de l'inventaire, l'intervalle chronologique approximatif qu'ils recouvrent.

2. Voir par exemple E. Brunod, La collegiata di Sant'Orso; P. Thiébat, La collegiata di Sant'Orso in Aosta.

3. R. Bordon et al. (dir.), Georges de Challant priore illuminato ; A. La Ferla, "Giorgio di Challant, un grande mecenate", p. 41-49; "La figura di Giorgio di Challant», p. 133-142; et : " "Et per tutto il suo nome era celebre" ", p. 423-426.

4. Pour l'histoire patrimoniale, les études ont pris en considération une source en particulier, le cartulaire du $\mathrm{Xv}^{\mathrm{e}}$ siècle: O.Zanolli (éd.), Cartulaire de Saint-Ours: A. Barbero, «Una comunità di canonici riformati nei secoli XII e XIII », p. 79-125; E. Corniolo, «Patrimonio e clientele di Sant'Orso »; J.-G. Rivolin, Pollein, materiali per una storia. Pour la liturgie, je signale un texte en particulier, P. Papone et V. Vallet, "Storia e liturgia nel culto di Sant'Orso », p. 217-400, très intéressant aussi pour un excursus sur l'histoire de la communauté de Saint-Ours jusqu'au XII ${ }^{\mathrm{e}}$ siècle.

5. J. Boson, L'insigne collégiale d'Aoste; É.-P. Duc, Le prieuré de Saint-Pierre et Saint-Ours d'Aoste ; J.-A. Gal, L'insigne collégiale de S. Pierre et de S. Ours d'Aoste.

6. Seulement deux des sources conservées aux AHSO ont été transcrites et publiées : J. Domaine (éd.), Les constitutions des chanoines de Saint-Ours... ; O. Zanolli (éd.), Cartulaire 
de Saint-Ours. Parmi les registres, j'ai travaillé sur trois recueils de reconnaissances féodales (AHSO, 12R, «1431-1436; 1444-1447; 1449-1459»; 21R, «1443-1454»; 44R, " $1456 »)$, sur un cartulaire ( $1 \mathrm{~m}$, "Cartulaire $\mathrm{xv}^{\mathrm{e}}$ siècle ») et sur les minutaires du notaire Pierre de Rovarey (1F2, « Rovarey, 1430-1443»; 1F3, «1433-1493»; 1F4, « 1442, $1447,1455 » ; 1 \mathrm{~F} 5$, «1442-1448»; 1F6, «1445-1450»; 1F7, «1450-1480»; 1F8, «1450, $1460,1484 » ; 2 \mathrm{~F} 1$, «1460-1475 »). Les chartes que j'ai étudiées se trouvent par contre dans les cartons qui portent une étiquette indiquant un arc chronologique compris entre 1406 et 1468, sans aucune spécification de fonction (par exemple "sacristie », « chapelle de... ») ni de localité : 7A11, « Varia Xve siècle »; 1B1, «1455-1469, Anglici »; 1B2, «1440-1455, Anglici»; 1C4, «1400-1408»; 1C5, «1409-1410»; 1C6, «1410-1414, Vallaise »; 1C7, «1414-1415, Vallaise»; 1C8, «1416-1420, Vallaise»; 7D2, «1420-1440»; 7E10, «Testaments des chanoines»; 4F1, «Bulles»; 4F3, « Documents »; 4F4, « Actes des prieurs, XIV siècle »; 4F8, « Documents 1400 ».

7. M.-R. Colliard, Atti sinodali e visite pastorali nella città di Aosta del XV secolo, p. 149-212. On trouve des transcriptions de ces documents également dans E. Roullet, « Vita religiosa nella diocesi di Aosta tra il 1444 e il 1525 », p. 1-424 et dans É.-P. Duc, Le prieuré de Saint-Pierre et Saint-Ours d'Aoste, p. 109-138, 140-154.

8. Les archives historiques de l'évêché et diocésaines ont été consultées de façon ciblée, selon les exigences de recherches apparues pendant l'analyse des documents conservés aux AHSO. En particulier, aux Archives historiques de l'évêché, les boîtes 23, 49, 135, 154, 169-171; aux Archives de la curie épiscopale, le fonds Tribunaux ecclésiastiques, cartons LXX, « Documents de particuliers », LXXVI, « Officialité ».

9. A.Zanotto, "Note sull'assetto urbanistico medievale della città di Aosta", p. 431-436; A. M. Cavallaro, «Ipotesi sullo sviluppo urbanistico di Aosta altomedievale », p. 5-94.

10. P. Papone, Il chiostro di Sant'Orso in Aosta e la sua interpretazione, p. 33-41.

11. E. Corniolo, «Istituzioni, famiglie e territorio. I canonici di Sant'Orso nel borgo di Aosta », p. 437-465.

12. Des quinze prieurs qui se succédèrent entre 1250 et 1440 , onze appartenaient à des familles valdôtaines et un à une importante famille de la Bresse; l'origine des trois autres est inconnue (É.-P. Duc, Le prieuré de Saint-Pierre et Saint-Ours d'Aoste, p. 55-162).

13. Ces informations ont été tirées des actes des visites pastorales de 1416 (M.-R. Colliard, Atti sinodali e visite pastorali nella città di Aosta del XV secolo, p. 158) et de 1419 (ibid., p. 170) et de deux actes capitulaires, datés de 1429 (AHSO, 7D2, «1420-1440 », doc. 10) et 1440 (AHSO, 4F3, « Documents », fol. 1 ro).

14. R. Bertolin, «Arnad : dalla casa forte della Costa al castello Vallaise», p. 7-128; G. Sergi, "Il Medioevo : Aosta periferia centrale», p. 51-53; O. Zanolli, «La question inédite des fiefs des seigneurs de Vallaise... ", p. 47-55.

15. Antoine de Vallaise avait sa maison de famille à Extilliano, près de Pont-SaintMartin, comme on peut le voir dans les quatre documents où il agit en tant que prieur : AHSO, 7D2, doc. 14 (16/10/1437), 16 (15/10/1437), 17 (20/02/1437), 18 (20/04/1437).

16. J.-B. de Tillier, Nobiliaire du duché d'Aoste, p. 618.

17. Ces informations ont été tirées de l'interrogatoire des chanoines de Saint-Ours par l'officiel épiscopal le 10 février 1419 (M.-R. Colliard, Atti sinodali e visite pastorali nella città di Aosta del XV secolo, p. 186). 
18. Ibid., p. 169-163 : « $1^{\text {er }}$ interrogatoire aux chanoines, fait le matin du 16 janvier $1419 » ;$ p. 175-177: « $2^{\mathrm{e}}$ interrogatoire aux chanoines, fait le 16 janvier $1419 »$; p. 186-188: «Interrogatoire aux chanoines du 10 février 1419»; p. 199-205: « Notification à la communauté des chanoines des ordres donnés par l'archevêque de Tarentaise ».

19. Ibid., p. 195-198 (s.d., probablement entre juin et décembre 1420, Moriset réfute les accusations faites contre lui par Vallaise); p. 263-271, doc. VI (s.d., Vallaise accuse Moriset face à l'archevêque); p. 273-275, doc. VII (s.d., Vallaise accuse Moriset face à trois arbitres); AHSO, 14m, S. Vesan, "Notes sur la collégiale de Saint-Ours », vol. I, ms. XIX sec., p. 86 (bulle du pape Martin V, datée 14/06/1418. La narratio nous apprend que Vallaise avait demandé au pape une modification des statuts de la collégiale. Le prieur souhaitait une séparation de sa propre mense de celle des chanoines).

20. M.-R. Colliard, Atti sinodali e visite pastorali nella città di Aosta del XV secolo, p. 161.

21. Pour approfondir l'étude de la vie de Mgr Moriset, voir D. Platania, Oger Moriset. Pour les déplacements des évêques entre les diocèses, voir A.-P. Frutaz, Le fonti per la storia della Valle d'Aosta, p. 308.

22. A.-P. Frutaz, Le fonti per la storia della Valle d'Aosta, p. 310-311. La bulle par laquelle François fut nommé évêque d'Aoste se trouve dans les Archives historiques de l'évêché, boîte 170, doc. 10 (04/04/1464).

23. Les informations sur la famille de Prez ont été tirées du texte É.-P. Duc, «Testament d'Antoine de Prez, évêque d'Aoste (1464) », p. 305-320.

24. Ibid., p. 310-316.

25. G. Castelnuovo, «Humbert le Bâtard », p. 5-25 ; A. de Riedmatten, Humbert le Bâtard, p. 157-163. On y trouve une analyse du testament du Bâtard, où on comprend le lien parental entre ce personnage et la famille Anglici.

26. O. Clottu, «Prélats vaudois à Aoste avant la réformation », p. $345 ;$ H. de Vevey, «La famille Angleis d'Estavayer », p. 65-71.

27. É.-P. Duc, La prévôté et la paroisse de St.-Gilles abbé à Verrès, diocèse d'Aoste, p. 185.

28. L'élection de Boniface Bordon eut lieu le 9 mars 1440 (AHSO, 4F3, «Documents", fol. $1 \mathrm{r}^{\circ}$ ).

29. Humbert fut élu administrateur du patrimoine (conrearius) en 1440, comme on l'apprend de l'acte capitulaire avec lequel le chapitre sépara la mense du prieur de celle des chanoines (AHSO, 1B1, «1455-1469, Anglici », doc. 1 et 11.1 ; il s'agit d'une charte et d'un dossier). Dans ma thèse, «Chiesa locale e relazioni di potere attorno al priorato di Sant'Orso d'Aosta (1406-1468) », je tente de démontrer qu'Anglici promut une réforme documentaire, par laquelle la forme-registre se substitua aux rouleaux de parchemin. Les registres furent utilisés pour classer selon l'ordre topographique la documentation en cours de typologie patrimoniale (inféodations et reconnaissances) et pour sélectionner la documentation antérieure, attestant les droits de l'institution.

30. Les notices à propos de la diffusion de la commende dans le contexte valdôtain du $\mathrm{XV}^{\mathrm{e}}$ siècle et dans les autres territoires du duché de Savoie se trouvent dans É.-P. Duc, $L a$ prévôté et la paroisse de St.-Gilles..., p. 108, 113, 117 ; J.-A. Duc, Histoire de l'église d'Aoste, IV, p. 441-442, 444 ; A. Erba, La Chiesa sabauda tra Cinque e Seicento, p. 200-224 ; L. Quaglia, La maison du Grand-Saint-Bernard, p. 189. 
31. Sur la mobilité du haut clergé à l'intérieur des domaines savoyards $d u x^{e}$ siècle, voir R. Brondy et al., La Savoie de l'an mil à la Réforme, p. 384-385.

32. AHSO, 1B1, « 1455-1469, Anglici », doc. 10.

33. Ibid., doc. 1 et 11.1 .

\section{RÉSUMÉS}

Parmi les aspects qui laissent transparaître le dynamisme du diocèse d'Aoste au Xve siècle, il faut souligner la mobilité transalpine interne au duché savoyard. Dans ce contexte, reflet d'un changement administratif et politique de l'Église locale, le prieuré de Saint-Ours représente un point d'observation révélateur et qui n'est pas encore étudié : la plupart des sources exploitées, tirées des archives du prieuré, de l'évêché et du diocèse ont donc été consultées en original. Cette institution, enracinée dans le territoire local depuis le XII siècle, se retrouve en effet, à l'aube de l'époque moderne, impliquée dans des relations - voire des conflits - où la dimension locale se croise avec la dimension transalpine. Face à un évêché ouvert sur des réseaux savoyards, le prieuré trouve, ironie du sort, dans un noble vaudois, bâtard des Savoie, le défenseur d'un système administratif et patrimonial appuyé sur le contexte local.

\section{AUTEUR}

\section{ELENA CORNIOLO}

Docteur en histoire médiévale, université de Turin 


\title{
Le réseau canonial de Sainte-
} Christine du Somport : mécanismes de son développement sur le versant nord

\author{
Jean Claude Lassègues
}

1 S'il est un axe transpyrénéen qui défie le temps, c'est bien celui qui emprunte les vallées colinéaires du gave d'Aspe et de la rivière Aragon entre les villes jumelles d'Oloron-Sainte-Marie et de Jaca ${ }^{1}$. Antique parcours de transhumance, couloir de la voie romaine Lescar-Saragosse, chemin de toutes sortes d'échanges entre les deux versants, il est entré dans la modernité grâce au percement d'un tunnel entre les Forges d'Abel et Canfranc, d'abord ferroviaire, puis routier'2.

2 Dans les temps anciens, franchir le col du Somport à 1632 mètres d'altitude n'était pas toujours chose facile, surtout en hiver. Autour des années 1100, lorsque les relations entre le Béarn et l'Aragon sont devenues particulièrement étroites, il s'est avéré nécessaire de faciliter les échanges par le Somport pour une grande variété de voyageurs qui allaient en Espagne ou en revenaient, que ce soit dans le cadre de la Reconquista, de la Repoblación ${ }^{3}$, du pèlerinage à Saint-Jacques en Galice ${ }^{4}$, ou tout simplement d'échanges commerciaux qui ont sans doute été l'activité la plus constante au cours des siècles.

3 La convergence des intérêts de la vicomté de Béarn, du royaume d'Aragon et du SaintSiège a favorisé l'installation d'un relais afin de faciliter le passage du col en toute saison. C'est ainsi qu'est né l'hôpital-prieuré de Sainte-Christine du Somport, à 1520 mètres d'altitude, sur le versant sud (fig. 1). Cet établissement est rapidement devenu la maison mère d'un réseau canonial prospère qui s'est étendu à l'ensemble de l'Aragon reconquis et au Béarn ${ }^{5}$. 
Fig. 1. - Liaisons routières avec l'Espagne des vallées béarnaises de Barétous, d'Aspe et d'Ossau, respectivement par le col de la Pierre-Saint-Martin ( 1766 mètres d'altitude) vers la vallée de Roncal, par le col du Somport (1 632 mètres d'altitude) vers la vallée de la rivière Aragon, et par le col du Pourtalet (1 794 mètres d'altitude) vers le val de Tena. L'hôpital prieuré de Sainte-Christine était situé près du col du Somport et de la route Oloron-Jaca. Le tunnel est figuré en pointillés.

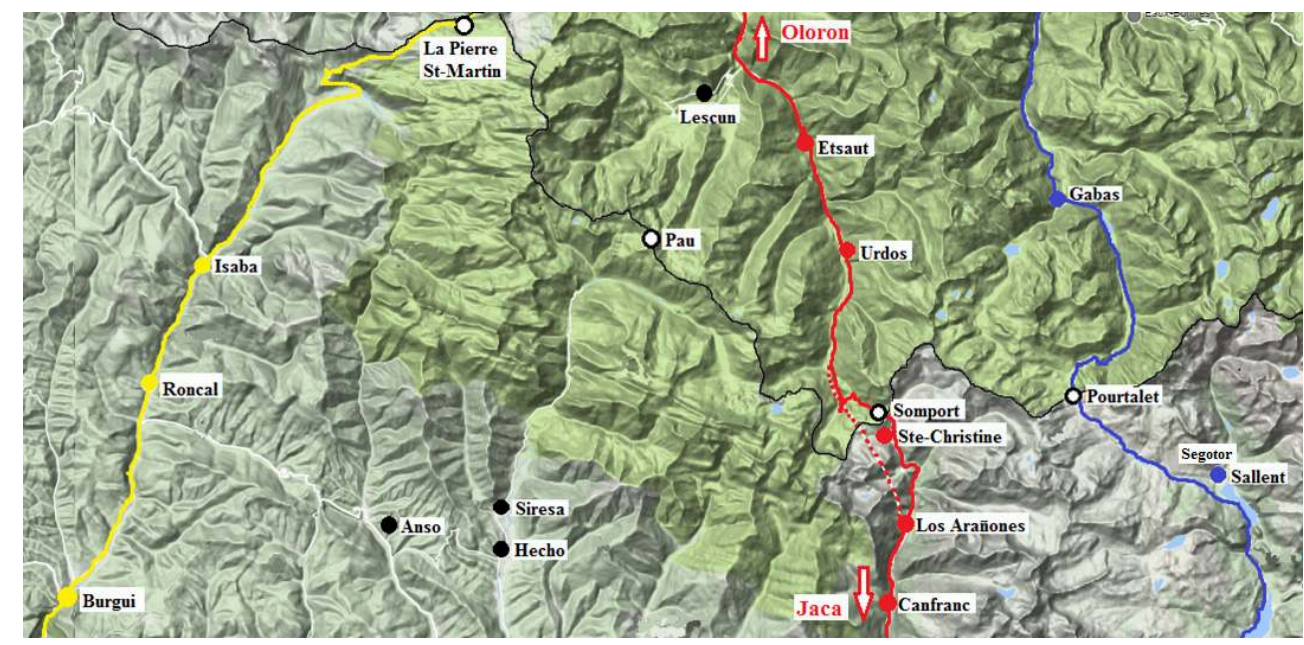

(C) Jean Claude Lassègues.

4 Comment s'est effectuée cette diffusion? Côté aragonais, la documentation montre qu'elle est directement liée aux progrès de la Reconquête ${ }^{6}$. Sur le versant nord, la situation est complètement différente, pour la simple raison que l'espace est déjà occupé. Il s'ensuit que les mécanismes d'implantation de nouvelles fondations hospitalières au XII siècle sont complexes. Ceux du développement du réseau ne sont pas plus simples. Outre des réticences locales, ils intègrent l'ingérence croissante du pouvoir laïc jusqu'au coup fatal porté par la Réforme à la fin du xvI ${ }^{e}$ siècle. Faute de pouvoir décrire l'ensemble de cette évolution, qui comporterait d'ailleurs de sérieuses lacunes, nous avons choisi de rappeler quelques aspects de l'installation du réseau sur le versant nord, pour illustrer ensuite la place et la vie des possessions de SainteChristine en Béarn par un cliché pris "à mi-parcours", du temps de Marguerite Moncade.

\section{La naissance du réseau de Sainte-Christine et son développement sur le versant nord au $\mathrm{XII}^{\mathrm{e}}$ siècle}

\section{L'implantation autour du Somport}

Les fouilles archéologiques ont mis au jour les fondations d'une église et de deux bâtiments de dimensions modestes, à la mesure d'un habitat de montagne, peu en accord avec la légende qui voudrait que cet hôpital ait été au XII ${ }^{e}$ siècle l'un des trois plus grands du monde chrétien ${ }^{7}$. Mais ce n'est pas par ses dimensions que cet établissement est devenu célèbre, c'est par son rayonnement en tant que maison mère d'un important réseau canonial ${ }^{8}$. Bien qu'il n'ait abrité au maximum qu'une douzaine de religieux, leur subsistance et celle des voyageurs nécessitèrent très tôt la mise en place d'une économie qui ne pouvait être, à cette altitude, que l'élevage. Or les estives étaient déjà toutes distribuées entre les montagnards des deux versants. Le roi d'Aragon Alphonse $\mathrm{I}^{\text {er }}$ dut faire acte d'autorité pour installer les nouveaux venus. Au 
prix d'un savant dosage de concessions et de menaces, un équilibre fut atteint, et c'est finalement dans la zone située entre les cols du Somport et du Pourtalet que les troupeaux de Sainte-Christine trouvèrent leur place ${ }^{9}$. En 1187, une Carta de patz entre los homis d'Ossau y d'Aspe est signée en présence de Benedet, prieur de Sainte-Christine, preuve que les religieux du Somport sont devenus des partenaires à part entière ${ }^{10}$.

Dans la dimension nord-sud (fig. 2), le domaine de Sainte-Christine s'étend d'abord d'Etsaut à Canfranc, incluant des pâturages, le droit de pêche dans les gaves et la possession d'un moulin et d'un four à Canfranc.

Fig. 2. - Réseau canonial de Sainte-Christine du Somport au nord de Jaca.

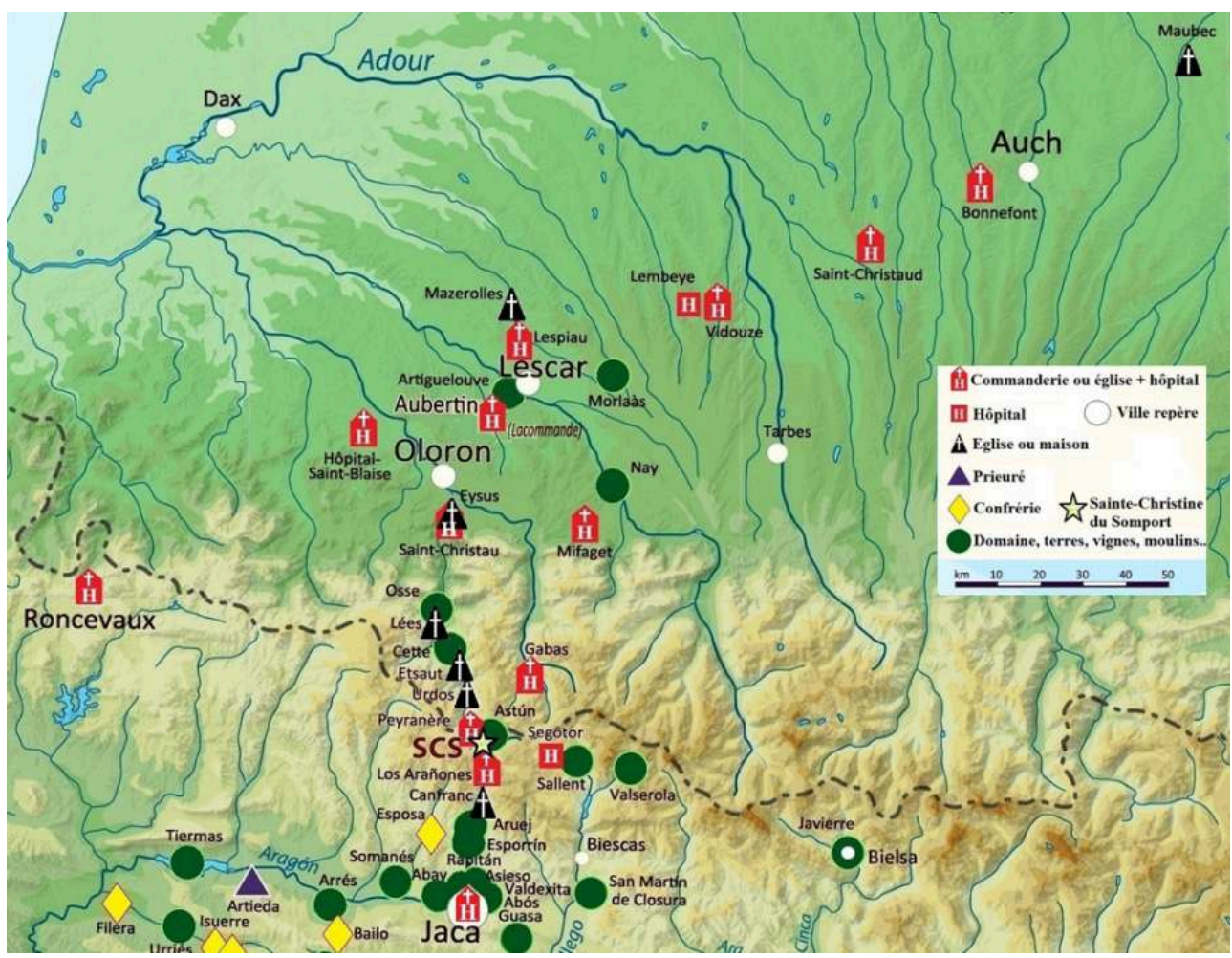

(c) Jean Claude Lassègues.

7 En même temps, de nouveaux hôpitaux sont fondés de part et d'autre du col du Somport (Peyranère, Los Arañones) et du col du Pourtalet (Gabas, Secotor près de Sallent). L'hôpital de Gabas devient même un relais important pour le passage de la vallée d'Ossau vers le val de Tena par le col du Pourtalet. Mais une étape encore plus décisive du développement du réseau est franchie lorsque le commandeur de Gabas achète des terres à Nay. Ainsi est facilité l'autre volet indispensable de l'élevage en montagne : l'accès à des pâturages dans la plaine pour la transhumance d'hiver.

8 Un autre point d'appui important est l'hôpital d'Aubertin. Dans un document très explicite de 1160, le seigneur d'Artiguelouve donne et vend des terres entre gave de Pau et Bayse à l'usage des troupeaux de Sainte-Christine et $d^{\prime}$ 'Aubertin ${ }^{11}$. Ces troupeaux sont composés de bœufs, vaches, brebis, chevaux, juments, porcs et chèvres. La recherche de pâturages d'hiver dans la plaine béarnaise va cependant être assez vite concurrencée, ou du moins complétée, par la disponibilité de terres reconquises dans la vallée de l'Èbre. 


\section{La diffusion vers le nord}

Il est maintenant bien établi que les hôpitaux de Gabas, de Mifaget, d'Aubertin et de l'Hôpital-Saint-Blaise furent fondés du vivant de Gaston IV (†1130) et sous l'épiscopat de l'évêque de Lescar, Guy de Lons ${ }^{12}$, et de celui d'oloron, Arnaud $\mathrm{I}^{\mathrm{er}} \mathrm{d}^{\text {'Araux }}{ }^{13}$. En revanche, les fondations des hôpitaux de Peyrenère ${ }^{14}$, de Saint-Christau (près d'oloron), de Saint-Christaud (près de Marciac), de Lespiau, de Vidouze, de Bonnefont ${ }^{15}$ et de Figarède, semblent un peu plus tardives, bien qu'antérieures à la bulle d'Innocent III de $1216^{16}$.

En ce début du XII ${ }^{\mathrm{e}}$ siècle, le contexte politique en Béarn est tout à fait particulier car la vicomté vient de renforcer son identité en fusionnant ce qui correspondait aux évêchés de Lescar et d'Oloron ; mais surtout, les conflits incessants avec les seigneuries voisines de Soule, de Dax et d'Armagnac sont mis en veilleuse pour cause de Reconquête en Aragon (fig. 3). Plus encore, une fraternité d'armes apparaît momentanément entre des seigneurs qui guerroyaient entre eux parfois depuis des générations. Ainsi, au siège de Saragosse en 1118, Gaston IV et son demi-frère Centulle de Bigorre sont accompagnés des vicomtes de Lavedan et de Gabarret, du comte de Comminges, de Gassion, vicomte de Soule, et d'autres encore.

Fig. 3. - Le Béarn et ses voisins vers 1130 avec indication, en rouge, des possessions de SainteChristine. Les traits pointillés verts correspondent aux chemins vicomtaux. L'abbaye de L'Escaladieu est indiquée pour commodité, bien que fondée après 1130 .

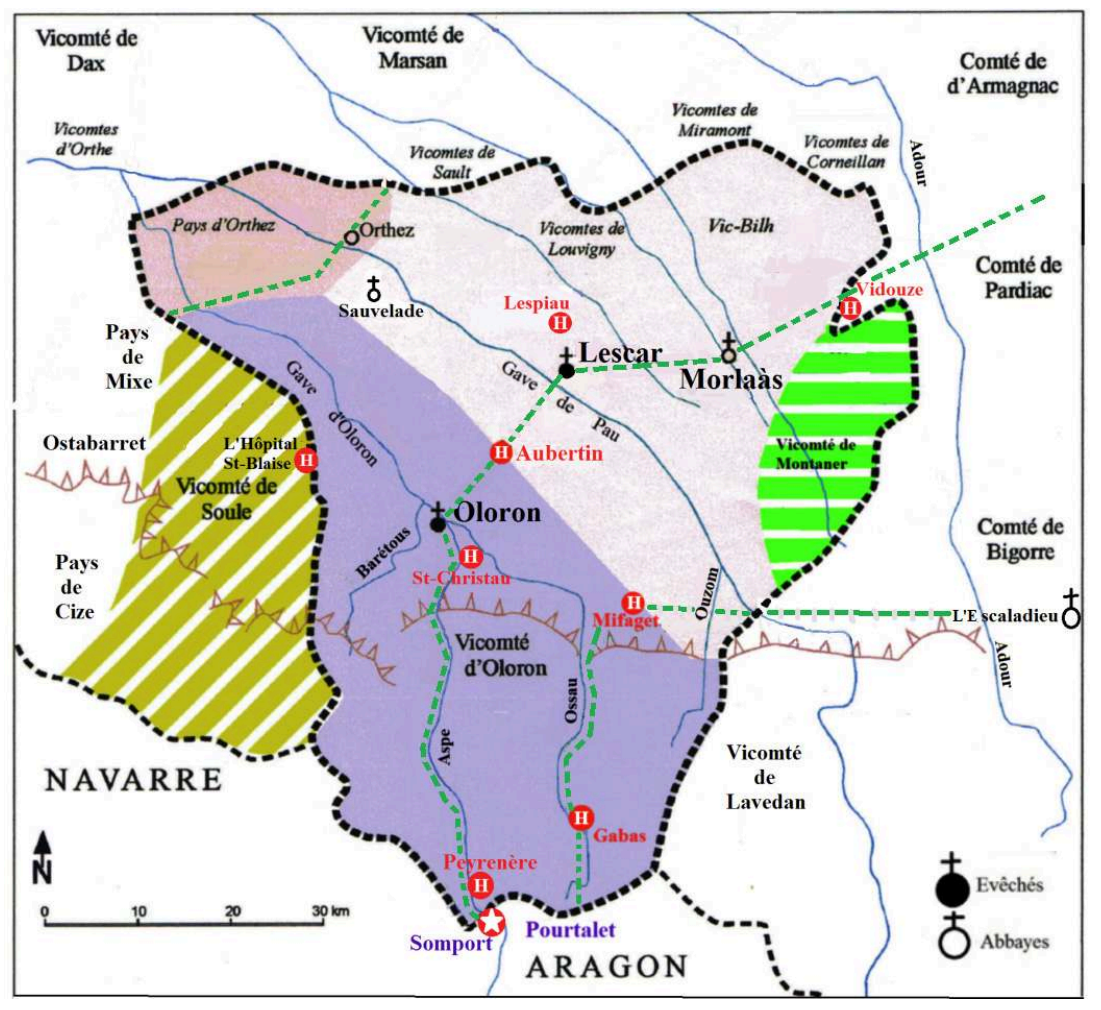

(c) Jean Claude Lassègues.

De son côté, le roi d'Aragon, Alphonse I ${ }^{\text {er }}$, ne se prive pas de récupérer et de valoriser les territoires reconquis après en avoir évacué les occupants musulmans. Il honore les nobles francos en les intégrant dans ses réseaux aristocratiques navarro-aragonais ${ }^{17}$. 
Gaston IV, devenu seigneur de Saragosse et de Uncastillo, est même chargé de redistribuer une partie des terres autour de Saragosse. Tout ceci entraîne un vaste mouvement de va-et-vient entre Béarn et Aragon pour des guerriers, colons, commerçants et religieux, qui participent à des titres divers à la grande aventure du moment. La fréquentation de la principale artère de communication, par le Somport, augmente ; elle justifie l'installation de nouveaux relais, d'autant que les pèlerins qui se rendent en Galice participent à ce flux qui est pour eux sécuritaire.

Pourtant, certaines contingences subsistent sur les terres béarnaises, comme l'illustre la fondation de l'hôpital d'Aubertin ${ }^{18}$. Après que Gaston IV, auréolé de sa gloire de croisé, a bâti un hôpital dans une hêtraie entre Lescar et Oloron, il se voit contester la propriété du sol par un petit seigneur local. Le conflit traîne en longueur, mais il lui faut finalement transiger devant la cour vicomtale de Pardies et dédommager le plaignant. Cet épisode serait anodin s'il n'illustrait une situation très contrastée de part et d'autre du Somport: en Aragon, de vastes territoires sont soudain disponibles; en Béarn, toutes les terres ont un propriétaire. Les autres hôpitaux, tels Gabas ou Mifaget, pour lesquels une charte de fondation nous est parvenue, nécessitèrent de la même façon l'assentiment des communautés environnantes et la caution de l'évêque d'Oloron.

Il s'avère que ces possessions sont situées dans des lieux isolés, avec une vocation de relais entre des établissements religieux bien implantés. Les évêchés d'Oloron et de Lescar ont déjà leurs propres hôpitaux, tout comme Morlaàs, siège de la vicomté, ou Auch, siège de l'archevêché. Aucune de ces villes ne concède d'établissement à SainteChristine. Le contraste est fort entre les deux versants. En effet, c'est à l'intérieur et autour des villes aragonaises que les possessions du prieuré de Sainte-Christine sont les plus nombreuses et les plus variées.

14 Par ailleurs, les possessions de Sainte-Christine en Gascogne paraissent se concentrer le long de la via Tolosana, et de ce que l'on appelle aujourd'hui la voie du Piémont, en accord avec l'idée souvent exprimée qu'elles ont été fondées pour accueillir les pèlerins se rendant à Saint-Jacques en Galice. Le chemin qui relie Toulouse à Auch, puis à Lescar et à la vallée d'Aspe est une voie de circulation fort ancienne, empruntée dès l'époque romaine, joignant l'archevêché d'Auch aux évêchés de Lescar et d'Oloron après la christianisation, principal chemin vicomtal du Béarn au début du XII ${ }^{e}$ siècle. Il est donc normal que les pèlerins en provenance de Toulouse et se rendant en Aragon aient emprunté ce trajet. Mais il est également logique qu'un chemin aussi fréquenté ait été équipé de relais à l'usage de tous les types de voyageurs, incluant les pauvres et les pèlerins, en vertu du principe chrétien fondamental de l'hospitalité. Le même genre de raisonnement peut être tenu pour la voie en provenance de Saint-Bertrand-deComminges, passant par Saint-Pé-de-Génerès, puis bifurquant éventuellement vers les relais de Mifaget et de Gabas pour accéder au val de Tena. Les pèlerins n'ont pas créé les chemins, ils ont suivi les chemins existants. Ils n'ont pas été accueillis en exclusivité dans les hôpitaux, mais en compagnie de toutes sortes de voyageurs et de nécessiteux, dans des proportions sans doute variables au cours des siècles et qui restent très mal connues.

15 Lorsqu'il procède à ses fondations hospitalières, le principal initiateur du réseau, Gaston IV le Croisé, a encore en tête les conflits incessants qui ont opposé la vicomté de Béarn à certains de ses voisins. Il n'est pas question d'installer des hôpitaux vers des territoires revendiqués par les vicomtés de Soule et de Dax, même si les conflits sont momentanément apaisés. L'Hôpital-Saint-Blaise marque la limite extrême entre Béarn 
et Soule. La région d'Orthez, objet de litiges avec la vicomté de Dax, n'est pas encore pleinement intégrée au Béarn. Elle dispose d'hôpitaux, mais reste vierge de fondations de Sainte-Christine. Une indication intéressante de la volonté de Gaston IV lui-même de ne pas étendre les possessions de Sainte-Christine dans la direction d'Orthez nous est donnée par la fondation de Sauvelade en $1127^{19}$. Cet établissement va devenir une abbaye cistercienne, qui constituera son propre réseau, indépendant de celui de SainteChristine. Avec le comté d'Armagnac, Gaston IV a aussi cherché une paix de compromis lors de l'entrevue de Diusse en 1104, mais les conflits sont prêts à ressurgir ${ }^{20}$.

Heureusement, la méfiance n'est pas de mise vers l'est, vis-à-vis du comté de Bigorre, tenu successivement par deux demi-frères de Gaston IV puis par Pierre de Marsan. Estce pour cela que la Bigorre fait l'objet d'une faveur particulière ? En 1142, le prieur de Sainte-Christine Aznar, avec l'entremise d'Arnaud de Lavedan, compagnon d'armes de Gaston IV, donne des terres au confluent du Luz et de l'Arros, afin que s'établisse l'abbaye de l'Escaladieu ${ }^{21}$. Cette institution, petite-fille de Cîteaux via Morimond, va elle-même constituer son propre réseau de part et d'autre des Pyrénées, en fondant les abbayes de Bouillas et Flaran, en Gascogne, et six autres filiales outre-Pyrénées ${ }^{22}$.

À la limite entre Béarn et Bigorre, on ne sait pratiquement rien sur l'hôpital de Lembeye, côté béarnais. Quant à celui de Vidouze, côté bigourdan, il ne passe sous le contrôle de Sainte-Christine qu'au xive siècle. Au-delà de cette limite, il y a eu manifestement une volonté d'expansion du réseau dans la direction d'Auch, facilitée par Arnaud de Monlezun ${ }^{23}$, troisième comte de Pardiac. Pourtant, l'église de SaintChristaud, située en Pardiac, semble avoir défrayé la chronique: les chanoines du chapitre de la cathédrale d'Auch en contestent la propriété aux clercs de SainteChristine. Ces derniers doivent se rendre à Toulouse, le 2 janvier 1124, pour jurer que cette église leur avait bien été donnée par Raymond, l'archevêque d'Auch ${ }^{24}$. Cet épisode pourrait être expliqué par le désir de l'archevêché d'Auch de donner un coup de frein à l'expansion du réseau. Malheureusement, le document concerné souffre de falsifications manifestes et il est difficile d'en tirer des conclusions fiables. Il n'en reste pas moins vrai que les contestations de propriété sont monnaie courante. Ainsi, l'église de Maubec, près de Faudoas, fait l'objet de démêlés entre la seigneurie locale et le prieur de Sainte-Christine en $1339^{25}$.

$\mathrm{Au}$ final, il apparaît que le réseau de Sainte-Christine s'est implanté essentiellement en Béarn et selon un effet de confinement exercé par des voisins belliqueux ou amicaux. Les tentatives d'expansion dans la direction d'Auch et de Toulouse, sur une voie très fréquentée, y compris par les pèlerins, semblent s'être heurtées à quelques réticences.

\section{Un élément du réseau inattendu : I'hôpital de Roncevaux}

De façon assez surprenante, les papes Eugène III en $1151^{26}$ et Innocent III en 1216 prennent sous leur protection «l'église de Roncevaux avec l'hôpital et toutes ses dépendances" au titre des possessions de Sainte-Christine du Somport. C'est à l'initiative d'Alphonse I ${ }^{\mathrm{er}}$, roi d'Aragon et de Pampelune, que le prieuré de SainteChristine s'est en quelque sorte approprié la gestion de Roncevaux par l'intermédiaire de deux évêques de Pampelune successifs, Guillaume de Lafitte et Sancho de Larrosa ${ }^{27}$. Cependant, à la mort d'Alphonse $\mathrm{I}^{\mathrm{er}}$ en 1134, la Navarre se sépare de l'Aragon et le monastère de Roncevaux acquiert une réelle indépendance, au point de développer son propre réseau sur les deux versants. Très logiquement, le roi de Navarre Garcia 
Ramirez et ses successeurs continuent sa promotion et celle du Camino Francès. La construction de l'église collégiale de Santa Maria la Real débute en 1209, et d'autres bâtiments viendront compléter un ensemble qui est d'une tout autre ampleur que le prieuré du Somport. Les deux établissements sont gérés par des chanoines réguliers de Saint-Augustin, ils ont le même souci de développer l'élevage ${ }^{28}$, mais ils se complètent plus qu'ils ne se concurrencent.

21 Nous retiendrons pour notre propos que le développement du réseau de Roncevaux est un facteur de plus qui contribua à limiter l'expansion vers l'ouest de celui de SainteChristine, tout en le rendant plus attractif pour les pèlerins.

\section{Un instantané au début du XIV ${ }^{\mathrm{e}}$ siècle, du temps de Marguerite Moncade}

\section{Grandeur et décadence du réseau de Sainte-Christine-du-Somport}

Le réseau a atteint sa plénitude au début du XIV siècle, et c'est plutôt sur le terrain juridique que se situent les batailles, côté aragonais. Il s'agit le plus souvent de contestations de propriété entre le prieuré de Sainte-Christine et des particuliers ou d'autres communautés monastiques. Divers procès se produisent dans les années 1300-1307, essentiellement autour des centres urbains de Jaca, Saragosse et Calatayud ${ }^{29}$. Ils sont accompagnés de chapitres de l'ordre assez nombreux dans cette période ${ }^{30}$. C'est finalement l'abondance des biens du prieuré en Aragon, Castille, Navarre, Catalogne et Gascogne qui génère des problèmes de gestion. Le paroxysme de cette évolution est atteint en 1374, lorsqu'un procès interne oppose le prieur et les chanoines à propos du partage des revenus. Les historiens aragonais considèrent que ce procès de 1374 marque un tournant dans l'histoire du prieuré3 ${ }^{31}$. Un déclin est amorcé, qui trouvera son point final lors des troubles de la Réforme, avec le départ des religieux du Somport vers Jaca en 1569 et le démantèlement du réseau.

Les possessions du versant nord, bien que beaucoup moins nombreuses et situées hors des centres urbains, connaissent une évolution semblable dans ses grandes lignes, avec en particulier une transformation de la plupart des hôpitaux en commanderies à la fin $\mathrm{du} \mathrm{XII}^{\mathrm{e}}$ siècle. Cependant, ces commanderies béarnaises acquièrent une identité qui les rend de moins en moins dépendantes de la maison mère du Somport, et de plus en plus en interaction avec le pouvoir vicomtal. Le col du Somport, qui était un trait d'union entre Béarn et Aragon, devient progressivement une frontière entre deux pays dont l'histoire diverge.

Nous allons essayer de saisir un moment de cette évolution, dans les années 1300, alors que d'autres ordres religieux, tels que les Hospitaliers de Saint-Jean de Jérusalem, ont fondé des établissements charitables en Gascogne, et que les possessions de SainteChristine ne sont qu'un des éléments du paysage hospitalier béarnais ${ }^{32}$.

\section{L'affirmation du pouvoir laïc à travers paréage et bastide}

Avec Gaston VII ( $† 1290)$, la vicomté est soumise à une refonte des systèmes administratif, juridique et financier et à une structuration de son territoire, incluant la fondation de bastides. Gaston VII avait fait d'Orthez sa capitale en 1242. Après son 
décès, sa fille Marguerite et son gendre Roger-Bernard III de Foix continuent à implanter des bastides et à se battre contre la maison d'Armagnac ${ }^{33}$.

Après avoir fondé Labastide-Villefranche en 1292, la vicomtesse de Béarn Marguerite Moncade s'intéresse à la commanderie d'Aubertin, important relais du prieuré de Sainte-Christine entre Lescar et Oloron. L'objectif n'est pas de transformer en bastide une communauté qui existe depuis presque deux siècles, mais d'établir un contrat de paréage avec le commandeur du lieu. L'affirmation d'une propriété indivise des deux partenaires et la définition de leurs droits respectifs en matière fiscale et juridique indiquent que la situation antérieure n'était pas satisfaisante pour le pouvoir laïc ${ }^{34}$. Le soin avec lequel est rédigé le contrat de paréage de 1297 laisse peu de doute sur la volonté de la vicomtesse de contrôler ce type d'établissement. Un peu plus tard, en 1302, Marguerite signe un autre contrat de paréage, avec cette fois le commandeur de Gabas, en vue de la fondation de la bastide de Nay ${ }^{35}$.

Dans les deux cas, il s'agit d'une intervention ferme et délibérée de la vicomté dans les affaires de Sainte-Christine, même si un chapitre de l'ordre se tient encore à Aubertin en 1307 , sous la direction du prieur, en présence d'un notaire d'oloron, du commandeur de Gabas et d'autres frères ${ }^{36}$. En 1311, cette même commanderie d'Aubertin est entre les mains de Jean de Béarn, demi-frère de Marguerite. L'année suivante, il devient prieur de Sainte-Christine ${ }^{37}$. La vicomtesse n'est certainement pas étrangère à cette promotion familiale, et on peut en conclure qu'elle porte un intérêt soutenu à la vie du réseau de Sainte-Christine en Béarn, tout en accentuant son contrôle sur certains de ses éléments.

\section{Un testament explicite sur le paysage hospitalier en Béarn}

En 1318, Marguerite Moncade établit un testament dans lequel elle lègue des sommes d'argent aux établissements religieux du Béarn ${ }^{38}$. On peut supposer que ces legs, effectués peu avant son décès, sont exempts de calculs politiques et nous donnent une liste assez exhaustive de ces établissements (fig. 4). De plus, les montants mis en jeu semblent refléter leur importance relative. Il est logique qu'apparaissent d'abord les quatre villes principales du Béarn, équipées d'un ou plusieurs hôpitaux, suivies des trois abbayes, puis des hôpitaux individuels qui parsèment les campagnes et enfin de toutes les églises et chapelles du Béarn et du Marsan. 
Fig. 4. - Institutions religieuses et hospitalières en Béarn citées dans le testament de Marguerite Moncade en 1318.

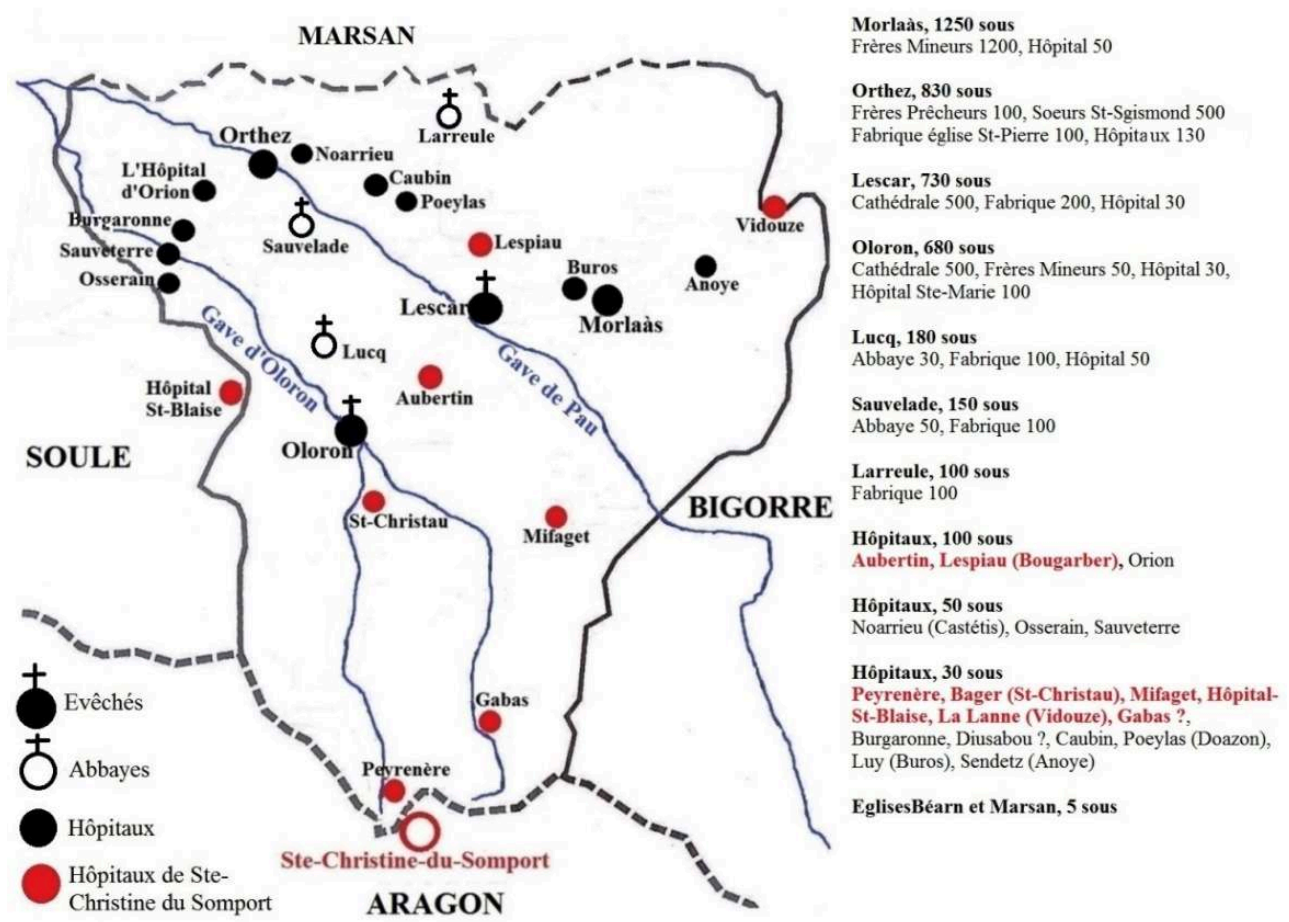

(c) Jean Claude Lassègues. appartiennent donc à des réseaux monastiques ou canoniaux distincts. Les legs de Marguerite se concentrent sur le Béarn. Il est normal que les établissements souletins et navarrais à l'ouest, bigourdans à l'est, ne soient pas dotés, car ils ne sont pas de son ressort. En revanche, le Marsan, dont Marguerite exprime la possession en léguant 5 sous à toutes les églises et chapelles du Béarn et du Marsan, n'apparaît que pour 10 sous attribués aux frères mineurs de Mont-de-Marsan.

31 Finalement, si l'on exclut la zone montagneuse, la couverture hospitalière du Béarn est assez homogène. Comme ailleurs en France, beaucoup de pèlerinages étaient actifs avant et pendant le développement de celui à Saint-Jacques. Les chanoines réguliers de Saint-Antoine, installés à Sauveterre et à Poeylas (Doazon) témoignent de la dévotion à ce saint, réputé guérir le mal des ardents, dû à l'ergot du seigle. La lèpre fut un autre fléau de cette époque, entraînant la création de léproseries près de Morlaàs, Oloron, Lescar et $\mathrm{Orthez}^{40}$. Il n'en reste pas moins que le pèlerinage à Saint-Jacques en Galice 
joua un rôle particulier en Béarn, même s'il reste à ce jour extrêmement difficile à quantifier.

\section{L'évolution du pèlerinage à Saint-Jacques en Galice}

32 Au début du XIV ${ }^{\mathrm{e}}$ siècle, le col d'Ibañeta a supplanté tous les autres cols pyrénéens, y compris celui du Somport, pour le passage des pèlerins vers la Galice. Le monastère de Roncevaux est devenu un solide établissement, qui a établi des hôpitaux dans le piémont souletin et navarrais. Ils sont hors de la gouvernance de Marguerite, mais beaucoup de chemins traversent le Béarn et le Marsan. Il est très probable que Marguerite est favorable à la pérégrination, en vertu de sa propre religiosité, qui s'exprime largement dans son testament. D'autres testaments de la même époque ont la même tonalité. Le salut de l'âme passe par des donations pieuses, mais il est aussi favorisé par des pèlerinages à Jérusalem, à Rome, à Compostelle ou ailleurs. Comme le testament est établi en fin de vie, c'est souvent une tierce personne qui est désignée pour l'accomplir en lieu et place de l'intéressé. Dans son testament, Marguerite ne parle pas d'envoyer qui que ce soit en pèlerinage, mais elle exprime clairement son intérêt pour cette dévotion en laissant son lit complet à l'hôpital de Roncevaux et 1000 sous pour la réparation des chemins de Saint-Jacques. Elle ne précise pas de quels chemins il s'agit, mais il y a fort à parier que ce sont les chemins vers Roncevaux, passant par exemple par les nombreux hôpitaux autour d'Orthez. En 1310, sa sœur Constance laisse 300 sous à répartir entre les hôpitaux placés sur le grand chemin qui va de Condom et Bazas à Roncevaux ${ }^{41}$. Amanieu VII d'Albret (†1326) lègue diverses sommes aux hôpitaux qui se trouvent sur le chemin des pèlerins, depuis Bordeaux jusqu'à Pampelune ${ }^{42}$.

À cette époque, les testaments des puissants contiennent donc des informations précieuses sur le pèlerinage et confirment la préférence pour Roncevaux, ce qui compense le mutisme de la collection diplomatique de l'hôpital de Sainte-Christine du Somport, qui comporte pourtant 345 chartes, mais aucune mention du pèlerinage en Galice ${ }^{43}$.

Marguerite Moncade a une quarantaine d'années quand son père, Gaston VII, sert d'intermédiaire entre le roi d'Angleterre Édouard I Ir et le roi d'Aragon Alphonse III lors de pourparlers interminables portant sur la libération du prince de Salerne, Charles II d'Anjou, roi de Naples, prisonnier du roi d'Aragon ${ }^{44}$. Ces entrevues s'étalent sur les années 1287 à 1289 et ont lieu entre Jaca et Oloron. Ce n'est rien moins qu'une paix européenne qui est finalement conclue en mars 1289 à Peyrenère, modeste possession du réseau de Sainte-Christine. Les deux cours royales et leurs suites se séparent ensuite, après avoir assisté à une messe en l'église de Sainte-Christine située sur l'autre versant, à moins de cinq kilomètres de Peyrenère.

Nul doute que cet étonnant épisode diplomatique autour du Somport marqua les esprits, aussi bien celui de Marguerite, devenue vicomtesse de Béarn en 1290, que celui du prieur de Sainte-Christine. Il concrétisait en effet la transition entre une époque où les passages par le Somport, en plus des échanges commerciaux traditionnels, étaient surtout liés aux activités de la Reconquête, et une nouvelle ère où l'Aragon stabilisé, devenu une grande puissance tournée vers la Méditerranée, voyait le royaume 
d'Angleterre avancer ses pions en Gascogne. La petite vicomté de Béarn, prise en étau entre de puissants voisins, allait devoir préserver une relative indépendance au prix d'une subtile politique des vicomtes successifs.

Quant aux possessions du réseau de Sainte-Christine sur le versant nord, elles ne jouent plus leur rôle de base arrière d'une Reconquête dont les échos s'estompent, mais elles sont tout simplement intégrées dans l'équipement hospitalier de la vicomté, souvent au titre de commanderies. Le testament de Marguerite et ses décisions vis-à-vis du réseau montrent que le pouvoir laïc affirme sa prééminence. L'organisation hospitalière est devenue un outil de gouvernement indispensable pour contrôler la "pieuse errance ", mais aussi pour faire face aux épisodes épidémiques d'ergotisme, de lèpre et de peste.

Comme nous l'avons déjà signalé, ce sont sans doute les échanges commerciaux qui auront été l'activité la plus constante entre Jaca et Oloron au cours des âges. Les multiples dispositions douanières prises dans les deux vallées en témoignent ${ }^{45}$. Elles étaient souvent assorties de l'obligation pour les habitants d'assurer l'entretien de la route en hiver.

Le percement de tunnels sous le Somport, avec aménagement des voies d'accès, est une tentative récente, toujours en gestation, de promouvoir cet axe européen en le modernisant. En attendant, les tunnels ont permis de creuser des salles annexes pour installer un laboratoire dédié à la recherche expérimentale en physique fondamentale, en physique des particules et en astrophysique. Ce laboratoire souterrain, géré par l'université de Saragosse, accueille des chercheurs de toute l'Europe pour un pèlerinage bien particulier vers la matière noire et les neutrinos, quelques centaines de mètres de roche en-dessous des ruines de l'hôpital-prieuré de Sainte-Christine.

\section{BIBLIOGRAPHIE}

BIDOT-GERMA Dominique, « Des Moncade aux Foix-Béarn : autour de Marguerite Moncade (vers 1245-1318) et de Jeanne d'Artois (1283-vers 1351) ", dans Valois Jean-Paul (dir.), Nouveaux regards sur le patrimoine médiéval, Nay, Amis de Nay et de la Batbielle, 2014, p. 41-58 (accessible en ligne).

CAVAILLÈs Henri, La transhumance pyrénéenne et la circulation des troupeaux dans les plaines de Gascogne, Paris, A. Colin, 1931.

DESPLAT Christian, PEYRÉ Pierre, POUEYs Fabienne, Histoire des hôpitaux dans les Pyrénées-Atlantiques, Pau, Société française d'histoire des hôpitaux, ICN, 2000.

DURÁN GUDIOL Antonio, El hospital de Somport entre Aragón y Bearn (siglos XII y XIII), Saragosse, Guara (Colección básica aragonesa), 1986.

FAUDOAS Jean-Louis de, Histoire généalogique de la maison de Faudoas en Guyenne, Paris, Nicolas Mazuel, 1688.

GROSCLAUDE Michel, Seuvalada deu Larvath : histoire de l'abbaye de Sauvelade, rééd. Crestian Lamaison, Lo Trebuc, Orthez, 2016. 
HERBERS Klaus et SANTOS NOIA Manuel (éd.), Liber Sancti Jacobi. Codex Calixtinus, Xunta de Galicia, 1998.

KEHR Paul, Papsturkunden in Spanien, vol. II : Navarra und Aragon, Berlin, Weidmannsche Buchhandlung, 1928.

KIVIHARJU Jukka, Colección diplomática del hospital de Santa Cristina de Somport, t. I : Años 1078-1304, Helsinki, Academia Scientiarum Fennica, 2004.

LABARÈRE Lucien, «L'entrevue de Peyranère entre Edouard I ${ }^{\mathrm{er}}$, roi d'Angleterre et Alphonse III, roi d'Aragon : 2 mars-9 mars 1289 », Annales de Notre-Dame de Sarrance, 1978.

LABORDE-BALEN Louis, Somport, Biarritz, J\&D, 1996.

LACARRA DE MIGUel José María, « Un arrancel de aduanas del siglo XI », dans Actas del Primer Congreso Internacional de Estudios Pirenáicos. San Sebastián, 1950, vol. 6, (sección V : Historia, arte y derecho), 1952, p. 21-36.

LALIENA CORBERA Carlos, « Une époque de héros ? La conquête de la vallée de l'Èbre et la mutation féodale (Aragon et Béarn, 1050-1130) » dans Cursente Benoît (dir.), Gaston IV le Croisé : le Béarn et son héros épique, actes des conférences de Lacommande de 2014 et 2015, Pau, Société des sciences, lettres et arts de Pau et du Béarn, 2016, p. 91-106.

LASSÈGUES Jean Claude, « Une bastide à Lacommande en 1297 ? » Revue de Pau et du Béarn, 38, 2011, p. 91-114.

LASSÈGUES Jean Claude, Lacommande, de l'hôpital à la commanderie et au village, Pau, Centre généalogique des Pyrénées-Atlantiques, 2012.

LASSÈGUES Jean Claude, « Alphonse I ${ }^{\text {er }}$ le Batailleur, Gaston IV le Croisé et l'Église », dans Cursente Benoît (dir.), Gaston IV le Croisé : le Béarn et son héros épique, actes des conférences de Lacommande de 2014 et 2015, Pau, Société des sciences, lettres et arts de Pau et du Béarn, 2016, p. 107-131.

LASSÈGUES Jean Claude, « Autour de la fondation de l'hôpital-commanderie d'Aubertin », dans Cursente Benoît (dir.), Gaston IV le Croisé : le Béarn et son héros épique, actes des conférences de Lacommande de 2014 et 2015, Pau, Société des sciences, lettres et arts de Pau et du Béarn, 2016, p. 211-255.

LE NAIL Jean-François, « L'installation de l'Escaladieu dans la haute vallée de l'Arros », dans Le Nail Jean-François (dir.), La vallée de l'Arros depuis la préhistoire, Association Guillaume Mauran / Archives départementales des Hautes-Pyrénées, 1995, p. 19-89.

LORBER Paul, «Traité de paix entre les communautés d'Ibos et de Pontacq signé en l'an 1311», dans VI congrès de l'Union historique et archéologique du Sud-Ouest, Tarbes, 1914, p. 193-194.

MANSILLA REOYO Demetrio, La documentación pontificia hasta Inocencio III (965-1216), Rome, Instituto Español de Estudios Eclesiásticos, 1955.

MARCA Pierre de, Histoire de Béarn, rééd. de l'ouvrage de 1640, Monein, Princi Néguer, 2000.

MASTRON J. de, « La commanderie de Bonnefont près Barran », Bulletin de la Société archéologique du Gers, 1904 (A5), p. 209 et 275.

MUÑOZ SESMA Angel José, La vía del Somport en el comercio medieval de Aragón. Los registros de las aduanas de Jaca y Canfranc de mediados del siglo XV, Prensas de la Universidad de Zaragoza, 2006.

ONA GONZALEZ José Luis, « Fulgor y ocaso del Hospital de Santa Cristina », Trébede, Mensual Aragonés de Anàlysis, Opinión y Cultura, nº 24, 1999, p. 35-50. 
SARRABÈrE Albert, « Sur les chemins de Compostelle : Sainte Christine-du-Somport. Son organisation et ses hôpitaux du versant français ", dans L'Identité gasconne, actes du XI Congrès national de généalogie, Bordeaux, Fédération française de généalogie, 1991, p. 67-86.

TUCOO-CHALA Pierre, Cartulaires de la vallée d'Ossau, Saragosse, Escuela de Estudios Medievales et Instituto de Estudios Pirenaicos, 1970.

TUCOO-CHALA Pierre, Quand l'Islam était aux portes des Pyrénées, Biarritz, J\&D, 2000.

VÁSQUEZ DE PARGA Luis, LACARRA José María, URÍA RíU Juan, Las peregrinaciones a Santiago de Compostela, Madrid, Consejo superior de investigaciones scientíficas, t. I, 1948 ; t. II et III, 1949.

\section{NOTES}

\section{L. Laborde-Balen, Somport.}

2. Le tunnel ferroviaire, inauguré en 1928, fut abandonné en 1970 suite à un accident côté français. Il sert actuellement de tunnel de secours pour le tunnel routier inauguré en 2003. Le projet d'une rénovation de la jonction ferroviaire n'est cependant pas abandonné.

3. P. Tucoo-Chala, Quand l'Islam était aux portes des Pyrénées.

4. L. Vásquez de Parga et al., Las peregrinaciones a Santiago de Compostela.

5. A. Durán Gudiol, El hospital de Somport entre Aragón y Bearn (siglos XII y XIII).

6. J. Kiviharju, Colección Diplomática del Hospital de Santa Cristina de Somport. I : Años 1078-1304.

7. K. Herbers et M. Santos Noia (éd.), Liber Sancti Jacobi. Codex Calixtinus, lib. V, cap. III, p. 237.

8. J. C. Lassègues, «Autour de la fondation de l'hôpital-commanderie d'Aubertin ». Voir la carte des possessions du prieuré de Sainte-Christine du Somport p. 220.

9. L'expansion vers l'ouest engendra de nombreux conflits avec les habitants des vallées de Hecho, d'Anso et de Roncal.

10. P. Tucoo Chala, Cartulaires de la vallée d'Ossau.

11. J. Kiviharju, Colección Diplomática del Hospital de Santa Cristina de Somport. I : Años 1078-1304, nº 87.

12. J. C. Lassègues, «Alphonse I ${ }^{\mathrm{er}}$ le Batailleur, Gaston IV le Croisé et l'Église ».

13. P. de Marca, Histoire de Béarn.

14. Aussi orthographié Peyranère.

15. J. de Mastron, « La commanderie de Bonnefont près Barran ».

16. A. Sarrabère, "Sur les chemins de Compostelle: Sainte-Christine-du-Somport »; D. Mansilla Reoyo, La documentación pontificia hasta Inocencio III (965-1216). La bulle d'Innocent III de 1216 est connue grâce à une copie du $\mathrm{XVI}^{\mathrm{e}}$ siècle conservée aux archives du Vatican.

17. C. Laliena Corbera, Une époque de héros? La conquête de la vallée de l'Èbre et la mutation féodale.

18. J. C. Lassègues, Lacommande, de l'hôpital à la commanderie et au village, p. 23-28.

19. M. Grosclaude, Seuvalada deu Larvath. Histoire de l'abbaye de Sauvelade. 
20. Ils ressurgiront avec force au $\mathrm{XIV}^{\mathrm{e}}$ siècle entre les maisons de Foix-Béarn et d'Armagnac, en particulier au temps de Marguerite Moncade.

21. J.-F. Le Nail, «L'installation de l'Escaladieu dans la haute vallée de l'Arros ».

22. Il s'agit des monastères de Fitero, Monsalud, Sacramenia, Veruela, La Oliva et Bujedo.

23. P. Kehr, Papsturkunden in Spanien, vol. II: Navarra und Aragon, p. 314-315. Cet auteur rapporte que le pape Pascal II confirme les dons reçus par Sainte-Christine du Somport, en particulier ceux venant des princes béarnais, dans une bulle du 16 juillet 1116. Dans une bulle du 16 févier 1125, le pape Honorius II confirmera les dons reçus de Gaston de Béarn et d'Arnaud de Monlezun.

24. J. Kiviharju, Colección Diplomática del Hospital de Santa Cristina de Somport. I : Años 1078-1304, $\mathrm{n}^{\circ} 24$.

25. J.-L. de Faudoas, Histoire généalogique de la maison de Faudoas en Guyenne, p. 28-29.

26. J. Kiviharju, Colección Diplomática del Hospital de Santa Cristina de Somport. I : Años 1078-1304, $\mathrm{n}^{\circ} 73$.

27. Un hospice était précédemment tenu à Roncevaux par des moines de Sainte-Foy de Conques.

28. H. Cavaillès, La transhumance pyrénéenne et la circulation des troupeaux dans les plaines de Gascogne, p. 57. Au milieu du XIII ${ }^{\mathrm{e}}$ siècle, plusieurs rois d'Angleterre successifs concèdent aux troupeaux du monastère de Roncevaux des droits de franche pâture sur leurs terres de Gascogne.

29. A. Durán Gudiol, El hospital de Somport entre Aragón y Bearn (siglos XII y XIII), p. $115-120$.

30. Des chapitres généraux furent tenus, le 27 janvier 1300 à Sainte-Christine-duSomport, le 11 juillet 1301 et le 21 août 1303 à Jaca, dans la maison de Sainte-Christine, et enfin le 22 mars 1307 à Aubertin.

31. J. L. Ona González, Fulgor y ocaso del Hospital de Santa Cristina.

32. C. Desplat et al., Histoire des hôpitaux dans les Pyrénées-Atlantiques.

33. D. Bidot-Germa, « Des Moncade aux Foix-Béarn ».

34. J. C. Lassègues, « Une bastide à Lacommande en 1297 ?».

35. Arch. dép. Pyrénées-Atlantiques, E289, fol. 9.

36. A. Durán Gudiol, El hospital de Somport entre Aragón y Bearn (siglos XII y XIII), p. 120.

37. P. Lorber, «Traité de paix entre les communautés d'Ibos et de Pontacq signé en l'an 1311 », p. 193-194. Il est rapporté que le 10 janvier 1311, à Orthez, Marguerite délègue ses pouvoirs à Jean de Béarn, chanoine d'oloron et de Bayonne, commandeur d'Aubertin. En 1312, son autre demi-sœur Constance lui lègue 300 livres de Bordeaux, six écuelles, six tasses et six cuillers d'argent. Jean de Béarn est alors dit prieur de Sainte-Christine.

38. Arch. dép. Pyrénées-Atlantiques, E296.

39. Certains hôpitaux, comme celui de Diusabou, sont même difficiles à localiser, tandis que celui de Gabas, qui figurait dans le testament de Gaston VII, semble avoir été oublié dans celui de sa fille Marguerite.

40. C. Desplat et al., Histoire des hôpitaux dans les Pyrénées-Atlantiques. 
41. Arch. dép. Pyrénées-Atlantiques, E294.

42. Ibid., E27.

43. J. Kiviharju, Colección Diplomática del Hospital de Santa Cristina de Somport. I : Años 1078-1304.

44. L. Labarère, "L'entrevue de Peyranère entre Edouard I ${ }^{\mathrm{er}}$, roi d'Angleterre et Alphonse III, roi d'Aragon ».

45. J. M. Lacarra de Miguel, « Un arrancel de aduanas del siglo XI »; S. Muñoz Sesma et J. Angel, La vía del Somport en el comercio medieval de Aragón.

\section{RÉSUMÉS}

Autour des années 1100, des relations particulièrement étroites se développent entre la vicomté de Béarn et le royaume d'Aragon. Elles accentuent l'importance de l'axe de communication Oloron-Jaca par le col du Somport et transforment l'hôpital de Sainte-Christine en maison mère d'un réseau canonial transpyrénéen. Les possessions de ce réseau se répartissent du Gers au sud de l'Aragon, selon une dynamique de polarisation qui doit beaucoup, sur le versant ibérique, aux avancées de la Reconquête. Sur le versant nord, les mécanismes de son expansion sont plus complexes. Les nouvelles fondations se font hors des centres urbains et selon un confinement qui résulte du contexte religieux et politique dans lequel se situe la vicomté de Béarn. La place du réseau de Sainte-Christine dans le paysage hospitalier béarnais au début du XIV ${ }^{\mathrm{e}}$ siècle permet de saisir un instant de son évolution "à mi-parcours ", avant son démantèlement sous Jeanne d'Albret lors de la Réforme.

\section{AUTEUR}

\section{JEAN CLAUDE LASSÈGUES}

Retraité CNRS 


\title{
Émigrer après la mort : le transfert du corps du roi Sanche VII de Navarre à Roncevaux et l'hypothèse Fontevraud
}

\author{
Fermín Miranda García
}

1 Au fait évident que les morts sont enterrés par d'autres personnes qu'eux-mêmes, il faut aussi ajouter qu'il n'est pas toujours possible d'établir, même dans le cas des monarques et leurs familles, dans quelle mesure le lieu du dernier repos correspond à la volonté du défunt, à celle de ceux qui entreprennent l'organisation des funérailles, ou à des circonstances particulières entourant le décès ${ }^{1}$. C'est encore plus évident dans les cas où, comme dans le royaume de Navarre, on ne dispose pas d'un panthéon royal établi, contrairement à ce qu'on peut observer, bien qu'avec de nombreuses exceptions, dans d'autres espaces politiques. Il faut attendre le milieu du XIV ${ }^{e}$ siècle, et seulement pendant un siècle et demi, pour que la cathédrale de Pampelune acquière le statut de siège privilégié, sinon officiel, des dépouilles du souverain et de ses proches.

2 Nous nous intéressons ici au cas de Sanche VII († 1234), enterré à Roncevaux, un espace unique de pèlerinage et de montagne, éloigné de tous les centres urbains les plus importants du royaume, contrairement aux pratiques habituelles d'enterrement royal de l'Occident chrétien de son temps; surtout si on prend en compte sa résidence prolongée jusqu'à sa mort, presque cloîtré aux dires de l'historiographie, à Tudela, la ville de Navarre la plus distante du lieu choisi comme lieu d'inhumation².

\section{Les antécédents immédiats}

3 La mort d'Alphonse ${ }^{\text {er }}$ en 1134 et la division immédiate de l'espace politique en deux royaumes, Navarre et Aragon, entraînèrent de très importants problèmes de reconnaissance de la légitimité des nouveaux souverains navarrais, en particulier par le pape, mais aussi par les monarques voisins. Il faut se souvenir que le souverain pontife 
refusait de reconnaître la souveraineté navarraise car le testament d'Alphonse $\mathrm{I}^{\mathrm{er}}$, qui avait décidé de donner le royaume de Navarre-Aragon aux ordres du Temple et de l'Hôpital, n'avait pas été respecté.

Dans ce contexte incertain qui dura un demi-siècle, jusqu'à la reconnaissance par le pape en 1197, la nouvelle dynastie au cours de ses premiers stades de fonctionnement avait besoin d'un cadre pouvant lui offrir solennité et prestige: Pampelune, la ville épiscopale qui avait donné son nom au royaume depuis deux cents ans, dont la cathédrale était le lieu de la proclamation royale, et dont le prélat apportait son soutien précieux.

5 C'est pour ceci, sans doute, que Garcia Ramirez ( $\dagger$ 1149) et Sanche VI ( $\dagger$ 1194) ont choisi la cathédrale de la capitale comme lieu d'inhumation ${ }^{3}$. L'enterrement de Sanche VII à Roncevaux est une exception qui doit être analysée de façon spécifique. Son neveu et successeur Thibaut $\mathrm{I}^{\mathrm{er}}(\dagger 1253)$ sera enterré au siège épiscopal, de même qu'Henri I ${ }^{\mathrm{er}}$ († 1274), le dernier roi de la dynastie de Champagne. Le mariage de sa fille et héritière, Jeanne I ${ }^{\text {re }}$, avec le futur roi de France Philippe IV, marquera un changement des coutumes funéraires du royaume.

\section{L'enterrement de Sanche VII à Roncevaux}

6 La position de Sanche devant le pape fut consolidée par la reconnaissance du titre royal au début de 1197, par la participation à la campagne de Las Navas contre les Almohades de 1212 et les attaques sur la frontière d'al-Andalus des années suivantes ${ }^{4}$. Ainsi, le panthéon de Pampelune ne lui était plus aussi nécessaire qu'à ses prédécesseurs. De plus, le monarque a préféré résider de façon quasi permanente à Tudela pendant les dernières années de sa vie. C'est là qu'il a été enterré provisoirement, dans la chapelle du château, à sa mort en 1234 .

7 Un long procès judiciaire s'ensuivit à propos du lieu de sa sépulture définitive, tout d'abord entre la collégiale de Tudela et le monastère de La Oliva, chargé de la chapelle du château, puis entre la cathédrale de Pampelune et la collégiale de Roncevaux, où son successeur Thibaut $\mathrm{I}^{\mathrm{er}}$ avait ordonné de transférer le corps en 1237. Mais rien ne prouvait que Sanche VII ait exprimé le désir de reposer auprès de ses ancêtres, et la collégiale de Roncevaux obtint finalement une décision favorable du pape Innocent IV en 1244. Dans la sentence, le souverain pontife déclarait que le monarque n'avait pas exprimé la volonté d'être enterré "à La Oliva ou ailleurs "; d'après cette dernière phrase et la propre interprétation de Thibaut, on peut déduire que Roncevaux aurait été le choix de Sanche au moins pendant quelques années 5 .

On peut sans doute comprendre la décision de Thibaud de favoriser Roncevaux de plusieurs façons. Il désirait peut-être répondre aux souhaits d'un chapitre dont il était assez proche; ou aussi, sans doute, mettre fin à un problème qu'il fallait certainement résoudre le plus rapidement possible; peut-être encore voulait-il respecter les éventuelles volontés de Sanche VII en faveur d'une inhumation à Roncevaux, qui avait été le principal bénéficiaire de sa générosité (très rarement accordée) et aussi de sa protection spéciale. Sanche VII avait financé la construction de l'église gothique vers 1205 et était intervenu en faveur du chapitre de Roncevaux à plusieurs reprises. Selon cette dernière option, la plus probable, il est possible que le roi ait voulu établir une distinction, comme ce fut le cas dans la plus grande partie de l'Occident, entre le lieu de 
la proclamation royale et celui de l'inhumation du souverain. Dans ce cas, pourquoi Roncevaux, et non un autre lieu mieux situé dans le cœur idéologique du royaume?

\section{Le panthéon de la dynastie Plantagenêt à Fontevraud}

9 Le premier tiers du XIII ${ }^{\mathrm{e}}$ siècle a vu un intense processus de développement des panthéons royaux, qu'ils aient ou non conservé longtemps ce rôle. L'exemple le plus connu est sans doute l'abbaye bénédictine de Saint-Denis, avec une longue et irrégulière histoire comme panthéon royal jusqu'à la période qui nous occupe, où reposaient les corps des monarques français les plus proches de Sanche VII, Philippe II Auguste ( $† 1223)$ et Louis VIII ( $† 1226)$. Au sud des Pyrénées, le monastère cistercien de Las Huelgas avait reçu les restes d'Alphonse VIII de Castille ( $\uparrow 1215)$, de son épouse Aliénor $(\dagger 1214)$ et de son fils et successeur Henri I ${ }^{\text {er }}(\dagger 1217)$. La cathédrale de SaintJacques de Compostelle a été le choix symbolique de Ferdinand II de Léon ( $† 1188)$ et d'Alphonse IX ( $†$ 1230), comme le monastère des chanoines de Saint-Augustin de SainteCroix de Coimbra pour Alphonse $\mathrm{I}^{\text {er }}(\dagger 1185)$ et Sanche $\mathrm{I}^{\text {er }}$ de Portugal $(\dagger 1211)$, ou la cathédrale de Worcester pour Jean $\mathrm{I}^{\text {er }}$ d'Angleterre $(\dagger 1216)^{6}$. Les uns et les autres étaient situés à l'intérieur de centres urbains au poids politique et/ou religieux considérable (Santiago, Coimbra) ou à proximité (Saint-Denis et Las Huelgas, proches de Paris et Burgos respectivement). Ces circonstances semblent se rapprocher du choix de Pampelune comme lieu d'inhumation de Garcia Ramirez et de Sanche VI de Navarre.

Bien sûr, les exceptions ne manquent pas : Alphonse II d'Aragon, premier héritier du domaine commun d'Aragon et de Catalogne, avait choisi le monastère cistercien de Poblet, fondé par son père à la frontière des nouveaux territoires conquis aux Almoravides et loin des lieux traditionnels d'inhumation de la monarchie aragonaise comme de la maison comtale de Barcelone ${ }^{7}$. Les excommuniés Alphonse II du Portugal (†1223) et Pierre II d'Aragon ( $† 1213)$ ont été enterrés respectivement dans le monastère cistercien d'Alcobaça et à l'hôpital de Sigena, mais ces exemples spécifiques ne s'expliquent pas par les décisions prises par leurs prédécesseurs immédiats.

11 L'autre grande exception, qui intéresse plus particulièrement cette étude, est constituée par le panthéon des Plantagenêt, l'abbaye de Fontevraud ${ }^{8}$. Gérée par une norme inspirée de la règle bénédictine, mais étrangère aux deux grands ordres des clunisiens et cisterciens, l'abbaye de Fontevraud est devenue l'espace funèbre de la monarchie anglo-normande dès la mort de Henri II (†1189). Après lui, ses enfants Richard $\mathrm{I}^{\text {er }}(\dagger 1199)$ et Jeanne, reine veuve de Sicile et comtesse de Toulouse ( $\left.\dagger 1199\right)$; Aliénor d'Aquitaine, épouse et mère des précédents ( $† 1204)$, y furent enterrés. Plus tard, à une période ultérieure à celle de notre étude, les dépouilles de Raymond VII de Toulouse et d'Isabelle d'Angoulême, veuve de Jean $\mathrm{I}^{\text {er }} \mathrm{d}^{\prime}$ Angleterre, y seront également déposées. Contrairement à ses proches, ce dernier ( $† 1216)$, suite à la perte des territoires tombés aux mains de Philippe Auguste (Normandie, Anjou et Poitou), qui comprenaient Fontevraud, a dû chercher un autre lieu et a choisi Worcester ${ }^{9}$; dès la génération suivante, la monarchie anglaise a opté pour Westminster, un modèle plus proche du modèle capétien de Saint-Denis.

12 Le site de Fontevraud présente une valeur géographique et symbolique unique. L'abbaye, favorisée depuis sa fondation au début du XII siècle par la noblesse régionale, y compris les Plantagenêt, a également tiré des bénéfices du mariage d'Henri II avec Aliénor en 1153, et du lien du duché d'Aquitaine avec l'univers féodo-vassalique du 
conglomérat dynastique des Angevins qui en a résulté ${ }^{10}$. Fontevraud est situé près de Poitiers, mais contrairement à Saint-Denis ou à Las Huelgas, à une certaine distance (cinquante à soixante kilomètres à vol d'oiseau) de la ville et des autres grands centres de la région, Angers et Tours. La région de Poitiers est un carrefour qui met en communication les grands axes de l'empire continental des Plantagenêt : du nord-ouest au sud-est, les terres de Bretagne avec le Limousin (axe Rennes-Angers-PoitiersLimoges) ; du nord-est en direction du sud-est, la Normandie (et plus loin l'Angleterre) avec l'Aquitaine (axe Rouen-Le Mans-Tours-Poitiers-Bordeaux). Mais le monastère de Fontevraud s'appuyait aussi sur les marges de la Loire, la grande voie fluviale qui traversait le territoire d'est en ouest. Les trois axes forment ainsi un triangle, à l'intérieur duquel se trouve Fontevraud. Sa situation géographique matérialise le lien symbolique entre l'«ancien» domaine des Plantagenêt hérité par Henri II et le «nouveau » apporté par Aliénor d'Aquitaine, situés respectivement au nord et au sud de la rivière (fig. 1).

Fig. 1. - Le domaine des Plantagenêt vers 1200.

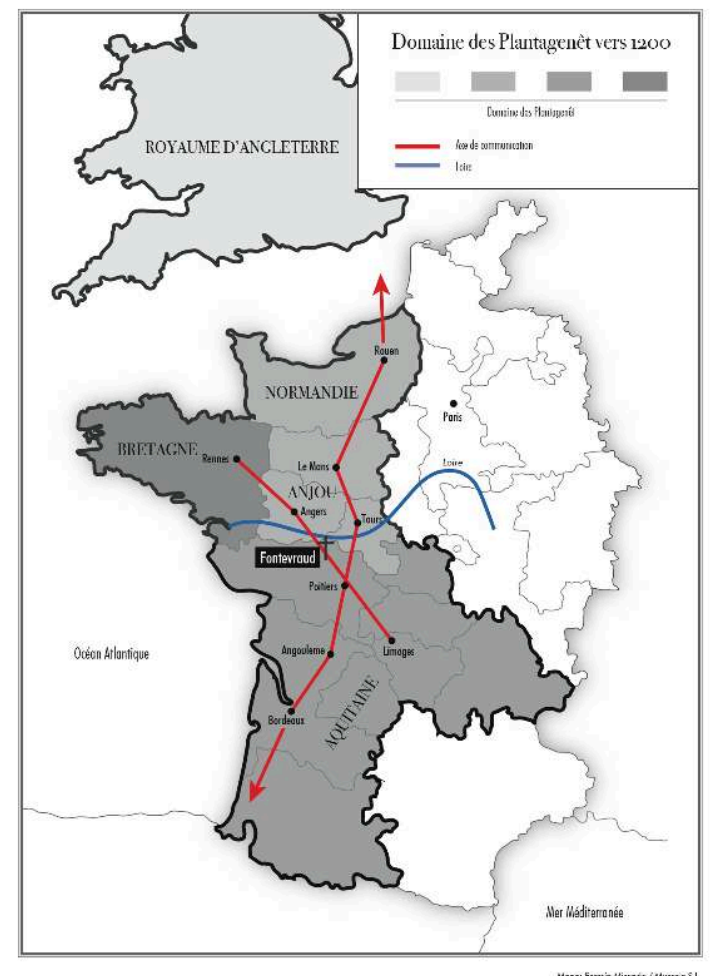

(c) Fermín Miranda García.

13 L'historiographie a souligné la possibilité que Fontevraud soit le modèle qui inspira le panthéon de Las Huelgas, sépulture d'Alphonse VIII de Castille et de sa femme Aliénor Plantagenêt, fille d'Henri II et d'Aliénor d'Aquitaine. Mais les dernières recherches sur cette question semblent réfuter ce point de vue et relient plus étroitement cette décision avec les réalités hispaniques antérieures ou contemporaines ${ }^{11}$.

Cependant, dans le cas de Sanche VII le Fort et de Roncevaux, on peut risquer une comparaison avec le modèle du panthéon de Fontevraud, dans le cadre des relations politiques et familiales de la dynastie royale de Navarre avec le monde ultra-pyrénéen. 
15 L'historiographie récente (en particulier les œuvres d'Eloísa Ramírez Vaquero, suivie par d'autres chercheurs), a insisté sur l'importance des relations stratégiques établies par la monarchie navarraise avec le monde normand depuis le deuxième tiers du XII siècle et jusqu'aux premières années $\mathrm{du}_{\mathrm{XIII}} \mathrm{e}^{\mathrm{e}}$ dans sa recherche de légitimation et de renforcement par rapport à ses voisins ${ }^{12}$. Cette volonté de rapprochement est illustrée par plusieurs traités d'une importance singulière, et même par la politique militaire de l'Aquitaine $^{13}$.

16 Ainsi, on peut souligner les divers mariages «croisés » contractés par la monarchie navarraise avec les Plantagenêt et la Sicile, unions qui étendent ses réseaux en dehors du monde normand proprement dit, jusqu'à Toulouse ou la Champagne. Non seulement Ramirezle Restaurateur avait épousé vers 1132, juste avant sa proclamation, Marguerite de L'Aigle, de la lignée Du Perche - très impliquée dans la conquête de la vallée de l'Èbre aux ordres d'Alphonse $\mathrm{I}^{\mathrm{er}}$ - ; mais aussi la sœur de Sanche VI, également appelée Marguerite, épousa en 1146 Guillaume I ${ }^{\text {er }}$ de Sicile ; leur fils Guillaume II épousa en 1177 Jeanne, fille d'Henri II Plantagenêt; la même Jeanne qui, une fois veuve, se remaria en 1196 avec Raimond VI de Toulouse, dont la fille d'un mariage précédent, Constance, serait l'unique épouse en 1195, ensuite répudiée, de Sanche VII de Navarre ${ }^{14}$. Le plus célèbre de ces liens est celui qui a uni Bérengère de Navarre (fille de Sanche VI et sœur de Sanche VII) avec Richard Cœur de Lion en 1191. Le mariage en 1198 de Blanche, une autre sœur de Sanche VII, avec le comte Thibaud III de Champagne - les futurs parents du roi Thibaud $\mathrm{I}^{\mathrm{er}}$ de Navarre - a eu un impact décisif sur les relations navarraises avec les lignées normandes, représentées par l'évêque de Chalons, Rotrou Du Perche.

17 Du côté symbolique, l'emblème de Sanche VII, l'aigle, a été hérité selon toute probabilité de la lignée normande de sa grand-mère, dont certains membres (ainsi Riquer de L'Aigle, frère de Marguerite) se servaient aussi au moins dès les années soixante-dix du XII ${ }^{\mathrm{e}}$ siècle ${ }^{15}$. Ce symbole apparaît au tout début du règne de Sanche $\mathrm{VII}^{16}$ ; et bien que les emblèmes animaliers soient aussi connus à cette époque dans des territoires comme le Léon, il nous paraît intéressant de signaler qu'à la même époque, Richard $\mathrm{I}^{\mathrm{er}}$ remplace le lion rampant tout d'abord par deux lions en 1195, et presque à la fin de son règne, en 1198, par trois lions passants, ou léopards ${ }^{17}$.

\section{Un panthéon navarrais à Roncevaux ?}

Juste avant la construction de l'église gothique de la collégiale de Roncevaux, qu'on peut dater entre 1205 et 1215 , a eu lieu la partie la plus importante de l'expansion du royaume de Navarre au nord des Pyrénées, dans la région connue sous le nom de "Terres de Ultrapuertos» (aujourd'hui Basse-Navarre), associée jusqu'alors au domaine des vicomtés de Labourd et de Dax et donc, dans la chaîne vassalique, à l'espace aquitain des Plantagenêt. Au début, les tensions furent vives entre les deux dynasties, mais elles se sont résolues de manière généralement pacifique. Cette négociation territoriale a commencé à la fin du XII siècle, à partir de 1189 , pendant le règne parallèle de Sanche VI et Richard I ${ }^{\mathrm{er}}$; elle s'est terminée vers 1205-1210, sous le règne de Sanche VII et Juan I ${ }^{\mathrm{er}}$. Durant les années de règne de Sanche VII et Richard $\mathrm{I}^{\mathrm{er}}$ (1194-1198), les deux souverains ont manifesté une volonté conjointe de mettre fin au problème ${ }^{18}$. Il s'agissait d'une petite région de seulement 1300 kilomètres carrés, mais elle apportait à la Navarre enclavée une ouverture géographique et même 
psychologique, compte tenu des caractéristiques socio-économiques et juridiques particulières du territoire : la création d'une « nouvelle Navarre ».

Sur la limite physique entre les deux Navarre, qui longe la chaîne pyrénéenne, se trouve la collégiale de Roncevaux. Cette communauté de chanoines de Saint-Augustin, protégée par la monarchie depuis l'époque de Garcia Ramirez, avait réussi à échapper à la tutelle du chapitre cathédral de Pampelune dans les dernières années du XII siècle, très probablement avec le soutien $\mathrm{du}$ roi $^{19}$. Roncevaux avait conservé une totale autonomie de gestion et d'organisation, tout comme Fontevraud, qui suivait la règle bénédictine mais en restant indépendante des grands réseaux monastiques. Seule la collégiale de Tudela bénéficiait dans le royaume de conditions similaires, mais en dépendant toutefois du diocèse de Tarazona, dans le royaume d'Aragon (fig. 2).

Fig. 2. - Le royaume de Navarre vers 1220.

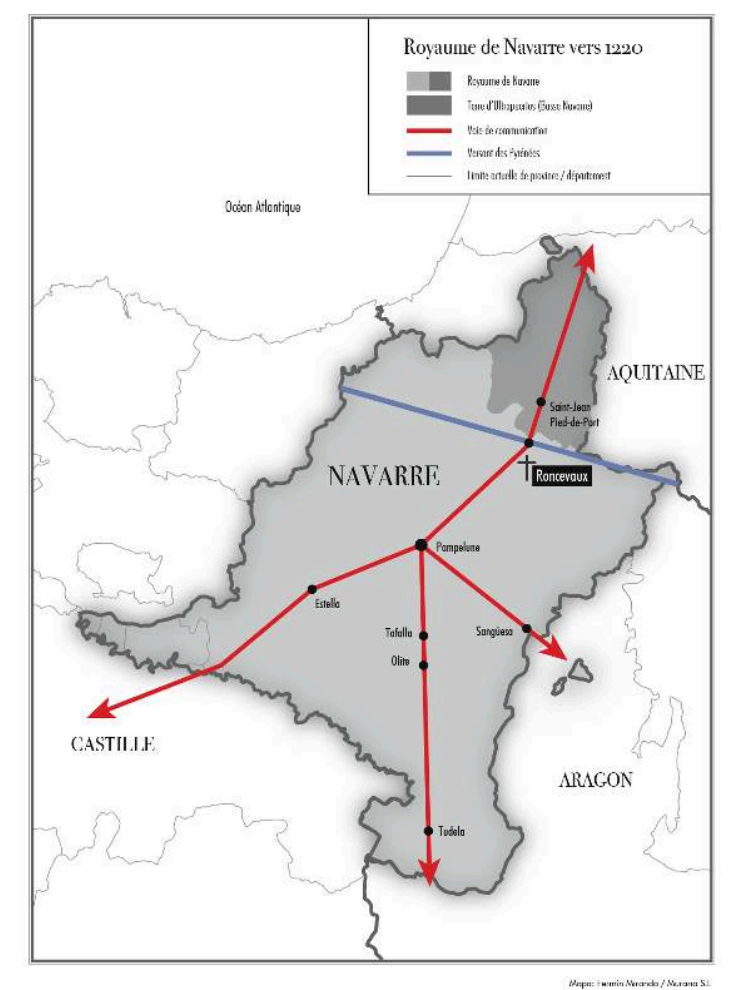

(c) Fermín Miranda García.

L'importance de la contribution financière de Sanche VII à la construction de l'église, au moins jusqu'aux environs de 1215, quand la partie principale du bâtiment fut érigée, est bien documentée et, comme on l'a souligné, ce sont des années où la domination navarraise sur les Terres d'Ultrapuertos a déjà atteint un certain degré de consolidation ${ }^{20}$. On peut rappeler ici le peu d'intérêt manifesté par Sanche VII envers les autres établissements ecclésiastiques du royaume ${ }^{21}$.

21 Sur le terrain du symbolique, on peut également souligner les similitudes entre le gisant de Sanche VII à Roncevaux et ceux de deux autres monarques Plantagenêt, Richard I ${ }^{\text {er }}$ à Fontevraud et Jean Sans Terre à Worcester. Au-delà des différences stylistiques entre les œuvres, les trois gisants représentent les rois munis de la couronne et de l'épée, contrairement aux autres gisants de rois plus ou moins contemporains qui ont été conservés : la représentation de Louis VII à Barbeau, érigée 
sur les ordres de sa veuve, inclut la couronne et le sceptre ${ }^{22}$; Henri II Plantagenêt reprend les mêmes symboles à Fontevraud; Alphonse IX de Léon ne présente ni le sceptre ni la couronne dans sa tombe de Saint-Jean de Compostelle; les effigies des souverains castillans, aragonais ou portugais contemporains ne sont pas sculptées ou n'ont pas été conservées.

Indépendamment du fait que l'image de l'épée est plus fréquente dans les sépultures des chevaliers anglo-normands que dans d'autres régions, il est intéressant de noter ici la coïncidence de ces représentations royales dans ce rapprochement des symboles auquel nous essayons de réfléchir. Étant donné la proximité des deux personnages, on peut envisager que le modèle idéologique du gisant de Sanche s'inspire avant tout de celui de Richard $\mathrm{I}^{\mathrm{er}}$, bien que d'un point de vue purement stylistique, il s'approche davantage de ceux des deux William Marshall (Guillaume le Maréchal), père et fils, au Temple de Londres; l'un des deux, probablement le second, décédé en 1231, était un important bienfaiteur de Roncevaux. En tout cas, il s'agit toujours de modèles anglonormands ${ }^{23}$. Que l'image ait été peut-être commandée par les chanoines de Roncevaux lorsque le corps du roi a été transféré à la collégiale ${ }^{24} n^{\prime}$ invalide pas l'hypothèse que ceux-ci ont essayé de respecter des souhaits manifestés par le roi de son vivant. En ce qui concerne les éventuelles intentions du roi d'établir un panthéon familial à Roncevaux, il faut rappeler qu'une femme (sa deuxième et hypothétique épouse, Clémence, ou sa sœur Constance ${ }^{25}$ ?) est également enterrée auprès de Sanche, bien qu'aujourd'hui ne soit conservée que la sépulture du souverain; mais l'absence de restes appréciables et de dates précises empêche d'aller plus loin sur une possible hypothèse de continuité, en tout cas interrompue par la décision de Thibaut I ${ }^{\text {er }}$ d'être inhumé à Pampelune.

23 Enfin, la collégiale de Roncevaux est située près du changement de versant des Pyrénées, sur la nouvelle frontière qui vient d'être organisée entre l'ancien pays du sud et le nouveau du nord lequel, du point de vue de la péninsule, est situé au-delà des ports pyrénéens (ultra puertos) ; tout comme Fontevraud était, sur la Loire, au confluent entre les premiers domaines normando-angevins et les nouvelles terres aquitaines des Plantagenêt. Dans le cas de Roncevaux, il n'y a pas de rivière symbolisant la rencontre, mais une chaîne montagneuse dont les « ports » font communiquer les deux espaces.

En outre, Roncevaux se trouve également sur l'axe principal de communication du royaume (axe Saint-Jean-Pampelune-Tudela-Estella-Sangüesa), sur la route de l'Aquitaine et des domaines des Plantagenêt, et aussi de Fontevraud avec les tombeaux d'Henri II, d'Aliénor et de Richard I ${ }^{\text {er }}$, bien que le monastère soit tombé entre les mains de Philippe Auguste en 1204. Mais certains membres de la lignée y seront encore enterrés jusqu'au milieu du siècle, y compris la veuve de Jean $\mathrm{I}^{\mathrm{er}}$, Isabelle d'Angoulême, et le bienfaiteur de Roncevaux, Raimond VII de Toulouse ${ }^{26}$, neveu de Richard I ${ }^{\text {er }}$. De plus, dans ce réseau de relations familiales avec le Nord, Roncevaux reste lié à la légende de la Chanson de Roland: il faut rappeler que c'était, à ses origines connues au milieu du xie siècle, un chant normand qui accompagnait les guerriers de Guillaume le Conquérant à Hastings; et il faut rappeler aussi que le texte des manuscrits conservés les plus anciens (1170-1180) est rédigé en anglo-normand par Turold, qui serait luimême un Normand ${ }^{27}$. 
Malgré les incertitudes sur les réelles dernières volontés de Sanche VII, on peut toutefois proposer que le roi a souhaité émigrer une fois mort sur la montagne de Roncevaux parce qu'il a considéré, au moins pendant un certain nombre d'années, que la collégiale, située sur le grand axe de communication nord-sud du royaume et au sommet des Pyrénées, représentait l'union entre la vieille et la nouvelle Navarre, qu'il avait acquise au cours des premières années de son règne.

\section{BIBLIOGRAPHIE}

AILES Adrian, The origins of the royal arms of England, Reading, University of Reading, 1982.

ALONSO ÁLVAREZ Raquel, « Los enterramientos de los reyes de León y Castilla hasta Sancho IV », eSpania, $\mathrm{n}^{\circ}$ 3, 2007 [doi : 10.4000/e-spania.109].

ARCo Ricardo del, Sepulcros de la casa real de Aragón, Madrid, CSIC, 1945.

AURELL Martín, L'empire Plantagenêt : 1154-1224, Paris, Perrin, 2004.

BIENVENU Jean-Marc, « Aliénor d'Aquitaine et Fontevraud », Cahiers de civilisation médiévale, $\mathrm{n}^{\circ} 29$, 1986, p. 15-27 [doi :10.3406/ccmed.1986.2310].

BIENVENU Jean-Marc, « Henri II Plantegenêt et Fontevraud », Cahiers de civilisation médiévale, $\mathrm{n}^{\circ}$ 37, 1994, p. 25-32 [doi : 10.3406/ccmed.1994.2575].

BRAULT Gerald J. (éd.), La Chanson de Roland: Oxford text and english translation, Londres, Pennsylvania University Press, 2013.

DЕСтот Xavier, Les tombeaux des familles royales de la péninsule Ibérique au Moyen Âge, Turnhout, Brepols, 2009.

ERLANDE-BRANDENBURG Alain, « Fontevrault, le cimetière des rois Plantagenêt », Dossiers archéologie et sciences des origines, $\mathrm{n}^{\circ} 311,2006$, p. 22-27.

FAVREAU Robert, « Aliénor d'Aquitaine et Fontevraud », Arts, recherches et créations, numéro hors série, 2004, p. 41-45.

FERNÁNDEZ-LADREDA Clara et HIDALGo Santiaga, « Sepulcros », dans Fernández-Ladreda Clara (dir.), Arte gótico en Navarra, Pampelune, Gobierno de Navarra, 2016, p. 126-127.

GARCíA GONZÁLEZ Sonsoles, «El panteón regio compostelano. La pérdida de la memoria », dans Los lugares de la memoria, Salamanque, Asociación de Jóvenes Historiadores, 2013, p. 974-997.

HALLAM Elizabeth M., « Royal burial and the cult of kingship in France and England, 1060-1330 », Journal of Medieval History, $\mathrm{n}^{\circ}$ 8, 1982, p. 359-380.

HERREROS LOPETEGUI Susana, Las tierras navarras de Ultrapuertos (siglos XII-XVI), Pampelune, Gobierno de Navarra, 1999.

JIMÉNEZ DE RADA Rodrigo, Historia de los hechos de España (éd. Rodríguez Valverde Juan), Madrid, Alianza, 1989. 
JIMENO JURÍO José María et JIMENO ARANGUREN Roldán, Archivo General de Navarra 1194-1234, SaintSébastien, Sociedad de Estudios Vascos, 1998.

LACARRA José María, Historia política del reino de Navarra desde sus orígenes hasta su incorporación a Castilla, Pampelune, CAN, 1972-1973, 3 vol.

MARICHALAR Carlos de, Colección diplomática del rey Sancho VIII (el Fuerte) de Navarra, Pampelune, BCMN, 1934.

MARTíNEZ ÁLAVA Carlos, « El modelo de Île-de-France : Santa María de Roncesvalles y los ecos del gótico clásico », dans Fernández-Ladreda Clara (dir.), El arte gótico en Navarra, Pampelune, Gobierno de Navarra, 2015, p. 50-68.

MARTÍNEZ DE AGUIRRE Javier, « La imagen del rey en la figuración gótica », dans Martín Duque Ángel J. (dir.), Signos de identidad histórica para Navarra, Pampelune, CAN, 1996, p. 375-386.

MENÉNDEZ PIDAL DE NAVASCUÉS Faustino, « Primeros emblemas regios », dans Á. Martín Duque (dir.), Signos de identidad histórica para Navarra, Pampelune, CAN, 1996, p. 175-186.

MIRANDA GARCíA Fermín, « Intereses cruzados de la monarquía navarra en el siglo XIII (1194-1270) », dans Ayala Carlos et Ríos Martín (dir.), Fernando III, tiempo de cruzada, Madrid / Mexico, Sílex / Unam, 2013, p. 325-349.

MIRANDA GARCíA Fermín, « De Bayona a Muret. Navarra y Occitania, una relación compleja », dans La encrucijada de Muret, Séville, SEEM, 2015, p. 211-238.

MIRANDA GARCíA Fermín, « Los lugares del rey muerto en el reino de Pamplona/Navarra (s. XXIII) », dans Arias Fernando (dir.) Espacios del rey. Poder y territorio en las monarquías hispánicas (ss. XII-XIV), Bilbao, UPV, 2018, p. 465-472.

MIRANDA GARCíA Fermín, Roncesvalles. Trayectoria patrimonial (s. XII-XIX), Pampelune, Gobierno de Navarra, 1993.

ostolaza María Isabel, Colección diplomática de Santa María de Roncesvalles (1127-1300), Pampelune, DFN, 1978

PINCHES John Harvey et PINCHES Rosemary, The royal heraldry of England, Slough, Hollen Street Press, 1974.

RAMÍREZ VAQUERO Eloísa, « La comunidad regular de Santa María de Roncesvalles (siglos XII-XIX) », Príncipe de Viana, vol. 54, nº 199, 1993, p. 357-402.

RAMÍREZ VAQUERo Eloísa, « De los Sanchos a los Teobaldos: ¿Cabe reconsiderar la historia navarra del siglo XIII? » dans Estepa Carlos et Carmona M. Antonia (dir.), La Península Ibérica en tiempos de las Navas de Tolosa, Madrid, SEEM, 2014, p. 395-423.

RIQUER Martín de (éd.), Chanson de Roland. Cantar de Roldán y el Roncesvalles navarro, Madrid, Acantilado, 2003.

SOMMERS WRIGTH Georgia, "A royal tomb program in the reign of St. Louis », The Art Bulletin, vol. 56, n 2, 1974, p. 224-243.

VILAR Hermínia, « Lineage and territory: royal burial sites in the early Portuguese kingdom », dans Spiess Karl-Heinz et Warntjes Immo (dir.), Death at Court, Weisbaden, Harrassowitz, 2012. WALKER Rose, « Leonor of England, Plantagenet queen of King Alfonso VIII of Castile, and her foundation of the Cistercian abbey of Las Huelgas. In imitation of Fontevraud? ", Journal of Medieval History, $\mathrm{n}^{\circ}$ 31, 2005, p. 346-368 [http ://dx.doi.org/10.1016/j.jmedhist.2005.08.002]. 
WOoD Charles T., " Fontevraud, dinasticism and Eleanor of Aquitaine ", dans Wheeler Bonnie et Parsons John C. (dir.), Eleanor of Aquitaine: Lord and Lady, New York, McMillan, 2002.

\section{NOTES}

1. Cette étude s'inscrit dans le cadre du projet de recherche « HAR2016-74846-P La mort $\mathrm{du}$ prince en France et les royaumes hispaniques (XI-XV siècles): modèles de comparaison ", de l'Agence de l'État pour la recherche du gouvernement de l'Espagne. ORCID : 0000-0002-0072-8224. ResearcherID : L-2531-2013. VIAF : 17338470.

2. Par exemple, J. M. Lacarra, Historia política del reino de Navarra..., p. 121, qui cite le chroniqueur contemporain du roi Rodrigo Jiménez de Rada; Historia de los hechos de España (éd. J. Rodríguez Valverde), 1. 5 c. 24, p. 216.

3. F. Miranda García, «Los lugares del rey muerto », p. 465-467.

4. F. Miranda García, «Intereses cruzados de la monarquía navarra », p. 329-335.

5. M. I. Ostolaza, Colección diplomática de Santa María de Roncevaux (1127-1300), $\mathrm{n}^{\text {os }} 93$ (1237) et 121 (1244); C. de Marichalar, Colección diplomática del rey Sancho VIII, $n^{\circ} 200$ (1237).

6. G. Sommers Wrigth, «A Royal tomb program in the reign of St. Louis »; X. Dectot, Les tombeaux des familles royales; S. García González, «El panteón regio compostelano »; H. Vilar, « Lineage and territory » ; R. Alonso Álvarez, « Los enterramientos de los reyes de León y Castilla hasta Sanche IV ; E. M. Hallam, «Royal burial and the cult of kingship in France and England ».

7. R. Del Arco, Sepulcros de la casa real de Aragón.

8. A. Erlande-Brandenburg, « Fontevrault, le cimetière des rois Plantagênet ».

9. Ch. T. Wood, «Fontevraud, dinasticism and Eleanor of Aquitaine », p. 407-422.

10. M. Aurell, L'empire Plantagenêt...; A. Erlande-Brandenburg, "Fontevrault: le cimetière des rois Plantagenêt ", et « Henri II Plantagenêt et Fontevraud »; R. Favreau, "Aliénor d'Aquitaine et Fontevraud».

11. R. Walker, « Leonor of England, Plantagenet queen of King Alfonso VIII of Castile ».

12. E. Ramírez Vaquero, «De los Sanchos a los Teobaldos»; F. Miranda, «Intereses cruzados de la monarquía navarra ».

13. L.J.Fortún Pérez de Ciriza, Sancho VII el Fuerte (1194-1234), p. 82-86; S. Herreros Lopetegui, Las Tierras de Ultrapuertos, p. 61-66.

14. L. J. Fortún Pérez de Ciriza, Sancho VII el Fuerte, p. 54.

15. F. Menéndez Pidal de Navascués, « Primeros emblemas regios », p. 182-183.

16. Le règne de Sanche VII commença le 27 juin 1194. Dans une copie des alentours de 1400 d'un diplôme de 1194, réalisée peut-être d'après l'original, le roi est symbolisé par la figure d'un aigle (J. M. Jimeno Jurío et R. Jimeno Aranguren, Archivo General de Navarra, 1194-1234, $\mathrm{n}^{\circ}$ 3).

17. J. H. Pinches et R. Pinches, The royal heraldry of England, p. 24-25; A. Ailes, The origins of the royal arms of England, p. 67-73.

18. S. Herrero Lopetegui, Las tierras navarras de Ultrapuertos, p.55-77; quelques réflexions sur ce sujet dans F. Miranda García, « De Bayona a Muret ». 
19. F. Miranda, Roncesvalles, p. 46-60 ; E. Ramírez Vaquero, «La comunidad regular de Santa María de Roncesvalles », p. 357-402.

20. C. Martínez Álava, «El modelo de Île-de-France », p. 60-61.

21. L. J. Fortún, Sancho VII el Fuerte, p. 293-296.

22. Voir un dessin du tombeau dans la collection Gagnières, $n^{\circ} 53$, de la BNF.

23. Les descriptions du tombeau indiquent qu'il présentait aussi des sculptures d'anges, comme celui de Jean $I^{\text {er }}$ à Worcester.

24. J. Martínez de Aguirre, «La imagen del rey en la figuración gótica », p. 379, et C. Fernández-Ladreda et S. Hidalgo, « Sepulcros », p. 126-127, suggèrent que le gisant de Sanche est inspiré de celui de Guillaume le Maréchal le Jeune et qu'il a été commandé par le chapitre de la collégiale. Voir les donations de Guillaume le Maréchal à Roncevaux dans F. Miranda García, Roncesvalles, p. 92-94.

25. L. J. Fortún, Sanche VII el Fuerte, p. 54-56.

26. En 1232, il donna 20 livres annuelles au péage de Marmande ; F. Miranda García, Roncesvalles, p. 92.

27. G. J. Brault (éd.), La Chanson de Roland, p. XI-XXIX. La date de la première version hispanique de la légende, le Cantar de Roncesvalles, écrite en navarrais est incertaine, peut-être sous le règne de Sanche VII. Il n'en reste qu'un fragment, publié par M. de Riquer, avec sa traduction en espagnol de la chanson (Chanson de Roland. Cantar de Roldán y el Roncesvalles navarro).

\section{RÉSUMÉS}

À la différence des rois immédiatement antérieurs et postérieurs, qui ont choisi d'être enterrés à la cathédrale de Pampelune, la dépouille de Sanche VII de Navarre a été déposée à la collégiale Sainte-Marie de Roncevaux, au sommet des Pyrénées. Cette étude essaie d'établir les causes d'un choix si singulier et analyse la possibilité d'une éventuelle volonté de Sanche VII de s'inspirer du panthéon de la dynastie Plantagenêt à Fontevraud, dans le cadre des relations entre les monarchies navarraise et anglo-normande aux alentours de 1200.

\section{AUTEUR}

\section{FERMÍN MIRANDA GARCÍA}

Universidad Autónoma de Madrid 


\title{
Cherchez la femme... sur le mont Athos?
}

\author{
Diane Pasquier-Chambolle
}

1 Dans les années 1930, alors qu'il se dirige vers le monastère de Saint-Jean-Prodrome, sur l'Athos, Kurt Weitzmann rencontre sur son chemin un jeune ermite. Une conversation s'engage alors, et l'historien d'art constate qu'elle s'oriente rapidement vers un sujet: la femme. Avec force gestes, le jeune moine cherche à démontrer qu'agissant tel un vampire aspirant le sang de ses victimes, la femme est le diable en personne. Pensant que le jeune homme a vécu de mauvaises expériences avec le sexe opposé ou subi quelques déboires amoureux qui l'ont conduit à se réfugier sur cette montagne coupée du monde, Weitzmann est stupéfait de l'entendre lui affirmer qu'il n'a jamais vu une femme de sa vie: sa mère est morte en couches et son oncle l'a conduit à l'Athos dès son plus jeune âge. Piqué par la curiosité, l'historien lui demande alors d'où peut lui venir cette vision d'un être qu'il n'a jamais côtoyé : le jeune homme le renvoie à la lecture de L'Échelle sainte de Jean Climaque, un moine syrien du... VII ${ }^{\mathrm{e}}$ siècle ${ }^{1}$.

2 Ce petit témoignage tendrait à décourager toute velléité de recherche concernant la présence des femmes sur le mont Athos : même au début $d u x^{e}$ siècle, elles continuent à apparaître comme des vecteurs privilégiés de la tentation aux yeux d'athonites abreuvés d'ouvrages résolument datés. Comme si le temps s'était arrêté en ces lieux, plus et plus tôt qu'ailleurs. Car en théorie, les femmes étaient interdites d'accès dans tous les monastères masculins de l'Empire byzantin et vice-versa: pour éviter toute tentation, dès le $\mathrm{VI}^{\mathrm{e}}$ siècle, les droits civil et canon codifient une règle imposant une séparation stricte entre les deux sexes. Apparue en 539, la novelle 133 de Justinien interdit l'entrée au monastère de membres du sexe opposé, même des défunts. Seuls les fossoyeurs font exception. Justinien interdit également aux hommes de visiter les monastères féminins ou aux femmes les monastères masculins pendant les services de commémoraison. Par la suite, le canon 47 du concile in Trullo interdit à une femme de passer la nuit dans un monastère masculin et vice versa. Enfin, le canon 18 du concile de Nicée II interdit aux femmes toute visite dans les monastères en toute circonstance ${ }^{2}$. L'abaton - terme signifiant littéralement « inaccessible » - fixe le principe selon lequel 
un monastère est interdit d'accès à tous ceux qui ne sont pas du même sexe que les membres de la communauté qui l'habite. Mais divers documents révèlent que la pratique était tout autre : les femmes bien nées pouvaient se permettre de rendre visite à leurs proches. Si l'intrusion du monde dans les institutions masculines n'était pas fréquente, du moins était-elle régulière. Un tel constat révèle donc que dans le paysage monastique byzantin, l'Athos se singularise.

3 Dès le $\mathrm{IV}^{\mathrm{e}}$ siècle, les montagnes, lieux reculés et difficiles d'accès, deviennent naturellement de parfaits refuges pour tous ceux qui éprouvent un profond désir de contemplation et fuient un monde qui les empêche de le satisfaire. Parmi ces refuges, le mont Athos connaît un grand succès : la situation de cette presqu'île, hérissée d'une succession de montagnes, très difficile d'accès par terre ou par mer ${ }^{3}$, favorise en même temps qu'elle impose un certain isolement ${ }^{4}$. À partir $\mathrm{du} \mathrm{IX}^{\mathrm{e}}$ siècle, à l'arrivée des moines de la Chalcidique voisine s'ajoute la venue de ceux, de plus en plus nombreux, qui viennent tenter l'expérience de l'ascèse et rejoignent parfois sur la sainte montagne un ermite de renom, tel saint Euthyme le Jeune ${ }^{5}$ ou Jean Kolobos ${ }^{6}$. Autour de ces anachorètes se constituent des groupes qui donnent naissance aux premiers monastères athonites : si bien qu'à la fin du $\mathrm{x}^{\mathrm{e}}$ siècle, la cinquantaine de monastères implantés sur cette montagne sacrée témoigne de la progression foudroyante du monachisme athonite, même si leur nombre va peu à peu décroître au profit des plus puissants.

4 Ce désir de retrait du monde, de rupture avec la civilisation, touche autant les hommes que les femmes de l'Empire byzantin. Mais alors que les institutions féminines, comme les institutions masculines, apparaissent sur tout le territoire de l'empire, les femmes semblent totalement absentes de la montagne sacrée : aucune femme ermite, aucune sainte n'est passée par l'Athos. Aucun monastère féminin n'y fut construit. Tout se passe comme si aucune femme n'avait approché la montagne sacrée, une montagne pourtant dédiée à la Vierge.

5 Toutefois, une lecture plus attentive des archives athonites permet de nuancer une telle affirmation. Non seulement ces archives révèlent des exceptions à cette prétendue absence totale des femmes, mais elles nous conduisent à constater que certaines d'entre elles vont jusqu'à tisser des liens avec des moines athonites. Aussi, si la montagne ne leur est pas accessible, elles entretiennent avec elle des relations particulières, qui les conduisent jusqu'à des rencontres avec ces moines : autrement dit, si elles ne peuvent se rendre sur la montagne, c'est celle-ci qui vient vers elles. En développant toutes ces données dans les lignes qui suivent, je m'attacherai d'abord à citer les différentes sources où l'on peut trouver les indications concernant l'absence de circulation des femmes sur la montagne sacrée de l'Athos, depuis son développement au IX ${ }^{e}$ siècle jusqu'à la disparition de l'Empire byzantin en 1453, avant de démontrer ensuite qu'on peut y trouver malgré tout une présence féminine, mais sous une autre forme.

\section{Des femmes sur le mont Athos?}

\section{Ce que disent les règlements : une interdiction indirecte et tardive}

6 On dispose de huit règlements monastiques, ou typika, pour les institutions de l'Athos. Parmi ces huit typika, seule une moitié mentionne la présence de femmes, et le plus 
souvent indirectement ou de manière allusive. Trois d'entre eux rappellent les prescriptions énoncées par Théodore Stoudite pour le monastère Saint-Jean-Baptiste du Stoudios, qui excluent tout animal de sexe féminin sur l'Athos ${ }^{7}$. Dans le monastère de Lavra, Athanase indique que ces femelles peuvent être, au même titre que les femmes, sources de tentation pour des moines vivant dans l'isolement le plus total :

«Vous ne posséderez pas d'animal de sexe féminin afin de réaliser des tâches qui

vous incombent, car vous avez totalement renoncé à la femme ${ }^{8}$.»

Constantin Monomaque en 1045, puis Manuel II en 1406, réitèrent cette interdiction pour toutes les institutions monastiques présentes sur la montagne sacrée. Le premier ordonne l'expulsion de tels animaux sur le mont Athos, notant que «malgré les règles antérieures, brebis, chèvres et même vaches étaient présentes sur l'Athos ${ }^{9}$ ". Manuel II explique la nécessité de cette interdiction afin de s'assurer de la pureté des moines " grâce au fait qu'ils n'ont pas sous les yeux d'être féminin ${ }^{10}$ ".

8 Par la suite, l'empereur ne consacre aucun article à la présence des femmes. Mais il l'évoque tout de même dans l'article imposant l'interdiction d'admettre sur la montagne sacrée des jeunes gens imberbes et des eunuques en tant que serviteurs ou novices, de peur « qu'une femme déguisée en homme et prétendant être un eunuque ou un jeune imberbe puisse entrer dans le monastère ${ }^{11} »$. Cette mise en garde indique au passage que les règles interdisant eunuques et jeunes garçons n'étaient pas prévues pour essayer de se prémunir contre l'homosexualité (comme d'autres typika le suggèrent), mais pour se prémunir contre des femmes qui pourraient se rendre sur l'Athos sous un tel déguisement ${ }^{12}$.

9 Le règlement de Manuel II est donc le seul à évoquer nommément le danger que représente la femme: dans les autres règlements des institutions athonites, l'interdiction qui la frappe n'est jamais explicite, alors même que d'autres montagnes sacrées sont régies par des instructions plus claires. L'application la plus extrême de cette règle d'exclusion revient au monastère de la Transfiguration, dans les Météores : au nom de cette prescription, les moines y sont autorisés à laisser mourir de faim toutes celles qui oseraient se présenter devant les portes du monastère ${ }^{13}$.

10 On peut ainsi légitimement se demander les raisons d'une telle absence dans les textes. Les interdictions répétées de la présence des eunuques, des imberbes et des femelles suggèrent probablement un enracinement de l'abaton dans les pratiques et coutumes athonites. La péninsule étant considérée comme un immense complexe monastique, la règle a dû s'imposer à tous les monastères sans qu'il ait été nécessaire de l'écrire noir sur blanc ni de la répéter à de nombreuses reprises. Mais ce qui apparaît comme une tradition est en fait une vraie règle : son existence est confirmée en négatif par deux épisodes de l'histoire de l'Athos, qui s'y inscrivent comme des événements exceptionnels.

\section{Les deux grandes exceptions qui confirment l'existence de la règle}

11 La première violation de l'abaton apparaît dans deux actes émanant du tribunal patriarcal de Constantinople. Ils mentionnent l'arrivée de plusieurs centaines de familles valaques, peuple venu des Balkans, sur la péninsule athonite aux alentours de 1100. À la recherche de nouvelles terres, ils trouvent en la montagne de l'Athos un lieu propice : non seulement leurs troupeaux de chèvres et de brebis trouvent à y paitre, mais ils peuvent également vendre les fruits de leur travail aux monastères. Le prôtos - 
celui qui représente l'Athos auprès des autorités civiles et ecclésiastiques de l'empire ${ }^{14}$ -, à cette époque Jean Tarchaneiotès, condamne sévèrement cette intrusion sur la montagne sacrée :

«Le Diable entra dans le cœur des Valaques. Ils étaient venus avec leurs épouses qui portaient des vêtements d'hommes. Elles faisaient paître les troupeaux et servaient les monastères, leur apportant fromage, lait et laine, leur fournissaient du pain pour le repas. Si bien que très rapidement, elles devinrent comme des servantes pour les moines et ces derniers les désiraient. Et c'est une honte aussi bien de raconter que d'entendre ce qu'ils firent ${ }^{15}$. »

Le texte s'arrête ici : par décence, l'auteur ne continue pas et invite ses lecteurs à imaginer la suite. La formulation du texte, très critique à l'égard des femmes, considérées ici très clairement comme des filles d'Ève, pourrait laisser penser que les épouses valaques se sont volontairement déguisées en hommes pour se rendre sur l'Athos. Mais l'historien Matyas Gyoni réfute clairement cette hypothèse en avançant qu'elles n'auraient pas pris cette peine : selon lui, elles portaient simplement des habits de bergers pour s'occuper de leurs troupeaux. Dissimulée ou pas, leur présence est, quoi qu'il en soit, considérée comme intolérable. C'est ce qu'indique un second acte qui rend compte de la réaction du patriarche face à cette scandaleuse intrusion : Nicolas III adresse des remontrances aux moines de l'Athos afin que ce type de situation ne se reproduise plus ${ }^{16}$.

13 La seconde exception qui confirme la règle d'interdiction de présence des femmes sur le mont Athos est relatée dans l'un des chrysobulles de l'empereur de Serbie Stefan Uros IV, dit aussi Stefan Dusan ${ }^{17}$. Le document établit en effet qu'il se rendit vers 1347 sur le mont Athos avec son fils et son épouse Hélène. Si le document ne précise pas où ils habitèrent, leur séjour dura quelques mois. Il indique en effet qu'au début de leur voyage, ils prièrent à Chilandar sur la tombe de saint Syméon, dans l'église de la Vierge, puis qu'ils visitèrent de nombreux monastères, les couvrant de dons. Après avoir fait le tour de la péninsule, ils revinrent à Chilandar ${ }^{18}$.

Différents historiens se sont interrogés sur les raisons de la présence du couple impérial sur l'Athos à ce moment-là : certains avancent que cette visite unique en son genre s'explique peut-être par le fait que les deux époux essayaient ainsi d'échapper à la peste noire, qui ravageait alors les Balkans ${ }^{19}$. Mais le contexte politique de l'époque suggère une hypothèse plus solide. En 1347, l'empereur serbe vient de conquérir une grande partie de la Macédoine. Fort de cette progression rapide et facile, il souhaite créer un empire byzantino-serbe, et peut-être même remplacer le basileus grec luimême. Or, pour réaliser ce projet, il a besoin du soutien de la noblesse et du clergé grec. Durant sa visite sur l'Athos, les multiples dons qu'il fait aux monastères avec son épouse et son fils visent à s'assurer le soutien des moines athonites, qui finissent d'ailleurs par le reconnaitre comme empereur. Nous ne disposons malheureusement d'aucune source rendant compte de la réaction des moines face à la présence de l'impératrice Hélène... Mais on sait qu'ils furent peu réticents à ouvrir leurs portes à un empereur triomphant, même accompagné de son épouse, conscients de pouvoir en tirer quelques dons ou privilèges, car aujourd'hui encore, tous deux sont considérés comme les patrons et grands bienfaiteurs d'Esphigmenou, de Saint-Panteleimon, de Kutlumus et de Chilandar ${ }^{20}$. 


\section{Une présence hors de l'Athos, mais à proximité}

l'Athos ou évoquant ce dernier ne vivent pas sur la montagne, mais à proximité. Les Vies de saints et les testaments de femmes nous indiquent en effet que beaucoup de mères, d'épouses, de filles d'hommes ayant décidé de se faire moines à l'Athos trouvent refuge à proximité de la montagne sacrée. Ainsi, si l'on ignore où la mère, les sœurs et l'épouse d'Euthyme le Jeune se font moniales, une de ses petites-filles devient abbesse de l'un des couvents que ce dernier a fondés à proximité de l'Athos ${ }^{21}$. Mais c'est sans nul doute le testament de Nymphodora, épouse d'un certain Markellos, au Xve siècle, qui exprime le mieux la situation des femmes par rapport au mont Athos. D'abord parce qu'elle s'y plaint d'avoir dû entrer dans un monastère féminin situé aux frontières de l'Athos, près d'Hiérissos. Mais aussi par la justification qu'elle apporte à cette restriction : «Le mont Athos est inaccessible - anepibatos - pour les femmes, excepté la mère de Dieu ${ }^{22} »$. C'est donc ce document, daté de 1445, qui exprime de la façon la plus explicite à quel éloignement de la montagne sacrée la femme est strictement contrainte.

16 Les règlements ont beau ne pas indiquer clairement que la femme est interdite d'accès sur l'Athos, les quelques cas rappelés ci-dessus et leur retentissement confirment l'enracinement de la tradition d'exclusion totale de tout individu féminin sur la montagne sacrée. Mais cette absence physique ne signifie pas pour autant une absence totale, différentes sources révélant une autre forme de présence féminine dans la vie des moines athonites.

\section{Une autre présence des femmes sur l'Athos}

17 En effet, grâce à certains documents de l'Athos, il est permis de quitter le domaine des règlements pour observer la participation des moines à la vie économique de la Macédoine orientale. Car les monastères présents sur la montagne ont conservé dans leurs archives des actes fiscaux relatifs aux biens qu'ils possédaient. Ayant en outre pour but d'évaluer les superficies des domaines ou d'établir le montant de l'impôt, les documents privés définissent également les droits de chacun sur la terre et rendent compte des diverses transactions. Or parmi les différents acteurs participant aux ventes, achats et autres donations de biens impliquant l'un des monastères athonites, on fait le constat que figurent des femmes ou des moniales. Bien que très peu nombreuses, ces interventions permettent de mesurer, quant à l'interdiction totale de rapport avec les femmes, l'écart notable qui existe entre le principe et la pratique.

\section{L'argent n'a pas d'odeur... ni de sexe : les ventes et les dons des femmes en faveur de l'Athos}

18 Autre forme d'intervention féminine: bien qu'exclues de l'Athos, les femmes lui manifestent leur attachement en multipliant les dons ou en vendant leurs biens aux monastères de la montagne sacrée. C'est ainsi que des femmes sont mentionnées dans quarante actes athonites (trente-cinq femmes vivant dans le siècle et cinq moniales) entre le $\mathrm{x}^{\mathrm{e}}$ et le $\mathrm{xv}^{\mathrm{e}}$ siècle. Dans le cas des quatorze ventes relevées dans les archives des 
dix principaux monastères athonites, le processus est sensiblement le même: des épouses et leur mari, des veuves, des sœurs, cèdent champs, vergers, vignes ou maisons à l'un des riches monastères athonites tels Chilandar, Iviron ou Lavra. Le fait qu'il soit précisé que ces vendeurs reçoivent pour la propriété vendue un paiement en argent laisse penser que ce type de transaction présentait l'avantage d'obtenir rapidement des liquidités pour ceux qui en avaient un besoin urgent. Ainsi, au début du XI siècle, la veuve Kalida vend un terrain au monastère d'Iviron, car il lui faut de l'argent pour payer la rançon de son fils Basile, capturé par les Arabes ${ }^{23}$. En 1349, Philippa Asanina vend au monastère de Xéropotamou la moitié du bien qu'elle possède à Hermélia, pas seulement parce que l'invasion des Serbes l'a rendu inexploitable, mais surtout afin de payer les dettes contractées par son père ${ }^{24}$. Connus pour leur richesse, les monastères athonites apparaissent comme des sources sûres à partir desquelles on pouvait obtenir rapidement de l'argent frais. Et l'exclusion des femmes de la montagne n'empêche pas ces monastères de faire affaire avec elles.

Dans le cas des dons, les femmes cherchent pour certaines à s'assurer que les moines prieront pour elles et leur famille après leur mort. On peut en citer quelques exemples. On a évoqué le cas de Nymphodora : en entrant au monastère de Hiérissos, elle donne tous ses biens au monastère de Xéropotamou afin que ses moines célèbrent sa mémoire par leurs prières après sa mort ${ }^{25}$. C'est également le cas d'Anysia, veuve de Théodore Cantacuzène, qui fait une donation au monastère de la Spèlaiotissa au début du XIV siècle en échange de la commémoraison de son époux défunt ${ }^{26}$.

Au-delà de l'assurance d'un salut éternel, il y a enfin celle de pouvoir vivre dignement jusqu'à la fin de ses jours. Par leur générosité, certaines cherchent à obtenir un adelphaton, c'est-à-dire une somme annuelle versée à vie par le monastère à ses généreux donateurs. De la nourriture pouvait également s'ajouter à l'argent reçu. Au début $d u \mathrm{Xv}^{\mathrm{e}}$ siècle, une veuve dénommée Marina trouve un arrangement avec les moines de Chilandar pour recevoir le reste de sa vie une rente annuelle de vingt-quatre mesures de blé, en plus du vin et de l'huile ${ }^{27}$.

En 1404, Marie Deblitzènè reçoit un versement annuel de trois adelphata du monastère de Docheiariou: les moines lui fournissent du blé, des légumes secs, de l'huile et du fromage afin de subsister. Le versement de ces adelphata survient après que Marie a porté plainte auprès du tribunal impérial. Ce versement était en premier lieu destiné à Deblitzènos; après sa mort, les moines de Docheiariou arrêtent le versement de la rente, alors même qu'ils s'étaient engagés à la transférer à la personne choisie par le défunt. Représentée par son gendre Bartholomée Komès, Marie obtient gain de cause en produisant tous les documents nécessaires ${ }^{28}$.

Ces différents exemples témoignent d'une réelle participation des femmes à la vie de l'Athos : si elles ne peuvent s'y trouver physiquement, elles prennent une part active dans les transactions économiques réalisées par ses moines. Ces derniers se montrent donc beaucoup moins sévères avec les femmes lorsqu'il s'agit d'argent, qui, apparemment, n'a pas de sexe !

\section{Si la femme ne peut aller à la montagne sacrée, la montagne sacrée va à elle}

Mieux encore, les documents concernant les actes de donation et les actes de vente aux monastères de la sainte montagne indiquent parfois clairement que les moines 
athonites engagent, cette fois face à face, des négociations avec des donatrices et des vendeuses. Quand, au XI ${ }^{e}$ siècle, la moniale Glykeria donne sa propriété de Skyros à Lavra, l'ecclésiarque du monastère vient de la presqu'île pour négocier et rendre officiel l'acte de donation ${ }^{29}$ : il est inscrit dans l'acte qu'elle a fait écrire le document " par l'ecclésiarque de Lavra Athanase, en présence de témoins dignes de foi ${ }^{30}$ ». Quand Maria Tzousménè donne une terre située à Hiérissos au monastère de Zographou, l'higoumène (abbé) de Zographou vient la voir pour discuter des termes du don ${ }^{31}$. Dans le cas des ventes, des représentants des monastères étaient présents lors de la conclusion de la transaction, pendant laquelle ils payaient les femmes directement, le plus souvent en liquide, et recevaient en retour un acte de donation signé par les vendeurs et confirmé par les témoins. Ajoutons que dans des cas de litige, les moines sont conduits à négocier avec des femmes, à de nombreuses reprises. Le combat le plus long est mené par Xénè Isarina : dès 1363, elle engage des poursuites judiciaires contre le monastère de Chilandar pour un désaccord concernant des biens lui appartenant. Elle devra se battre pendant onze ans pour faire reconnaitre ses droits sur ses terres ${ }^{32}$. Durant ces années, les représentants de l'Athos qui défendent les intérêts de la sainte montagne sont en contact avec Xénè.

Ainsi, si les femmes ne peuvent se rendre sur la montagne sacrée, les Athonites viennent à elles. Mais cette forme de présence n'est pas encore suffisante pour certaines, qui rêvent de l'idéal de vie ascétique et louent les vertus des saints anachorètes, comme le laissent transparaitre quelques sources.

\section{Créer des liens spirituels à défaut d'être présentes}

En désespoir de cause, les femmes, exclues de la montagne, vont se contenter d'exprimer dans les actes de donation leur attachement à cette dernière et leur ferme aspiration à créer des liens spirituels avec elle. Marie Tzousménè écrit dans son acte de donation : «Quand j'entends parler de la sainte montagne, mon âme a soif de Dieu, et je souhaiterais avoir ma part sur la sainte montagne [...] et je voudrais être commémorée sur la sainte montagne ${ }^{33}$. Glykeria, qui donne à Lavra toutes ses propriétés sur l'île de Skyros, appelle Eustratios, l'abbé de Lavra, son " père spirituel ${ }^{34}$ ». Les propos de Marie Lagoudès vont plus loin encore : comme Marie Tzousménè, lorsqu'elle donne avec son époux Constantin une propriété à Théodoretos, abbé de Lavra, elle le désigne comme étant son "père spirituel ». Mais elle affirme au début de l'acte de donation qu'elle a été "élevée par les moines de Lavra, alors même que sa mère la portait ». Ceci peut signifier qu'elle vivait grâce à un adelphaton de Lavra. Cependant le terme est si fort qu'il montre un attachement viscéral à la montagne. Elle continue en affirmant :

«Toute notre vie, nous [mon époux et moi] nous sommes dévoués à Lavra et nous avons toute foi en ses moines, compte tenu de la vertu des pères qui y vivent et de leur compassion. Maintenant que nous avons atteint un âge avancé, et n'avons pas d'enfants qui pourraient prendre soin de notre esprit, nous avons vu en Lavra un refuge, un havre de salut. Ainsi les moines peuvent inscrire nos noms dans les saints diptyques de l'église afin que nous soyons commémorés. À partir de maintenant, nous serons liés avec les moines par l'esprit, devenant un seul esprit, et nous devenons frères de Lavra ${ }^{35}$. »

Cette dernière expression suscite la curiosité : le terme d'adelphoi, frères, n'est pas anodin, surtout si l'on prend en compte la tonalité de cet acte où Marie exprime avec une certaine passion son attachement à la sainte montagne. Paul Lemerle a ainsi émis 
l'hypothèse de l'existence d'une confrérie, s'appuyant également sur l'acte de donation d'une certaine Thomais. En échange de dons de différents objets et d'argent, du partage de ses propriétés, cette dernière souhaite qu'elle-même et les deux copropriétaires des biens cédés soient commémorés comme "frères du monastère aussi bien pendant qu'après leur mort ${ }^{36} »$. Paul Lemerle suggère donc qu'il existait des sortes de confréries d'honneur, dont l'accès était réservé aux plus généreux bienfaiteurs des monastères. Les femmes pouvaient ainsi y trouver un moyen d'être présentes sur la montagne, non pas physiquement, mais spirituellement ${ }^{37}$. Maigre compensation, mais fondamentale pour celles qui cherchent, toute leur vie durant, à assurer leur salut éternel.

Ainsi donc, on voit que les moines athonites acceptent, voire convoitent les biens, les dons, l'argent des femmes. Mais il n'en reste pas moins que celles-ci n'ont jamais été admises à pénétrer sur leur montagne, bien qu'elle soit dédiée à la Vierge. Les multiples demandes formulées ces dernières années en faveur de la levée de l'interdiction des femmes sur l'Athos montrent que la tradition a perduré. Malgré une résolution du parlement européen en 2003 et une demande du conseil œcuménique des églises en 2013, les moines de l'Athos continuent à refuser l'accès des femmes sur la montagne, mettant en avant le vœu de chasteté. Comme au Moyen Âge, les femmes n'ont donc qu'une solution pour pénétrer sur la montagne: se déguiser en homme. C'est ce que firent quelques-unes d'entre elles, provoquant un immense scandale, telle Maryse Choisy, écrivaine et journaliste, en 1929. L'ouvrage qu'elle publia quelques mois plus tard, Un mois chez les hommes, qui racontait son expérience, provoqua un tollé, pas vraiment parce qu'il montrait qu'elle avait réussi à pénétrer sur l'Athos, mais parce qu'elle y évoquait l'obsession des moines pour la femme. Quelques années plus tard, c'est Aliki Diplarakou, miss Europe 1930, qui fit de même, apparemment par défi... Mais les moines ne l'auront vue que déguisée en berger ! La seule autorisation récente émise par ces derniers date de 2008, où des réfugiées moldaves s'étaient échouées à proximité de la montagne. Les moines avaient alors accepté de permettre aux femmes d'accoster quelques heures sur l'Athos, et cela seulement par charité chrétienne.

\section{BIBLIOGRAPHIE}

ALBERIGO Giuseppe et al. (dir.), Les conciles œcuméniques. Les décrets. Nicée I à Latran V, t. II, vol. 1, Paris, Le Cerf, 1994.

BEES Nikos, « Symbole eis ten historian ton monon ton Meteoron », Byzantis, nº 1, 1909, p. 191-331.

BOMPAIRE Jacques, Actes de Xéropotamou, Paris, P. Lethielleux (Archives de l'Athos, III), 1964.

BOMPAIRE Jacques, LEFORT Jacques, KRAVARI Vassiliki, GIROS Christophe, Actes de Vatopédi I. Des origines à 1329, Paris, P. Lethielleux (Archives de l'Athos, XXI), 2001. 
DESEILLE Placide (trad.), L'Échelle sainte de saint Jean Climaque, $2^{\mathrm{e}}$ éd., Bégrolles-en-Mauge, abbaye de Bellefontaine (Spiritualités orientales, 24), 1993.

GAUTIER Paul, « Le typikon de la Théotokos Evergétis », Revue des études byzantines, n 40,1982 , p. 5-101.

GAUTIER Paul, «Le typikon du sébaste Grégoire Pakourianos », Revue des études byzantines, $\mathrm{n}^{\circ} 42$, 1984, p. 5-145.

GREENFIELD Richard et TALBOT Alice-Mary (éd. et trad.), Holy men of Mount Athos, Cambridge / Londres, Harvard University Press (Dumbarton Oaks Medieval Library, 40), 2016.

GRUMEL Venance, Les regestes des actes du patriarcat de Constantinople, vol. I : Les actes des patriarches, fasc. III : Les régestes de 1043 à 1206, Socii Assumptionistae Chalcedonenses (Le patriarcat byzantin, série 1), 1947.

GYONI Matyas, «Les Valaques du mont Athos au début du XII ${ }^{\mathrm{e}}$ siècle », Études slaves et roumaines, $\mathrm{n}^{\circ}$ 1, 1984, p. 30-42.

KORABLEV Basily et PETIT Louis, Actes de Chilandar, Saint-Pétersbourg, Ti. Imperatorskoj Akademii Nauk (Buzantina Hronika), 1911.

LEFORT Jacques, OIKONOMIDÈs Nicolas, PAPACHRYSSANTHOU Denise, Actes d'Iviron, I : Des origines au milieu du XI e siècle, Paris, P. Lethielleux (Archives de l'Athos, XIV), 1985.

LEMERLE Paul, GUILlou André, svoronos Nicolas, Actes de Lavra I, Paris, P. Lethielleux (Archives de l'Athos, V), 1970.

LEMERLE Paul, GUILLOU André, svoronos Nicolas, PAPACHRYSSANTHOU Denise, Actes de Lavra III : de 1329 à 1500, Paris, P. Lethielleux (Archives de l'Athos, X), 1979.

LEMERLE Paul, GUILlou André, svoronos Nicolas, PAPACHRYSSANTHOu Denise, Actes de Lavra IV, Paris, P. Lethielleux (Archives de l'Athos, XI), 1982.

MEYER Philipp, Die Haupturkunden für die Geschichte der Athosklöster, Leipzig, 1894.

OIKONOMIDÈs Nicolas, Actes de Docheiariou, Paris, P. Lethielleux (Archives de l'Athos, XIII), 1984. PAPACHRYSSANTHOU Denise, Actes du prôtaton, Paris, P. Lethielleux (Archives de l'Athos, VII), 1975. PAPACHRYSSANTHOU Denise, Actes de Xenophon, Paris, P. Lethielleux (Archives de l'Athos, XV), 1986. REGEL Wilhelm, KURTZ Eduard, KORABLEV Basily, Actes de Zographou, Amsterdam, Hakkert (Buzantina Hronika), 1969.

RYDELL JOHNSEN Henryk, Reading John Climacus. Rhetorical argumentation, literary convention and the tradition of monastic formation, Lund University, 2007.

soulis George, « Tsar Stephan Dusan and Mount Athos », Harvard Slavic Studies, n 2, 1954, p. 349-363.

TАLвот Alice-Mary, «A comparison of the monastic experience of Byzantine men and women », Greek Orthodox Theological Review, $\mathrm{n}^{\circ}$ 30, 1985, p. 1-20.

THOMAS John et HERO Angela (éd.), Byzantine monastic foundation documents: a complete translation of the surviving founders' typika and testaments, Washington (Dumbarton Oaks Research Library and Collection), 2000.

WEITZMANN Kurt, Sailing with Byzantium from Europe to Americ: the memoirs of an art historian, Munich, Maris, 1994. 
ZIVojINovic Mirjana, « De nouveau sur le séjour de l'empereur Dusan à l'Athos », Zbornik Radova Vitantoloskog Instituta, $\mathrm{n}^{\circ}$ 21, 1982, p. 119-126.

ZIVOJINOVIC Mirjana, KRAVARI Vasiliki, GIROs Christophe, Actes de Chilandar, des origines à 1319, Paris, P. Lethielleux (Archives de l'Athos, XX), 1998.

\section{NOTES}

1. K. Weitzmann, Sailing with Byzantium from Europe to America, p. 135. Jean Climaque, dit aussi Jean le Sinaïte, moine syrien des $\mathrm{VI}^{\mathrm{e}} / \mathrm{VII}^{\mathrm{e}}$ siècles, rédige ce traité afin de former les moines. Il y décrit l'itinéraire spirituel à la manière d'une montée vers Dieu à travers trente degrés. Sur Jean Climaque, voir la traduction L'Échelle sainte réalisée par le père P. Desseille et H. Rydell Johnsen, Reading John Climacus.

2. G. Alberigo et al. (dir.), Les conciles œcuméniques, p. 336.

3. Athanase l'Athonite le dit lui-même dans le typikon de l'Athos de 973 : P. Meyer, Die Haupturkunden für die Geschichte der Athosklöster, p. 105.

4. Concernant la géographie et la situation de l'Athos, voir D. Papachryssanthou, Actes du Prôtaton, p. 3-8 ; R. Greenfield et A.-M. Talbot (éd. et trad.), Holy Men of Mount Athos, p. i-vii.

5. Originaire d'un village de l'Opsikion, Euthyme de Thessalonique s'enfuit de chez lui à l'âge de dix-huit ans afin de se faire moine sur l'olympe. Quinze ans plus tard, il décide de se rendre sur le mont Athos dans le but de vivre différentes expériences ascétiques. Celles-ci lui apportant une grande renommée, il attire à lui nombre de disciples. Sur ce point voir D. Papachryssanthou, Actes du Prôtaton, p. 22-29.

6. Ibid., p. 30-31.

7. J. Thomas et A. C. Hero, Byzantine monastic foundation, documents, p. 86.

8. P. Meyer, Die Haupturkunden für die Geschichte der Athosklöster, p. 113. Une règle similaire est édictée par le prôtos Paul pour le monastère de Xénophon : aucun animal de sexe féminin ne doit être introduit dans le monastère : D. Papachryssanthou, Acte de Xenophon.

9. Ibid., p. 227.

10. Ibid., p. 260.

11. Ibid., p. 260.

12. C'est l'empereur Jean Tzimiskès qui, le premier, a édicté cette prescription au $\mathrm{x}^{\mathrm{e}}$ siècle, sans que son règlement comporte la moindre mention concernant précisément les femmes : ibid., p. 212.

13. N. Bees, "Symbole eis ten historian ton monon ton Meteoron », p. 251. Les typika des monastères de l'Evergetis et de la Théotokos de Petritzonitissa à Backovo se contentent d'interdire la présence de femmes lors des distributions charitables: P. Gautier, «Le typikon de la Théotokos Evergétis », p. 83; "Le typikon du sébaste Grégoire Pakourianos », p.104-105. Sur les autres saintes montagnes, on tente de contrôler la présence des femmes en permettant l'établissement d'un simple monastère féminin qui accueille le plus souvent des proches ou des parentes des moines: A.$\mathrm{M}$. Talbot, "A comparison of the monastic experience of Byzantine men and women ", p. 2-3. 
14. Concernant les différentes attributions du prôtos, voir D. Papachryssanthou, Actes $d u$ Prôtaton, p. 123-129.

15. Voir le texte intégral dans P. Meyer, Die Haupturkunden für die Geschichte der Athosklöster, p. 163. On retrouve l'analyse diplomatique dans les regestes du patriarcat de Constantinople : V. Grumel, Les regestes des actes du patriarcat de Constantinople, vol. I, fasc. III, p. 62-63 ; M. Gyoni, "Les Valaques du mont Athos au début du XII siècle ", p. 39.

16. V. Grumel, Les regestes des actes du patriarcat de Constantinople, vol. I, fasc. III, p. 168 ; voir aussi l'analyse diplomatique p. 62-63. Nicolas III se défend d'avoir établi un décret établissant des règles pour l'Athos, car il n'a pas ce pouvoir. Ce document est d'ailleurs une réponse de l'empereur à des moines athonites venus se plaindre de la prétendue attitude de l'empereur.

17. P. Lemerle a proposé une analyse de ce chrysobulle en langue grecque destiné à la Grande Lavra. Il suppose qu'il fut délivré à l'issue du voyage de Dusan sur l'Athos afin d'y confirmer tous les privilèges donnés à ce monastère : P. Lemerle et al., Actes de Lavra IV, p. 41. Pour démontrer que Dusan se trouvait à son avis sur le mont Athos au moment de l'émission de l'acte, M. Zivojinovic utilise trois autres chrysobulles en langue serbe, dont deux s'adressent à Chilandar, et le dernier au kellion de Saint-Sabbas, à Karyès : M. Zivojinovic, «De nouveau sur le séjour de l'empereur Dusan à l'Athos ", note 6, p. 120.

18. Nous nous appuyons sur le chrysobulle en langue grecque rédigé par Dusan pour le monastère de la Grande Lavra en 1347, mais l'empereur évoque son séjour et ses bienfaits dans au moins trois autres documents. Sur cet événement, voir G. Soulis, "Tsar Stephan Dusan and Mount Athos », p. 353, et M. Zivojinovic, « De nouveau sur le séjour de l'empereur Dusan à l'Athos », p. 119-126.

19. M. Zivojinovic, ibid., p. 124.

20. G. Soulis, «Tsar Stephan Dusan and Mount Athos », p. 355.

21. R. Greenfield et A.-M. Talbot (éd. et trad.), Holy men of Mount Athos, p. 117.

22. J. Bompaire, Actes de Xéropotamou, p. 217.

23. J. Lefort et al., Actes d'Iviron I, p. 190-193.

24. J. Bompaire, Actes de Xéropotamou, p. 189-196.

25. Elle émet le souhait que les moines de Xéropotamou chantent pour elle une prière à la Vierge aux vêpres du lundi et la messe le mardi, et qu'ils boivent une coupe de vin à la trapéza : ibid., p. 217.

26. J. Bompaire et al., Actes de Vatopédi I, p. 172-174.

27. M. Zivojinovic et al., Actes de Chilandar, p. 156.

28. N. Oikonomidès, Actes de Docheiariou, p. 15-18.

29. P. Lemerle et al., Actes de Lavra I, p. 155-161.

30. Ibid., p. 161.

31. B. Korablev et L. Petit, Actes de Chilandar, p. 320.

32. Ibid., p. 324-326. Cet acte présente l'issue du combat de Xénè Isarina, qui est morte depuis.

33. W. Regel et al., Actes de Zographou.

34. P. Lemerle et al., Actes de Lavra I, p. 160. 
35. Ibid., p. 150.

36. Ibid., p. 195.

37. Ibid., p. 197.

\section{RÉSUMÉS}

Parmi les montagnes de l'Empire byzantin, la presqu'île de l'Athos devient, dès la fin du viII siècle, un centre monastique majeur : ceux et celles qui sont poussés irrésistiblement à fuir un monde empêchant toute méditation y voient le lieu le plus propice au recueillement solitaire. Les institutions qui s'y multiplient présentent une singularité révélée dans leurs règlements : ce sont les seuls monastères où la présence des femmes, et même des femelles lorsqu'il est question d'animaux, y est totalement interdite. Pourtant, d'autres archives de l'Athos permettent d'observer la participation de celles qui sont présentées comme des sources de tentation à la vie économique de la Macédoine orientale. Bien que très peu nombreuses, ces interventions permettent de mesurer l'écart existant entre l'interdiction totale pour les femmes de se trouver sur la montagne et la pratique. Une autre forme de présence est possible pour celles qui louent les vertus des saints anachorètes athonites.

\section{AUTEUR}

\section{DIANE PASQUIER-CHAMBOLLE}

Professeur d'histoire-géographie au collège Langevin-Wallon (Tarnos) 


\title{
Ancrage territorial d'une communauté monastique : le mont Athos
}

\author{
Pierre-Yves Péchoux
}

1 L'évidence de l'Athos s'impose dans tout le nord de l'Égée, entre la Troade et l'Olympe : un promontoire montagneux allongé, étroit, «dressé sur le dos de la plaine liquide ${ }^{1}$ ", comme jeté dans la mer depuis la Chalcidique et culminant au sud à plus de deux mille mètres d'altitude, souvent venté et nuageux, pluvieux et même neigeux en hiver. Ses quelques replats vers 400 ou 600 mètres d'altitude sont inscrits entre des versants pentus séparés par des vallons ou brisés par des escarpements rocheux, qui dominent les rivages étroits d'une côte accore peu hospitalière. À parcourir l'Athos, on le ressent comme une île, même si cartes et atlas y reconnaissent une péninsule. On n'y accède que par la mer, en bateau. Il n'est rattaché au continent que par un isthme si bref et si mince que gens de mer et stratèges avaient entrepris d'y ouvrir un canal. La raideur des versants dressés au sud au-dessus de cet isthme et l'épaisseur et la densité de la forêt qui les couvrent en font une digue difficile à franchir, même à pied, surtout depuis la construction d'une barrière de neuf kilomètres.

2 Une fois débarqué par l'ouest, on reconnaît le mode d'organisation spatiale des îles grecques : une échelle, à Daphni, la skala, subordonnée à une petite bourgade bâtie plus haut, Karyès ; la khôra, qui rassemble tous les services d'intérêt général pour un espace d'à peu près 330 kilomètres carrés, où est distribuée une population de l'ordre de 2500 habitants. Découvrir plus tard, dans cette solitude habitée, que sont conservés près de cimetières étriqués, d'amples ossuaires contenant les restes d'innombrables défunts, fait se demander si les habitants du moment ne sentent pas leur nombre augmenté de celui de leurs prédécesseurs, d'autant qu'ils travaillent souvent en murmurant que le Christ a terrassé la mort, qu'il a donné la vie à ceux qui sont dans les tombeaux.

3 L'Athos est une île singulière, car il est autrefois devenu et continue d'être tenu pour le plus fameux sanctuaire de l'Église grecque. J'y suis allé en géographe pour observer les paysages sensibles et tenter d'y découvrir leur sens en m'attachant aux rapports entre les lieux et ceux qui les habitent, les ont façonnés, en ont fait leur pays en même temps 
qu'une représentation de leurs aspirations et de leurs convictions religieuses. Au-delà de l'impression d'insularité, mon expérience y fut celle de la pénétration dans une hétérotopie hors du siècle : un ailleurs, une extériorité par rapport aux références de mes autres enquêtes en Grèce.

\section{Longue consécration religieuse de l'Athos}

4 Inutile de s'attarder sur le fait que cette montagne est définie comme un bloc tectonique surgi de l'écorce terrestre. Car elle est vécue par ses habitants comme un lieu de communication directe avec le divin, qualité qui fait que les contraintes de site y sont, à l'exception de l'accessibilité permanente à une eau potable, reléguées au second rang par ceux qui ont décidé depuis des siècles de s'y établir pour y mener une vie d'ascèse qui réponde à leur vocation spirituelle et religieuse. Cela a entraîné que la trame des paysages y soit rythmée par une imposante série de monastères, de prieurés, d'ermitages séparés les uns des autres par des pans de forêt ou de garrigue: vingt monastères aujourd'hui, plus du double autrefois ; cela a entraîné que cette montagne péninsulaire soit ponctuée par un millier d'églises, rarement volumineuses mais partout présentes.

5 Deux d'entre elles méritent d'être évoquées. Parce qu'elles sont bâties presque au sommet du mont Athos proprement dit, ce qui leur vaut le soir de paraître couronnées d'étoiles, très près du ciel, en un lieu dont on tenait depuis longtemps qu'il relève du domaine divin et du règne de Zeus ${ }^{2}$, dont il porta un temple. On imagina plus tard d'y dresser une statue à la ressemblance du grand Alexandre. Gestes et intentions qui, inspirées par la force des lignes et du volume de la montagne, en faisaient le symbole d'une personne ou interprétaient son élévation comme une métaphore du divin dans le tangible. La première de ces deux églises est dédiée à la Panayia, la Toute Sainte, parce qu'elle est le témoin de l'incarnation, soit de la double nature, divine et humaine, de Jésus qu'elle a mis au monde. La seconde est consacrée à la transfiguration du Sauveur, témoignage de la vérité de la résurrection promise.

6 Pour modestes qu'ils soient, les deux monuments bâtis là illustrent deux des principes dogmatiques qui sont comme le lien matriciel entre les lieux qu'ils dominent et la communauté de foi, l'assemblage résidentiel d'ermites et de moines qui vivent et meurent dans l'Athos, et auxquels est dévolu ce territoire reconnu comme leur pays, où leurs gestes quotidiens perpétuent leur passé séculaire. Ces deux monuments suffiraient à comprendre pourquoi l'Athos fut surnommé Ayion Oros, la sainte montagne, et comment l'usage et la nécessité de ce surnom imposèrent qu'il devînt, par décision impériale arrêtée à Constantinople, son toponyme officiel. Le chrysobulle de 1144 a entériné l'identité narrative de la montagne en y reconnaissant l'expression d'un rapport d'ordre sacré entre un lieu et ses occupants; il a sans doute contribué à élargir dans l'imaginaire d'une grande partie de la chrétienté la place et le rôle de la société religieuse fixée dans cette belle montagne écartée et malcommode.

7 Ces deux églises et la multitude des autres que l'on vénère dans l'Athos, pas toutes situées dans les enceintes des monastères, aident à comprendre comment la montagne rayonne du fait de son caractère historique et spirituel. À comprendre comment ce rayonnement en fait un territoire de référence commun au christianisme orthodoxe des temps présents. Cependant, les divergences doctrinales des interprétations de ce christianisme et l'émiettement territorial et politique des nations, des pouvoirs et des 
États qui peuvent ou veulent s'en réclamer, suggèrent que l'Athos leur est commun du simple fait de leurs rivalités et de leurs compétitions. La sainte montagne est vite devenue un enjeu, et le demeure dans son actualité contemporaine. Son importance n'est pas limitée à ses dimensions muséales, patrimoniales ou paysagères, mais elle ne semble plus jouer un grand rôle dans le façonnement des échanges savants entre les communautés orthodoxes, ni dans leur formation intellectuelle.

\section{Interrogations sur l'autorité exercée dans la montagne}

La personnalité de l'Athos a presque toujours été respectée, même au prix de contributions fiscales. Son autonomie territoriale, admise par l'empire byzantin, a résisté à son délitement et fut conservée par les Ottomans après la prise de Salonique (1430) et de Constantinople (1453). Au fil des siècles, les puissances du voisinage ont en général, sauf quand l'Athos prit parti en 1821 pour les Grecs, admis que la péninsule échapperait à leurs ambitions d'étendre sur leurs marges des avantages commerciaux, diplomatiques, militaires ou frontaliers. En organisant en mai 1913 l'effacement de la Turquie en Europe, le traité de Londres établit, au prix de longues discussions entre Angleterre, Autriche et Russie, la neutralité de la sainte montagne, sans mettre en question l'autorité spirituelle et juridique du patriarcat œcuménique de Constantinople sur chacun des monastères établis dans ce territoire et sur les habitants qui y sont reclus. C'était reconnaître la tradition spécifique de cet «îlot» parmi «les archipels ethnologiques » évoqués par Élisée Reclus aux confins entre Balkans et Égée ${ }^{3}$. Mais les négociations entre Grèce, Roumanie, Serbie et Monténégro, d'une part, et Bulgarie de l'autre, qui aboutirent en juillet 1913 au traité de Bucarest, écartèrent les réclamations de la Grèce qui ne furent, à propos de la possession de l'Athos, satisfaites ou presque qu'au traité de Lausanne, dix ans plus $\operatorname{tard}^{4}$.

On est donc confronté dans l'Athos à quelques ambiguïtés. L'ensemble des monastères fixés là dispose d'une administration spécifique, selon une charte statutaire perpétuant une tradition pluriséculaire, modernisée en dernier lieu en 1924 pour restaurer les principes de leur assise territoriale et les relations de coopération qu'ils entretiennent entre eux. Or, on y débarque en territoire grec. Les traités qui l'ont intéressé de 1913 à 1923, à l'issue des guerres balkaniques, usaient à son propos d'une dénomination géographique: "péninsule du mont Athos». Les recensements officiels de la population de la Grèce dénombrent ensuite sa population comme celle d'Ayion Oros, district inscrit dans un alinéa qui le distingue des 47 départements grecs en 1948 et des 12 départements de la Macédoine à partir de 1951 : rappel typographique discret de son autonomie ${ }^{5}$. Car un dernier compromis a fait en 1926 de la sainte montagne une sorte de protectorat grec, ce qui prive les monastères d'une souveraineté absolue sur leur pays.

10 Mais on mesure bientôt la distance qui sépare l'illusion de la souveraineté de la réalité du pouvoir. Il faut atteindre Karyès, qui est dans l'intérieur, bien plus haut que la skala, un modeste centre multiservices pour toute la péninsule : un lieu d'entrepôt, un khani, et plusieurs échoppes, un pazari, où loger, boire un café, se nourrir, faire des emplettes, chercher la poste, louer un porteur ou approcher, entre deux douzaines de voitures qui usent depuis peu des quelques pistes poussiéreuses de la péninsule, celle qui pourrait épargner un peu de marche. On peut croiser là deux gendarmes grecs aussi modestes 
que désœuvrés, y rencontrer un fonctionnaire grec du rang de préfet qui ne paraît pas surchargé de tâches.

11 Il faut avant tout se présenter devant un comité de cinq moines pour solliciter un permis de séjour, qui vaut assurance de disposer du gîte et du couvert dans les monastères : le visiteur est accueilli avec aménité, comme un hôte, même s'il ne vient pas en pèlerin. Chacun des quatre premiers membres de ce comité est délégué là par chacun des quatre groupes de monastères formés dans la montagne. Ils constituent la commission exécutive chargée par une réunion délibérative des représentants de chaque monastère de régir et d'administrer opportunément l'ensemble de l'Athos dans l'intérêt général, tel que défini par ces représentants et par leur président, le prôtaton, le tout premier par le mérite, lequel préside aussi le comité exécutif.

Cette double présidence est au fil du temps toujours confiée à un moine du même monastère, celui d'Ayios Athanasios, dont la majesté n'est pas discutée, probablement parce qu'il passe pour le plus ancien des vingt. Le privilège d'usage dont jouit de la sorte ce monastère et le fait que tous les autres demeurent libres d'accepter ou pas les propositions de leur réunion devraient persuader, même si aucune de ces appellations n'a d'écho dans l'Athos, que celle de "confédération » lui convient mieux que celle de "république monastique ». L'Athos se trouve donc en Grèce, mais dans une situation d'extraterritorialité, puisque l'État grec y renonce à ses compétences législatives et juridiques au profit d'une société locale, des règles qu'elle perpétue et des institutions spécifiques dont elle se réclame. Ce statut a été garanti dans les textes consacrant en 1981 l'adhésion de la Grèce à la Communauté économique européenne.

Cette confédération monastique, une figure d'autorité spiritualisée dans la vaste orthodoxie, assure le contrôle séculier de son petit territoire dans une perspective souvent conservatrice. Pour résister à la pression touristique, dont les effectifs surpassent ceux des pèlerins, et pour éviter que la sainte montagne ne soit affectée par la consommation de loisirs, elle a récemment diminué la durée du permis de séjour. Pour signifier à la Grèce que sa souveraineté ne lui donne pas tous les pouvoirs, elle a rejeté le projet de déclaration d'un parc naturel national dans l'Athos. Mais en acceptant que la péninsule soit inscrite par l'Unesco en 1988 au Patrimoine mondial de l'humanité, puis en consentant à son intégration au programme européen Natura 2000, elle affirmait son existence dans le champ des relations internationales tout en reconnaissant qu'elle manque de moyens pour préserver ou restaurer ses forêts et ses édifices.

\section{Masculinité exclusive de l'Athos}

14 Une autre ambiguïté de l'Athos tient à ce que l'on y vit, on y prie, on y travaille, on y réfléchit sans y être jamais né : aucun registre des naissances dans la péninsule. Ermites et moines y sont tous des immigrés arrivés d'un peu partout, de la Grèce voisine, de quantité de provinces des Balkans et de leurs confins orientaux et septentrionaux, telles la Moldavie, l'Ukraine, la Russie, et parfois de plus loin, comme la Géorgie ; tous sont admis, sans plus, parce qu'ils sont la postérité d'Abraham, comme l'avait rappelé Paul aux Galates. Mais on fait peu de cas dans l'Athos des mots de Paul qui assurent qu'il ne doit, de ce fait, être de discrimination entre les femmes et les hommes ${ }^{6}$. Or l'absolu de la masculinité de l'Athos, entraînant l'exclusion de toutes les femmes, leur interdiction de résidence ou de séjour, semble établi par des rescrits de l'empire 
byzantin, dont les plus anciens dateraient du $\mathrm{XI}^{\mathrm{e}}$ siècle, et dont on assure qu'ils furent maintes fois confirmés sans qu'il soit assuré qu'ils appartiennent à l'histoire plutôt qu'à la fable. Est-ce pour répondre à l'inégalité d'un tel absolu que quelques monastères féminins avaient autrefois choisi d'approcher de la sainteté de l'Athos en se fixant en Chalcidique, au voisinage de sa péninsule, comme si l'isthme qui les sépare n'était rien?

Un interdit d'autant plus difficile à comprendre que l'Athos est sous la protection de la Vierge, dont c'est le jardin, et que la sainte montagne est profondément marquée par la vénération de Marie, la Toute Sainte, et des représentations qu'en proposent avec diverses épithètes les icônes de ses églises. Un géographe osera-t-il risquer une explication fondée sur des enquêtes dans le voisinage? Des troupeaux de pasteurs semi-nomades ou transhumants n'ont-ils pas pâturé replats et pentes de l'Athos en hiver, à une saison où agnelage, lactation, préparation du fromage, puis tonte de la laine rendent bien plus nécessaire le travail des femmes et des filles des pâtres que dans leurs estives d'altitude du côté du Pangée, du Kaïmaktchalan et du Rhodope? La cohabitation saisonnière entre de tels troupeaux et des paysanneries sédentaires est parfois conflictuelle. Serait-il arrivé que les effectifs d'un tel bétail menacent de réduire la surface agricole nécessaire aux moines à un moment où leur nombre et celui des monastères augmentaient ? Serait-il venu à leur esprit que parvenir à un règlement qui, excluant les femmes, les débarrasserait de troupeaux privés de bergères?

Débarquer à Daphni fait cependant découvrir que moines et ermites n'y sont pas les seuls hommes : quelques dockers, quelques ouvriers, quelques muletiers, qui depuis longtemps sont souvent des Albanais, assurent le contact entre le reste du monde et l'Athos; ils s'activent entre le mouillage, les amarres, les bâtisses et les rares services qui complètent la skala et aident au menu trafic vers la khôra. Pénétrer la péninsule ou la contourner en fait rencontrer d'autres, sommairement installés, isolés aux bords de plusieurs arsa, ces petits mouillages distribués sur ses côtes ouest et est selon les commodités du littoral, pour approcher et desservir irrégulièrement les monastères bâtis plus haut ; leur nombre est parfois grossi par des pêcheurs de passage, raréfiés par la modernisation de leurs caïques. Tous ces hommes de la côte, quelques dizaines, sont des étrangers, des kosmiki, parce qu'ils appartiennent au monde profane et non à la communauté de vocation des ermites et des moines, tous sortis de ce monde pour échapper à la vue de la foule, jouir du silence et tenter d'atteindre Dieu.

\section{Trois types d'occupation du sol dans l'Athos}

Parcourir l'Athos ou consulter son imagerie satellitale y fait distinguer à moyenne échelle trois compartiments, dont les paysages, les aménagements et les usages diffèrent.

\section{La frontière forestière du nord}

Au nord, une marche forestière, forêt épaisse de six ou sept kilomètres, taillis et futaies de chênes, frênes, châtaigniers, difficile à franchir, est très peu habitée sinon lors de quelques chantiers d'exploitation du bois qui la déséquilibrent plus qu'autre chose depuis trente ou quarante ans, après les incendies désastreux de 1890, 2004 et 2012. C'est largement une forêt de substitution, élargie et accrue sur des quartiers agricoles 
délaissés ou des pâturages d'hiver abandonnés depuis des siècles. Ce fut une source de matériaux pour les monastères : charpentes, planchers, menuiserie, charbon de bois, et elle demeure une certitude d'y récolter quantité de châtaignes et de noisettes à consommer sur place ou à exporter. C'est aujourd'hui un capital, dont l'exploitation est confiée à la main-d'œuvre d'entreprises extérieures qui exportent bois et charbon après avoir marchandé les droits de coupe aux monastères, et qui paraissent peu soucieuses de bonne gestion forestière. Ce peut être un abri, et c'est un danger perceptible à deux échelles : les deux derniers incendies ont ravagé près de six mille hectares, et sa faune de sangliers menace vignes et jardins du voisinage.

\section{Le front érémitique du sud}

19 Tout au sud, on découvre une marge de quelques centaines de mètres d'épaisseur sur les trois faces du mont Athos, Pinès, Karoulia, Akrathos : falaises, versants rocailleux, pentus, exposés au vent, aux embruns, au froid, au soleil. Cela vaut le désert. Les rochers sont plus usés qu'ailleurs, les sols discontinus et amaigris, et la végétation arbustive réduite à des témoins : signes d'usage et défaut d'entretien, hormis quelques jardinets. C'est le refuge écarté de quelques dizaines d'ermites isolés, de la majorité de ceux qui vivent encore et meurent en anachorètes dans la péninsule : ils demeurent là loin des sollicitations et des tentations du monde, qu'ils ont comme abolies en choisissant ces lieux pour s'y vouer à la prière de la contemplation et atteindre la sérénité, ce qui entraîne qu'ils soient qualifiés d'hésychastes. Mal abrités sous un rocher ou une cahute fragile, mal vêtus, peu équipés, se contentant souvent d'un sac, d'un bol, d'un couteau; frugaux, nourris de ce qu'ils cueillent ou entretiennent parfois sur place et du pain que leur abandonnent pèlerins et marins, ou que leur apportent les moines les plus proches. Ils n'ont pas d'icônes, pas d'église. Ils se sentent là plus proches du verbe divin, disent converser avec le Seigneur, avoir des visions qui les inspirent. Leur foi est manifestée et affirmée dans le sens d'une croyance personnelle.

Ce sont des «bordiers », pour reprendre ce mot à la géographie rurale, des marginaux, si on les compare à la société monastique conventuelle avec ses horaires, ses hiérarchies, ses principes, qu'ils tiennent pour des concessions aux modes de vie du monde profane. Mais leur présence témoigne de ce que furent, voilà quinze siècles, la découverte et l'occupation de l'Athos par de nombreux solitaires décidés à rompre avec le monde et qui furent peu à peu confinés à l'écart, du côté des forêts ou des côtes, sinon exclus, à partir du moment où, vers la fin du $x^{e}$ siècle, le monachisme commença, avec la bienveillance des puissants de l'empire byzantin, d'être institutionnalisé et discipliné en collectivités organisées selon les tâches, les fonctions et les responsabilités de chacun, définies par des règles acceptées par tous ou imposées, mais incompatibles avec l'individualisme érémitique, qu'il concurrençait.

\section{Les aîtres du monachisme conventuel dominant}

21 Entre la marche du nord et la marge du sud, le monachisme conventuel a donc marqué, occupé et pris le contrôle de la plus grande partie de la péninsule en y métamorphosant d'une part les modes d'habitat et d'occupation des sols: concentration plutôt que dissémination ; et d'autre part, les modalités de l'expression et du témoignage de la foi : rassemblement, ekklésia, plutôt que dispersion. La plus ancienne de ces collectivités 
religieuses, établie au $\mathrm{x}^{\mathrm{e}}$ siècle par l'ermite Athanasios, conserve l'appellation de Méghali Lavra, la Grande Laure, un nom qui évoque un abri allongé, bâti sous un toit, pour rapprocher et réunir plusieurs moines qui se consacreraient ensemble au service divin.

Il reste là depuis deux siècles vingt monastères imposants, propriétaires de leurs terroirs, entre lesquels l'espace est innervé par un réseau de petits chemins malcommodes, sinueux, pentus, pierreux ou dallés, dont les bifurcations sont parfois balisées par des croix de métal. Chaque monastère est inscrit dans une clairière conquise autrefois au détriment de la forêt, dont l'état signale qu'elle manque de soins et dont l'observation des lisières suggère qu'elle s'élargit.

Tous ces monastères ont une allure de petite ville ceinturée par de beaux remparts, construits sous des toitures de tuiles pour être habités et imaginés pour être défendus, ce dont témoignent souvent une ou deux tours qui les complètent, plus élevées avec des murs plus épais pour mieux protéger reliques, icônes précieuses, livres, archives et titres de propriété. Tous sont flanqués de leur petit cimetière. Tous dominent un ager longtemps travaillé à la pioche ou à l'araire pour entretenir des jardins desservis par des rigoles et des bassins pour l'irrigation, des vergers, de la vigne, quelques labours à céréales ou à légumineuses organisés en jachère biennale, et d'où l'on passe à un saltus voué à l'entretien de bovins pour le travail de la terre et de petits chevaux pour les transports. On y reconnaît l'aspiration à l'autosubsistance, mais l'impression n'est pas d'une activité très productive.

Le dispositif intérieur de toutes ces clôtures répond à un même modèle dicté par l'usage collectif. Un solide portail ouvre pendant la journée sur une entrée en barbacane qui débouche sur une cour intérieure en carré ou en trapèze et encombrée. Elle contient une fontaine très soignée et décorée, nécessaire aux gestes quotidiens et aux rites liturgiques, une simandre frappée au maillet pour signaler tous les temps forts de chaque journée, quelques arbres, dont parfois un ou deux cyprès plantés là parce qu'ils semblent s'élever pour approcher de l'ineffable divin, et parce que leur feuillage toujours vert évoque la vie éternelle.

Dans la cour de chaque monastère sont bâties, comme au hasard, sinon leur orientation, plusieurs églises dont l'une, plus volumineuse, est reconnue comme prééminente et dite katholikos parce qu'elle rassemble et réunit la communauté monastique pendant ses longs offices. D'un monastère à l'autre, malgré les différences de bâti et de dimensions et la diversité des matériaux et des teintes des briques blanches ou roses, la monumentalité de son iconostase, la sonorité de ses voûtes, la lumière dominante bleue de ses crépis intérieurs et les reflets des cierges sur ses icônes à fond d'or persuadent qu'elle est bien le foyer et le point nodal de la société conventuelle. Dans quelques monastères, sa prééminence est magnifiée par la couleur rouge du crépi extérieur de ses murs: elle évoque le manteau pourpre jeté sur les épaules du Christ avant le Golgotha et elle demeure celle de la joie de sa résurrection. Tout autour de la cour et de cette église, les hauts murs à galeries rouges ou bleues ponctués de fenêtres à contrevents peints servent à habiter, contiennent sur plusieurs étages les cellules et le réfectoire des moines, et conservent des provisions : imposants et harmonieux, ils paraissent très rigides au-dessus des toitures de tuiles des églises et des coupoles qui gonflent leurs nefs, leurs absides, leurs transepts.

Au-delà des originalités de leurs sites, des nuances de leurs architectures et de l'âge possible de leurs décors, la seule différence essentielle entre ces monastères, peu 
perceptible par un hôte de passage, tient à ce que la discipline de la plupart d'entre eux est cénobitique, régie par l'absolu quotidien de la prière et de la vie en commun et de la réunion pour les offices. Leur minorité, qui va en se réduisant, est idiorythmique : les obligations collectives imposées à chaque moine - qu'il s'agisse des moments dévolus à la prière, de l'assiduité aux agapes, repas fraternels consommés tous ensemble, ou de l'assistance aux offices - y sont moins strictes, comme un compromis entre principes conventuels et survivances du monachisme érémitique. Le visiteur perçoit mieux les degrés hiérarchiques qui structurent la société religieuse : chaque monastère se choisit un guide spirituel, l'higoumène, dont l'autorité s'exerce aussi, en chef de maison, dans les domaines matériels. Les moines sont affectés selon les vœux qu'ils ont prononcés, selon qu'ils sont prêtres ou non, aux obédiences auxquelles les prédisposent leurs forces et leurs savoirs : archives, cuisines, jardins, pêche, apiculture, accueil des pèlerins... et très rarement à l'étude. Mais l'égalité de tous est signalée partout, hors des cérémonies liturgiques, par leur vêture et leur coiffure uniformes: bonnets noirs, soutanes noires à ceinture de cuir; cela fait du noir une composante picturale essentielle des paysages de l'Ayion Oros; cette couleur de deuil renvoie chacun à la passion du Christ, mais aussi à l'espérance et à la joie, ou à la grâce, de la résurrection.

$\mathrm{Au}$ voisinage et dans la dépendance de chaque monastère s'étendent des faubourgs ou des satellites d'allure pavillonnaire, qui disposent de leurs propres petites églises: agglomérations de skites, des maisons dont la construction est tolérée par les monastères sur des terrains qui leur appartiennent et qu'ils louent. Y résident des groupes de trois ou quatre moines, comptant souvent un tout jeune et parfois un très vieux, qui ne se sentent pas encore ou plus capables d'accepter la discipline conventuelle et qui n'ont pas plus de voix aux délibérations du monastère voisin qu'à celles de leur réunion. Quelques-uns sont des réfugiés ou des fugitifs. D'autres, des retraités retirés du monde. Quelques-uns travaillent des vignes ou des vergers, en métayers des monastères. La plupart s'activent là, en artisans, pour gagner leur vie en découpant du bois, en le tournant, en le sculptant ou en peignant des icônes. Les produits de leurs ateliers sont vendus à l'extérieur, souvent au-delà des frontières de la Grèce, grâce à la réputation de l'Athos et suite à la renaissance ecclésiastique dans les sociétés qui avaient été soviétisées après 1945.

\section{Permanence des relations entre l'Athos et le monde profane}

Si modestes soient-ils, ces flux commerciaux rappellent que l'économie de l'Athos est, depuis le développement du monachisme conventuel, très dépendante des ressources extérieures, ce qui a souvent permis à des intérêts extérieurs à la péninsule d'y afficher leur richesse, de manifester leur puissance, de démontrer leur influence et leurs appétits géopolitiques. Par ailleurs, l'espace de la communauté monastique de la sainte montagne n'a pas toujours été contenu dans la péninsule qu'elle habite.

La fondation des monastères, la définition de leur assiette foncière, leur construction, leurs agrandissements, leurs décors, leur mobilier, leurs bibliothèques, reposent sur des donations, parfois des investissements, venant de gens préoccupés de leur reconnaissance sociale, de leur renommée et du salut de leur âme, qu'ils aient été byzantins, latins, amalfitains, turcs, géorgiens, bulgares, serbes, russes, orthodoxes ou romains, princes, empereurs ou marchands. Cela se lit dans les toponymes, les 
appellations des monastères, la nature et la façon de leurs matériaux et de leurs ornements. Cela se découvre dans l'observation de matériaux antiques: dalles de marbre, pièces de sculptures ou de bas-reliefs, colonnes de porphyre, récupérés parfois très loin pour répondre aux besoins des églises ou manifester l'entregent ou le pouvoir de leurs donateurs.

Quant à leurs dépenses de fonctionnement, particulièrement élevées à l'apogée du $\mathrm{Xv}^{\mathrm{e}}$ siècle, où l'on dénombrait 50000 moines, elles étaient couvertes aussi par des donations, et surtout par les revenus de la grande quantité de métokhia, des domaines agricoles ou forestiers détenus au-delà de la péninsule avec le statut de biens de mainmorte, et dont la jouissance était acquise et dévolue à tel ou tel monastère. Il reste de rares métokhia, surtout forestiers, en Grèce et jusqu'en Roumanie. Mais la plupart ont échappé à leurs bénéficiaires au cours $\mathrm{du} \mathrm{xx}^{\mathrm{e}}$ siècle, du fait de la réforme agraire en Grèce, de l'éviction des Grecs d'Anatolie, puis de l'étatisation et de la collectivisation des terres en Russie, en Bulgarie, en Yougoslavie, en Épire du Nord. Cela a appauvri tous les monastères en réduisant leur assiette foncière, les faisant passer de l'austérité à la frugalité, accompagnant ou provoquant des épisodes de crise dans leur recrutement, fragilisant les équilibres de leurs terroirs.

31 Depuis la fin du $\mathrm{xx}^{\mathrm{e}}$ siècle, des remplacements sont recherchés du côté des institutions internationales préoccupées par la conservation des écosystèmes, des ensembles monumentaux ou des œuvres d'art, ou parfois du côté des États ou des dirigeants qui continuent d'attacher de l'importance au mythe ou au rayonnement spirituel de l'Athos, et ils sont acceptés de Grecs généreux, de pèlerins attendris, d'hommes d'affaires soucieux de leur apparence chrétienne ou de poètes. Quand Elytis écrit entre 1940 et 1951, dans un grand poème dont le titre, Axion Esti, est une formule de la liturgie byzantine et dont Théodorakis fit un oratorio en 1963, « Mémoire de mon peuple, tu te nommes Pinde et tu te nommes Athos », comment ne pas imaginer qu'il évoque les deux mots de l'épithète d'une icône conservée dans une église de Karyès, qui passe souvent pour la toute première dans l'Athos ${ }^{7}$ ?

Cependant, outre l'intérêt que lui portent toujours les Grecs et leur État, divers incidents montrent que la sainte montagne continue d'être tenue par quelques puissances pour un instrument géopolitique désirable. Au cours de l'été 1991, alors que le président socialiste de la Serbie, Milosevic, caressait le projet de refonder une Grande Serbie dans la Yougoslavie vacillante, commençant par des discours sur les monastères serbes du Kosovo, continuant par une guerre contre la Croatie, il décida de rechercher dans l'Athos l'onction du monastère de Khilandari, fondé au XIII siècle par un prince Savas, qui venait de refuser le trône de Serbie. Les moines rejetèrent son entrée et, réfugiés dans les forêts voisines, n'en revinrent qu'après son départ pour procéder aux rites de purification réclamés par son intrusion. Comment savoir si le monastère brûla vingt-cinq ans plus tard à cause de cette visite, comme il arrivait autrefois que les anachorètes le fissent de leurs cabanes, pour s'écarter un peu plus du monde?

On peut apprécier les efforts du président de la Russie, Vladimir Poutine, pour affirmer dans l'Athos comme une continuation de la politique des tsars depuis le Congrès de Vienne en 1815 : s'y présenter en protecteur de la foi et de l'église orthodoxe face au monde entier et tenter d'y réduire le poids du patriarche œcuménique, en augmentant 
celui du patriarche de Moscou. Les vieux monastères russes de l'Athos ont disparu. Mais les tsars $\mathrm{y}$ achetèrent au cours du XIX ${ }^{\mathrm{e}}$ siècle des biens fonciers pour doter leurs monastères favoris, y poussèrent des moines russes, qui atteignirent bientôt la moitié de la population, et investirent dans la construction moderne d'un vaste monastère, Ayios Pantéléïmon, dit Roussikon, qui fut le seul dans l'Athos à soutenir en 1913 l'hypothèse d'une protection russe des provinces cédées par les Turcs. Délabré au fil des années de soviétisme, le monastère est reconstruit depuis 2006 avec l'argent d'oligarques russes, et ses effectifs de religieux se sont multipliés au point de représenter la moitié de la croissance démographique de l'Athos depuis une douzaine d'années. Empêché par le vent en 2001 d'approcher la montagne en hélicoptère, rappelé en vol en Russie en 2004 par l'urgence d'une prise d'otages, Poutine réussit à l'atteindre en 2005 et à y nouer des contacts, et il y débarqua de nouveau le 24 mai 2016 : il veut affirmer une des lignes constantes de la politique orthodoxe de l'État russe comme une poursuite de la politique impériale des tsars dans les Balkans et en Méditerranée orientale.

Il s'agit, comme au XIXe siècle, de chercher à amarrer l'Athos à Moscou sans remettre en cause l'ancrage des monastères dans leur montagne, tout en courtisant la Grèce qui passe pour un maillon faible de l'Union européenne, pour l'en écarter. Il paraît clair que la sainte montagne de l'Athos et ses monastères sont une fois de plus redevenus une pièce dans un jeu dont ils ne peuvent pas toujours parvenir à maîtriser les ressorts et les règles.

\section{BIBLIOGRAPHIE}

ÉLYTIS Odysseus, To Axion Esti, Athènes, Ikaros Ekdotiki Etairia, 1951.

ESCHYLE, Orestie, Agamemnon, Paris, Les Belles Lettres (Collection des universités de France), 2009.

HOULIARAKIS Mikhaîl, Istoria ton apographon plythismou is tin Ellada, 1821-1971, Athènes, EKKE, 1973.

RACINE Jean, Phèdre, Paris, Hachette (Grands écrivains de la France), 1919.

RECLUS Élisée, L’Europe méridionale, Paris, Hachette (Nouvelle géographie universelle, 1), 1876.

SEGOND Louis, La Sainte Bible, Londres, impr. Billing and Sons Ltd., 1932.

THUAL François, Le douaire de Byzance. Territoires et identités de l'orthodoxie, Paris, Ellipses (L'Orient politique), 1998.

\section{NOTES}

1. J. Racine, Phèdre, V, VI, vers 1513.

2. Eschyle, Orestie, Agamemnon, vers 285, p. 20.

3. É. Reclus, L'Europe méridionale, p. 217. 
4. F. Thual, Le douaire de Byzance, p. 30.

5. M. Houliarakis, Istoria ton apographon plythismou is tin Ellada, 1821-1971.

6. L. Segond, La Sainte Bible, Nouveau Testament, épître de Paul aux Galates, 3, 26-31, p. 179.

7. Élytis, Axion Esti, p. 40.

\section{RÉSUMÉS}

La péninsule de l'Athos, montagne isolée du nord de l'Égée, est devenue à partir du v siècle un espace de l'érémitisme chrétien, et à partir du $\mathrm{x}^{\mathrm{e}}$ siècle un grand foyer du monachisme conventuel orthodoxe, ce qu'elle demeure. Quelques ermites y subsistent en marge. L'institutionnalisation des collectivités religieuses a permis aux moines de façonner les paysages et d'organiser le territoire qu'ils habitent, tout en faisant admettre aux souverains byzantins, puis ottomans, puis à l'État grec, que ce pays où ils vivent, prient et meurent leur appartient. Le déclin de leur population exclusivement masculine, aujourd'hui vingt fois moins nombreuse qu'au $\mathrm{xv}^{\mathrm{e}}$ siècle, n'empêche les vingt monastères qui la possèdent et les ermitages qui les flanquent ni de préserver l'extraterritorialité de l'Athos, ni d'entretenir le prestige de leur réunion. L'Athos demeure un lieu de mémoire commun à toutes les Églises d'Orient, en même temps qu'un objet de leur compétition.

\section{AUTEUR}

\section{PIERRE-YVES PÉCHOUX}

Agrégé de géographie, président de la Société de géographie de Toulouse 


\title{
Architecture et décor des couvents mendiants dans le Massif central (début du XIII ${ }^{\mathrm{e}}$ siècle-fin du XV siècle) : tradition, expérimentation ou modernité des modèles gothiques?
}

\author{
Claire Bourguignon
}

1 Les premiers travaux effectués sur les ordres mendiants en France à la fin du XIX siècle ont parfois fortement déterminé l'orientation de la recherche. C'est le cas de la problématique de l'architecture et du décor dits "mendiants », qui a longtemps reposé sur l'affirmation que les ordres mendiants ont bâti des couvents en suivant des modèles architecturaux et décoratifs propres, excluant les modèles artistiques contemporains. Cette thèse a été remise en question à la fin des années 1970 dans les études réalisées notamment par Marcel Durliat et Bernard Montagnes ${ }^{1}$. Malgré des analyses récemment menées sur des aires géographiques ciblées ${ }^{2}$, beaucoup reste à faire pour définir, caractériser et synthétiser les modalités de construction et d'ornementation des complexes conventuels mendiants au Moyen Âge central et tardif. Dans le Massif central, Anne Courtillé a travaillé sur l'introduction et le développement de l'art gothique, mais le rapport des ordres religieux, en particulier les ordres mendiants, aux modèles gothiques a peu été abordé3.

Le terme architecture est entendu dans son sens large, celui d'art et de technique de la construction, de l'aménagement et de la restauration des édifices. Le décor est défini comme l'ensemble des éléments peints et sculptés employés pour orner les édifices. Les ordres mendiants sont des ordres religieux « inspirés à la fois de l'érémitisme oriental (carmes, ermites de saint Augustin) et d'un retour à la pauvreté évangélique et à une prédication par l'exemple (franciscains, dominicains). Tous se distinguent du monachisme traditionnel - celui des moines et des monastères - par le refus de la 
possession foncière, un apostolat plus orienté vers le monde nouveau que constituent les villes, un moindre goût pour la hiérarchie ${ }^{4}$ ». L'étude porte sur les couvents des dominicains, des franciscains (branches masculine et féminine) et des carmes dans les diocèses de Clermont, du Puy et de Saint-Flour, des années 1220, période de construction des premiers couvents, au dernier tiers du $\mathrm{xv}^{\mathrm{e}}$ siècle, qui correspond à la dernière vague de fondations médiévales dans les diocèses étudiés.

3 La réflexion qui suit constitue les prolégomènes du problème de l'adaptation des modèles architecturaux et décoratifs dans les couvents mendiants d'Auvergne. L'objectif est double : apporter un nouvel éclairage sur l'appropriation des formes du gothique par les ordres mendiants et proposer une réflexion sur les expériences architecturales et décoratives des ordres mendiants en moyenne montagne. L'étude est fondée sur les vestiges lapidaires et le mobilier conservés dans les musées, la documentation iconographique et planimétrique médiévale et moderne et un premier travail d'analyse in situ. Sont successivement abordés l'architecture puis le décor des églises conventuelles mendiantes.

\section{L'architecture : tradition romane et modernité des modèles gothiques}

4 En Auvergne, avant la construction de la cathédrale de Clermont dans la première moitié du xIII $^{\mathrm{e}}$ siècle, moins d'une cinquantaine d'églises utilisent des modèles architecturaux gothiques. Celles-ci sont concentrées dans le nord et le centre du diocèse de Clermont ${ }^{5}$. L'implantation des ordres mendiants dans la deuxième décennie $\mathrm{du}$ siècle contribue à bouleverser le paysage architectural gothique.

5 Si l'on se réfère au frère Léon de Viterbe, « scribe, confesseur et gardien de la mémoire de François ${ }^{6} »$, le poverello d'Assise préconise dès les premiers temps de l'ordre que les églises des couvents soient petites ${ }^{7}$. Les plans des premières églises sont simples. L'église à nef unique, de plan rectangulaire et aux modestes dimensions, est prédominante. C'est le cas des églises des franciscains, des dominicains et des carmes à Clermont ou des dominicains à Saint-Flour ${ }^{8}$. Ce type de plan, qui n'est pas une création gothique, connaît un essor rapide grâce à son adoption par les fabriques des églises paroissiales et par les ordres mendiants ${ }^{9}$. Il est particulièrement représentatif du gothique méridional ${ }^{10}$.

6 Le plan de l'église-halle, dont la nef est composée de plusieurs vaisseaux de même hauteur communiquant entre eux, est rapidement adopté dès la fin du XIII ${ }^{e}$ siècle. C'est le cas de l'église des dominicains au Puy (Haute-Loire), dont la nef est reconstruite dans les années 1330, qui atteint les dimensions, monumentales à l'échelle de l'Auvergne, de 66 mètres sur $22,5^{11}$.

7 Ces deux types de plan ne sont pas nouveaux dans les diocèses d'Auvergne. Lors de sa reconstruction dans la première moitié du XIII ${ }^{\mathrm{e}}$ siècle, l'église Saint-Cerneuf de Billom (Puy-de-Dôme) adopte le plan de l'église-halle ${ }^{12}$. Les raisons expliquant l'adoption de ces plans sont multiples: respect des préconisations des saints fondateurs et de la législation propre à chaque ordre, facilité de mise en œuvre et rapidité du chantier de construction. Ces plans pourraient également constituer une preuve de la recherche spirituelle et matérielle d'une nouvelle spatialisation en adéquation avec la mission pastorale des frères (prédication, accueil des sépultures) ${ }^{13}$. 
Concernant l'aspect extérieur des lieux de culte, la législation édicte rapidement des règles relatives à la hauteur des églises. Le paragraphe De edificiis des constitutions dominicaines de 1228 recommande ainsi que les églises ne dépassent pas 30 pieds (environ 9 mètres) ${ }^{14}$. Les élévations extérieures semblent d'abord marquées par une forte muralité, comme le montrent la première église franciscaine (fig. 1) et l'église dominicaine de Clermont (fig. 2). Les baies sont petites, étroites et dotées d'un arc en plein cintre. Elles s'inscrivent pleinement dans le style roman qui se développe dans les anciens diocèses de Clermont et de Saint-Flour, visible par exemple au chevet de l'église Saint-Martin à Sauvat (Cantal). La persistance de ce type de baie au XIII ${ }^{e}$ siècle n'est pas propre aux églises mendiantes. Dans l'église Saint-Sidoine d'Aydat (Puy-de-Dôme), les baies sont placées dans la partie supérieure de la façade, elles sont étroites, terminées par un arc en plein cintre et soulignées à l'extérieur d'un sourcil. Au XIve siècle, malgré le développement des lancettes, la muralité demeure importante. L'espace occupé par les baies des façades nord et sud des églises des franciscains et des carmes à Clermont ou des dominicains à Saint-Flour en témoignent.

Fig. 1. - Chapelle de Beaurepaire à Clermont-Ferrand (Puy-de-Dôme), première église conventuelle des franciscains.

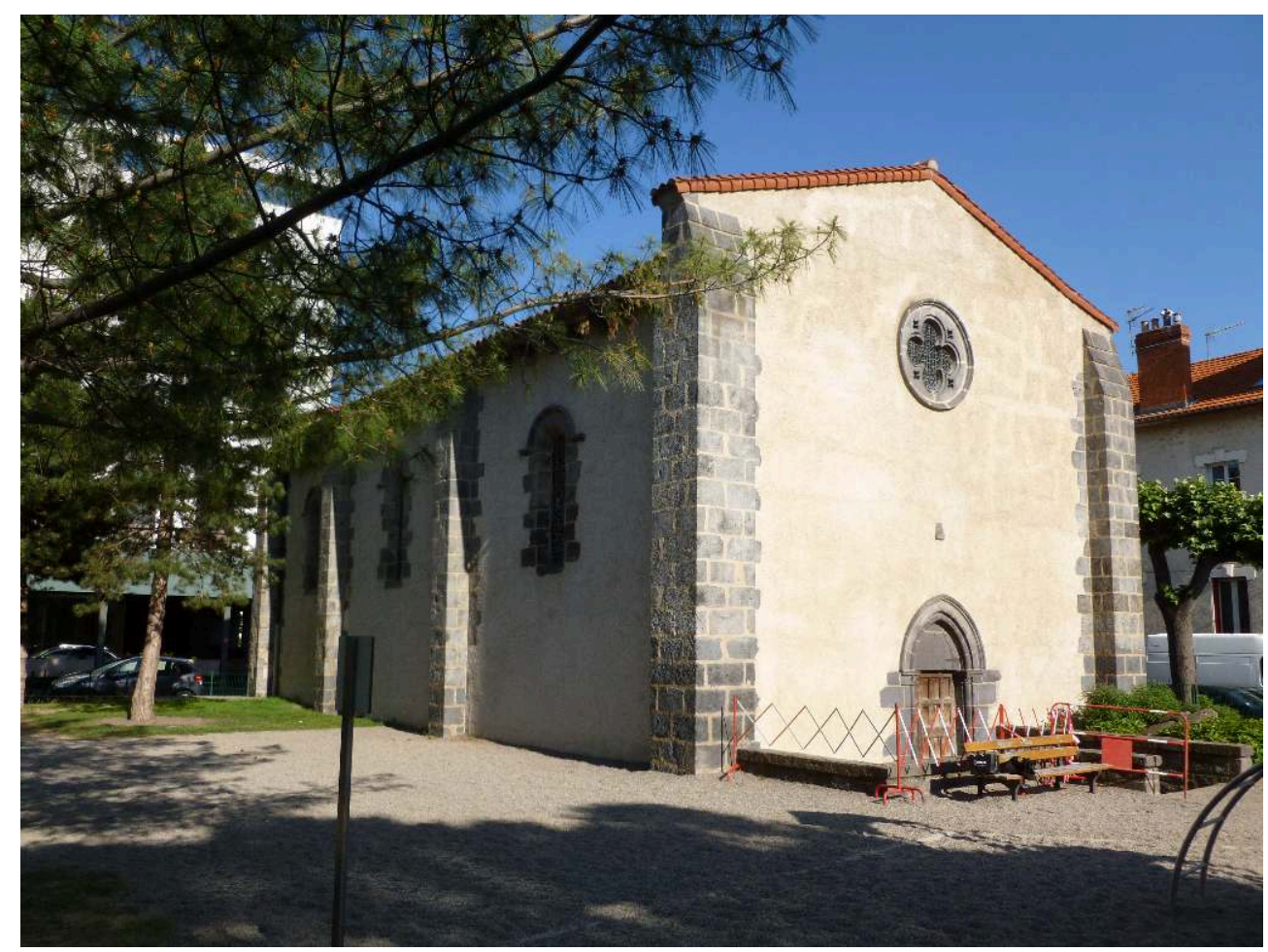

(c) Claire Bourguignon. 
Fig. 2. - Chapelle de la Visitation à Clermont-Ferrand (Puy-de-Dôme), église conventuelle des dominicains.

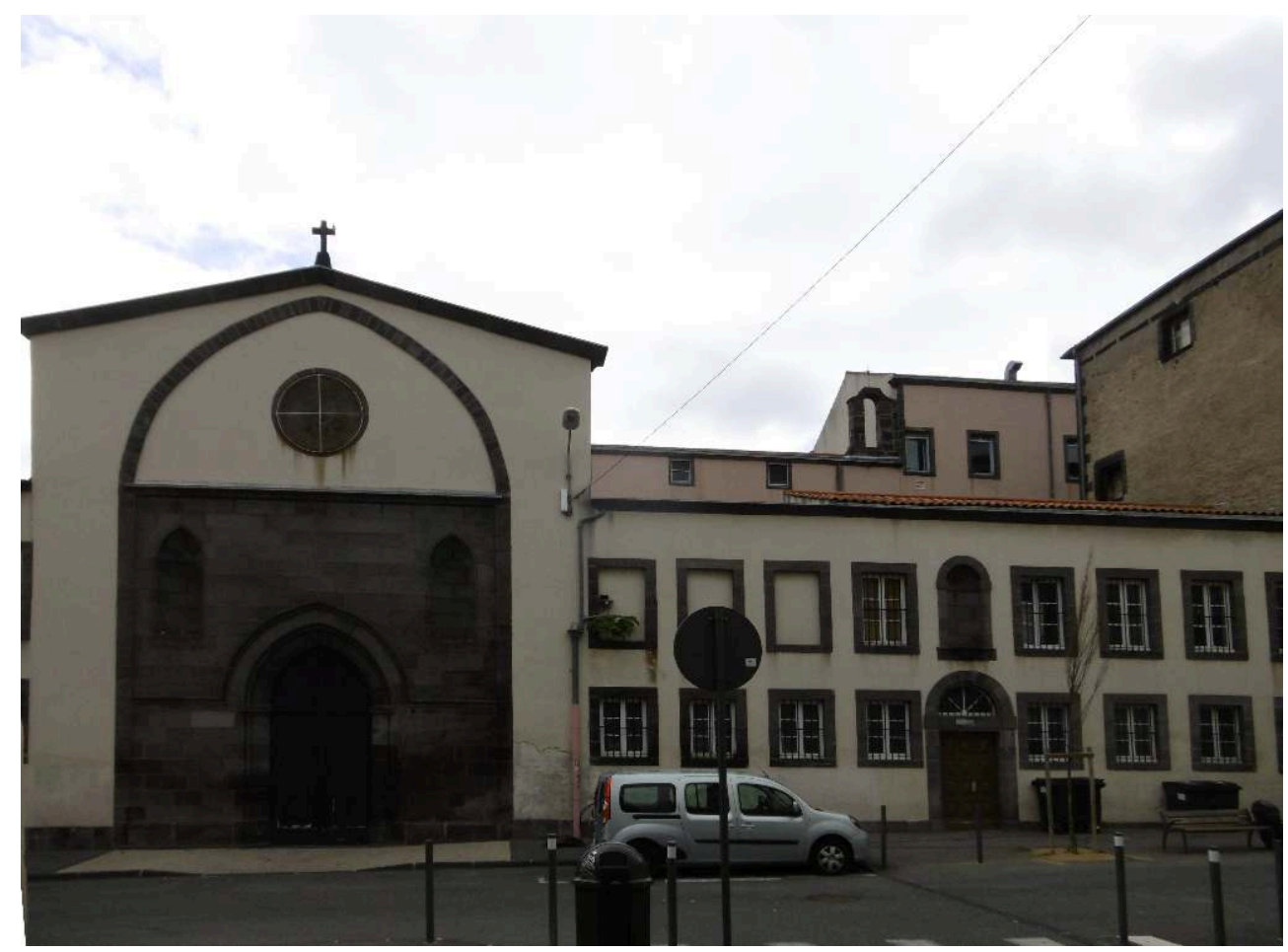

(c) Claire Bourguignon.

9 L'une des caractéristiques des églises conventuelles réside dans l'adjonction de chapelles latérales adoptant les modèles architecturaux gothiques de l'église. Celles-ci sont fondées par des bienfaiteurs laïcs pour abriter leur dépouille et celles de leur famille et pour disposer d'un lieu de dévotion privé. Elles se multiplient dès la seconde moitié du XIII ${ }^{\mathrm{e}}$ siècle, après que les deux principaux ordres ont reçu l'autorisation du pape d'enterrer des fidèles dans leurs couvents: les dominicains obtiennent du pape Grégoire IX l'autorisation d'inhumer des frères et des laïcs en 1227 ; en 1250, le pape Innocent IV autorise les franciscains à accueillir la dépouille de laïcs dans leurs couvents. Avant cette date, seuls des accords locaux avec le clergé séculier le permettaient ${ }^{15}$. À Nades (Allier), des chapelles dédiées au culte privé sont établies autour du chœur de l'église paroissiale Saint-Jacques dès le XII ${ }^{\mathrm{e}}$ siècle $^{16}$. Mais les ordres mendiants ont pleinement contribué au développement de cette pratique, qui connaît un grand essor jusqu'au $\mathrm{Xv}^{\mathrm{e}}$ siècle. À Saint-Flour, six chapelles latérales ont été édifiées à l'instigation des puissantes familles locales comme les Dienne et les Scorailles de la fin du xIV à la fin du xve siècle (fig. 3). 
Fig. 3. - Église Saint-Vincent à Saint-Flour (Cantal), chapelles latérales ouvrant sur la nef de l'église des dominicains.

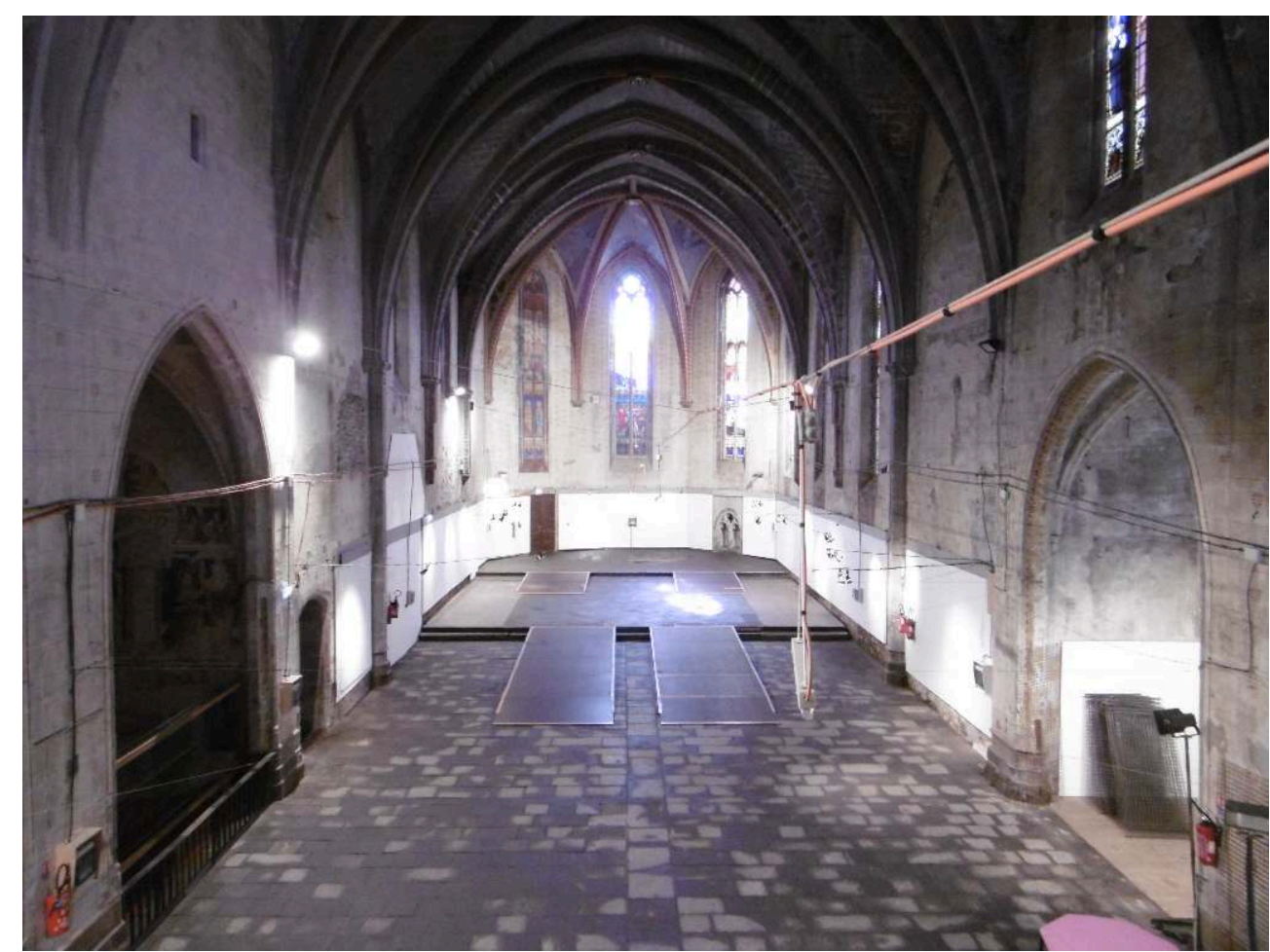

(C) Claire Bourguignon.

10 À l'intérieur des églises, la législation dominicaine recommande que seuls le chœur et la sacristie soient voûtés ${ }^{17}$. Dans les diocèses d'Auvergne, il ne semble pas que cette préconisation ait été respectée, tout au moins dans les derniers siècles du Moyen Âge. La majorité des églises mendiantes conservées est dotée d'un système de voûtement quadripartite. C'est le cas des églises conventuelles des carmes à Clermont et au Puy, des franciscains à Aurillac et des dominicains à Saint-Flour. La voûte sexpartite est attestée dans la seconde église des dominicains (bâtie vers 1250-1270) (fig. 4) et des franciscains (consacrée en 1284) à Clermont. 
Fig. 4. - Chapelle de la Visitation à Clermont-Ferrand (Puy-de-Dôme), voûtement de la nef.

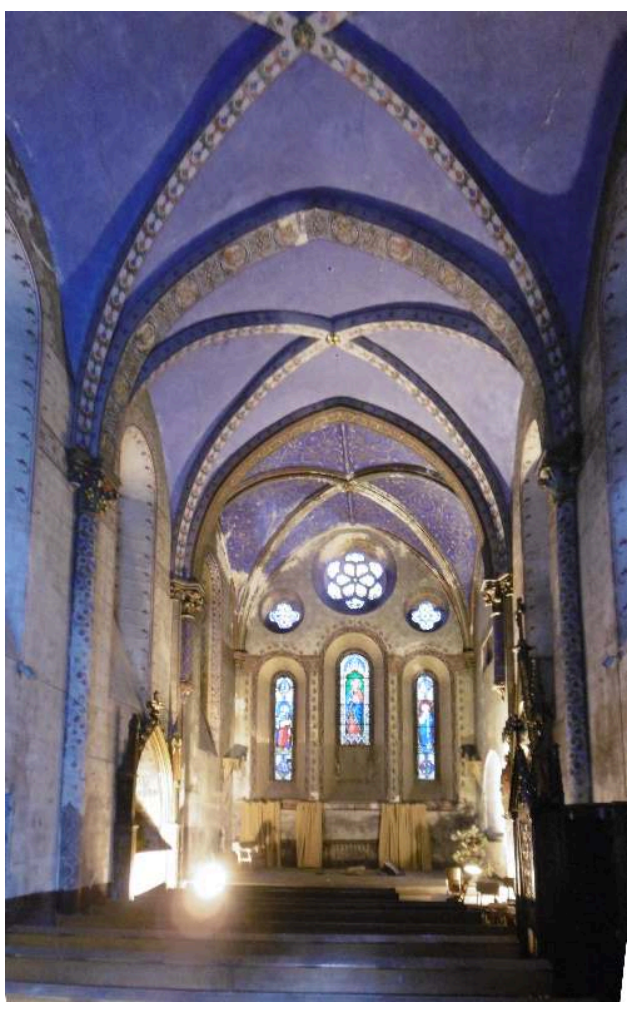

(c) Claire Bourguignon.

11 Comme l'a mis en exergue Anne Courtillé18, l'adoption de la voûte sexpartite est ici paradoxale. D'une part, le voûtement couvre l'ensemble de l'édifice. D'autre part, ce système de voûtement demeure une technique de pointe dans la seconde moitié du XIII ${ }^{\mathrm{e}}$ siècle ${ }^{19}$. À cette époque en effet, l'utilisation de l'ogive est ponctuelle et limitée à l'ouest de la rivière Allier, dans une zone ouverte aux modèles gothiques plantagenêts du Limousin et du Poitou ${ }^{20}$. Ainsi la première église des franciscains à Clermont est-elle dotée d'une voûte en berceau ; elle fait partie des édifices dits « de transition » (fig. 5). 
Fig. 5. - Chapelle de Beaurepaire à Clermont-Ferrand (Puy-de-Dôme), voûtement de l'église.

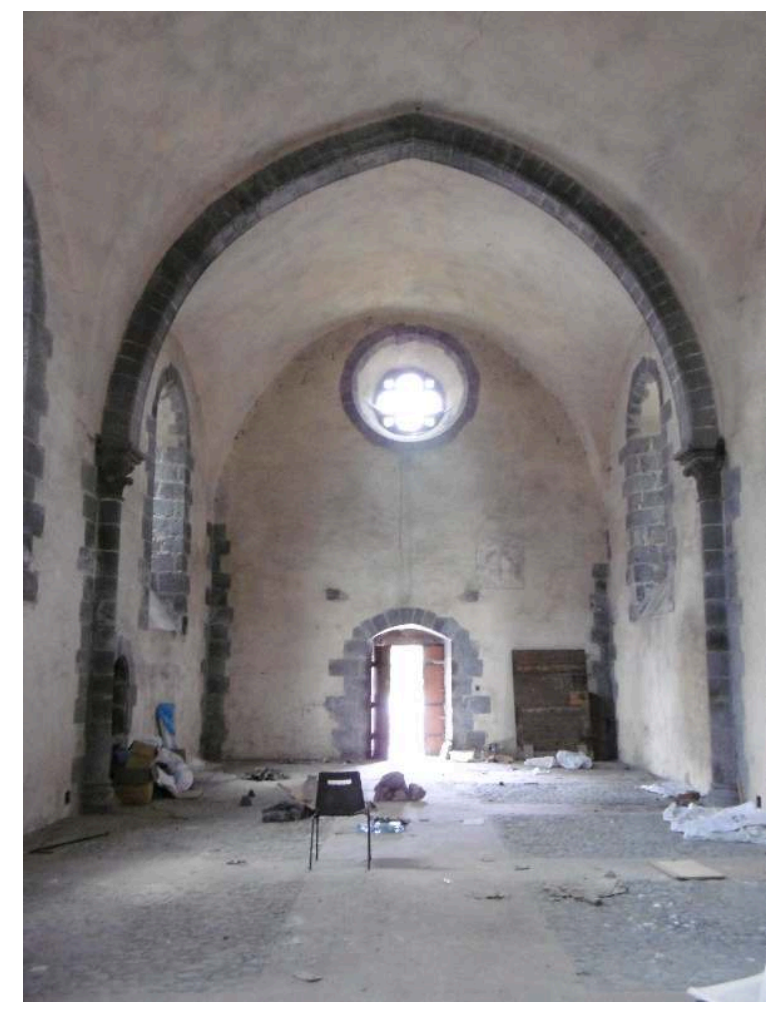

(c) Claire Bourguignon.

12 Les architectes des églises conventuelles mendiantes ont d'abord recours à des modèles architecturaux anciens tels que le plan à nef unique ou de l'église-halle, une forte muralité, des baies en plein cintre étroites. Le paysage architectural «romanisant » demeure donc prégnant ${ }^{21}$. Il semble néanmoins contribuer à populariser des formes architecturales proprement gothiques, comme la voûte d'ogives, ainsi que certains éléments décoratifs.

\section{Le décor : entre tradition et expérimentation des modèles gothiques}

Dès le deuxième quart $\mathrm{du} \mathrm{xIII}^{\mathrm{e}}$ siècle, la législation des ordres proscrit diverses composantes du décor (vitraux, scènes peintes, sculptures, icônes, ornements liturgiques) dans les églises et les bâtiments conventuel ${ }^{22}$. Cependant, «l'importance des images peintes ou sculptées en tant que vecteurs de sacralité et guides dans l'expression de la dévotion individuelle ou collective ${ }^{23}$ " conduit à des aménagements de la règlementation dans les deux derniers siècles du Moyen Âge.

14 À l'extérieur des églises conventuelles, le décor est essentiellement concentré sur les portails et les baies. Le portail sud de l'église Saint-Genès des carmes de Clermont (fig. 6), daté $\mathrm{du} \mathrm{xv}^{\mathrm{e}}$ siècle, présente des piédroits ornés de chapiteaux à motif végétal. Ils supportent trois voussures moulurées. Une archivolte en accolade couronne l'ensemble. L'extrados de l'archivolte est parsemé d'éléments de feuillages sur lesquels sont disposées régulièrement des feuilles de choux frisés. Le portail est encadré de deux 
pinacles dont la partie supérieure est surmontée de fleurons rappelant le décor de l'archivolte.

Fig. 6. - Église Saint-Genès-des-Carmes à Clermont-Ferrand (Puy-de-Dôme), portail sud.

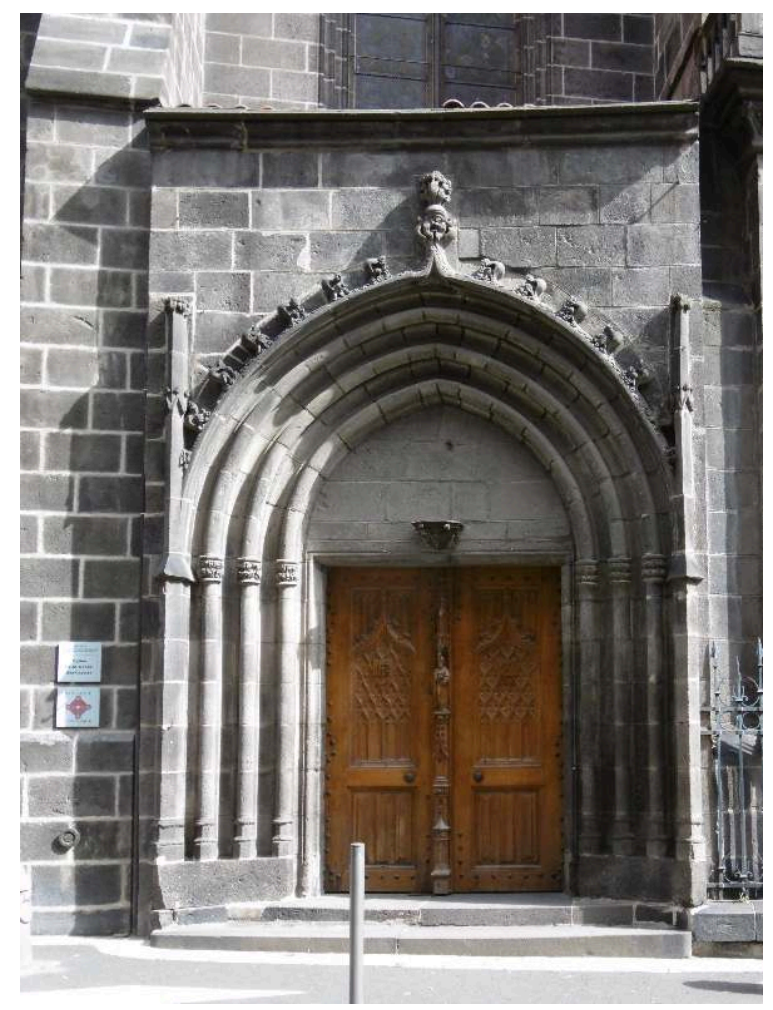

(c) Claire Bourguignon.

Des portails contemporains sont connus dans le Livradois, à La Chapelle-Agnon par exemple $^{24}$. Le portail à décor flamboyant, bien représenté dans le Puy-de-Dôme, témoigne de la richesse des couvents à l'extrême fin du Moyen Âge. Il montre également l'appropriation par les ordres mendiants d'un modèle décoratif attesté sur les façades d'églises paroissiales et abbatiales à la même période. L'adoption de baies flamboyantes en constitue un autre indice, malgré des variations dans la mise en œuvre de ce modèle décoratif. À Saint-Flour, les baies de l'église Saint-Vincent présentent des remplages tympanaux complexes dont l'organisation diffère selon l'emplacement des baies : hexalobe encadré de deux soufflets dans la baie axiale du chœur, mouchettes et soufflets couronnés d'un trèfle dans le reste du chœur et dans la nef. À Moulins, situé à limite des diocèses de Clermont et d'Autun, les baies flamboyantes de la nef et des chapelles latérales de l'église Saint-Pierre-des-Carmes sont larges, composées de trois lancettes tréflées surmontées d'un remplage tympanal développé composé de mouchettes et de soufflets (fig. 7). Les chantiers contemporains de la cathédrale à SaintFlour et de la collégiale des princes de Bourbon à Moulins semblent avoir joué un rôle important dans la diffusion des formes décoratives $d u$ « flamboyant authentique ${ }^{25}$ » sur les chantiers religieux voisins. 
Fig. 7. - Église Saint-Pierre-des-Carmes à Moulins (Allier), baies flamboyantes de la nef.

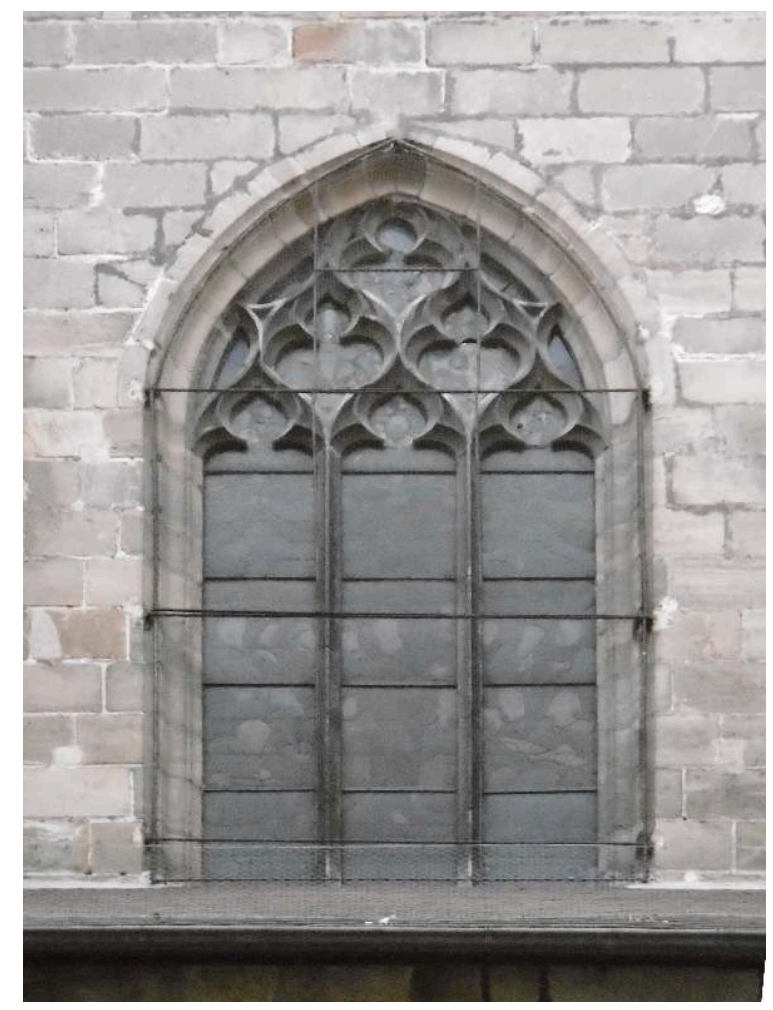

(c) Claire Bourguignon.

16 Évoquer le décor interne des églises mendiantes demeure complexe, en raison des destructions et pillages dont ces édifices ont fait l'objet depuis la fin du Moyen Âge. Pour l'architecture funéraire par exemple, plusieurs descriptions effectuées aux XVI ${ }^{\mathrm{e}}$ et $\mathrm{XVII}^{\mathrm{e}}$ siècles donnent un aperçu relativement précis de l'aspect de certains enfeus. Au début du XIX ${ }^{e}$ siècle, divers témoignages font état des destructions opérées durant la période révolutionnaire (blasons bûchés, tombeaux ouverts), mais également d'éventuelles restaurations réalisées sur les monuments. C'est le cas par exemple de l'enfeu du connétable Bertrand du Guesclin, décédé le 13 juillet 1380 lors du siège de Châteauneuf-de-Randon (Lozère), inhumé peu après dans l'église des dominicains au Puy-en-Velay ${ }^{26}$.

Le chœur des églises conventuelles concentre l'essentiel des éléments de décor, en particulier les chapiteaux et les clefs de voûtes. Dans l'église des carmes au Puy-enVelay, le chœur, bâti vraisemblablement dans le deuxième quart du XIve siècle, est orné d'une clef de voûte portant un médaillon central représentant l'Agnus Dei. Ce décor figuré est connu. À Lavoûte-Chilhac (Haute-Loire), le chœur de la priorale Sainte-Croix est doté d'une clef de voûte très similaire au milieu du $\mathrm{Xv}^{\mathrm{e}}$ siècle. Représentation du Christ sacrifié pour racheter les fautes de l'humanité, l'Agnus Dei est un symbole de la Résurrection ${ }^{27}$. Sa présence rappelle au fidèle l'importance de son œuvre ici-bas pour gagner l'accès à l'au-delà̀ ${ }^{28}$. Ce décor témoigne de l'importance du ministère des âmes dont les carmes sont en charge depuis le pontificat d'Innocent IV (1243-1254). En effet, au mois d'août 1253, le pape Innocent IV demande au prieur général des carmes de confier les ministères de la prédication et de la confession aux frères de l'ordre qu'il 
juge aptes à cette fonction. Cette mesure contribue au passage des carmes d'un ordre érémitique à un ordre mendiant ${ }^{29}$.

Le décor du chœur participe du nouveau sens donné à l'espace ecclésial, corrélativement à la recherche d'une nouvelle spatialisation par l'architecture. Ouvertes aux fidèles laïcs, les églises conventuelles ont une portée spirituelle d'autant plus importante. Au Puy-en-Velay, la toile peinte intitulée La Vierge au manteau, datée vers 1400-1410, est le résultat probable d'une commande du prieur des carmes à des artistes de cour parisiens par l'intermédiaire du frère Nicolas $\mathrm{Coq}^{30}$. La Vierge Marie est représentée protégeant sous son manteau vingt-huit fidèles en prière, groupés en ordre hiérarchique. L'origine sociale des fidèles est reconnaissable aux vêtements portés. En bas à droite du tableau, placé en quatrième position en vis-à-vis du frère carme Nicolas Coq, se trouve le vicomte de Polignac. La famille de Polignac est l'une des familles les plus influentes du Velay au Moyen Âge. Cette peinture sur toile pourrait être un ornement d'autel ou avoir été tendue sur un mur ${ }^{31}$. Elle était donc destinée à être vue de tous, et devait par conséquent rappeler aux fidèles leur place dans la société ponote. Cette toile peinte, vraisemblablement réalisée avec le soutien du vicomte de Polignac ${ }^{32}$, pourrait constituer l'expérimentation locale d'un modèle décoratif rare (la thématique de la Vierge de Miséricorde est associée à celle des trois Marie) à destination de l'espace sacré.

Les bâtiments conventuels ne sont pas dépourvus de décors. Mais les destructions opérées lors de la période révolutionnaire et les réaménagements des dépendances entre le XVII ${ }^{e}$ et le $\mathrm{XIX}^{\mathrm{e}}$ siècles ont souvent entrâné leur destruction. Dans les diocèses de Saint-Flour et du Puy, deux salles capitulaires du xive siècle dotées d'un riche programme décoratif sont conservées.

20 Au couvent dominicain du Puy-en-Velay, la salle de réunion du chapitre suit un plan similaire : un chevet pentagonal ouvre sur six travées presque carrées. Les voûtes d'ogives, de forme torique à filet, sont dotées de clefs de voûte ornées du même blason. Les culots, sculptés de personnages imaginaires, accueillent la retombée des arcs des ogives. Ce décor s'accompagne d'un programme peint développé dans les voûtains. Dans chaque voûtain occidental se trouve un dominicain agenouillé, associé à trois figures de saints répartis dans les trois autres voûtains ${ }^{33}$. Une chapelle voûtée jouxte la salle du chapitre. Elle est ornée d'une clef de voûte et de culots sculptés. Deux blasons figurent également de chaque côté de l'entrée de la chapelle (fig. 8). 
Fig. 8. - Programme décoratif de la chapelle de la salle capitulaire du couvent dominicain au Puyen-Velay (Haute-Loire).

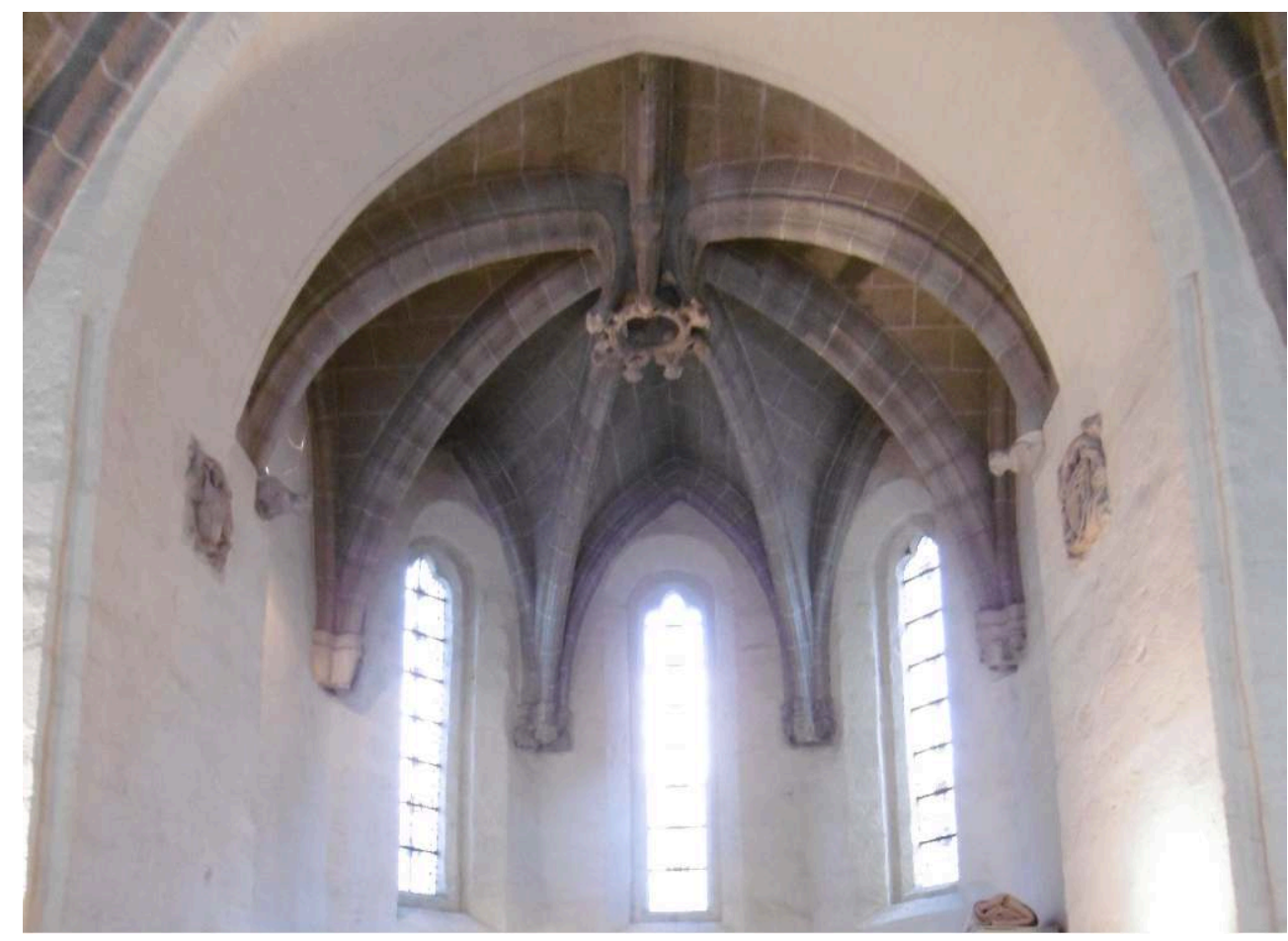

(c) Claire Bourguignon.

21 Ce programme décoratif n'est pas propre aux dominicains du Puy. La salle capitulaire du couvent dominicain de Toulouse (Haute-Garonne), reconstruite en 1300 sous le priorat d'Yter de Compreignac, comporte six travées et est voûtée. Une chapelle, également voûtée, est attenante au lieu de réunion. Elle est ornée d'une clef de voûte figurant l'Agneau, ainsi que des armoiries du maître Arnaud Villar. Dans la salle, quatre des six clefs de voûte figurent le blason du maitre ${ }^{34}$.

22 Malgré des implantations conventuelles parfois éloignées l'une de l'autre, des similitudes existent dans la mise en œuvre des programmes iconographiques dans les bâtiments conventuels au sein d'un même ordre. La nature et la localisation des décors montrent en outre que certains supports en pierre tels que les chapiteaux, les culots et les clefs de voûte sont également privilégiés. Cela témoigne du respect de certaines normes prescrites dans la législation des ordres en matière de décor.

Dans les couvents mendiants d'Auvergne, le décor est donc attesté dans les églises et les bâtiments conventuels. Les modèles décoratifs semblent d'abord être caractérisés par une pérennité d'utilisation des formes romanes. Celle-ci n'est pas exempte d'introductions de nouveautés stylistiques telles que les décors flamboyants à l'extrême fin du Moyen Âge. Ces apports semblent cependant limités aux portails et aux remplages tympanaux des baies.

Pour conclure, nous insisterons sur le caractère pragmatique des modèles architecturaux et décoratifs des ordres mendiants implantés dans les diocèses d'Auvergne. L'architecture des églises conventuelles témoigne d'une persistance des 
modèles romans au moins jusqu'au début du XIV ${ }^{\mathrm{e}}$ siècle dans les diocèses de Clermont et de Saint-Flour ${ }^{35}$. Les ordres mendiants contribuent néanmoins à populariser certains modèles du gothique rayonnant, inspirés notamment des programmes aquitains, comme la voûte d'ogives, introduite très tôt à Clermont par exemple. Les programmes décoratifs semblent également tributaires des décors romans, bien que des décors «flamboyant authentique ${ }^{36}$ » soient présents sur les façades extérieures et intérieures des églises à la fin du Moyen Âge. Là encore, les ordres mendiants semblent s'être rapidement approprié certains modèles grâce à leurs expériences décoratives propres.

L'intérêt de la réflexion réside dans la mise en exergue de modèles architecturaux et décoratifs et leur confrontation avec des modèles contemporains mis en œuvre dans les chantiers religieux voisins. Cela confirme l'existence de la circulation des courants artistiques et des savoir-faire selon certains axes privilégiés, en particulier dans le diocèse de Clermont. Cette première analyse permet déjà d'établir des comparaisons avec les modèles identifiés, notamment dans le sud du royaume de France. Les perspectives de recherche sont multiples. En premier lieu, étudier de manière plus précise les étapes et les acteurs (frères, évêques, laïcs...) de l'introduction et du développement du gothique dans l'architecture des couvents mendiants d'Auvergne. En deuxième lieu, approfondir l'analyse comparative avec les diocèses septentrionaux (gothique d'île-de-France) et méridionaux (gothique méridional) afin de mieux définir les influences. En troisième lieu, caractériser les rapports entre décor et liturgie, en déterminant les relations existant entre les laïcs bienfaiteurs et les ordres.

\section{BIBLIOGRAPHIE}

ALEXANDRE-BIDON Danièle et TREFFORT Cécile (dir.), À réveiller les morts : la mort au quotidien dans l'Occident médiéval, Lyon, Presses universitaires de Lyon, 1993.

BIHL Michael, « Statuta generalia ordinis edita in capitulis generalibus celebratis Narbonae an. 1260, Assisii an. 1279 atque Parisiis an. 1292 », Archivum Franciscanum Historicum, t. XXXIV, 1941, p. 37-94, 284-358.

BRUZELIUS Caroline, « The dead come to town: preaching, burying and building in the mendicant orders ", dans Gajewski Alexandra et Opacic Zoe (dir.), The Year 1300 and the creation of a new European architecture, Turnhout, Brepols, 2007, p. 203-224.

CAZENAVE Michel (dir.), Encyclopédie des symboles, Paris, Pochothèque (Encyclopédie aujourd'hui), 1996.

CHERVAliER Jean, « Le mausolée de Du Guesclin au Puy », Cahiers de la Haute-Loire, 1977, p. 199-223.

CHIFFOLEAU Jacques, La comptabilité de l'au-delà : les hommes, la mort et la religion dans la région

d'Avignon à la fin du Moyen Âge (vers 1320-vers 1480), Rome, École française de Rome (Collection

École française de Rome, 47), 1980.

COURTILLÉ Anne, «La chapelle des Jacobins de Clermont », dans Courtillé Anne, Auvergne et

Bourbonnais gothiques, Nonette, Créer, 1991, p. 573-580. 
COURTILLÉ Anne, Auvergne, Bourbonnais, Velay gothiques : les édifices religieux, Paris, Picard (Les monuments de la France gothique), 2002.

DENIFLE Heinrich von, « Die Constitutionen des Predigerordens vom Jahre 1228 », Archiv für Litteratur und Kirchengeschichte des Mittelalters, vol. 1, 1885, p. 165-227.

DURLIAT Marcel, « L'architecture gothique méridionale au XIII ${ }^{\mathrm{e}}$ siècle ", École antique de Nîmes, $\mathrm{n}^{\text {os }}$ 8-9, 1973, p. 63-132.

ERLANDE-BRANDENBURG Alain et MÉREL-BRANDENBURG Bénédicte, Histoire de l'architecture française du Moyen Âge à la Renaissance : IV siècle-début XVI siècle, Paris, Mengès, Éditions du Patrimoine, 1995.

FAVIER Jean, Dictionnaire de la France médiévale, Paris, Fayard, 1993.

FRÜHWIRTH Andreas et REICHERT Benedictus Maria (dir.), Acta capitulorum generalium Ordinis Praedicatorum, Stuttgart, Jos Roth (Monumenta Ordinis Fratrum praedicatorum historica, 3), vol. 1, 1898.

GUYONNET François, «Les ordres mendiants dans le sud-est de la France (XIII -début XVI ${ }^{\mathrm{e}}$ s.) : essai de synthèse sur la topographie et l'architecture des couvents (Comtat Venaissin, Provence, Languedoc oriental) », dans Moines et religieux dans la ville (XII $-\mathrm{XV}^{e}$ siècle), Toulouse, Privat (Cahiers de Fanjeaux, 44), 2009, p. 275-312.

HÉLIOT Pierre, «Sur les églises gothiques des ordres mendiants en Italie centrale », Bulletin monumental, vol. 130, $\mathrm{n}^{\circ}$ 3, 1972, p. 231-235.

MILLET Hélène, RABEL Claudia, MOTTIN Bruno, La Vierge au manteau du Puy-en-Velay : un chef-d'œuvre du gothique international (vers 1400-1410), Lyon, Fage Éditions, 2011.

Moines et religieux dans la ville (XII ${ }^{e}-X V^{e}$ siècle), Toulouse, Privat (Cahiers de Fanjeaux, 44), 2009.

MONSIGNANI Eliseo (dir.), Bullarium carmelitanum plures completens summorum pontificum constitutiones ad Ordinem fratrum beatissimae, semperque virginis Dei gentriis Mariae de Monte Carmelo spectantes, Rome, G. Plachi, 1715-1718, 2 vol.

MONTAGNES Bernard, Architecture dominicaine en Provence, Paris, CNRS éditions (Publication de l'Unité de recherche archéologique, 6 / Archéologie médiévale méditerranéenne, 1), 1979.

La mort et l'au-delà en France méridionale (XIII ${ }^{e}-X V^{e}$ siècles), Toulouse, Privat (Cahiers de Fanjeaux, 33), 1998.

MORVAN Haude, «La politique funéraire des frères prêcheurs et mineurs au XIII ${ }^{\mathrm{e}}$ siècle $:$ réflexions autour des sources normatives ", Rivista di Storia della Chiesa in Italia, vol. 68, nº 1, 2014, p. 11-43.

PHALIP Bruno, « Aux origines du gothique "flamboyant" en Auvergne (diocèses de Clermont et de Saint-Flour) ou l'art instrumentalisé et sécularisé par les grands laïcs ", à paraître, Presses universitaires du Septentrion.

PHALIP Bruno et LUNEAU Jean-François (dir.), Restaurer au XIX ${ }^{e}$ siècle, Clermont-Ferrand, Presses universitaires Blaise Pascal (Histoires croisées), 2012.

PIRON Sylvain, «Les écrits de frère Léon : introduction », dans Dalarun Jacques (dir.), François d'Assise : écrits, vies, témoignages, Paris, Le Cerf, 2010, t. I, p. 1165-1184.

POUSTHOMIS-DALLE Nelly, « Les ordres mendiants dans le sud-ouest de la France : état de la recherche sur l'implantation, la topographie et les choix architecturaux des couvents ", dans Moines et religieux dans la ville (XII ${ }^{e}-\mathrm{XV}^{e}$ siècle), Toulouse, Privat (Cahiers de Fanjeaux, 44), 2009, p. 223-273. 
PRIN Maurice, L'ensemble conventuel des Jacobins de Toulouse : son histoire, son architecture, son sauvetage et sa renaissance. Regard et description, Toulouse, Amis des archives de la Haute-Garonne, 2007.

SABATIER Paul et LITTLE Andrew George, Le Speculum Perfectionis ou Mémoires de frère Léon sur la seconde partie de la vie de saint François d'Assise, Manchester, Manchester University Press, 1931.

VOLTI Panayota, Les couvents des ordres mendiants et leur environnement à la fin du Moyen Âge : le nord de la France et les anciens Pays-Bas méridionaux, Paris, CNRS éditions, 2003.

voLTi Panayota, « L'explicite et l'implicite dans les sources normatives de l'architecture mendiante ", Bibliothèque de l'École des chartes, t. 162, 2004, p. 51-73.

YBERT Arnaud, «Évolution et stylistique de la voûte d'ogives du XII ${ }^{\mathrm{e}}$ au XVI ${ }^{\mathrm{e}}$ siècle. Application de ces recherches à la cathédrale de Noyon ", thèse de doctorat d'histoire de l'art et d'archéologie, Amiens, université de Picardie - Jules-Verne, 2013.

\section{NOTES}

1. M. Durliat, "L'architecture gothique méridionale au XIII ${ }^{\mathrm{e}}$ siècle ", p.63-132 ;

B. Montagnes, Architecture dominicaine en Provence.

2. Voir par exemple la thèse publiée de P. Volti, Les couvents des ordres mendiants et leur environnement à la fin du Moyen Âge; les contributions de N. Pousthomis-Dalle, «Les ordres mendiants dans le sud-ouest de la France » et de F. Guyonnet, "Les ordres mendiants dans le sud-est de la France », dans les actes du colloque de Fanjeaux Moines et religieux dans la ville ( $\mathrm{XII}^{e}-\mathrm{XV}^{e}$ siècle).

3. A. Courtillé, Auvergne, Bourbonnais, Velay gothiques : les édifices religieux.

4. J. Favier, Dictionnaire de la France médiévale, p. 629.

5. B. Phalip, « Aux origines du gothique "flamboyant" en Auvergne... », p. 1.

6. S. Piron, « Les écrits de frère Léon. Introduction », p. 1165.

7. P. Sabatier et A. G. Little, Le Speculum Perfectionis..., t. II, p. 26.

8. À Clermont (Puy-de-Dôme), la deuxième église des dominicains mesure $23 \times 8 \mathrm{~m}$, celle des carmes 40,3 ×10,9 m. À Saint-Flour (Cantal), les dimensions de l'église des dominicains sont de $45 \times 15 \mathrm{~m}$.

9. Ce plan est par exemple adopté lors de la construction de l'église paroissiale SaintMichel, à Carcassonne (comté de Toulouse), dans les premières décennies du XIII ${ }^{\mathrm{e}}$ siècle ; la nef mesure alors $18 \mathrm{~m}$ de largeur. La première église des dominicains à Toulouse adopte également ce plan dès 1229 ; les dimensions de l'église sont alors de $46 \times 25 \mathrm{~m}$.

10. A. Erlande-Brandenburg et B. Mérel-Brandenburg, Histoire de l'architecture française... , p. 363.

11. C'est également au début du XIV ${ }^{\mathrm{e}}$ siècle, à partir de 1307, qu'est reconstruite la nef de l'église des dominicains de Strasbourg (Bas-Rhin). Celle-ci adopte le plan de l'églisehalle avec trois vaisseaux de hauteur identique.

12. A. Courtillé, Auvergne, Bourbonnais, Velay gothiques : les édifices religieux, p. 145-146.

13. Sur ce dernier point, voir par exemple C. Bruzelius, "The dead come to town", p. 210-219. 
14. H. von Denifle, "Die Constitutionen des Predigerordens vom Jahre 1228 », t. I, p. 225.

15. Voir H. Morvan, «La politique funéraire des frères prêcheurs et mineurs au XIII siècle ».

16. A. Courtillé, Auvergne, Bourbonnais, Velay gothiques, p. 74.

17. H. von Denifle, «Die Constitutionen des Predigerordens vom Jahre 1228 », t. I, p. 225.

18. A. Courtillé, « La chapelle des Jacobins de Clermont », p. 575.

19. Sur l'évolution du système de voûtement à l'époque gothique, voir notamment les travaux de A. Ybert, "Évolution et stylistique de la voûte d'ogives du $\mathrm{XII}^{\mathrm{e}}$ au $\mathrm{XVI}^{\mathrm{e}}$ siècle ».

20. B. Phalip, « Aux origines du gothique "flamboyant" en Auvergne... », p. 2.

21. Ibid., p. 1.

22. Les dominicains soulèvent cette question lors du chapitre général de Paris en 1239 (Acta capitulorum generalium Ordinis Praedicatorum, éd. A. Frühwirth et B. M. Reichert), les franciscains dans les Constitutions de Narbonne en 1260 (M. Bihl, «Statuta generalia ordinis edita...», p. 45-46).

23. P. Volti, «L'explicite et l'implicite dans les sources normatives de l'architecture mendiante », p. 69.

24. Sur les portails du Xve siècle, voir A. Courtillé, Auvergne, Bourbonnais, Velay gothiques, p. 69-74.

25. Ibid., p. 52.

26. L'évolution de l'architecture et du décor de l'enfeu du connétable a notamment été étudiée par J. Chervalier, "Le mausolée de Du Guesclin au Puy ", p. 199-223. Sur les réaménagements et les restaurations des édifices et des décors au cours $\mathrm{du} \mathrm{xIX}^{\mathrm{e}}$ siècle, voir B. Phalip et J.-F. Luneau (dir.), Restaurer au XIX siècle.

27. M. Cazenave (dir.), Encyclopédie des symboles, p. 10.

28. Sur la préparation à l'épreuve de la mort, voir par exemple J. Chiffoleau, $L a$ comptabilité de l'au-delà ; D. Alexandre-Bidon et C. Treffort (dir.), À réveiller les morts; le colloque de Fanjeaux La mort et l'au-delà en France méridionale (XIII ${ }^{e}-\mathrm{XV}{ }^{e}$ siècles).

29. Le texte est publié dans Bullarium Carmelitanum, éd. E. Monsignani, 1715.

30. H. Millet et al., La Vierge au manteau du Puy-en-Velay, p. 109.

31. Ibid., p. 99.

32. Ibid., p. 109-111.

33. Ibid., p. 330.

34. M. Prin, L'ensemble conventuel des Jacobins de Toulouse, p. 213-214.

35. La survivance des formes architecturales romanes au début de la période gothique n'est pas propre aux diocèses étudiés. Elle est également attestée dans la partie méridionale du royaume et dans certaines régions méridionales voisines, comme l'Italie. Voir notamment P. Héliot, « Sur les églises gothiques des ordres mendiants en Italie centrale ", p. 232.

36. A. Courtillé, Auvergne, Bourbonnais, Velay gothiques, p. 52. 


\section{RÉSUMÉS}

Y a-t-il une architecture mendiante ? Cette question a longtemps conditionné la recherche sur la structure et l'organisation des couvents mendiants. Malgré des études récentes sur les débuts de l'art gothique en Auvergne, peu de travaux questionnent le rapport des ordres religieux bâtisseurs aux modèles du gothique rayonnant et du gothique flamboyant. L'étude pose les données du problème de l'introduction et du développement des modèles architecturaux et décoratifs dans les couvents mendiants situés dans les diocèses de Clermont, du Puy et de SaintFlour. Elle est fondée sur la documentation iconographique médiévale et moderne, les vestiges lapidaires et le mobilier conservés en musées et une première analyse de l'architecture et du décor des édifices. Ce travail apporte un éclairage sur la problématique de l'appropriation des modèles architecturaux du gothique septentrional et méridional et propose une réflexion sur la diffusion des expériences architecturales mendiantes en moyenne montagne.

\section{AUTEUR}

\section{CLAIRE BOURGUIGNON}

Doctorante contractuelle en histoire de l'art et archéologie médiévale, Centre d'histoire espaces et cultures (EA 1001), université Clermont-Auvergne 